\title{
THE REMOVAL OF DONOR ANONYMITY IN THE UK: THE SILENCING OF CLAIMS BY WOULD-BE PARENTS
}

\section{Ilke TURKMENDAG BRUNSNES, MA.}

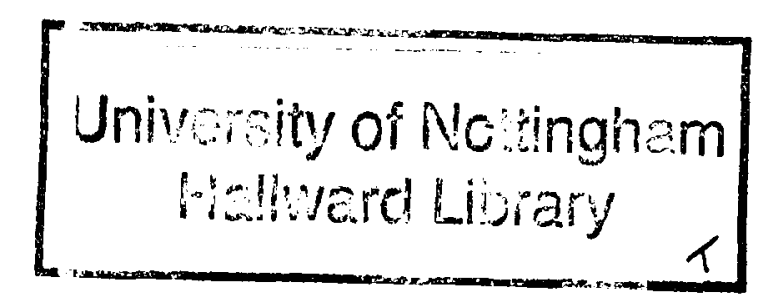

Thesis submitted to the University of Nottingham for the degree of Doctor of Philosophy

January 2009 


\begin{abstract}
From 1 April 2005, UK law was changed to allow children born through gamete donation to access identifying details of the donor. The decision to abolish donor anonymity was strongly influenced by a discourse that asserted the 'child's right-to-know' their genetic origins. Under the current regulation, if would-be parents want to receive treatment in the UK, they have no option but to use gametes/embryos from identifiable donors. For a majority, this also means that they will be on lengthy waiting lists due to the donor shortage. Interestingly, the voice of would-be parents - those who would be most affected by a contraction in donor supply and would carry the burden of informing children of their origins, should they so choose- were not heard during the donor anonymity debate or thereafter.

Adopting a social constructionist approach, this thesis studies removal of donor anonymity as a social problem and examines why would-be parents remained silent during the public debate. There are two major steps taken: first, examining the donor anonymity debate in the public realm through media presentations, and secondly investigating would-be parents' reactions through ethnographic studies: a virtual ethnography study and interviews.

The accounts of a sub-group of would-be parents reveal that having a donor-conceived child constitutes a permanent charge of deviance against the family. Many would-be parents were reluctant to raise their voices during the donor anonymity debate because they did not want to be exposed to publicity. Their reluctance to mobilise around pressing claims against the removal of donor anonymity reflects the variety of ways in which they can avoid the impact of this legislation.
\end{abstract}

The thesis concludes by underlining the importance of having an informed public debate about the disclosure policy, and of developing mechanisms to protect both would-be parents' and donor offspring's interests.

Journal article published during thesis period:

TURKMENDAG, I., DINGWALL, R. and MURPHY, T., 2008. The Removal of Donor Anonymity in the United Kingdom: The Silencing of Claims by Would-be Parents. International Journal of Law, Policy and the Family, 22(3), 283-310. 


\section{Acknowledgements}

My thanks go first of all to my supervisors, Professor Robert Dingwall and Professor Thérèse Murphy, for their continual support, strategic guidance, and for all their help in converting my ideas into the thesis.

Thanks also to the Institute for the Science and Society (ISS) and to the School of Law for providing a stimulating academic home for this work. ISS and the International Office provided funding for my tuition costs. Without the scholarship I could never have conducted a doctoral work in the UK. My thanks go to Gill Farmer, Patricia Hulme, Alice Phillips and my colleagues at ISS for making me feel at home.

Thanks to my family and friends for having faith in me. I am grateful to my mother, Hulya Bahtiyar Turkmendag for her encouragement and endless support. My special thanks also go to Thomas Brunsnes who helped me on both the academic and the domestic front. This thesis benefited from numerous conversations with him. Thanks to Richard Elliot for helping me with the bibliography. Thanks are also due to my friends Cecily Palmer and Emilie Cloatre who helped in at least a hundred ways. And finally to Emil Brunsnes for his patience, who arrived in April 2007 to put it all into perspective.

Finally I would like to acknowledge all those who gave up their precious time to be interviewed and to share their experiences with me.

This thesis is dedicated to Hulya Bahtiyar Turkmendag. 


\section{TABLE OF CONTENTS}

Chapter One: Introduction ................................................................................. 1

The research question ................................................................... 2

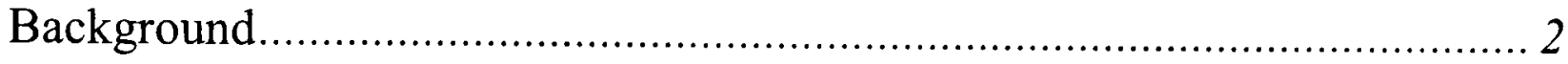

The process of project design ................................................................ 7

Structure of the thesis ........................................................................ 11

$\begin{array}{ll}\text { Limitations of the study } & 15\end{array}$

Chapter Two: Social Constructionist Studies of Social Problems ............. 16

The functional approach to social problems ............................................ 17

Challenges to functionalism ..................................................................... 19

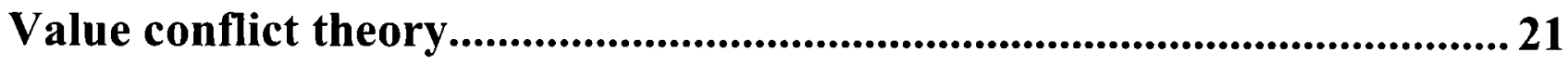

The rise of social constructionism ..................................................... 25

Theoretical controversy: challenges to constructionist theory ..................2 28

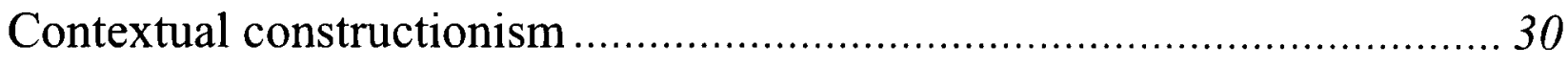

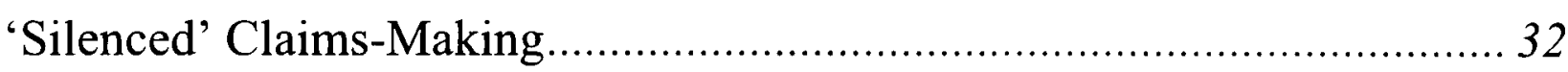

Natural history models ............................................................................ 35

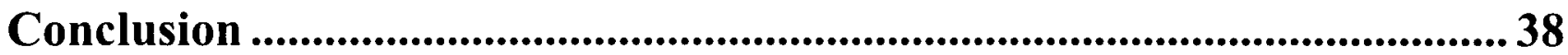

Chapter Three: Natural history of Donor Anonymity Debate ................... 40

Claims-making activities in Stage 1: constructing the problem ..................42

The Children's Society's call............................................................. 43

A study on donor conceived adults....................................................... 45

Rose and Another v. Secretary of State for Health ([2002] EWHC 1593 (Admin))

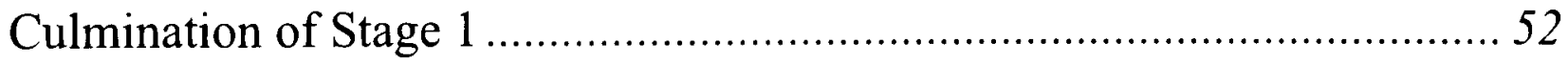

Claims-making activities in Stage 2: recognition of the problem...............53

The Donor Information Consultation, a MORI poll and the HFEA's survey53

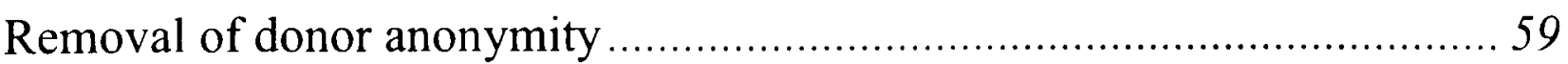

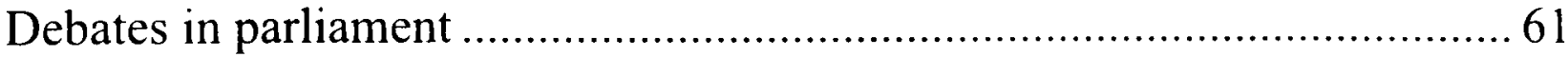


Claims-making activities in Stage 3: re-emergence of claims and controversy 63

Claims against the new law from the child's right - to - know camp..........64

Claims against the law from opponents of the open donation system.........69

Silent resistance of would-be parents ................................................... 77

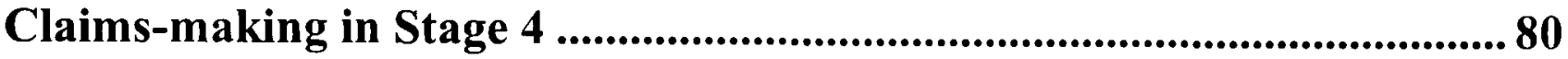

How did children's rights come to monopolise rights claims? ..................81

The adoption analogy .................................................................... 81

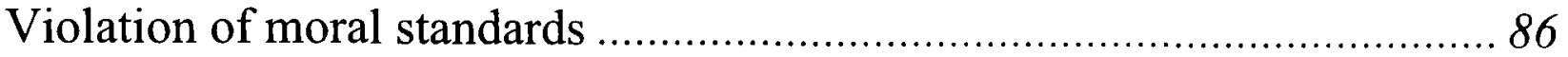

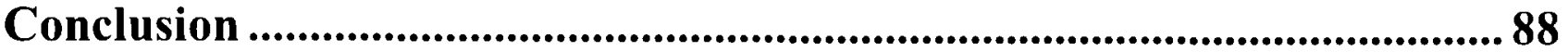

Chapter Four: Research Design and Process..............................................92

Rationale of the study undertaken .......................................................94

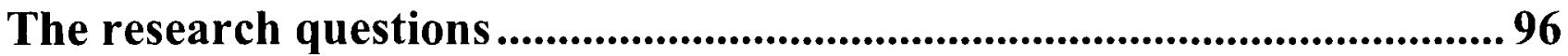

Why perform another study on donor conception families? ......................99

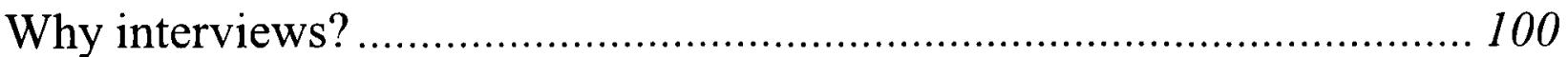

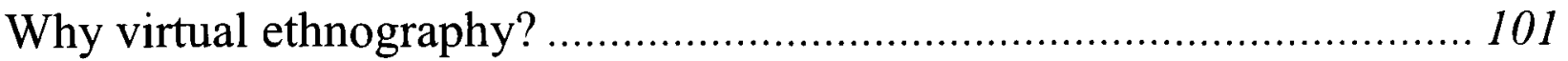

Sampling, access and recruitment............................................................. 104

Recruiting participants for the interviews...................................... 105

Access negotiations to the online support groups: Locating an informant. 106

Problems with recruitment and snowballing ..................................... 109

What kind of interviews? ...................................................................... 113

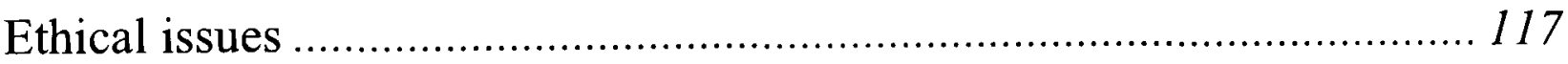

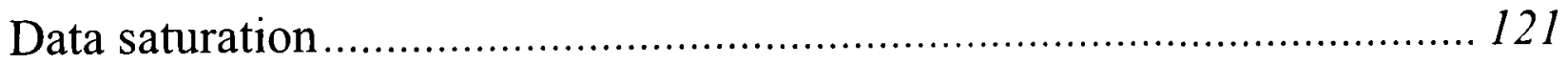

Description of the virtual ethnography study .......................................... 122

Virtual community.................................................................. 123

Virtual ethnography ............................................................ 126

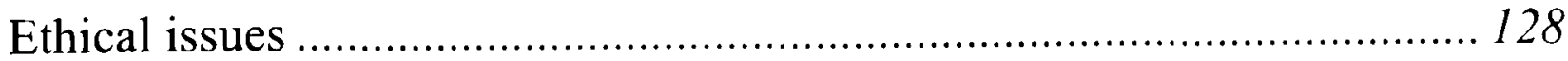

Online pseudonyms and copyright ................................................. 133

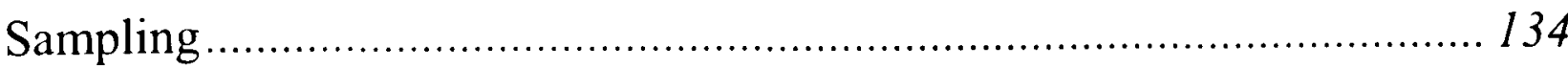

Representativeness.................................................................... 135 


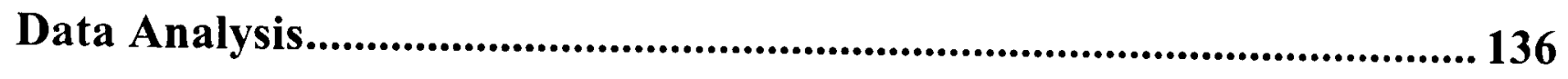

Posts on discussion boards......................................................... 137

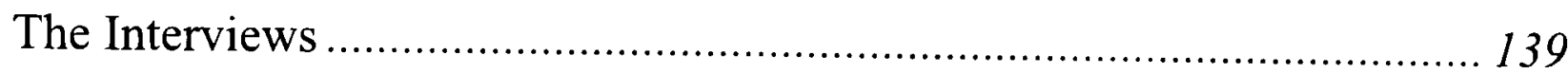

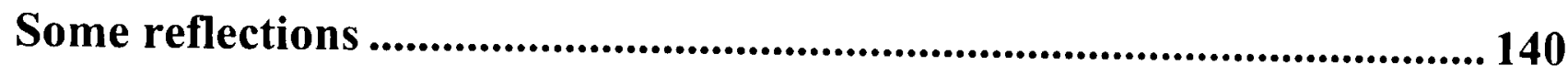

Chapter Five: Virtual Ethnography on Repromed ................................... 142

Repromed as a research setting............................................................ 148

Demographic information and the user identities............................. 150

Emoticons and avatars .............................................................. 154

The setting up of the 'donor gamete' forum on Repromed ........................ 155

Themes from the postings ..................................................................... 157

The donor shortage ..................................................................... 158

Matching donors …...................................................................... 163

Egg sharing: being a donor ............................................................ 167

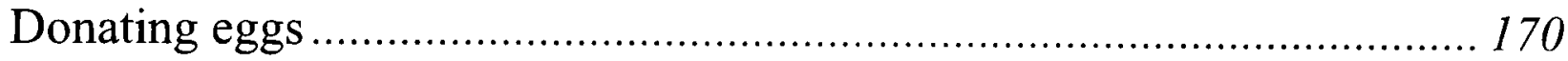

Disclosure ................................................................................ 174

Fertility travel f............................................................................. 185

Closure of the forum............................................................................ 190

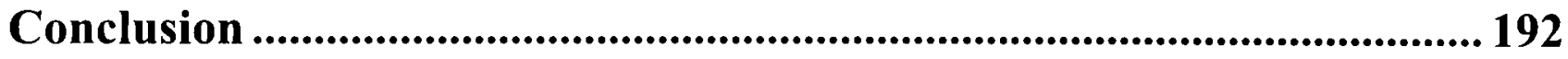

Chapter Six: Stigma and Deviance .......................................................... 198

'Failing' to reproduce.......................................................................................... 201

Infertility, deviance and stigma ............................................... 202

Defeating the charges of deviance: infertility and choice ..................... 204

A choice to reproduce: using donor gametes/embryos to conceive ..........210

The importance of a genetic link ................................................ 213

Defeating the charges of deviance: "it is absolutely like a biological baby" 217 
Chapter Seven: 'Passing' as 'Normals': Information Management........ 225

'Passing': disclosing infertility and infertility treatment ..........................226

Disclosing having a donor-conceived baby to others: having a 'sort of a monster'

Disclosing to the child

Parents' right to pass information on child's behalf. 242

Having the genetic parent in the picture

Accidental disclosure.

The truth may hurt the child

The disclosure policy and discrimination 256

Conclusion 260

Chapter Eight: Fertility Travel as an Avoidance Strategy ....................... 265

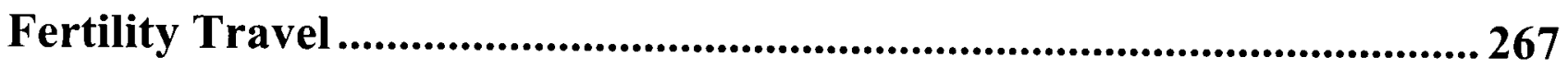

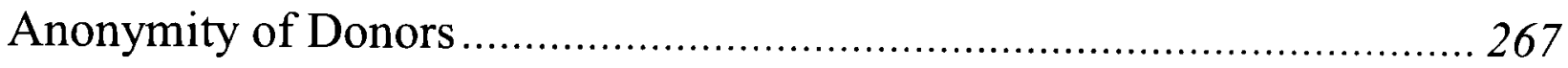

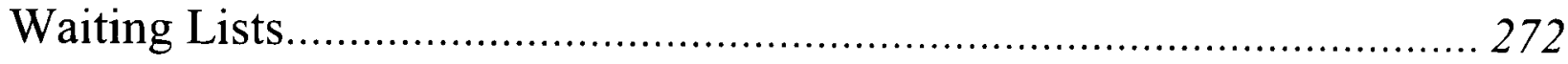

Donors with a physical resemblance to the would-be parents................. 274

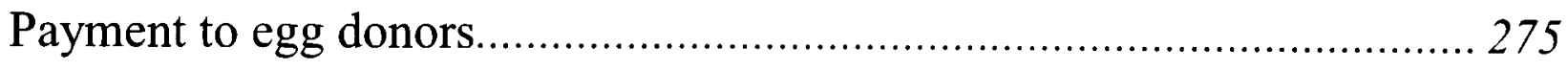

High standards of clinics abroad...................................................... 278

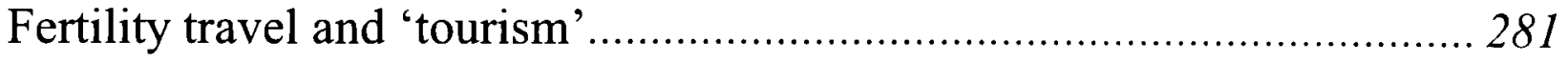

Reactions to the disclosure policy............................................................... 285

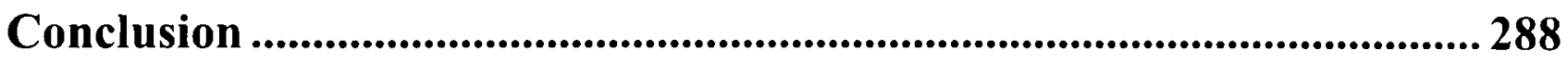

Chapter Nine: Conclusion.......................................................................2290

Social problems around donor anonymity ............................................. 291

The child's right to know as a social problem............................................ 293

The donor anonymity problem as defined by would-be parents.............. 295

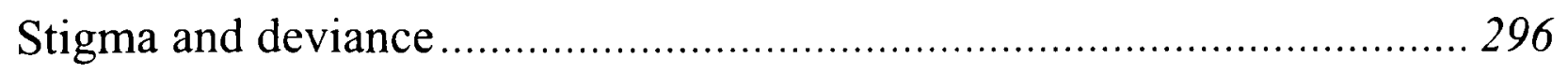

Information control and disclosure ................................................... 298

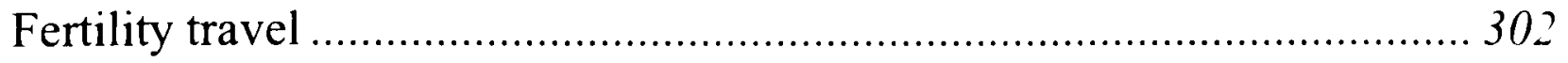

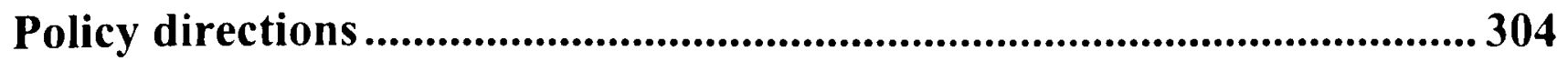




\section{CHAPTER ONE: INTRODUCTION}

On 1 April 2005, with the implementation of the Human Fertilisation and Embryology Authority (Disclosure of Donor Information) Regulations 2004, UK law was changed to allow children born through gamete donation to access identifying details of the donor. Once they reach the age of 18 , children born from ova or semen donated after that date will have the right to obtain identifying information about the donors. Previously, they only had access to non-identifying information, including the opportunity to ascertain whether they might be biologically related to a prospective marriage partner.

The removal of anonymity has generally had a negative impact on both the demand for, and the recruitment of, gamete donors (Cook and Golombok, 1995a; Paul, Harbottle and Stewart, 2006; Robinson et al., 1991; Schover, Rothmann and Collins, 1992). It has been argued that the UK's policy of nonanonymous and non-remunerated donation not only causes long waiting lists for donor conception (Dreaper, 2006; British Fertility Society, 2006), but also drives an increasing number of would-be parents abroad to seek treatment (Infertility Network UK, 2008). British would-be parents cite the shortage of gametes (particularly the shortage of eggs) in the UK as a major reason for receiving treatment abroad (British Fertility Society, 2006; Infertility Network UK, 2008). A further effect of the change in legislation has been that the cost of donor insemination (DI) has risen enormously in many centres; and the programme has effectively been removed from the NHS as standard practice in 
most areas (British Fertility Society, 2007). In other words, fewer people now have access to the treatment in the UK.

A sub-group of would-be parents have been using online discussion forums to express their reactions to the law however their voices were not heard during the public donor anonymity debate or thereafter. This thesis focuses on their absent voices and attempts to understand why would-be parents remained silent during the donor anonymity debate, whilst advocates of the child's right-toknow managed to get their claims recognised by the parliament and regulatory bodies.

\section{The research question}

Adopting a social constructionist approach, this study focuses on would-be parents' reactions to the law. The thesis is guided by an over-arching question: how may donor conception families' reactions to the disclosure policy in the UK better be understood? There are two major steps taken to answer this question: first, examining the donor anonymity debate in the public eye through media presentations, and secondly investigating a sub-group of wouldbe parents' reactions and concerns through ethnographic studies.

\section{Background}

Prior to the 1980s, there was little awareness of donor conception in the UK (Snowden and Mitchell, 1983). Semen donation was performed without central record-keeping or regulation (Frith, 2001). Children born by this means were technically illegitimate: the donor rather than the mother's husband was 
considered the legal father (O'Donovan, 1989). In practice, though, the husband was usually recorded on the birth certificate as the legal father (Frith, 2001). This deception, potentially a criminal offence, contributed to the desire to keep the child's history secret. In the absence of social and legal acceptability (Vercollone, Moss and Moss, 1997), concealing the method of conception from the offspring protected the adults involved - prospective parents, donors (Daniels and Taylor, 1993), and medical practitioners (Haimes, 1993).

The legal vacuum around assisted conception was challenged by the birth of Louise Brown, the world's first 'test-tube baby', in 1978. Although this resulted from in vitro fertilisation (IVF) rather than gamete donation, the technology clearly opened the way to new combinations of biological and social parentage that would need legal specification and recognition. In 1982, the UK government commissioned the Committee of Inquiry into Human Fertilisation and Embryology, chaired by Baroness Warnock, a prominent philosopher, to report on the ethical and legal issues associated with assisted conception and related technologies. The Committee reported in the following year. Among its conclusions was a proposal that children born from donation should be defined as legitimate and that the donor should have no parental rights or duties (O'Donovan, 1988). This recommendation was enacted in the Family Law Reform Act 1987. The Committee also proposed that, in the case of gamete donation, the birth certificate should state 'by donation' entered by the father's or mother's name, as appropriate (Frith, 2001). The latter recommendation did not survive the House of Commons debate that led to the 
Human Fertilisation and Embryology Act 1990 (HFE Act) as it was thought that it would cause unnecessary embarrassment to the child (Lee and Morgan. 2001). The Act's main effect was to create the Human Fertilisation and Embryology Authority (HFEA) to license and regulate clinics that carry out IVF, donor conception, and human embryo research.

The Warnock Committee had endorsed the principle of anonymity in gamete donation to encourage donation and protect family privacy. By the early 1980s, however, some researchers were suggesting that it might be desirable to give offspring information about the donor's identity (e.g. Snowden and Mitchell, 1983). Section 31(3) of the HFE Act allowed offspring conceived through gamete donation the right to apply for information about the donor when reaching the age of 18 . Although the Act did not specify the content of the information, the HFEA Code of Practice $6^{\text {th }}$ Edition directed that donors should be told that 'the Act generally permits donors to preserve their anonymity' (HFEA, 1991: 4iii). In practice, donors were asked to provide some nonidentifying information, which could be passed to potential recipients.

In January 2001 the Department of Health announced that the legislation governing access to information for those conceived through gamete donation would be reviewed. The government then launched a public consultation, which ended in January 2003. A significant majority of respondents endorsed the provision of non-identifying donor information to donor-conceived children, while a smaller portion of respondents proposed the complete removal of donor anonymity (Blyth and Frith, 2008). Nevertheless, the 
government accepted 'a strong argument in principle for children conceived using donated sperm, eggs and embryos being able to find out the identity of their donor' (Hazel Blears, the minister of public health in Dyer, 2003). The government subsequently announced, in January 2004, that people who donated eggs, sperm, or embryos in the UK were to lose their right to anonymity from 1 April 2005. Anyone born using sperm, eggs, or embryos donated after that date may ask the HFEA for identifying information about their donors, when they reach the age of 18 . Donors may only be told whether any children were born from their donation and some limited information about them - number, gender, and the year(s) in which they were born.

The HFE Act 1990 was amended with effect from 5 July 2007 to bring the EU Tissues and Cells Directive (EUTCD) into UK law. Following the implementation of the EUTCD, the procurement, testing, processing or distribution of any embryo or sperm and eggs intended for human use must be licensed by the HFEA or be subject to an agreement with a licensed service (HFEA, 2008b). If patients are considering obtaining sperm, eggs or embryos from within the EU, a licensed UK clinic can organise for a transfer to be made from that country. However, the sperm, eggs or embryos transferred must meet UK requirements. All medical fertility and non-medical fertility services such as Internet sperm providers also have to abide by the UK standards, which include all donors being identifiable. There are other requirements: that the donors have consented to the transfer of their gametes/embryos to the UK; that they have been made aware of the legal position in the UK on identifying donors and implications for donors; and that they must have only received 
reasonable expenses or reimbursement of loss of earnings (no inconvenience payment should be made to a donor). Although would-be parents can exercise their rights to travel within the EU to receive gametes or embryos from a clinic that does not comply with UK standards, the gametes/embryos cannot travel if they do not meet UK requirements on screening. In short, if would-be parents want to receive treatment in the UK, they have no option but to use gametes/embryos from identifiable donors. For a majority, this also means that they will be on lengthy waiting lists due to the donor shortage.

It has been argued that allowing fertility travel is "a form of tolerance that prevents the frontal clash between the majority who imposes its view and the minority who claim to have a moral right to some medical service" (Pennings, 2002: 337). ${ }^{1}$ On the one hand, fertility travel has been a safety valve for those who want to avoid the new law. On the other hand, would-be parents are being warned against seeking treatment abroad. In April 2006, Suzi Leather, the then chair of the HFEA, issued a public statement warning British citizens of the dangers of poorly regulated treatment provided abroad (HFEA, 2006).

Under the current regulation, would-be parents are not compelled to tell their children about their donor origins. In spite of the greater encouragement in recent years for parents to disclose their children's donor origins, a recent study shows that less than eight per cent of egg donation parents, and less than five per cent of those who used donor insemination, disclosed to their children

\footnotetext{
${ }^{1}$ The movement of would-be parents to seek treatment in the international market is often referred to as 'reproductive tourism' or 'fertility tourism'. For the reasons I present in Chapter Eight, this term is perceived as offensive by the participants in this study, therefore throughout the thesis I will refer to 'reproductive tourism' as 'fertility travel'.
} 
(Golombok et al., 2006). This shows that donor conception is often kept secret. As a matter of fact, any right to find out (identifying or non-identifying) information about the donor does not in itself eliminate secrecy surrounding the child's means of conception unless the use of donor gametes is registered on the child's birth certificate (Jackson, 2001). So far, none of the countries that have removed donor anonymity have formalised a system for informing the child. However, in the UK, in August 2007 the Joint Committee on the Draft Human Tissue and Embryo Bill considered whether the draft Bill should be amended to give donor-conceived people a 'legal' right-to-know and parents the 'legal' duty to tell, and also whether donor conception should be registered on the birth certificates of donor-conceived people. The government's response, published in October 2007, rejected the Committee's suggestion of putting 'by donor' on the birth certificates of donor offspring. It did however indicate that the matter would be kept under review.

\section{The process of project design}

This research started with a keen interest in the donor anonymity debate in the UK. By the time I started my PhD course, it had been almost four years since the Department of Health had announced that the legislation which maintained donor anonymity was under review. Even before the removal of donor anonymity, clinics in the UK had experienced difficulty in obtaining a sufficient supply of gametes (Murray and Golombok, 2000). Therefore, this announcement generated increased media interest in gamete supply and demand issues, particularly in relation to sperm. So, for example, in November 2004, an article in The Times noted: 
TWELVE hundred years ago, the Danes spread their genes in Britain by rape and occupation. Now they are taking a less confrontational approach: a Danish sperm bank is stocking up large amounts of semen ready to flood the British market when sperm donation rules are changed next year (Browne, 2004).

The article went on to explain that Cryos International, the world's largest sperm bank, based in Denmark, had recruited 40 donors -mostly blonde, blueeyed students over $6 \mathrm{ft}$ tall -who would meet British regulatory requirements. While the managing director and founder of Cryos interpreted the new regulations as a business opportunity, the media reported that clinicians in the UK were expressing concern about the said developments: the system in the UK would collapse if anonymity was lifted - donors wanted to remain anonymous.

In the years that followed the removal of donor anonymity, fertility travel began to be featured in the media. The media reported that, donors had become scared and donations had dropped sharply; that there were now long waiting lists; and that some clinics would have to turn patients down. There was also a concern that those who receive donor conception treatment would prefer anonymous donors and that lifting anonymity would encourage people to buy unscreened sperm (which could be purchased through websites), or drive people abroad, as had happened in Sweden following the introduction of a similar law in $1985 .^{2}$

\footnotetext{
2 Since the removal of donor anonymity, many Swedish patients receive treatment in Denmark where anonymity is permitted.
} 
During the donor anonymity debate that preceded the new law, representatives of children's organisations, a number of academicians and donor-conceived adults pressed claims for the child's right-to-know, a movement that is described more fully in Chapter Three. Interestingly, the government did not face resistance from would-be parents - those who would be most affected by a contraction in donor supply and would carry the burden of informing children of their origins, should they so choose. My interest in the absence of would-be parents from these debates led to this study.

This interest further developed in the course of reading the discussion forums of these online support groups. Support groups increasingly use an online environment to offer affirmation, consolation and understanding to individuals in distressed or vulnerable situations (Mann and Stewart, 2000). In the UK, many patients who undergo infertility treatment use discussion forums (hosted by patient support groups or clinics) to express and exchange their views anonymously. These discussion boards were snowed under with posts about clinics in countries such as Spain, Poland and Russia. The fact that the most popular countries for fertility travel were the ones that maintained donor anonymity indicated a 'resistance' to the new law that needed empirical investigation. Although I was keen to explore would-be parents' reactions to the new law, it was evident that reaching this population would be a challenge. As I have mentioned earlier, previous research in this area shows that the majority of couples who reproduce with the assistance of gamete donation do not intend to disclose this to the resulting child (Daniels and Taylor, 1993; Klock, Jacob and Maier, 1994; Golombok et al., 2006). It is then questionable 
whether would-be parents would be willing to lodge formal complaints which might make them and their donor conceived children known. One might assume that would-be parents are caught in a vicious circle: those who prefer anonymous donation are reluctant to press their claims because confidentiality matters to them. Given this reticence, their voice goes unheard by public bodies, like the HFEA, which can only deal with issues through formal and transparent modes of communication.

But would-be parents have been expressing their discontent anonymously on online discussion boards. I envisioned that I would visit these websites in order to: (1) recruit participants for interviews; (2) collect data from discussion boards to understand the reactions of would-be parents to the new law; and (3) explore whether there was any collective activity performed by would-be parents in alternative modes of communication to challenge the law. 


\section{Structure of the thesis}

Chapter Two introduces the conceptual framework adopted in the thesis: social constructionist study of social problems. In this chapter, different traditions of studying social problems - functionalism and value-conflict theories - are briefly discussed. A social constructionist approach is shown to have advantages for this study, as it provides useful tools and concepts to understand how people define certain conditions as troublesome, lodge complaints, and change conditions they perceive as problematic. In Chapter Two, after presenting the ontological debate within social constructionism, I conclude that contextual constructionism, which locates claims within their broader social context, should be adopted in the thesis as this approach is more applicable and relevant to the public debate than strict constructionism. The chapter also introduces constructionism's vocabulary: claims; claims-making; and claimsmakers as well as natural history models, which will be used in the following chapters.

Chapter Three examines how the donor anonymity problem was promoted in the UK. The chapter details the natural history of the child's right-to-know movement, and analyses the claims-making that succeeded in defining donor anonymity as a social problem, sufficient to change the law. The chapter deals with the ways in which claims were formed and presented during the debate by the stakeholders, identifies a number of important claims that were made by the proponents of the child's right-to-know, and explains how donor conceived children came to monopolise rights language. It presents the principal claimants, the specific claims lodged against the anonymous-donation system, 
and the reasons why the counter claims-makers were overwhelmed. This chapter reveals the absence of would-be parents in the debate, the stakeholders who would be directly affected by the new arrangements regarding donor conception.

Chapter Four presents the rationale and design of the study, and describes how the empirical research - the interviews and the virtual ethnography - was conducted. The chapter discusses the methodological challenges of conducting a study on hidden or hard-to-reach populations, such as donor conception families in the UK. It captures sampling, recruitment, access negotiations, and ethical issues, and reflects on how data analysis was undertaken.

Chapters Five to Eight present the accounts of would-be parents and form the core empirical chapters of the thesis. These four chapters use the existing literature on donor conception families. Chapter Five presents the virtual ethnography study that I conducted on an online support group, Repromed, for infertility patients. Repromed was clearly one of the most active sites during the review of the law and represents an important source of data on voices that were not fully heard in the public debates over ending donor anonymity. The focus of this study is would-be parents' own communications and interactions in a setting where they discuss issues about gamete and embryo donation. The chapter analyses the posts, demonstrates that an interaction exists among the users, and gives examples of alternative claims-making activities. The findings indicate that the users of the website clearly associate the donor shortage with the change in the law to remove anonymity and criticise the HFEA for not 
taking precautions in advance. The users also criticise the HFEA's new donor selection and recruitment strategy. The findings suggest that their understandings of welfare and kinship are very different from those of the policy elites responsible for this legal reform.

Chapters Six, Seven and Eight draw on data collected by semi-structured and open-ended interviews. Goffman's Stigma (1963) theory provides the background to my data analysis in these chapters and I draw on sociology and anthropology of kinship.

Chapter Six focuses on would-be parents' presentations of 'failing to reproduce'. Having failed to conceive, the participants experienced stigma as they departed from the social norm. In order to satisfy their desire for a child they agreed to have their gametes substituted, but they then bear a double stigma, because the means of conception and the resultant child are marginalised.

Chapter Seven deals with information control. The stigma that donor conception creates can be easily concealed. If the child's origins are kept as secret, the family can 'pass' as normal. Given that the donor-conceived child is perceived as non-natural and manufactured, revealing the child's origins is perceived as potentially stigmatising both for the family unit as a whole, and the resultant child who does not need to know his/her deviance. By keeping donor conception secret the participants want to protect the family unit as a whole from stigma. 
Chapter Eight focuses on would-be parents' reluctance to mobilise around pressing claims against the new law. In this chapter I examine the variety of ways in which they can avoid the impact of this legislation and discuss fertility travel as an avoidance strategy.

The accounts of the would-be parents reflect social assumptions about biological and social parenthood, and the stigma that surrounds donor conception. It is evident that these assumptions play a role in how they assess themselves as potential parents, and the best interests of the resultant child. These assumptions also have an impact on disclosure, and how the would-be parents want to present themselves within and outside their families. This examination helps to explain their reticence during the donor anonymity debate. These parents feel that maintaining secrecy, or limiting information, about the child's conception is the safest way to protect the child, themselves, and the extended family. Fertility travel acts as a safety valve for would-be parents that allow them to avoid the legal imposition of disclosure in the UK.

In the final chapter, I retrace the steps that I have taken in the thesis. This concluding chapter brings together all the elements to answer the research question, and explains how the would-be parents react to the new law that forces them to display their differences. To close, I discuss the implications of the work as whole. 


\section{Limitations of the study}

This study does not claim to be a definitive account of would-be parents' reactions to the removal of donor anonymity or to include a representative sample of people seeking donor conception in the UK. Firstly, men, single women, and couples in same sex relationship are, though not entirely absent, only a minority of the sample. Secondly, being a 'would-be parent' is an inherently transient status; their views about the law or donor conception may change as they move into the status of a 'parent', or some may accept their status as non-parents and give up trying. Thirdly, as I used Internet as a recruitment channel, a majority of the accounts presented belong to those who have Internet access, or those who favour expressing their views in cyberspace. Finally, the difficulty of capturing the views of those who choose to remain more 'silent' than the would-be parents in this study is self-evident. Some voices will always remain silent. 


\section{CHAPTER TWO: SOCIAL CONSTRUCTIONIST STUDIES OF SOCIAL PROBLEMS}

In this thesis, adopting a social constructionist approach, I study the removal of donor anonymity as a social problem. Before I examine what makes donor anonymity a social problem in the UK, I will provide a review of social problems literature and introduce the conceptual framework, contextual constructionism, adopted in the thesis.

There are different sociological perspectives on the definition of social problems and how to study them. Between the 1920s and 1970s, studies of social problems were heavily influenced by a functionalist approach. Some scholars sought to create a different kind of sociology of social problems: the 'value conflict' approach was the result. However, a theoretically integrated and empirically viable research tradition did not develop until the emergence of 'social constructionist' theory (Blumer, 1971; Spector and Kitsuse, 1977; Schneider, 1985). The radical proposition of social constructionism is that social problems result from the definitional activities of people around conditions: thus the analyst should focus on monitoring the activities of the people who are trying to alter these putatively 'undesirable' conditions.

Although a detailed discussion of the different traditions of social problems analysis is not within the scope of this thesis, it will be helpful to locate and justify my approach through a brief consideration of the history of these ideas. 
Following this, a review of Spector and Kitsuse's approach to social constructionist studies of social problems is provided. Spector and Kitsuse's work is subject to both 'strong and weak interpretations' (Best, 1993; Holstein and Miller, 2006). A strong reading of constructionism urges the analysts to avoid discussing social conditions. A weak reading, on the other hand, locates claims within their broader social context. An ontological debate on these different interpretations resulted in the emergence of two different perspectives on the study of social problems: strict constructionism and contextual constructionism. Both approaches focus on the claims-making processes, however the latter proposes that understanding social problems claims often depends upon understanding their context, because claims-makers have particular reasons for choosing particular rhetoric to address particular problems. After explaining my rationale for taking a contextual constructionist epistemological approach to study the donor anonymity problem, I will briefly discuss the empirical model suggested by social problems theorists: natural history. The natural history model was first introduced by value conflict theorists and further developed by Spector and Kitsuse (1977). This model will then be applied to the donor anonymity debate in Chapter Three to identify the claims that defined the donor anonymity as a social problem.

\section{The functional approach to social problems}

The functional approach dominated writings on social problems for almost 50 years. In functionalism, society is perceived as an orderly system where a majority of the members share common beliefs, values and norms. Society develops institutions (e.g., family, religion) and patterns in order to maintain 
itself and keep it running efficiently. Societies can be treated as systems whose parts should be examined in terms of their interrelationships and their contribution to the society in general (Cotterrell, 1992). If anything adverse happens to one of these parts, the system cannot function properly. Therefore, the core of the functional etiological approach was identifying conditions and behaviours that impeded the fulfilment of a society's goals, throwing that society into disequilibrium (Spector and Kitsuse, 1977). To the functionalist, all elements in a social system may contribute to stability or change.

Despite the fact that some functionalists, such as Durkheim, suggested that crime should be regarded as not only an inevitable but also a normal and even healthy social phenomenon (Cotterrell, 1992), the objective condition which created a social problem was generally seen as having an intrinsically harmful or malignant nature standing in opposition to a normal society (Blumer, 1971): it was a state of dysfunction, pathology, disorganisation or deviance. Accordingly, functionalism centred on the concepts of 'social pathology' in the 1920s, 'social disorganisation' in the 1930s, and 'social dysfunction' by the 1950s.

Functionalists attempted to rationalise the changes in society in systemic terms rather than seeking to explain why pressures for change arise with reference to human actions. In consequence, they have been accused of leaving human beings out of the sociological picture (Cotterrell, 1992). They also claimed that there were invariant social laws that could explain social phenomena across societies, and social problems could be defined in terms of particular social 
conditions. The objective knowledge of social conditions was obtainable through scientific methods, and such scientific study would demonstrate that some social conditions were truly social problems. By proposing that social conditions existed separately from people's interpretation of them, functionalist theory paid little attention to individual agency. ${ }^{3}$

\section{Challenges to functionalism}

Value conflict theorists recognised the limitations and inadequacies of the functionalist model. Waller (1936) argued that attempts to treat social problems in a scientific matter had proved useless due to the emphasis given to the objective side of the problems, and the lack of attention to the value judgements constituting them as problems. Likewise, (Becker, 1966) suggested that no social problem was solely a matter of objective conditions but rather a product of a process of definitions.

Another critique of functionalism was that it gave the sociologist a privileged status in identifying a social problem, like a medical practitioner who was

\footnotetext{
${ }^{3}$ The work of Merton (1971), however, demonstrates how values were included in the functional approach to social problems. Merton divides social problems into two categories: deviant behaviour and social disorganisation. Deviant behaviour is the violation of institutionalised forms. Accordingly, this definition requires assumptions about the social norms and some notion of value consensus. Still, the approach does not require a "full-blown functional theory of social systems" (Spector \& Kitsuse, 1977). In contrast, the second concept, social disorganisation, explains social problems with an elaborate set of assumptions and assertions. Merton notes: "Social disorganization refers to inadequacies or failures in a social system of interrelated statuses and roles, such that the collective purposes and individual objectives of its members are less fully realized than they could be in an alternative workable system..." (p. 820). As Merton himself acknowledges, this is not an easy task. The designation of a condition as social disorganisation requires that we assume our basic unit of analysis to be a 'system' and that we identify the 'collective purposes' and 'individual objectives'. In other words, the sociologist is required to make technical judgements about the workings of a social system.
} 
diagnosing an illness. Lemert (1951a) argued that sociologists put their ethical tags of 'good' and 'bad' on various conditions and behaviours according to their (or what they believed to be commonly shared) value judgements. Likewise, Blumer (1971) pointed out that a sociologist may note what he believed to be a malignant condition in a society, but the society may completely ignore its presence, or could perceive and approach it differently.

According to Rose (1971), functionalists gave great weight to the 'functional prerequisites' of any social system - 'necessities of nature' - and to the limitations of social action in modifying these functional prerequisites. According to this approach, a problem caused by a functional prerequisite could never be avoided. Therefore, sociological research could only show why the problem must exist.

Waller (1936) noted that concepts such as social disorganisation were necessary for purposes of logical presentation but never adequate in explaining social problems. Blumer (1971) argued that there was no clear definition of the concepts of 'deviance', 'dysfunction', and 'structural strain', and more importantly, there was no explanation of when deviance became a social problem. Even if these concepts were clearly defined, there was no universal guide for diagnosis, assessment and treatment of the subject matter.

More recently, Miller and Holstein (1997) suggested that treating social problems as signs of social disorganisation and pathology was related to Western ideas of guaranteeing justice, equality and respect to everyone; hence, 
those definitions were circumstances that departed from cultural ideals rather than interpretations of reality.

\section{Value conflict theory}

The functionalist theorists sought to explain how society functioned when a social problem emerged, whereas the value conflict theorists analysed how members of society came to see a condition as problematic. Waller (1936) and Fuller and Myers (1941) were early proponents of the value conflict approach. Their attempts to add 'subjectivity' (without totally discarding objective conditions) to the functionalist formulations of social problems inspired other value conflict theorists such as Lemert (1951a; , 1951b) and Becker (1966).

In functionalism, social problems are seen as an effect of objective conditions. That leads the sociologist to explain social problems with a focus on objective conditions rather than subjective definitions (e.g., people's interpretations of the social problems). According to value conflict theorists, however, the objective condition is not sufficient to constitute a social problem itself. Waller (1936) notes that it is value judgements that define conditions as social problems:

Various attempts to treat social problems in a scientific manner have proved useless because they have dealt only with the objective side of social problems and have failed to include the attitude which constituted them problems (1936: 922).

To Waller, 'the attitude' - the value judgement - is the subjective side of social 
problems. Underlining the tension between culture - the realm of beliefs, values and norms - and social organisation, Waller believes that social problems are moral problems originating from the conflict of humanitarian and organisational mores. Organisational mores are the basic mores upon which social order is founded (e.g., private property, individualism, monogamous family). Humanitarian mores are mores aimed at making the world better or to remedy the misfortunes of others. Conditions that we see as social problems emanate from the organisational mores; therefore they can only be solved by changing the organisational mores from which they arise.

Waller claims that social problems did not exist when every primary group cared for its own helpless and unfortunate. Accordingly, social problems are a phenomenon of secondary group society, in which the primary group is no longer willing and able to take care of its members. He argues that this breakdown brought 'humanitarianism' into existence; feeling sympathy for those whom we had never seen.

Waller notes that if one attempts to treat a social problem scientifically, one should try to understand why it is considered as a problem. Thus, the sociologist must investigate the growth and functioning of the humanitarian mores, study the cultural and psychological background of reformers, and the processes of social change.

By introducing the conflict between organisational and humanitarian mores, Waller opened a new door to social problems studies. He did not abandon the 
concept of objective conditions in his social problems formulation. However, he did argue that without value judgements a condition could not constitute a social problem. In social problems literature, Waller's approach was radical, if not revolutionary:

We are all, as Galsworthy remarked, under sentence of death, but death is not a social problem; death becomes a social problem only when men die, as we think, unnecessarily, as in war or by accident or preventable disease. Not all the miseries of mankind are social problems (1936: 924).Like Waller, the work of Fuller and Myers (1941) also contributed to the study of social problems by adding subjectivity to the functionalist conceptualisation:

[I]f conditions are not defined as social problems by the people involved in them, they are not problems to those people, although they may be problems to outsiders or to scientists (1941: 320).

Fuller and Myers defined a social problem as "a condition, which is defined by a considerable number of persons as a deviation from some norm, which they cherish" (1941: 320). According to the authors, every social problem consisted of an objective condition and a subjective definition. This objective condition was a verifiable situation (such as trends in the birth rate) and could be checked by trained observers. The second component of the definition involved subjectivity: the awareness of certain individuals that the condition was a threat to certain cherished values.

Similarly to Waller, Fuller and Myers noted that cultural values play an important role in the definition of a social problem. They suggested that value 
judgements cause people to define the same condition and solutions differently. According to Fuller and Myers, social problems involved a dual conflict of values. First, with regard to some conditions, people disagreed as to whether the conditions were a threat to fundamental values. Secondly, even if they agreed on that, they would disagree over programmes of reform due to lack of other values relative to means or policy. The authors argued that social problems arose and were sustained since people did not share the same common values and objectives (Waller also had noted that social problems existed because people did not want to solve them). Finally, not only Waller but also Fuller and Myers suggested the same solution: sociologists must not only study the objective condition phase of a social problem but also the value judgements of the people involved in it.

Blumer (1971) drew attention to 'collective definitions'. He argued that "social problems are fundamentally products of a process of collective definition instead of existing independently as a set of objective social arrangements with an intrinsic make up" (1971: 298). According to him objective conditions could not constitute a social problem. Rather, it was the process of collective definitions that determined the career and fate of the social problem. Other value conflict theorists introduced similar definitions. For example Rubington and Weinberg (1971) defined a social problem as: "an alleged situation that is incompatible with the values of a significant number of people who agree that action is needed to alter the situation" (1971: 6). Yet another definition reads: A social problem is a condition affecting a significant number of people in ways considered undesirable, about which it is felt something can be done 
through collective social action" (Horton and Leslie, 1981: 4).

Critics questioned these elements of subjectivity introduced by proponents of the value conflict approach (e.g. humanitarian mores, value judgements, or collective definitions). Some argued that the value conflict definition of social problems was largely dictated by the given society: "if 'significant groups' are relied upon to define what the social problems are, it is most likely that these are also the powerful groups who sit in central positions of the status quo" (Westhues, 1973: 425). To them, value conflict theory remained class-biased: it accepted the judgements of the powerful social classes in defining what conditions were social problems (Westhues, 1973).

Another criticism was raised by Spector and Kitsuse (1977). Despite having argued for basic changes in the functionalist approach, the value conflict theorists neither abandoned the concept of objective conditions in their social problems definition, nor did they suggest a simple empirical model to study social problems. Spector and Kitsuse argued that the objective condition in the formulation should be abandoned altogether, and all emphasis should be put on subjective definitions.

\section{The rise of social constructionism}

The opening line of Constructing Social Problems (Spector and Kitsuse, 1977) is: "there is no adequate definition of social problems within sociology, and there is not and never has been a sociology of social problems" (1977: 1). By 
rejecting the dominant conventional social problems definitions that are suggested by functionalists and value conflict theorists, Spector and Kitsuse suggested a radical change in social problems theory.

According to the authors, although value conflict theorists acknowledged that objective conditions were not in themselves sufficient to constitute a social problem, they did not discard them in their formulation. For example, Fuller and Myers (1941) had argued: "the subjective definition is the awareness of certain individuals that the condition is a threat to certain cherished values" (1941: 45). According to Spector and Kitsuse this formulation is ambiguous because the 'awareness' of that condition as a 'threat' is not clear: it is unknown whether the condition is in fact a 'threat'. If the subjective definition is based on a 'belief' that the condition is a threat, the sociologist does not need to verify the existence of the imputed condition. In other words, Spector and Kitsuse reject the dualism of putting both objective conditions and subjective definitions into the formulation. They define social problems as "the activities of individuals or groups making assertions of grievances and claims with respect to some putative conditions" (1977: 75). With this definition, they replace the concept of 'objective conditions' by 'putative conditions'.

The proponents of the value conflict approach, Fuller and Myers (1941), also claimed that an objective condition was a verifiable situation, the existence of which could be confirmed or discarded by impartial and trained observers. To Spector and Kitsuse, a problematic condition does not exist until it is defined as 
such, thus there are no existing conditions waiting to be discovered by experts. ${ }^{4}$

The authors further note that there is not necessarily a relationship between any objective indicators of social problem conditions and what people worry about.

There can be objective conditions that create harm without subjective worry, or people can start to worry about a condition when objective indicators seem to show that the condition is not new or growing. Spector and Kitsuse therefore suggest that social problems are constructed through social claims and explanations about how these problems should be understood (Spector and Kitsuse, 1977). These definitional activities are defined as 'claims-making activities'. Claims-making activity has nothing to do with social problem conditions; all attention is on the activity of people who try to persuade the audience to evaluate a condition as a problem.

The social constructionist definition of social problems was subject to criticism. One of these was that it still involved objectivism, despite its rejection of this aspect of more conventional forms of social problems research. In response to this, Ibarra and Kitsuse suggested that 'claims-making constitutes social problems' (1993: 34). A social problem "points to that class of social interactions consisting of members' analytically paraphrasable means for formulating, describing, interpreting, and evaluating a symbolically

\footnotetext{
${ }^{4}$ In functionalism, the sociologist is positioned as an expert who diagnoses a problem. With regards to the sociologist's stand, Spector and Kitsuse argue that the significance of objective conditions are the assertions made about them, and not the validity of those assertions as judged from some independent standpoint, as for example, that of a social scientist. Spector and Kitsuse also oppose the value conflict theorists' interest in values and mores. According to them, there is no sense in discussing how society defines values; rather than speaking of society in the abstract, it is sensible to examine some concrete instances where definitions are constructed. According to the authors, the sociologist should not be the participant in the problem. If a sociologist acts as an expert in treating a social problem, then he/she will be a participant rather than an analyst. Paradoxically, in social constructionism, by pointing out a claims-making activity, the sociologist herself becomes a claimant.
} 
constructed and morally charged inter-subjective existence" (1993: 48). The main modification in this formulation is a linguistic turn: a redefinition of the focus of inquiry from the claims-making activities to the discursive strategies. As opposed to this approach which limits social problems work to the examination of rhetorics, others have argued that the inclusion of socio-cultural context is an important feature of claims-making (Best, 1993). According to these latter theorists, evaluation of social problems claims is an important part of studying social problems: In fact, it is what makes it relevant to public debate. The epistemological debate that resulted in the emergence of two different perspectives will be detailed in the following section.

\section{Theoretical controversy: challenges to constructionist theory}

Contrary to the realist stance of functionalism which proposes that an external world exists independently of our representations of it, Spector and Kitsuse posited a relativist approach that was based on the doctrine that, since any such external world was inaccessible to us in both principle and practice, it did not need to be postulated or considered (Cromby and Nightingale, 1999). The authors also rejected the value conflict school's approach that objective conditions might help to explain the subjective elements of social problems. To them, social constructionists study how a condition is defined as a social problem, not the social condition itself.

By bracketing attention to objective conditions, constructionist theory opened its doors to critics. However, critics have tended to come from within 
constructionism rather than outside. The principal controversy has been the attack on 'ontological gerrymandering'. Woolgar and Pawluch (1985) argued that Spector and Kitsuse adopted a theoretically inconsistent stance by bootlegging assumptions about social conditions into their analyses. According to the authors, constructionism frequently involves the selective application of scepticism, allowing or denying the existence of phenomena according to the analyst's attitude towards them:

The successful [constructionist] social problems explanation depends on making problematic the truth status of certain states of affairs selected for the analysis and explanation, while backgrounding or minimizing the possibility that the same problems apply to assumptions upon which the analysis depends (1985: 216)

A first reaction to this critique was to call for analysts to avoid all assumptions about social conditions. In response to this criticism, some social constructionists have acknowledged their epistemological shortcomings. Nevertheless, they argued that claims-making should be examined within its context and inclusion of the socio-cultural context is an important feature of claims-making (Best, 1993). As a result, two main streams emerged: strict constructionism and contextual constructionism.

Strict constructionists avoid making (even implicit) assumptions about objective reality. To them, the actual social conditions are irrelevant - all that matters is the perspectives of claims-makers. Some critics argue that strict constructionism has little to say about the everyday practices of social construction. For example, as Loseke (2003) notes, a question might be whether such an understanding of social constructionism diverts attention from 
more important questions about social problems. Questions associated with subjective definitions might not seem as real or immediate as those associated with objective conditions. Another criticism of strict constructionism is raised by Best (1993). He argues that all sociological analysis requires stepping back from the subjects of research, calling at least a portion of the taken-for-granted social world into question. Strict constructionists however advocate stepping back even further. By distancing themselves from the research subject, they are assuming less and calling more into question. Best claims that this is an unattainable goal because analysts use a language, and a culture's assumptions are built into its language. As a result, no matter how far analysts distance themselves from their subject matter, ontological gerrymandering is inevitable. Most importantly, Spector and Kitsuse dismiss interests as antecedents to claims-making and they suggest that the analyst cannot interpret interests as "anything other than imputations made by participants" (1977: 91). For that reason Spector and Kitsuse run the risk of creating a theory of claims-making "devoid of meanings, intentionality, and motives" (Bockman, 1991: 453). Strict constructionism comes at a cost; it constrains the analysis (Best, 1993).

\section{Contextual constructionism}

While the debate over strict constructionism occupied the attention of a few theorists seeking to locate claims-making within its context, some sociologists developed a more pragmatic approach, namely contextual constructionism. Best (1995) was one of the pioneers: 
Claims emerge at particular historical moments in particular societies: they are made by particular claimsmakers, who address particular audiences. Claimsmakers have particular reasons for choosing particular rhetoric to address particular problems. Such specific elements from claimsmaking's context, and contextual constructionists argue that understanding social problems claims often depends upon understanding their context (1995: 345).

Similar to value conflict theorists, contextual constructionists reconcile objectivism and realism, thus performing ontological gerrymandering; a form of epistemological deconstruction. They focus on the construction of meaning, yet they acknowledge making some assumptions about objective conditions.

Some critics argue that although contextual constructionism is more applicable than strict constructionism, it is not flawless; it re-raises questions that social constructionism was designed to overcome in the first place. It is claimed to be incoherent, inconsistent, and confused (Loseke, 2003). But, assumption-free sociology is a rather unattainable goal. As Cromby and Nightingale (1999) argue:

The history of critical thought shows that both realism and relativism are typically deployed strategically. Writers ground their critiques in aspects of the world which they wish to make or remain real and, from this grounding, relativise aspects of that they want to question or deny. Which aspects of the world are to be relativised and which 'real-ised' is a choice typically shaped by moral, political or pragmatical precepts, not epistemology or ontology (1999: 8).

Best (1993) argues that ontological gerrymandering is inevitable but not a weakness. It is neither necessary nor possible for analysts to avoid all assumptions or ignore the context of claims. Besides, even the strict constructionist cannot escape objectivism entirely (Woolgar and Pawluch, 
1985). On the other hand, Best (1993) notes that contextual constructionism will "...not to be sure, meet the strict constructionists' tests for epistemological consistency, but it just might help us understand how social problems emerge and develop" (1993: 144). He argues:

Just as quantitative researchers continually risk sacrificing sociological substance for more elaborate research designs and more sophisticated statistics, qualitative researchers must balance substance against the demands of theoretical consistency. Analytic purity can come at a terrible cost. The sociology of social problems began with the assumption that sociological knowledge might help people understand and improve the world; strict constructionism sells that birthright for a mess of epistemology (1993: 143).

Best (1993) suggests that researchers turn away from the attractions of postmodern ethnography, and instead develop "grounded theories through analytic induction" (1993: 144). This is the main approach adopted in this thesis.

\section{'Silenced' Claims-Making}

As I will show in Chapter Three, donor anonymity problem was owned by the advocates of the child's right-to-know in the UK. During the public debate the potential impact of the disclosure policy on would-be parents could have been raised as a social problem. However, the government did not face resistance from would-be parents - those who would be most affected by a contraction in donor supply and would carry the burden of informing children of their origins, should they so choose. As I mentioned in Chapter One, my interest in the absence of would-be parents from these debates led to this study. 
From strict constructionist perspective, one might assume that silence of the would-be parents in the donor anonymity debate indicates that there is no problem for them to be postulated. On the other hand, there are many indications of discontent among would-be parents which lead me to challenge the basic assumptions of strict constructionism and study the removal of donor anonymity as a social problem which cannot be expressed by would-be parents in formal modes of communication.

Although this thesis adopts a social constructionist position on social problems -concentrating on explaining the subjective elements of social problems - it avoids a strict relativist stand. There are two main reasons for this. First, a strong reading of Spector and Kitsuse's social problems definition (1977) has focussed attention on successful claims-making activities that gain public awareness. As a result, social problems research has paid little attention to 'silenced' claims-making. Spector and Kitsuse (1977) note that social problems activity commences with collective attempts to remedy a condition that some group perceive as offensive: "social problems arise from statements by groups that certain conditions are intolerable and must be changed" (1977: 148). According to Spector and Kitsuse, there will be preparatory stages of claims-making activities. However, not all such preparations will lead to social problems, "some may be abandoned, some groups may disband before they ever get to the stage of making a claim.[...] In many instances no social problem will develop, but in others, claims-making may emerge" (1977: 129). According to this statement, the validity of a social problem depends on the success of claims-making. If the claims-making activity fails, the problem that 
generated the activity will not be considered as a social problem. This assumption rules out the possibility that some stakeholders can perceive a condition as a problem but repress their claims. For example, like would-be parents in the donor anonymity debate, those who have confidentiality concerns might not be able to identify themselves publicly. As I show in Chapter Seven and Eight, they might also be reluctant to lodge complaints in formal ways. The rigid ontological stand of strict constructionism does not leave room for the analyst to explore a potential problem which could not be articulated, because no social problem exists unless it is defined as such. Strict constructionism also encourages the analyst to leave all her assumptions about a troublesome condition aside. But, following this suggestion, the social problems which did not reach the analyst's attention will not be studied because the analyst cannot theoretically justify the reasons that led her to consider a condition as potentially problematic. This is to say that, the study of absent voices is a challenge to the conventional view of social problems. In analysing an important source of data on voices that were not fully heard in the public debates over ending donor anonymity, - one aim of this thesis is to suggest a more inclusive approach to 'claims-making' definition in social constructionist theories of social problems.

Secondly, linked to the problem above, the social constructionist approach proposed by Spector and Kitsuse says little about studying definitional activities which are made in alternative ways, rather than the formal modes of pressing claims. For example, the social constructionist approach to social problems raises a few practical problems if one is to examine the claims- 
making activities of marginalised, hidden or hard-to-reach populations. Individuals, particularly ones who have confidentiality concerns, can participate in claims-making activities through a variety of ways other than public gatherings or protests about the definitions of troublesome conditions. In Chapters Six and Seven, I draw on Goffman's Stigma (1963) theory to understand the reticence of the interview participants in voicing their concerns: a majority of them consider donor conception as deviance, and a potentially stigmatising condition. Therefore, they employ information control strategies to conceal using donor gametes/embryos to conceive. As they do not want to be exposed to publicity, they engage in claims-making activities in alternative modes of communication (e.g. using online discussion boards to express their reactions or giving anonymous interviews) rather than formal ways. Given this reticence, their voice is unheard by public bodies which can only deal with issues through formal and transparent modes of communication. As a result, they can come to be colonised by the views of those who are less constrained.

\section{Natural history models}

Early work on social problems followed a natural history model. It was argued that every social problem had a history, and social problems developed through a series of stages. Natural history models are useful tools for the development of empirical research for studying social problems. In Chapter Three, I will apply a natural history model to the donor anonymity debate; therefore, it will be helpful to provide a brief review of these models. 
The natural history model was first introduced by Fuller and Myers (1941) who posited that social problem recognition followed an orderly, linear trajectory. Following Fuller and Myers, some other value conflict theorists (Becker, 1966; Blumer, 1971) and social constructionists (Spector and Kitsuse, 1977) also suggested a heuristic natural history model.

In Fuller and Myers' natural history of social problems, first, groups come to see that important values are being threatened by a given situation. In the second stage, sides are chosen since people who propose solutions soon find that these solutions are not acceptable to others. Consequently, ends and means are discussed and proposals for action offered. The final stage is the institutionalised phase of the social problem, in which some groups successfully influence the course of action on behalf of their value definition of the situation. Moreover, administrative units get engaged in putting policy into action.

This kind of categorisation however is open to criticism. Fuller and Myers note that these three stages in natural history are not mutually exclusive, and that they tend to overlap; however, for conceptual purposes, the three general phases may be set off from each other.

As a case study, Fuller and Myers presented a study of a trailer-camp problem in Detroit. The authors claimed that the residence-trailer problem was a situation which could be observed on a local and emergent basis in specific neighbourhoods and communities. They argued, "the factors of localism and 
emergence offer the investigator a delimited area and a timeliness of observation which permit a current, intimate focus on the items of awareness, policy determination, and reform" (1941: 327). However, Lemert (1951b) claimed that these stages could not be completely observed that way. Following Fuller and Myers' work, Lemert investigated the newspapers in several cities in California to study the articulation of the value conflicts over trailer camps. The results did not indicate that a public interest and concern with trailer camps was a critical focus in the newspapers. Lemert did not claim that there was no public awareness of trailer camps as problems: however he argued that neighbourhood awareness of trailer camps as problems manifested itself only in "sporadic and attenuated" form (1951b: 218). According to Lemert, policy formation towards trailer camps in other California cities was largely unilateral on the part of administrative offices. The trailer camps developed in different ways in Detroit than in Southern California. Finally, he concluded that Fuller and Myers' formulation of social problems was inapplicable to the rise and regulation of Californian cities: “...it appears to be an insufficient conceptualization of the interplay of public opinion in culture conflicts in modern society" (1951b: 221). In other words, Lemert thought that the concept of natural history was inadequate to explain the life-cycle of a social problem.

Another theorist, Becker, pointed out that little research had been done on the stages of development of natural history; therefore it was not possible to present a commonly accepted scheme of analysis. According to him, one had to consider the various definitions proposed by interested parties to start an 
analysis. He suggested that every social problem has a history and develops through a series of stages, each stage reflecting a change in who defines the problem, the kind of definition it is given, and the resulting actions taken to solve the problem (1966). Becker went on to propose a natural history model of five stages: the emergence of a social problem; the legitimation of the problem; the mobilisation of action; the formation of an official plan; and the implication of the official plan.

Spector and Kitsuse also proposed a natural history model to monitor the emergence and life cycle of a social problem. Their formulation shares the characteristic features that are presented above, but it is more flexible and provides guidance for monitoring claims-making activities that can be observed in each developmental stage of social problems. The authors divide the natural history of the problem into several periods, each characterised by its own distinctive kind of activities, participants and dilemmas. This is the natural history model that I will apply to the donor anonymity debate, and it will be detailed in Chapter Three.

\section{Conclusion}

My analysis entails several theoretical assumptions. First, I assume that in some cases, claims-making may be repressed by an opposing group, or may not emerge due to lack of public support or institutional power. My second assumption is that in order to study such a problem, the analyst might consider a particular objective condition as an indicator of a social problem as it is neither necessary nor possible for analysts to avoid all assumptions (Best, 
1993). Third, I argue that strict constructionist studies of social problems constrain the analysis of the problems which are not or cannot be articulated in transparent modes of communication; empirical research may require focusing attention on what people cannot do, rather than what people do. Finally, I suggest that analysis of such social problems may necessitate looking into alternative definitional activities where performing a collective activity is not possible or preferable by the stakeholders of the problem.

Arguably, in the UK, the child's right-to-know movement succeeded in the absence of any public articulation of the rights of would-be parents. In Chapter Three, where I present the natural history of the donor anonymity problem, I will also discuss the claims-making activities of the interest groups, and analyse the nature of their claims. Studying the accomplishment of successful claims-making enables the analyst to understand what kind of elements these claims adopt from the socio-cultural context and, hence, what kind of discourse is perceived as legitimate. Such analysis can also help us to understand why some stakeholders cannot press claims due to the perceived illegitimacy of their claims. On the other hand, the accounts from would-be parents that I analyse in Chapters Five, Six, Seven and Eight will illustrate the reactions of would-be parents to this dominating discourse and the new law. I believe that studying suppressed claims as much as successful claims will give a broader perspective to understanding social problems, with a potential to inform policymaking - not least because suppressed claims are likely to generate new problems as stakeholders may find a way to cope with their problem in alternative, potentially less legitimate ways. 


\section{CHAPTER THREE: NATURAL HISTORY OF DONOR ANONYMITY DEBATE}

Social constructionist theories of social problems help us understand how people come to define certain conditions as problematic. Spector and Kitsuse (1977) suggest that social problems should be understood as demanding and responding activities rather than as essential features of a condition, so analysts should focus on claims-making that promotes a particular definition of a problem. In this social constructionist view, a claim is a demand that one party makes upon another (e.g. demanding services, lodging complaints, supporting and opposing some governmental practice or policy). Claims-makers are the people who make claims, and audiences are the people who judge and evaluate the importance of these claims (Loseke and Best, 2003).

Social problems are not static conditions or instantaneous events but a sequence of activities that may move through different stages (Loseke and Best, 2003). For example, the activities of claims-makers in defining a problem are different from the activities they perform once the problem is recognised. As Becker (1966) suggests: "every social problem has a history and develops through a series of stages, each stage reflecting a change in who defines the problem, the kind of definition it is given, and the resulting actions taken to solve the problem" (1966: 13). Natural history models enable analysts to identify these stages. In this chapter, I apply the natural history model proposed by Spector and Kitsuse to the donor anonymity problem in the UK to identify 
these stages and illustrate the way in which certain interests, assumptions and claims led to a change in the law. It must be said, while applying the natural history model, I am more interested in the discourse of claims, and less interested in presenting the sequence of activities in a chronological order. There are two reasons for this. First, the construction and legitimation of the problem is too complicated to be explained by a simplistic model that offers a rigid structure of development stages. This is a critique of all natural history models. ${ }^{5}$ Secondly, my research interest required understanding the nature of claims rather than providing a historical account of the donor anonymity debate.

While presenting the natural history of the donor anonymity problem and the claims-making activities performed in each stage, I will draw on newspaper reports, web-based material, consultation documents, responses from interest organisations to these consultations, and speeches from parliamentary debates. Monitoring social problems requires analysts to be observant of the images and the information available in the public sphere. Conrad (1997) suggests that these presentations can be called 'public eye'. He argues that we can see the public eye as containing the lenses through which people come to understand particular problems. The public eye includes news, television, documentaries, periodicals, fiction and the Internet. Conrad notes that the public eye also "incorporates opinion polls that tell us what we or others believe, government reports or statistics that place an official imprimatur on information, political speeches that frame issues in particular fashions, social movements that bring

\footnotetext{
${ }^{5}$ Spector and Kitsuse (1977) argue that in the life-cycle of a problem some stages can be skipped: "if a Stage can be skipped, it isn't a Stage" (1977: 154-158).
} 
problems to public attention and professionals and organizations (like us) who ruminate about problems" (1997: 140). Similarly, in the career of a social problem it is claims-makers who select the lenses through which the public will come to understand the problem. How these lenses are chosen is central to the promotion of a social problem. In this chapter what is revealed is the way that claims-makers in the donor anonymity debate in the UK shaped these lenses by using distinct kinds of claims about abolishing anonymity.

\section{Claims-making activities in Stage 1: constructing the problem}

Towards the end of the 1990s, there was an alarming decrease in the numbers of people coming forward as sperm donors in the UK. For example, 437 sperm donors were recruited in 1994-1995, but only 271 were recruited in 19981999. ${ }^{6}$ Due to the shortage, it was claimed that some would-be parents became so desperate that they placed advertisements in papers. The problem was perceived to be so severe that there were efforts to establish a new independent organisation to promote egg and sperm donation to infertile couples (BBC News, 1998). ${ }^{7}$ There can be objective conditions that create harm without subjective worry, or people can start to worry about a condition when objective indicators seem to show that the condition is not new (Loseke, 2003). Interestingly, as we shall see, it was not the donor shortage which was

\footnotetext{
${ }^{6}$ Human Fertilisation and Embryology Authority (HFEA) registers (HFEA, 2008d). ${ }^{7}$ The organisation was the brainchild of Fertility Nurses Forum, a sub-group of the Royal College of Nursing. It was claimed that those who wanted to find donors had started placing advertisements in the newspapers. The new organisation aimed to raise awareness and encourage people to come forward as donors.
} 
defined as a social problem, but donor anonymity. Donor anonymity was not a new condition in the UK, but, it emerged as a social problem at the end of 1990s.

Despite the fact that social problems are not characterised by a profound sense of historicity, identifying by whom and when the problem was first articulated in the public sphere may give clues about its emergence as a social problem. My analysis shows that the Children's Society (a national charity involved in campaigning and social policy work to support children) was the first organisation that attempted to transform the anonymity of donors into a public concern.

\section{The Children's Society's call}

In Stage 1 of the natural history model, groups attempt to assert the existence of some condition, define it as offensive or undesirable, publicise their assertions and turn the issue into a public or political matter. The complaining group may or may not be the victim of the said condition: for example, the complaint may be made by an organisation of social workers or another humanitarian group.

In November 1998, the Children's Society called for a change in the law so that people who were born by sperm or egg donation could access the same information about their donors that adopted children could access about their natural parents: 
There are a generation of children growing up today who do not know who they are. We have learned from people who have been adopted how important it is to have access to medical information so they can make informed decisions about themselves. These children's rights have been overlooked and we are sitting on a timebomb (Julia Feast, Project manager of the Children's Society in Simpson, 1998 [emphasis added])

There are a number of claims in this statement: that donor conceived children do not know who they are; and that access to medical information is important to make informed decisions about one's self; that children's rights have been overlooked; that it is only a matter of time before donor conceived children will protest against the status quo. According to the statement, donor anonymity creates identity problems for donor-conceived children who have similar needs to adopted children, and denying access to their identity infringes their rights. As we shall see later, the donor anonymity debate was characterised by this definition in the public sphere.

Activist groups such as the Children's Society make effective owners of social problems because they have resources (leaders, members, budgets, etc.), ideologies and persistence (Best, 1999). The Society's characterisation of the problem was significant and influential as they drew strategically on trends in adoption law, and the search movement. Its call for legal change brought a response from government agencies. In 1999 the Department of Health confirmed that it was looking at the issue and would publish a consultation paper, although, as we shall see, it took two more years to start a consultation, the Children's Society had successfully initiated a controversy. The first reaction to the child's right-to-know claims came from the medical community: 
It [removal of donor anonymity] will effectively deny a lot of infertile couples the chance of being parents. A sperm or egg donor does not create a human being, that needs a womb to give it life. There is a major difference between adoption and egg and sperm donation (Dr Sam Abdallah of the Lister Fertility Clinic in Simpson, 1998).

The National Fertility Association stressed that the government's intention to review the law was bad news for donors:

This may be a victory for children, but it certainly is not for the donors. Their rights have to be protected too. People already give for altruistic reasons and now they are going to be hammered for it (Tim Hedgeley of the National Fertility Association in BBC News, 1999).

\section{A study on donor conceived adults}

Experts may also play a key role in definitional activities because their expertise supports particular interpretations (Best, 1999). They benefit from new opportunities for publications, funding, press coverage, etc. In the donor anonymity debate, the timely findings of a psychological study supported the claims of the Children's Society about the identity problems of donor offspring. The study on donor conceived adults was conducted by Turner and Coyle (2000). Sixteen participants (13 male, three female, age range 26-55 years) recruited through donor insemination support networks in the UK, USA, Canada and Australia were sent semi-structured questionnaires by e-mail and post. The data were qualitatively analysed using interpretative phenomenological analysis. The participants consistently reported mistrust within the family, negative distinctiveness, lack of genetic continuity, 
frustration in being thwarted in the search for their "biological fathers ${ }^{.8}$ and a need to talk to a significant other. Turner and Coyle argued that these experiences could be seen as being indicative of a struggle to assimilate, accommodate and evaluate information about their new identities as donor offspring. The authors claimed that non-disclosure of DI can cause 'psychological damage' and that, for these participants, it undermined the socially valued principles of honesty and trust. The authors suggested that this lack of trust was observed in one participant's behaviour during the study:

It could be postulated therefore that this lack of trust might be replicated in the donor offspring's other relationships. Indeed, the investigators found that it was often difficult for participants to trust them and one donor offspring did not take part because she was doubtful about our intentions (2000: 2049).

The findings of Turner and Coyle's study created controversy in academia. For example, Schilling and Conrad (2001) sent a letter to the journal which published the study in which they criticised the study for having considerable methodological problems. They suggested that its findings were unsubstantiated:

Regarding the interpretative phenomenological analysis of data, the problem may arise that the researchers will only find in the data the facts they have been looking for (...) Although the authors themselves discuss essential differences between adopted children and donor insemination (DI) children, the applied questionnaires are based on findings from research on adoption (...) To our mind it is of vital importance to differentiate between these two groups. In particular, the conclusion that non-disclosure of donor insemination can cause psychological damage seems to be unsubstantiated (2001: 2244-2245).

\footnotetext{
${ }^{8}$ While referring to donors, I avoid using biological 'mother', 'father' or 'parent' as these expressions are linked to certain moral assumptions in the donor anonymity debate.
} 
Social problems that reach Stage 1 may disappear or remain at this stage indefinitely, but sometimes government (politicians and bureaucrats) may support institutionalising the problem because it gains them additional support, resources and/or press coverage (Best, 1999). During the donor anonymity debate, it was not only a call by an interest organisation or expert opinion that made the UK Government act, but also a successful application for judicial review by two donor-conceived individuals.

\section{Rose and Another v. Secretary of State for Health ([2002] EWHC 1593}

\section{(Admin))}

In December 2000, the Department of Health confirmed that there would be a consultation exercise on the rules governing access to information for those conceived through gamete donation. One month later, in January 2001, the Secretary of State for Health received a letter from Joanna Rose, and the family of a child, EM, seeking access to information regarding their anonymous donors. ${ }^{9}$ The Secretary of State's decision on these requests was communicated in a letter of June 2001: he refused access, emphasising that "there was to be a consultation exercise, that the consultation document would be published shortly and that the various points would be considered by ministers following completion of the consultation exercise". ${ }^{10}$

Joanna Rose and EM sought judicial review of this decision. Rose, an adult woman, had been conceived in the UK using donor insemination prior to the

\footnotetext{
${ }^{9}$ Joanna Rose wanted access to non-identifying information, and where possible identifying information, in respect of the anonymous donor. They also wanted directions or regulations to
} 
HFE Act. She had not been able to discover any information about the sperm donor. The other claimant, EM, a six-year old, had been conceived using donor insemination after the coming into force of the Act. ${ }^{11}$ As noted above, these claimants had sought access to information about their anonymous sperm donors and the establishment of a contact register, but the Secretary of State had rejected their requests on the grounds that a consultation exercise on the issue of anonymity was underway.

In the course of the application for judicial review, Rose explained why genetic connections were "very important" to her, "socially, emotionally, medically, and even spiritually":

\begin{abstract}
[N]on-identifying information will assist me in forming a fuller sense of self or identity and answer questions that I have been asking for a long time... With the revelation of my donor conception I am now unable to complete medical history forms...I do not know about half of my ethnicity or racial identity... Without this information these feelings of distress and inequality will not go away. The need to discover this information has become a central feature of my life, along with the need for recognition for this. I need to find out more about my medical, genealogical and social heritage.
\end{abstract}

She also emphasised to the Court that:

[o]ther people who come from families, where they have known both of their natural parents are able to discover this through the process of time. This includes information about their background and religion, where certain of their talents and skills may come from (e.g. parents or relations with musical or artistic skills), why they look the way they do etc. I have a strong need to discover what most people take for granted. While I was conceived to heal the pain of others (i.e. my parents'

be made concerning matters identified in the letter. EM's family was seeking non-identifying information about the donor and the establishment of a contact register.

10 [2002] EWHC 1593 (Admin) at [14].

${ }^{11}$ In the case EM's mother acted as her litigation friend. 
inability to conceive children naturally), I do not feel that these are sufficient attempts to heal my pain. ${ }^{12}$

EM's need for access to information about her donor was explained to the Court by her mother as something that was important to the whole family: for them, secrecy posed a risk for the family not just for EM herself. EM's mother also explained that "[i]f in the future our daughter wanted to make contact with the donor then we would completely support her and help her in this". ${ }^{13}$

In support of their application, the claimants relied on Articles 8 and 14 of the European Convention on Human Rights (ECHR). Article 8 provides for a right to respect for private and family life, ${ }^{14}$ and the European Court of Human Rights has held that this right incorporates the concept of personal identity, including the right to obtain information about a biological parent. ${ }^{15}$ The claimants also invoked Article 14 in conjunction with Article 8, arguing that there should not be discrimination between donor offspring and adoptees or between donor offspring (like Rose) born before the coming into force of the 1990 Act and those (like EM) born thereafter.

\footnotetext{
12 [2002] EWHC 1593 (Admin) at [7].

13 [2002] EWHC 1593 (Admin) at [12].

14 Article 8 provides" 1 . Everyone has the right to respect for his private and family life. his home and his correspondence; and 2 . There shall be no interference by a public authority with the exercise of this right except such as is in accordance with the law and is necessary in a democratic society in the interests of national security, public safety or the economic wellbeing of the country, for the prevention of disorder or crime, for the protection of health or morals, or for the protection of the rights and freedom of others."
}

${ }^{15}$ See e.g. Mikulic v Croatia Application no 5317699. 
The judge, Scott Baker J, outlined a series of principles based on which he concluded that "Article 8 is engaged both with regard to identifying and nonidentifying information". ${ }^{16}$ The principles were as follows:

- Private and family life is a flexible and elastic concept incapable of precise definition.

- Respect for private and family life can involve positive obligations on the state as well as protecting the individual against arbitrary interference by a public authority.

- Respect for private and family life requires that everyone should be able to establish details of their identity as individual human beings. This includes their origins and the opportunity to understand them. It also embraces their physical and social identity and psychological integrity.

- Respect for private and family life comprises to a certain degree the right to establish and develop relationships with other human beings.

- The fact that there is no existing relationship beyond an unidentified biological connection does not prevent Article 8 from biting. ${ }^{17}$

The judge said that he found it "entirely understandable that A.I.D. children should wish to know about their origins and in particular to learn what they can about their biological father or, in the case of egg donation, their biological mother". He emphasised that "[a] human being is a human being whatever the circumstances of his conception and an A.I.D. child is entitled to establish a

${ }^{16}$ [2002] EWHC 1593 (Admin) at [46]. 
picture of his identity as much as anyone else". It was in his view quite clear that Article 8 ECHR and the existing jurisprudence of the European Court of Human Rights supported the idea that "everyone should be able to establish details of his identity as a human being", and that this clearly included the "right to obtain information about a biological parent who will inevitably have contributed to the identity of his child". ${ }^{18}$

Scott Baker J's judgment says nothing however about whether there had been a breach of Article 8 in this case: it focuses only on the fact that Article 8 is engaged. The reason for this is that, at a case management conference prior to the hearing, the judge had decided that the issue of breach should be "stood over":

Once the consultation exercise was under way, and it was clear that the government was giving serious consideration to how to tackle this extremely difficult problem, it was obviously sensible that many of the issues in this litigation should be stood over pending ministerial decisions on what if any government action was appropriate. ${ }^{19}$

Furthermore, Scott Baker J's judgment in Rose is very clear that "the fact that Article 8 is engaged is far from saying there is a breach of it... Whether or not there is breach of it is...an entirely different matter ...". ${ }^{20}$ Ultimately, although Rose and EM's application for judicial review was successful at the first stage, the later hearing to determine whether there had in fact been a breach of Article 8 was delayed and, as we know, regulations passed in 2004 abolished donor anonymity.

17 [2002] EWHC 1593 (Admin) at [45].

${ }^{18}$ [2002] EWHC 1593 (Admin)at [47]-[48].

${ }^{19}$ [2002] EWHC 1593 (Admin)at [16]. 


\section{Culmination of Stage 1}

A feature of Stage 1 in the promotion of social problems is that not only are claims formed and presented but strategies are also developed to press these claims and gain support; through the creation of public controversy. Spector and Kitsuse note that such controversy is the culmination of Stage 1. Claims may provoke reactions from other groups that prefer existing arrangements or who would lose something if they were altered. The claims-making process is characterized by claims-competitions "claims-makers operate within a social problems market place, bidding for public awareness, official recognition, program funding, and other scarce resources" (Best, 1997: 74). Accordingly, while there are many groups competing for social problem status, only a few succeed in convincing the audience (Loseke, 2003). Such conflicts may facilitate the creation of public awareness of the imputed condition. I identified three major claims in Stage 1: that donor-conceived children should have the same rights as adopted children; that donor-conceived adults have personal identity problems because of the missing information about their origins and; that it is donor conceived children's right-to-know find about their origins. In the absence of a significant opposition to right-to-identity claims (except for concerns about donor shortage) the government started a consultation process. Under the natural history model, one might argue that the problem was transformed to Stage 2 .

20 [2002] EWHC 1593 (Admin)at [61]. 


\section{Claims-making activities in Stage 2: recognition of the problem}

In Stage 2, the legitimacy of the claims is recognised by some official organisations. This may lead to proposals for reform, an official investigation or the establishment of an agency to respond to those claims.

\section{The Donor Information Consultation, a MORI poll and the HFEA's survey}

In February 2002, following the announcement that the legislation governing access to information for those conceived through gamete donation would be reviewed, the Department of Health published a consultation paper, Donor Information Consultation, (2001) asking what information should be available to people born as a result of gamete or embryo donation. The paper proposed three main alternatives: non-identifying information on existing donors should be provided on request; more comprehensive non-identifying information should be collected on future donors and made available on request; or identifying information should be collected and provided. The consultation paper did not address the question of whether donor offspring should be told by their families about the means of their conception, which was considered to be "a matter for the parents themselves to decide" (para. 1.10). The Department of Health was cautious in its reference to adoption (paras 2.8-2.12) as a helpful model in considering how the law can protect the best interests of donor offspring: paragraph 2.10 noted that "the parallel with adoption is inexact".Of the 237 responses to the public consultation, 132 favoured making identifiable information available, 70 were opposed and 23 were undecided. There was widespread agreement (211 responses) that more 'non-identifying' information 
about donors should be made available to people conceived as a result of gamete donation (Department of Health, 2003).

Spector and Kitsuse (1977) note that when governmental agencies respond to the complaints of a particular group, the social problems activity undergoes a considerable transformation. They argue that "even the simplest response to the claims may bring about a transformation in the protest groups or create new organizational crises for it" (1977: 149). Recognition of its claim can mean that a group gets involved in official proceedings on the problem. In the donor anonymity problem it was the Children's Society that took part in starting official proceedings. In March 2002, a MORI poll was commissioned by the Society to explore public opinion on whether children born using donated sperm or eggs should have a right to know their genetic history at the age of eighteen. The poll found that the public was in favour of allowing people conceived from donor gametes to gain more information about their genetic parents. These results were welcomed by the Society:

[t]he results from this poll are too powerful for the government to ignore. Children have been living under the shadow of legislation that has denied them the right to the most basic information about themselves for too long (Julia Feast in BioNews, 2002).

The Children's Society's efforts were supported by Baroness Warnock, one of the architects of the 1990 legislation. She noted that children conceived with donor insemination should have access to information about their biological father, including genetic details which could be crucial to their health. Her 
view received wide coverage in the media. She argued that it was "morally wrong to deceive children and deprive them of knowledge about who they are, especially when now, we all understand so much more about the importance of genetic inheritance". She also stressed that her opinion about the matter had changed in the last two decades:

It's absolutely deplorable for a child not to know what other children know... I am speaking out now because I wanted to make sure that nobody used our 1984 report which is almost 20 years old as an argument (BBC News, 2002a).

During the debate one of the most influential counterclaims-making groups was the British Fertility Society (BFS). ${ }^{21}$ Other major professional groups (e.g., Royal College of Obstetricians and Gynaecologists and British Medical Association) were also opposed to the disclosure policy on the grounds that this would have an adverse impact on donor supply. After the consultation was closed, BFS published their response to the consultation paper. The BFS recommended that the regulations allow only for non-identifying information. It claimed that it was not the right time for a radical change to remove anonymity because the majority of donors and recipients were not ready for this. It also suggested a new framework under which donors could choose to be either anonymous or identifiable (British Fertility Society, 2002). Dr John Mills, Chairman of the BFS said:

The BFS welcomes the Donor Information Consultation and timely debate on this complex, sensitive and very important matter. The Society has a multidisciplinary membership of doctors, nurses,

\footnotetext{
${ }^{21}$ The BFS was founded in 1972, with the encouragement of IVF pioneer Patrick Steptoe. It is a multidisciplinary professional non-profit organisation whose membership includes clinicians, counsellors, nurses, embryologists, andrologists, and research scientists, working in the field of infertility and assisted reproduction. The main purpose of the Society is to increase knowledge and understanding in this field.
} 
scientists and counsellors and while there are areas of general consensus there is also some disagreement particularly over the question of donor anonymity. The BFS view is to avoid a position that is resistant to change and to adopt a progressive and informed approach (British Fertility Society, 2002).

Media coverage showed that the medical community was worried about losing potential donors:

The vast majority of donors we have would not be prepared to donate if they thought there was a real possibility they would be identified to their donor offspring (Dr Gillian Lockwood, medical director of Midlands Fertility Services in Dyer, 2002).

Contrary to what Lady Warnock said, I think there would be a significant drop. I know of one or two clinics that are close to packing up already. There will still be people who want to donate, but I think the numbers will drop significantly (Dr George Ndukwe, clinical director at the CARE clinic at Park Hospital, Nottingham in Dyer, 2002).

The proposed changes in the Human Fertilisation and Embryology Authority (HFEA) review (HFEA, 2005a) and the EU directive on standards relating to the handling and use of human tissues and cells may also lead to further reductions in donor treatment activity. On the other hand, the demand for donor sperm is likely to increase because of a possible decline in the semen quality in the general UK population (Dr Jane Stewart, honorary lecturer at the University of Newcastleupon-Tyne and consultant gynaecologist and specialist in reproductive medicine at the Newcastle Fertility Centre at LIFE, in Willson, 2005).

The numbers of donors in this country are actually reducing, and particularly in terms of egg donation. If donors feel someone's going to knock on their door in 18 years' time, they'll think twice about donating (Glen Atkinson, medical director of the fertility clinic CARE, in BBC News, 2002b).

There is a danger that if we cannot recruit donors we may find that many infertile couples will be unable to receive treatment. We are concerned that if this happens, some couples may seek treatment overseas (Dr Allan Pacey of the British Fertility Society in BBC News, 2004). 
The only interest group that represented would-be parents, INUK (Infertility Network UK) expressed similar concerns:

We worry that the removal of donor anonymity will only further the diminishing number of egg and sperm donors (Sheena Young of the Infertility Network UK-patient support group in BBC News, 2004).

Following the Department of Health's consultation, the health minister Hazel Blears told the House of Commons that any decision on waiving anonymity would be put off for at least six months to allow more discussion with clinics and donors:

We agree that there is a strong argument in principle for children conceived using donated sperm, eggs or embryos being able to find out the identity of their donor...However, we believe that this sensitive area needs further consideration and debate - very few fertility clinics responded to our consultation exercise (Arthur, 2003).

The media reported that Ministers feared that donors would be put off by the possibility of being identified in the future against their wishes, and that this would lead to a drop in sperm or eggs made available for infertility treatments (Arthur, 2003). The media also reported that various charities supported the consultation exercise:

The whole business of [anonymous] sperm donation, where children are reduced to commodities, is wrong, and the fact that resulting children never know their biological fathers compounds this. Children have a right to know their biological background for medical and emotional reasons. Protecting sperm donors' anonymity encourages the view that fatherhood is to be undertaken lightly (Nuala Scarisbrick, of the charity Life, in Arthur, 2003).

However, some charities were worried that, following the medical community's veto, the government would backtrack. For example, Rupert 
Rushbrooke, director of Bloodlines, a pressure group campaigning for the rights of children created by sperm donation, said Ms Blears had "backtracked" from ministers' earlier proposals to remove anonymity for future conceptions. He claimed:

The Government was clearly ready to remove the secrecy in donor conception, but their decision has very obviously been vetoed by the medical profession (Arthur, 2003).

The HFEA was also concerned that the government would not move towards an open donation system as fast as the Authority hoped. One might argue that it is rather unusual for a regulatory body to make its moral stance explicit. The following extract demonstrates HFEA's position in the debate:

Clearly we are disappointed that the Government feel we can't move to an open system now but today's proposals are a step in the right direction. What is now needed is a change in the climate of thinking about infertility. A move towards open donation is a move towards a genuine acceptance of donor insemination. A detailed register of donors is kept, yet people still cannot find out who their parents are. It is essentially a matter of principle (Suzi Leather, chairwoman of the HFEA in Arthur, 2003).

The Department of Health sought further information from clinics and donors.

Responses were received from 140 donors and 42 clinics. "Most but not all" clinics said they were opposed to the removal of anonymity. Some respondents were concerned that fewer donors would come forward at a time when there were already not enough of them. In addition, it was pointed out that removing anonymity would have no effect on secrecy since many parents chose never to tell their children that a donor was involved in the conception. Twelve donor offspring wanted non-identifying information and 11 identifying information. Fifty-eight donor insemination (DI) parents advocated the availability of non- 
identifying information and 38 the availability of identifying information. Twenty-two of the donors agreed with the provision of non-identifying information but only eight agreed with the provision of identifying information (Lawford-Davies and Forsyth, 2004).

During the spring of 2004, the HFEA conducted a survey of clinics to develop a detailed understanding of the current demand for, and provision of, treatment using donated gametes or embryos, as well as to identify relevant trends (HFEA, 2005b). Sixty-two of the 99 surveyed clinics responded. The removal of donor anonymity was the most frequently cited factor anticipated negatively to affect sperm and egg donation. These findings indicated that many practitioners expected the removal of donor anonymity to have a negative impact on the provision of treatment services with donor gametes. The clinics were already suffering from a donor shortage. ${ }^{22}$

\section{Removal of donor anonymity}

The UK government subsequently announced, in January 2004, that people who donated eggs, sperm or embryos in the UK were to lose their right to anonymity from 1 April 2005. Anyone born using sperm, eggs or embryos donated after that date may ask the HFEA for identifying information about their donors, when they reach the age of 18 . Donors may only be told whether

\footnotetext{
${ }^{22}$ The total number of donors for general use was estimated to be 1,024 . This number is subject to a number of caveats. First, it may include donors who have donated at more than one donor recruitment centre, in which case the number would be an overestimate (the HFEA Code of Practice $7^{\text {th }}$ Edition (HFEA, 2008f) currently imposes a limit of 10 live birth events per donor). Secondly, it may capture some donors with sperm held in storage at more than one clinic. If this were the case, it would further reduce the number of individual donors available. Thirdly, for many clinics the donor sperm in storage originates from donors recruited at other UK
} 
any children were born from their donation and some limited information about them - number, gender and the year(s) in which they were born. With regards to non-identifying information, a donor-conceived person aged 18 or older can obtain a list of non-identifying information about their donor from the HFEA if they ask for that information and if that information is on the HFEA's register.

The then Parliamentary Under-Secretary of State for Health, Melanie Johnson, indicated that the government's decision to remove donor anonymity was based on the public consultation; a programme of work with clinics and donors; consideration of the position in other countries; and a comparison with the information available to adopted people:

I firmly believe donor-conceived people have a right to information about their genetic origins that is currently denied them, including the identity of their donor (...)We live in an age where, as technology continues to develop, our genetic background will become increasingly important. I have listened to the views of donor-conceived people and they would like more information about their genetic origins - perhaps for themselves, perhaps for their children, perhaps because they feel the information belongs to them. That it is rightly theirs. (...)There is a growing body of opinion, which I agree with, that donor-conceived people should not be treated so differently from adopted people. Today's new regulations will align their positions, removing the major discrepancy that exists between the rights of donor-conceived people and those of adopted people (HC Deb (2003-04) 416 col. 60WS.).

The government's announcement provoked reactions from different groups. A number, including the HFEA, supported the decision:

centres and may be stored for specific use at clinics. Therefore, 1,024 may not reflect the actual number of donors available to every centre. 
We have been asking for this for a long time. I can understand why people want to know who their genetic parents are (Suzi Leather, chairman of the HFEA, in BBC News, 2004).

It's like adoption. It helps some people who are adopted to know who their parent is (Laura Spoelstra, chairman of the National Gamete Donation Trust, which raises awareness of the need for egg and sperm donors, in BBC News, 2004).

This announcement has the potential to lift the stigma of secrecy from the field of donor conception (Marilyn Crawshaw, a spokeswoman for UK DonorLink - a voluntary contact register for donors and their children, in BBC News, 2004).

\section{Debates in parliament}

Following the government's announcement, on 18 May 2004, Melanie Johnson opened the first standing committee on delegated legislation, draft HFEA Regulations 2004 (Disclosure of Donor Information). During her speech she stated that the position of donor-conceived people should be more closely aligned with that of adopted people; the regulations therefore provided for donor-conceived people to have access to information about their genetic origins. She pointed out that the draft regulations were strongly supported by the Donor Conception Network, the British Association for Adoption and Fostering, other children's organisations and the HFEA itself (Stg Co Deb, 2003-04).

Following the debate held in the House of Commons, on 9 June, 2004 the House of Lords discussed the issue. In her opening speech, Baroness Andrews explained the reasons that made this provision seem so necessary (HL Deb, 2003-04a: col. 344-349). Some of the issues that she raised were: that the secrecy and even stigma surrounding assisted conception had faded (col. 345); 
that public attitudes towards information and rights to information have changed dramatically (referring to the Rose case, col. 345$)^{23}$; and that such openness had worked successfully in recent years in relation to adoption (col. 348). Baroness Andrews also addressed a few concerns raised by the opponents of the new law:

Although we recognise that there is likely to be a dip in donor numbers - certainly in the short term - evidence from other countries suggests that donor levels will rise again (HL Deb, 2003-04a: col. 346)

One of the fears that has been raised is that parents might be deterred from telling their children that they are donor-conceived, but I understand that research soon to be published by Susan Golombok, Director of the Family and Child Research Centre at City University, indicates that more parents are planning to tell their child about donor conception - about 50 per cent intend to do so (HL Deb, 2003-04a: col. 347).

During the debate, some peers stated their concerns about the potential shortage of eggs and sperm. However the government said that it was planning a campaign, which would cost $£ 200.000$. The campaign would be conducted with the support of three organisations: National Gamete Donation Trust ${ }^{24}$, the British Fertility Society ${ }^{25}$, and the Donor Conception Network. ${ }^{26}$ Baroness Andrews noted that the aim of the initiative was "to accompany the transition

\footnotetext{
${ }^{23}$ She argued: "Information now is much more readily accessible than it was in 1991...In a century where access to information is regarded as a personal and political right, this does not seem any longer to be appropriate. It has already proved to be a bone of contention-the Government are very likely to be challenged about the provision of information to donorconceived people, as the Department of Health has already been in an application brought by Liberty. That application related to the provision of non-identifying information."

${ }^{24}$ The National Gamete Donation Trust was set up in 1998 as a national government-funded charity, to raise awareness of, and seek ways to alleviate the national shortage of sperm, egg and embryo donors.

${ }^{25}$ BFS's response to the Call for Evidence of the House of Commons Select Committee about anonymity was: "The loss of anonymity for donors remains an area of concern with regard to its impact on donor recruitment. A review should allow for reconsideration of a twin track approach."

${ }_{26}^{26}$ The Donor Conception Network is a group started in 1993 by parents who had decided to tell their children about their origins and who came together to support each other.
} 
to donor identifiability with a positive, proactive campaign for public awareness of the value of donation, so that the government can help clinics to recruit identifiable donors" (HL Deb, 2003-04a: col. 347).

\section{Claims-making activities in Stage 3: re-emergence of claims and controversy}

Spector and Kitsuse's description of Stage 3 is different from its counterparts; whereas past natural history models end with legitimation and implementation, theirs is open-ended since official acceptance is seen as a possible ground for a 'new generation' of definitional activities (Schneider, 1985). Spector and Kitsuse (1977) argue that Stage 3 is the re-emergence of claims and demands by the original group(s) or by others, expressing dissatisfaction with the established procedures. These activities are not concerned directly with the conditions imputed in Stage 1, but with the organisational procedures of dealing with the complaints. If claims-makers are not satisfied with the official response in Stage 2, for example, Stage 3 may begin.

In the UK, neither the claims-makers who proposed the removal of donor anonymity, nor their opponents were satisfied by the policy change. Lifting anonymity was perceived as a positive step towards openness by the children's organisations, but it was not their ideal solution. As Wallbank (2004) argues, the government's reluctance to compel disclosure sent a half-hearted message to parents, although it offered no practical reassurance to prospective donors. 
In fact, none of the countries that have removed donor anonymity has formalised a system for informing the child (Frith, 2001): all leave the decision to the parents. The issue is perceived as one of family privacy. Where the child does not suspect his or her circumstances of conception, no question of tracing their genetic origins exists (Liu, 1991: 85). As Thévoz (1997) points out, openness and truthfulness in family relationships and respect for the child's autonomy are ethical demands, which are almost impossible to convert into legal obligations. Similarly, Waldman (2007) argues:

Parental disclosure patterns in an era of evolving social norms are resistant to change .... Changes in social norms may help parents feel more comfortable with the complex relationships ART creates, but existing data reveals that the changes are slow and legislative initiatives exert a less powerful gravitational pull than we might expect (Waldman, 2006: 549).

Spector and Kitsuse have an interesting observation for explaining similar policies. They argue that the official response or established procedures may, in fact, turn out to be a public relations solution in which the imputed conditions are ignored on the view that the social problems activities can be "cooled out". Nevertheless, as we shall see in the following section, these public relations solutions can be challenged by the claims-makers.

\section{Claims against the new law from the child's right - to - know camp}

The child's right-to-know camp was not convinced that lifting anonymity would encourage openness and claims on the right-to-know soon re-emerged as an issue. In their response to a consultation ${ }^{27}$ on the HFE Act in 2005 the

\footnotetext{
${ }^{27}$ The Department of Health undertook a public consultation exercise over the summer and autumn of 2005 on possible changes to update the law and regulation relating to human
} 
British Association for Adoption and Fostering (BAAF) demanded that donor conception should be registered on a child's birth records. They expressed their dissatisfaction with the new law as follows:

We have a responsibility not to collude with the parents who have chosen not to be truthful with their child about his and her genetic origins. Prospective adoptive parents would not be approved as adoptive parents if it was thought that they would not tell their child that $\mathrm{s}$ /he was adopted.(...) this is why it should be a statutory requirement for prospective parents of a donor conceived child to undergo an assessment and preparation period, where such matters can be addressed. One way of encouraging parental disclosure would be to annotate birth records in a way analogous to adoption and parental order registration. The birth record should not endorse a biological untruth and if parents know that the information is recorded somewhere in official documentation it may prevent deceit and secrecy. The "short" birth certificate, which can be used for most purposes, would not indicate the individual's status as donor-conceived (British Association for Adoption \& Fostering, 2005: para 45).

This proposal was not accepted (Department of Health, 2006). However, in its initial proposals for revising the HFE Act 1990, the government did indicate that it would recognise in law some reciprocal rights of donors, and widen access in relation to consanguinity:

For the first time, the law will make clear the right of donors to access limited nonidentifying information about children conceived as a result of their donation. Also, the law will, in some circumstances, allow donors to be informed when their identifying details have been requested by those children. In addition, donor-conceived children will be able to find out if they have donor-conceived siblings, as part of the information accessible to them at age 18 (Department of Health, 2006: para 2.58).

Nevertheless, during the review of the Human Tissue and Embryos Draft Bill, 'legal' right-to-know claims re-emerged. In August 2007, the Joint Committee on the Bill considered the right to know and the need to be told. Some of the 
witnesses suggested that the draft Bill should be amended to give donor conceived people a 'legal' right to know and the parents the legal duty to tell. It was argued that, as the state was involved in assisted conception, it should not be actively involved in deception (Department of Health, 2007: Ev 44).

Related to the arguments about a legal right to know, the Joint Committee considered whether donor conception should be registered on the birth certificates of donor-conceived people. A donor-conceived person argued that a man or woman whose gametes are not used to create a child should be referred to not as a parent but as an "adoptive parent" or a "step parent" (Joint Committee on the Human Tissue and Embryos (Draft) Bill, 2007: Ev 16, para. 16). The provisions that he would like to see in the draft Bill included that Parliament should bring donor-conceived people on a par with adoptees by applying 'donor' identification legislation retrospectively: if a person is donorconceived this must be indicated on the birth certificate; and that gamete recipients must pass the same stringent checks passed by adopting adults.

This witness's view that donor conception "must be required to be indicated on the birth certificate because a person must know they are donor conceived" was supported by several other witnesses. The Joint Committee's decision on the issue was " $[\mathrm{t}]$ his is a complicated area involving the important issue of privacy, as well as issues of human rights and data protection. We therefore recommend that, as a matter of urgency, the Government should give this matter further consideration" (Department of Health, 2007: Recommendation 28, para. 276). 
One witness pointed out that the right to know should be protected through law, because "the right to information at the age of eighteen is largely illusory in the case of donor-conceived children unless they know they are donorconceived". He also claimed that there was a "very strong trend" in English domestic law to get at the truth of biological origins (Department of Health, 2007: Ev 14, paras. 5-9). The BAAF also wanted to see an urgent review of how children born as a result of donor-assisted conception have their status reflected in official records (2007: Ev 37). These proposals were designed to make sure that parents tell their children about their donor-conceived beginnings. Would-be parents expressed their anger and anxiety at these proposals on online discussion boards. The Donor Conception Network, an NGO which advocates for the child's need to be told about the donor conception, stated that it did not support the proposal. The organisation sent a briefing to Members of Parliament on this matter (and others within the Bill) and also invited would-be parents to take action to protest against the proposal. On the discussion forum of an online patient support group, fertilityfriends.co.uk, some would-be parents asked whether the proposal included those who received treatment abroad. A representative from the Donor Conception Network commented that, based on their interpretation of the policy, if it was agreed by Parliament that a symbol or wording should appear on the birth certificate indicating that a child had been conceived by donor conception, all parents would be expected to tell the Registrar of Births about a donor conception, no matter where the conception took place.

When the Joint Committee reviewed the draft Bill, it was not only the BAAF but also the British Medical Association who hoped that the government would 
change the law. The BMA was one of the organisations that had opposed the removal of donor anonymity. It was disappointed that the government had not taken the opportunity of this Bill to review that decision. It reported that the removal of donor anonymity was having a detrimental impact upon the availability of treatment with donor gametes and, despite reports from the HFEA that the number of men registering as sperm donors had increased, the number of women registering as egg donors continued to fall. The BMA also stressed that the number of people registering as donors may not give an accurate picture of the number of donor conception treatments taking place and the length of time that prospective patients had to wait for treatment:

The BMA would like to see increased openness between parents and their donor-conceived children. We are concerned that the removal of donor anonymity may have made such openness less likely. Parents who are unwilling for their child to make contact with the donor when they reach 18 may be less likely to tell their child they were donor conceived (British Medical Association, 2008).

Eventually, although the Joint Committee believed that it was in the best interests of the child to know of their donor conception, the Committee did not endorse of the view of those who called for a statutory duty on parents to tell their child of his or her donor conception. The government agreed that it was preferable that parents were educated about the benefits of disclosure rather than forcing the issue through the annotation of birth certificates. The government's response published in October 2007 rejected the Committee's suggestion of putting 'by donor' on birth certificates of donor offspring, but decided to keep the matter under review. The government's response to this recommendation was that it is preferable that parents are educated about the 
benefits of disclosure rather than forcing the issue through the annotation of birth certificates. However, the government considered this as a sensitive area that should be kept under review: "We believe that the issues need to be considered carefully, including constructive dialogue with stakeholders, and we will keep the matter under review" (Department of Health, 2007: paras. 69$70)$.

\section{Claims against the law from opponents of the open donation system}

It was not only the advocates of the child's right-to-know who expressed discontent about the 2004 law, but also opponents of the open donation system for whom the steady decline in the number of sperm donors was a serious concern.

Acute donor shortages and long waiting lists for would-be parents were regularly reported in the media. According to a $\mathrm{BBC}$ investigation in 2006, 50 of the 74 clinics in the UK reported that they had insufficient sperm or none at all. The BBC found only 169 registered donors in the UK, with none in Northern Ireland, one in Scotland, and six in Wales (Dreaper, 2006). A BBC Scotland survey of Scotland's five IVF clinics found a crisis in supply that had completely halted treatment in two clinics and brought long waiting lists in others (BBC News, 2006a). ${ }^{28}$ Dr Evan Harris MP, a former GP and member of the House of Commons Science and Technology Committee, blamed the new law:

\footnotetext{
${ }^{28}$ The survey revealed that two of Scotland's four NHS clinics have suspended services because of a lack of donors. In one clinic, the waiting time for egg donation treatment has more than doubled since the law was introduced, from 2 years to at least 5 years. Another clinic had no new donations since the law was introduced and there had been between 30 and 40 patients that the clinic was unable to treat. One clinic reported that for the first time they had to start a waiting list for treatment using donor sperm at the end of last year and they were no longer able to offer any treatment until supplies became available.
} 
The decision to abandon donor anonymity was stupid and misguided (Woolf, 2006a).

The Government should reopen this issue. It's urgent because people are waiting. They will either go abroad, to unregulated sperm producers or go childless. What the Government is effectively saying is, it is better for children never to be born than not to be able to contact their parent (Woolf, 2006b).

Clare Brown, chief executive of Infertility Network UK, called for an urgent recruitment drive by the Department of Health to persuade men to come forward and replenish the country's sperm banks:

There is not just a shortage of donor sperm in the UK - we are actually facing a crisis. The number of donors started to decline when the removal of anonymity of donors was first broached - even before it became law. But since the removal the situation has worsened and something has to be done to help the many, many couples who will never have a family unless we do something. Many couples face a childless future just because of a lack of sperm (Woolf, 2006b).The situation facing infertile couples was so acute that the HFEA called on sperm banks to consider using stocks of sperm reserved for couples who may want a second child (Woolf, 2006b). Nevertheless, the HFEA did not consider removal of donor anonymity as a reason behind the sperm shortage. The Authority accused some clinics of 'hoarding' their supplies of sperm and refusing to release it to other clinics. These clinics responded that they were forced to stop supplying other fertility centres because the sperm shortage meant that they could not meet the needs of women on their own books (Woolf, 2006b). 
The BFA claimed that short term effect of the change in legislation had been that the cost of DI had risen enormously in many centres, and the programme had effectively been removed from the NHS as standard practice in most areas (British Fertility Society, 2007). According to the National Gamete Donation Trust, over 500 sperm donors are needed annually in the UK. The HFEA registers show that in 2000 , there were 325 men registered as donors. The latest figures from the Authority show that this figure dropped to 259 in 2005, and reached 307 in 2006. There is a sharp decrease in egg donor numbers. In 2000 there were 1242 egg donors, in 2006 this figure dropped to 812 . As a subset of total egg donors, there were 500 egg sharers in 2004. This figure dropped to 323 in 2006. The National Gamete Donation Trust notes on its website that there is an acute shortage of egg donors and many couples wait for several years to benefit from donated eggs.

\begin{tabular}{|l|l|l|l|}
\hline & & & \\
Year & $\begin{array}{l}\text { Sperm } \\
\text { donors }\end{array}$ & Egg donors & $\begin{array}{l}\text { Egg share donors } \\
\text { (subset of total egg } \\
\text { donors) }\end{array}$ \\
\hline 2000 & 325 & 1242 & \\
\hline 2001 & 328 & 1315 & \\
\hline 2002 & 278 & 1179 & \\
\hline 2003 & 255 & 1056 & \\
\hline 2004 & 247 & 1064 & 500 \\
\hline 2005 & 259 & 956 & 409 \\
\hline 2006 & 307 & 812 & 323 \\
\hline
\end{tabular}

Table: Donor registration at centres per year ${ }^{29}$ (HFEA, 2008d)

\footnotetext{
${ }^{29}$ It must be noted that the figures that HFEA currently publishes may include duplicates where an individual donor has registered again at a different clinic.
} 
The HFEA has referred to the drop in sperm donor numbers as a 'myth' (HFEA, 2007a). It must be said that the donor shortage issue has been controversial, as the figures can be read differently. Although the HFEA acknowledges that there is a donor recruitment problem in the UK, it does not consider this to be a consequence of the change in the law. The Authority interprets any recovery in donor numbers as evidence that the new law did not affect recruitment. The HFEA blames the shortage on clinics' poor recruitment strategies:

Our figures show that it's a myth that the change in the law has caused a sudden fall in sperm donors. What we see is a patchy provision across the country (HFEA spokesman John Paul Maytum in BBC News, 2006b).

Many commentators continue to claim that the change in the law to remove anonymity for sperm and egg donors would lead to an immediate and steep fall in the number of donors. These new figures show that the predicted drop in sperm donor numbers is a myth. The HFEA's role in the donor system is to keep a register of every person who becomes a donor and to provide guidelines for the donation system. We have no role in encouraging donors to come forward. However we do think it is important to inform the work of those people working in the donor system by providing information about trends in donor recruitment. Professionals working in the sector say that there are a complex set of reasons which led to a fall in donor numbers from 1997 onwards. The British Fertility Society, the National Gamete Donation Trust and other organisations have been looking at ways to improve the numbers of sperm donors recruited in the UK. It is acknowledged that egg donations have fallen during this period but the procedures for and issues involved in egg donation are much more complex, as are the reasons why women may or may not choose to donate (Shirley Harrison, chair of the HFEA, in HFEA, 2007a).

In its response to the HFEA's press release, INUK draws attention to the fact that the number of donors in the UK has been declining since the possible removal of anonymity was first raised back in 1997, and that due to donor shortage patients have no choice but to go abroad for treatment: 
We are pleased to see the slight increase in the number of sperm donors in the UK in 2006 compared to 2005 figures. However, the number of both sperm and egg donors in the country falls far short of the numbers needed to allow patients to access donor treatment. The shortage of donors means that some clinics are no longer even accepting patients on a waiting list. The number of donors in the UK has been declining since the possible removal of anonymity was first raised back in 1997/98 and what is needed now is an ongoing national campaign to recruit donors in local areas, backed up with the infrastructure to support them and give patients the opportunity to have their treatment without waiting years or being forced to consider going abroad for treatment (Clare Brown, Chief Executive of Infertility Network UK, in Medical News Today, 2007).

The groups that the HFEA mentioned in its briefing such as the BFS and the

National Gamete Trust also raised the problem of the donor shortage:

The BFS notes with interest the HFEA's report of a slight increase in the number of sperm donors registering in the UK in 2006. The BFS remains concerned that availability of sperm donation services remains patchy at best throughout the country. The Society is aware of several centres which have now withdrawn donor insemination services to patients, and for those who may be fortunate to be able to access treatment, costs and waiting times have greatly increased (Mark Hamilton, chairman of the British Fertility Society, in Henderson, 2007).

The National Gamete Donation Trust addressed the shortage as follows:

It is crucial to remember that we haven't reached the required 500 sperm donors per year and we are nowhere near solving the problem of the shortage of egg donors. Most of the increase in numbers is down to the sustained work of a small number of committed clinics (Laura Witjens, chairwoman of the National Gamete Donation Trust, in Henderson, 2007) 


\section{PAGE/PAGES EXCLUDED UNDER}

INSTRUCTION FROM

UNIVERSITY 
Campaigns were launched throughout the country to promote sperm donation and the BFS established a working party to examine sperm donation in the UK. Its report was launched at a HFEA meeting in February 2008. The report made a number of recommendations about how the existing pool of donors could be used to more effect: "the report gives a helpful impression of the current state of sperm donation services in the UK, showing an undeniable mismatch between supply and demand". The HFEA's response in July 2008 was that the Authority's remit did not extend to the recruitment of donors; this was a matter for the sector and should be addressed as a matter of urgency (HFEA, 2008a). It was not until later in 2008 that the HFEA expressed 'great concern':

[T] he number of donor insemination cycles and births continues to fall. While more couples are able to take advantage of techniques such as ICSI, for those patients whose treatment requires donor sperm, this is of great concern. The HFEA is supportive of clinics that are actively recruiting donors and we welcome the BFS Working Party proposals to introduce a national system for donor recruitment (Lisa Jardin, chair of HFEA, in HFEA, 2008e).

Not only in Stage 3, but in all stages of natural history of the problem, opponents of the open donation system based their claims on the donor shortage. The law was also criticised for several other reasons. In a letter to The Times (21 September 2006) Professor Sir Colin Campbell, founding chair of the HFEA (1990-1994), called for the restoration of anonymity for sperm donors. In his view, the putative interests of a person not yet conceived should not take precedence over the legitimate interests of would-be parents: "the policy is causing anguish to couples who are unable to conceive without assistance, and putting serious impediments in the way of those otherwise 
willing to assist with donations. The policy must be changed" (Campbell, 2006). He was supported by his successor as chair, Baroness Deech (19942002):

The lobby for the removal of anonymity asserted a misleading parallel with adoption, but adoption has a history and a relinquishment that call for explanation. The argument that one needs to know one's father in order to ascertain health issues is also false. Medical predictions can be made just as accurately from one's own body (Deech, 2006).

Professor Lord Winston from Imperial College, London, also contributed to the discussion by drawing attention to two other adverse effects of the regulations abolishing anonymity. First, more couples undergoing these treatments were stating a firm intention to conceal the method of conception from any child. Second, a woman donating eggs to another infertile woman during her own treatment, but whose own treatment fails, may be distressed to learn that she has a genetic child of whose existence she was not aware (Winston, 2006).

Advocates of the child's right-to-know joined this debate. Eric Blyth, Professor of Social Work at the University of Huddersfield asserted: "Sir Colin Campbell (letter, Sept 21) allows expediency to trump a significant human rights issue: the interests of donor-conceived people to learn about their genetic history" (Blyth, 2006). A number of letters were contributed by donor offspring. Their main theme was that awareness of one's parents was a norm in society and withholding such information was discriminatory. It was argued that donor offspring had a "terrible fate" and "suffered harm". In response to these letters, Dr Andrew Lawson, from the Medical Ethics Unit at Imperial College, noted that all treatments and therapies have the potential to harm and that, if doing no 
harm was the prime code of medicine, then practitioners were bound to do nothing (Lawson, 2006).

\section{Silent resistance of would-be parents}

Would-be parents remained silent during the debate. They had the possibility of accessing to anonymous treatment in other medically advanced countries. Fertility travel and purchase of sperm online increasingly featured in the media after the new law came into effect. The titles of many news reports presented dramatic pictures of fertility travel: "EU faces fertility tourism threat" (BBC, 30 June 2004); "Plea for egg and sperm donors" (BBC, 30 December 2004); "Fertility tourism 'is inevitable" (BBC, 20 June 2005); "We went to Hollywood for IVF" (BBC, 14 December 2006); "Donor Crisis 'fuels IVF tourism" "(BBC, 14 December 2006); "Personal story: IVF in Barbados" (BBC, 15 December 2006); "IVF Tourism: an ethical dilemma?" (BBC, 19 December 2006); "Personal story: IVF in Istanbul" (BBC, 19 December 2006); “Warning over 'fertility tourism' (BBC, 28 April 2006); "Call for EU-wide fertility rules" (BBC, 2 July 2007); India's surrogate mother industry (BBC, 12 October 2008); "Baby chase" (The Guardian, 26 June 2004); "Loss of anonymity could halve number of sperm and egg donors"( The Guardian, 19 October 2005); "British couples desperate for children travel to India in search of surrogates" (The Guardian, 20 March 2006);"Cruel cost of the human egg trade" (The Guardian, 30 April 2006); "The fertility tourists" (The Guardian, 30 July 2008). 
DIAGRAM ON THIS PAGE EXCLUDED

UNDER INSTRUCTION FROM THE UNIVERSITY 
The discussion boards of online support were snowed under with posts about clinics abroad. These alternative counter claims-making activities will be discussed in Chapter Five.

The HFEA warned patients about the consequences of seeking treatment abroad:

We know that a relatively small number of people choose to travel abroad to undergo fertility treatment and that sometimes the treatment is packaged as a "holiday" where the patient can convalesce in the sun. However, we are concerned about people who choose to have their treatment abroad should know about the potential risks. We have heard of some clinics which offer treatment to patients that is so dangerous that it has been banned in the UK. For example implanting five embryos which significantly raises the chance of multiple pregnancy, the biggest risk of IVF for both mothers and babies. It is very sad when we receive complaints from patients about their treatment abroad and we are not able to help or reassure them. We would urge patients to think twice and consider the risks and implications before going abroad for treatment (Suzi Leather, chair of the HFEA, in HFEA, 2006).

Similar warnings were published on the website of the Donor Conception

Network, a self-help network for donor conception families. 
DC Network is increasingly being approached by people seeking information about clinics outside the UK that provide donor conception, usually egg donation (...) Anyone planning any sort of medical treatment abroad may have to face the prospect of travelling to what may be an unfamiliar country with different laws, language difficulties and potentially different clinical standards. However those seeking donor treatment in overseas clinics face a number of additional issues. There have been reports that women in some countries have been recruited as egg donors in circumstances that suggest a degree of exploitation. The Tissues and Cells Directive says that EU donors should not be paid for donating but can be compensated for inconvenience. There seem to be very wide discrepancies in how this is interpreted. It is often difficult to get meaningful assurances about the circumstances in which donors have been recruited (Donor Conception Network, 2007).

There were also warnings against buying sperm online. In July 2007 the HFE Act was amended to prohibit any attempt to "procure, test, process or distribute" any gametes (sperm and eggs) intended for human application without a licence from the HFE Authority. One year later, in response to a news report about women purchasing sperm through Internet, the chair of the HFEA, Professor Lisa Jardine noted:

Your article about the growing number of single women seeking to have children without a relationship with a man (G2, September 17) raises many issues which it is important to air and discuss. Since July 2007 it has been a criminal offence to "procure, test, process or distribute" any gametes (sperm and eggs) intended for human application without a licence from the Human Fertilisation and Embryology Authority. Prospective patients seeking donated gametes should only use licensed centres. That way, they can be assured that the gametes have been subject to screening checks and that the centre complies with the standards set out in the HFEA code of practice. A further difficulty with using unlicensed centres is that the HFEA is unable to hold, in its statutory registers, information relating to donors or children conceived from gametes obtained from such centres. Responsibility for prosecuting criminal offences rests with the police, and it is the practice of the HFEA to refer concerns about internet procurement to them. We strongly advise any person who becomes aware that a person or organisation may be procuring, testing, processing or distributing gametes without a licence to contact the 
police. The women whose stories you tell are entitled to make such fundamental choices about their personal lives within a safe, clinically sound framework. It is the HFEA's responsibility to provide that framework, and to be vigilant for the safety of those who undergo fertility treatment. The internet sperm providers referred to in one of your examples are not licensed by the HFEA. The service they offer is unlawful and unsafe (Jardine, 2008).

These concerns about fertility travel and online sperm providers suggest that demand for gametes may be leading many would-be parents to cope with the donor shortage problem in alternative ways. Despite their reticence in voicing their reactions in the public realm, many patients have been using online discussion forums to express and exchange their views anonymously about the new law and fertility travel. In Chapter Five I explore these alternative claimsmaking activities that escaped from the public eye.

\section{Claims-making in Stage 4}

Spector and Kitsuse (1977) argue that Stage 4 occurs with claimants' "contention that it is no longer possible to 'work within' the system" (1977: 153). This last stage involves rejection by the complainant group(s) of the agency's response and the development of activities to create alternative responses to the established procedures. The donor anonymity problem had not reached this stage at the time this study was conducted. 


\section{How did children's rights come to monopolise rights claims?}

One of the HFEA's core principles is "the right of people seeking assisted reproductive treatment to proper consideration of their request" (HFEA, 2003: 9). Another is "a concern for the welfare of children, which cannot always be adequately protected by concern for the interests of the adults involved". These two principles do not necessarily conflict. Nevertheless, the natural history of the donor anonymity problem in the UK indicates that would-be parents' right to seek treatment has been compromised for the perceived needs of unborn children who will come to life as a result of donor conception. The donorconceived children's right-to-know their origins is based on an adoption analogy, and would-be parents who deny this right are condemned.

\section{The adoption analogy}

Studies of adopted children have found that a child's knowledge of his or her background is crucial to the formation of positive self-identity (McWhinnie, 2001; Triseliotis, 1973). On this basis, it is argued that the disclosure of such information is in the best interests of the child and that these should override any preference for secrecy on the part of the parents, whether natural or adoptive (Maclean and Maclean, 1996). Accordingly, the Adoption and Children Act 2002 gives the child the right to access any available information unless the High Court orders otherwise. ${ }^{30}$ During the debate on the

\footnotetext{
${ }^{30}$ An adoption is registered in the Adopted Children Register in a similar way to registration of donated gamete children in the HFEA register. On reaching the age of 18 , people who are adopted (between 12 November 1975 and 30 December 2005 and live in England or Wales) have the right to receive any information which would enable him to obtain a certified copy of
} 
government's plans to abolish donor anonymity, Melanie Johnson explained that "Our conclusion is that the interests of the child are paramount, and that the position of donor-conceived people should be aligned more closely with that of adopted people, with access to identifying information about their donor when they reach age 18" (HC Deb, 2003-04 416 col. 61WS). Johnson also noted "Today's new regulations will align their positions, removing the major discrepancy that exists between the rights of donor-conceived people and those of adopted people" (Johnson, 2004).

By lifting anonymity for gamete donors, the government would be according similar rights to children born by this means. In Melanie Johnson's words, the government decided that "donor-conceived people should not be treated so differently from adopted people".

During the donor anonymity debate the needs of donor-conceived children were "typified" by the claims-makers. In this typification the adoption analogy was used. On 26 June 2002, The Observer published a commentary by Julia Feast of the Children's Society. This commentary perfectly exemplifies how the adoption analogy was employed:

This Sunday, millions of families throughout Britain will celebrate Fathers' Day - a day to celebrate and honour the importance of family values. Yet the 1500 children born each year through donor-assisted

the record of his birth, unless the High Court orders otherwise' (Adoption and Children Act 2002, Chapter 38,60(a)13). Donor-conceived children who were born after the 1 April 2005 can, on reaching the age of 18 , obtain identifying information including their donor's name (and their name at birth, if different), date and place of birth, and last known address from the HFEA register. Unlike adoptees, donor gamete children's access is not subject to potential restrictions by the High Court. 
conception are denied the rights to even know who their biological parents are (Feast, 2002).

By referring to Father's Day, the importance of family values is emphasised, and then donors are conceptualised as "biological parents".

The experience of allowing adopted children to know about their past strongly supports the case for change. Since 1975, adopted children have been entitled to information about their biological history - a copy of their original birth certificate, showing their original name and place of birth and the names and addresses of their birth parents. Many adopted children have benefited tremendously as a result, gaining a fuller sense of their own identity (Feast, 2002).

Having mentioned how adopted children benefited from accessing information on their birth parents, Feast portrays donor-conceived children as victims of a policy which denies them rights that adopted children enjoy.

It's time for the government to acknowledge that openness and honesty should now become the accepted practice, so that all of tomorrow's children grow up with dignity and a right to their identity (Feast, 2002).

In the statement above Feast addresses humanitarian mores such as 'openness', 'honesty' and 'dignity', and draws attention to the conflict between these humanitarian mores and government policy. She further notes that by denying them access to donor identity, the government infringes the donor-conceived children's human rights:

It is a basic human right, as laid down in the European Convention on the Rights of a Child [sic], which says children have the right to develop and retain a sense of their own identity (Feast, 2002). 
Feast also claims that the right to information about identity is also "central to mental health":

And this is an issue about child rights - the right to information about identity is central to mental health. Evasiveness and mistrust are a dangerous environment in which to bring up a child. Many people who were born through donor assisted conception will confirm these feelings (Feast, 2002).

Typification is a common strategy that is adopted by activists. Typifying is the backbone of claims-making activity. It occurs "when claimsmakers characterise a problem's nature" (Best, 1995: 8). Typification can take many forms; to give an orientation toward a problem and arguing that a problem is best understood from a particular perspective is one form. When a new problem is constructed as a different instance of an already existing problem, the audience will be more likely to understand the problem: successful claimsmaking changes the old in novel ways (Loseke, 2003). The adoption analogy is an excellent example. The rights of donor-conceived children is a complex issue, but when the public is convinced that there are similarities between adoption and donor conception the problem will be more comprehensible and people will know how to think about it. Typification of adopted people as 'others' has also been a strategy adopted by search movement activists in America. Wegar (1997) argues:

The agenda of search movement draws upon society's view of adoptees as simultaneously familiar, to the extend that the public can identify with their quest for identity, and different, to the extend that they are perceived as standing outside the order of nature, as Others (1997: 13).

A significant part of claims-making is associated with 'new social movements' or 'identity movements' (Loseke and Best, 2003). These social movements 
focus on changing public perception by increasing the social regard accorded to types of people, particularly socially discredited people. As opposed to old social movements which coalesced around shared grievances and perceptions of injustice, new social movements articulate grievances that are not based on economic and class interests (Johnston, Laraña and Gusfield, 1994). These movements are based on elements such as identity, status, humanism and spirituality. The values represented by new social movements reflect the ethos of individual freedom, choice and self-fulfilment (Wegar, 1997); they often involve "new or formerly weak dimensions of identity"; they attempt to "reclaim a self-robbed of its identity", and aspire to "empower members to "name themselves"” (Johnston, Laraña and Gusfield, 1994: 7-10, quoted in; Wegar, 1997).

They (the new social movements) are associated with a set of beliefs, symbols, values and meanings related to sentiments of belonging to a differentiated social group; with the members' image of themselves; and with new, socially constructed attributions about the meaning of everyday life (Johnston, Laraña and Gusfield, 1994: 7).

The Women's movement, gay rights and the adopted children's search movement exemplify this trend. The child's right-to-know claims seem to adopt ideas from new social movements, particularly from the 'search movement' for adopted people. This is not to say that the donor anonymity problem can be subsumed by the social movements by which it was inspired; we might better argue that claims about social problems are embedded in a broader cultural context which provides cultural resources from which claims draw (Best, 1999). 


\section{Violation of moral standards}

There are strategies of constructing a social problem so as to convince audiences that "a condition is prevalent and troublesome enough to violate morality, that it contains victims who deserve sympathy" (Loseke, 2003: 82). Claims-makers construct an image of a condition, the victims who are harmed by it and the villains who cause it. Based on the adoption analogy, advocates of an open donation system portrayed donor conceived children not only as victims of a policy which infringed their right to identity, but also as victims of their parents who deny this information to them. Some commentators criticised parents of donor-conceived children who kept donor conception as a secret for committing an immoral act. For example, Baroness Warnock argued:

It's perfectly possible for parents of a child born by artificial insemination by donor to allow him to be brought up under a misapprehension that the father he calls father is in fact his genetic father. I think that is actually morally wrong (Rhodes, 2002, emphasis added).

Claim-makers who adopt a moral orientation typically advocate giving people guidance to discourage immorality (Best, 1995). The following extract from Baroness Warnock's speech offers such guidance: parents should acknowledge the donor origins of their children:

There can be no moral justification whatever in deceiving a child about the circumstances of his birth. It is a very awkward doctrine to enunciate, considering the number of children born by adulterous relationships. Nevertheless, it is deeply morally wrong to pretend that a child is the son or daughter of a father or mother who is not his or her real biological parent. To insist on pretending shows selfinterest on the part of the parents - that they are interested in their own status, not that of the child. It may be deeply traumatic for the child, because children nearly always guess that there is something a bit funny about their birth if it has taken place by donation or they were 
adopted. To treat a child as though it were a toy or a pet- to suggest that it does not particularly matter where it came from because it is your child-is genuinely immoral (HL Deb, 2003-04b: 662 col. 356 emphasis added).

The extracts quoted above indicate that it is "genuinely immoral" to "pretend" that a child is the son or daughter of a father or mother who is not his or her real biological parent. The would-be parents' inclination toward secrecy is portrayed as a potential threat to the resultant child's welfare, and parents who intend not to disclose are accused of deception and violation of moral standards.

Feast, from the Children's Society and BAAF, also approached the openness in child-parent relationship as a matter of balance of rights. She expressed concern that the rights of infertile parents had historically been put before those of unborn children:

The current legislation [the HFE Act 1990] puts the right of a parent to have a child before the needs of a child. This imbalance must change (Feast, 2002).

The following extract from Baroness Warnock's speech also exemplifies the discourse that the unborn child's rights should be protected against the parents' passionate desire to bring them to life at any cost:

I think they [the would-be parents] have been treated as though this passionate desire they have to have a child must override all other considerations and I don't think that's right (Rhodes, 2002). 


\section{Conclusion}

Earlier in this chapter, I noted that any social condition is a potential subject for claims-making (Best, 1995), and it is claims-makers who shape the public's sense of what the problem is, and what must be done to solve it. The natural history of the donor anonymity problem in the UK shows that the problem was owned by the advocates of the child's right-to-know in the UK.

In the UK, a large number of infertile couples seek donor conception; according to the HFEA registers in 20061124 children were born using donated eggs and sperm (HFEA, 2008d). During the donor anonymity debate the potential impact of the disclosure policy on would-be parents could have been raised as a social problem. Nevertheless, without any significant objection from would-be parents, abolishing anonymity was framed as an action which would have effects on only two interest groups: the resultant offspring and the donors. A number of assumptions prevailed: (1) potential offspring had as much right to find out about their genetic origins as adopted people did; (2) the secrecy and stigma surrounding assisted conception had faded; (3) by abolishing anonymity, donation culture would change and future donors would be altruistic people who wanted to help infertile couples; and (4) more parents were planning to tell their child about donor conception. In response to the medical community's concerns about a potential donor shortage, the government claimed that any shortage would be a short-term problem and would be solved through promotions and recruitment campaigns. 
Donor shortage was not ignored by the mass media; on the contrary, during the debate the media focused on the decreasing donor numbers. According to Best, the media play an important role in promoting social problems. It is not, however, enough to institutionalise the social problems; other cultural entrepreneurs, such as activists, government and experts also play an important part. Social movement activists are among the strongest competitors (Loseke and Best, 2003). These activists were present in the donor anonymity debate, and indeed were influential in raising awareness of the child's right-to-know based on an adoption analogy. On the other hand, their lack of interest in representing would-be parents' rights was evident.

In the absence of an explicit reaction or opposition from would-be parents, counter-claims activities were performed by the medical community and the patient support group, INUK. These counter-claims making activities focused on the donor shortage and drew attention to detrimental effects of the new law: donors are reluctant to donate; UK clinics cannot meet the demand for gametes; long waiting lists for patients who wish to get treatment; and increasing numbers of patients travelling abroad to avoid the law. A few claims-makers also addressed the argument that the new law might discourage parents from being open with their donor-conceived child.

The nature of these claims was significantly different from that of their opponents. Whereas the child's right-to-know claims addressed humanitarian mores, these counter-claims focused on the supply-demand problems in the gamete market. The fact that would-be parents would suffer due to the donor 
shortage could only find little sympathy when weighed against the child's welfare arguments raised by the child's right-to-know camp.

It is evident that reticence of would-be parents in voicing their concerns did not help their case. Especially in new social movements, individuals also play an important role in pressing claims. The impact of Rose's case on the donor anonymity debate exemplifies this. Johnston et al. (1994) argue "many contemporary movements are 'acted out' in individual actions rather than through or among mobilised groups" (1994: 7). Presumably, involvement of would-be parents in the debate could have changed the problem's trajectory if these parents had attempted to create a public or political issue by talking about their experiences, their rights, or their understanding of the welfare of their unborn children. The political significance of self-narratives and life stories can be seen in many social movements (Wegar, 1997). Indeed, for members of marginalised social groups, self narratives and autobiographies are "often the only means of making their voices heard or of formulating experiences independently of dominant cultural and institutional frameworks" (Wegar, 1997: 74).

Loseke and Best (2003) note that "claims-makers often greatly expand their grounds and diagnostic frames by constructing full-blown typifications of the types of people harmed by social problems and the types of people causing these problems" (2003: 110). During claims-making activities, advocates of a child's right-to-know portrayed donor-conceived children as potential victims of their parents. Arguably, the socio-political climate was not ideal for would- 
be parents, or their representatives, to defeat the charges against them. Given the ways in which they were framed during the debate, their reticence should come as no surprise.

The natural history of the donor anonymity problem reveals that, in the UK, the child's right-to-know movement succeeded in the absence of any public articulation of the rights of would-be parents. Since the removal of donor anonymity, and despite the absence of any public articulation of the rights of would-be parents, it is evident that there is a severe donor shortage in the UK and that growing numbers of people are seeking treatment abroad. The movement of would-be parents to jurisdictions where anonymity is still permitted indicates that some people choose to cope with the problem by avoiding the law, rather than making official claims to challenge the policymakers. This 'silent resistance' to the new law deserves to be subject to empirical investigation. This issue will be investigated in later chapters through would-be parent's own accounts. 


\section{CHAPTER FOUR: RESEARCH DESIGN AND PROCESS}

Constructing Social Problems by Spector and Kitsuse (1977) issued a call for more qualitative empirical work in the field of social problems. In order to illustrate how social problems research could be undertaken, one chapter provided a detailed empirical example of claims-making activities: a controversy that developed out of efforts to publicise the use of psychiatry to control political dissidents in the Soviet Union. Spector and Kitsuse argue that the public discourse of claims-making can be examined in the myriad circumstances in which the construction of social problems takes place (Holstein and Miller, 2003). These circumstances include "demanding services, filing out forms, lodging complaints, filing lawsuits, calling press conferences, writing letters to protest, passing resolutions, publishing exposes, placing ads in newspapers, supporting or opposing governmental practice or policy, setting up picket lines or boycotts" (Spector and Kitsuse, 1977: 79).

Although their case study focused on institutional or organisational claimsmaking activities, the authors suggested that social problems research should not be limited to such contexts. Since the book was published, the constructionist perspective has produced an impressive collection of empirical studies. I read Constructing Social Problems with the UK's donor anonymity debate on my mind. I found its theoretical approach useful to understand and monitor social problems; however I did not find an answer to the question as to 
how one can study a social problem which has not gained public awareness, which is not documented, or which is not articulated in formal modes of communication. In short, if I were to study the claims-making activities of the would-be parents in the donor anonymity paradigm, there was an obvious obstacle: collecting material of the kind specified by Spector and Kitsuse as data for this approach would prove difficult, if not impossible.

My theoretical interest in alternative forms of claims-making led me to consider employing two different methods for collecting data: interviews and a virtual ethnography. Although observation remains at the heart of ethnography, interviews are recognised as one of the most important methods that researchers use to gather data to explore the meaning of concepts, categories and events for their informants and they are especially important in ethnographic work. Although interviews are widely used in social problems research to examine formal modes of communication (e.g., interviewing the representatives of NGOs or governmental agencies), cyberspace provides excellent opportunities to monitor claims-making activities performed by hidden populations, who are not willing to engage in political action. Lately, in constructionist approaches to social problems, ethnographic studies have been seen as having a central place in developing theoretical understanding. It has been argued that any form of communication has the potential to be read as a claim (Lynxwiler and DeCorte, 1995). Hence, I believe that the virtual ethnography study that is presented here has the potential to contribute to social problems research. 
In what follows, I will first outline the rationale of my study. I will then reflect on the methodological challenges of conducting a study on hidden or hard-toreach populations, such as donor conception families in the UK, and how I solved this problem by using the Internet as a recruitment channel and a data collection source. I will then go on to describe how the interviews and virtual ethnography were conducted, including the ethical issues. Finally, I will discuss how data analysis was undertaken and reflect on the potential impact of this study on problem definition.

\section{Rationale of the study undertaken}

Before embarking on a description of the work undertaken, I will consider the rationale for undertaking an empirical study on would-be parents. As I explained in Chapter One, this research started out with an interest in understanding the reactions of would-be parents to the disclosure policy. In Chapter Two, I justified my adoption of a contextual constructionist approach to study the donor anonymity debate as a social problem. In Chapter Three, I presented the natural history of the donor anonymity debate to reveal the ways in which right-to-know claims became successful and led to the 2004 regulations. This examination helped me to understand the nature of claims opposing the use of anonymous gametes for conception. It also gave me insight into the way in which donor-conceived children and their parents were portrayed in the public sphere. Fertility travel, Internet sperm providers and the grey market in gametes are phenomena addressed as 'unsafe', 'illegal', unethical', respectively, by policy makers, and would-be parents are warned 
against the consequences of considering any solution to their infertility, other than treatment in a licensed UK clinic. On the other hand, neither the reasons behind the development of these coping or avoidance strategies, nor the potential solutions to the problem that lead would-be parents to use 'illegitimate' ways of obtaining gametes are articulated as often as the horrors of the unlicensed gamete market, or the ignorance of would-be parents who cannot see the merits of using gametes from identifiable donors.

Remarkably, despite their reticence during the donor anonymity debate, wouldbe parents continue to protest anonymously against the new law, and the warnings against fertility travel, on the discussion forums of online support groups for those who receive infertility treatment. During and after the donor anonymity debate, many patients who are undergoing infertility treatment have been using these discussion forums to express and exchange their views anonymously about the many issues surrounding infertility treatment. While exploring the counter claims-making activities of would-be parents, I visited a number of these websites (fertilityfriends.co.uk; infertilitynetworkuk; repromed; acebabies; and ivfconnections) to familiarise myself with the concepts, issues, community culture and abbreviations that the members use in their posts. These posts include inquiries as to where one can receive treatment abroad by using gametes from anonymous donors, stories about fertility travel, complaints about the long waiting lists and the donor shortage in the UK, and criticism of the new regulations. These postings show that the removal of anonymity has had identifiable detrimental effects: first, donors are reluctant to donate, UK clinics cannot meet the demand for gametes and there are long 
waiting lists for patients who wish to get treatment. Second, being citizens of an EU member state, UK patients can exercise their right to get treatment abroad elsewhere in the EU. However, when it comes to donor conception, they are urged to think twice by the regulatory body, the HFEA. Third, in the public sphere there is an intimidating discourse of openness and transparency. These claims demonstrate that the silence of would-be parents in the public realm does not mean that they do not view the removal of donor anonymity as a social problem. Therefore, their reticence in voicing their concerns deserves to be subject to empirical investigation. I consider that hearing would-be parents' voices on this matter can have a potential influence in identifying policy failures and impact on future policy-making.

\section{The research questions}

Studying the natural history of the donor anonymity debate has helped me to understand what kind of elements successful claims adopt from the sociocultural context, and hence what kind of discourses are perceived as legitimate. Chapter Three presented the assumptions behind the new law and the discourse that dominated the donor anonymity debate in chapter three. The assumption behind the ethnographic work described in this chapter is that the analysis of accounts gathered through interviews and excerpted from online discussion forums can help me to identify and analyse cultural assumptions about donor conception through the perspectives of would-be parents. 
Such analysis can also help us to understand why some stakeholders cannot press claims due to the perceived illegitimacy of their claims. The subsequent chapters also reflect an interest in what my informants said about, for example, the meaning of having a donor-conceived child, receiving donor gametes to conceive, and how to control this information about their family life. The main questions that I aim to answer by the empirical work undertaken are as follows:

(1) What do would-be parents have to say about the moral and legal expectations about their parenting?

(2) What is their response to the legislative and other measures taken by the government to encourage them in being open with the resultant child?

(3) How do they deal with the tension between socially acceptable parenting, which advocates openness with the child, and parental autonomy? What are their coping/avoidance strategies?

(4) Why did they remain silent during the debate?

\section{Why perform another study on donor conception families?}

Donor conception has been intensively studied by sociologists and psychologists in recent years. Whilst public understanding of the practice has been a focus of recent sociological studies, psychological studies have dealt with the emotional experiences of those who have received donor gametes, family functioning in families conceived with gamete donation, and parents' decision-making in relation to telling their children about their donor origins. For example, one study by Golombok et al. (2004a) based on interviews with 
donor conception families (which was quoted during the donor anonymity debate by the advocates of open donation) indicated that an increasing number of parents reported that they intended to disclose. There authors note that, in contrast to the findings of earlier investigations, both donor insemination and egg donation parents appeared to becoming more open toward disclosing the mode of conception to the child. The earlier studies had found that not one set of donor insemination parents and only one set of egg donation parents in samples of four to eight year old children born in the 1980s had told their child (Golombok et al., 1995; Golombok et al., 1996; Golombok et al., 1999). Golombok et al. therefore conclude that:

[r]egarding the issue of disclosure of the donor conception to the child, there appears to have been a marked change in attitude in recent years (2004b: 451).

Interestingly, two years later, a follow-up study on the same families showed that that a majority of parents had not told although they had reported that they would:

\begin{abstract}
Although it was expected from their reported intentions when their child was aged 1 that more of the gamete donation parents would have begun to discuss with their children the circumstances of their birth, it seems that these intentions had not been acted upon by the time the child turned 3 years old (Golombok et al., 2006: 1923).
\end{abstract}

The follow-up study shows that in spite of the greater encouragement in recent years for parents to disclose their children's donor origins, less than eight per cent of egg donation parents and less than five per cent of donor insemination parents had begun to do so by the time their child had reached age three. This 
contrasts sharply with the finding that 56 per cent of these same oocyte donation parents and 46 percent of these donor insemination parents reported when their child was one year old that they planned to tell their child about the donor conception. My reading of these findings is that, regarding the issue of disclosure of the donor conception to the child, there appears to have been a marked change in parents' discourse in the recent years, but not necessarily in their actual behaviour and practice. It must be noted that these families' decisions about disclosure may change over time, and these parents may tell their children about their donor origins. On the other hand, what people say during an interview might be different from what they really think or do. More importantly, given the current public discourse encouraging openness, the parents might have felt compelled to give responses that they perceived as acceptable.

Interview respondents may frequently answer according to what they believe is expected of them, so-called "social desirability" (Silverman, 2001). During the interview the respondent is concerned with presenting him/herself with his/her competence as a member of whatever community is invoked by the interview topic:

The data produced by interviews are social constructs, created by the self-presentation of the respondent and whatever interactional cues have been given off by the interviewer about the acceptability or otherwise of the accounts being presented (Dingwall, 1997: 59).

The interviewer's reactions about the acceptability of the respondent's account affect the whole interview process. In short, an interview is a social situation in which the facts and identities are created through the interaction of the people 
involved. Interview data therefore cannot offer literal descriptions of a respondent's reality (Murphy and Dingwall, 2003). This is not a particular critique of the study discussed above, but a critique of all interviews.

\section{Why interviews?}

If interviews cannot offer the respondent's reality, why did I consider conducting interviews with would-be parents? One reason was, as I mentioned earlier, to evaluate the accounts of the respondents in the socio-cultural context which was described in Chapter Three. I thought it would be possible to contribute to the literature by evaluating the accounts of donor conception families in a broader, socio-legal context which asserted openness. Furthermore, although interview data are a joint product of the interviewer and the respondent, this does not mean that no use can be made of them. When I put together the accounts in my study, despite each respondent's different view about openness to the child, there was a story being told by all informants in a consistent and repetitive fashion.

The constructionist approach assumes that there are multiple realities: how the researcher views reality shapes the data generated, and the findings of the study. However, to facilitate the policy relevance of this research, I avoided the strict constructionist approach where interviews are treated as constructed narratives which cannot give access to experiences. I treated the data gathered by ethnographic studies as a vehicle to access meaning located outside the interview encounter; but I was also aware that these meanings were socially 
situated by the respondents and by me, therefore they could be interpreted and understood in many ways. As Murphy and Dingwall argue, "data are never merely accounts or versions, such that any reading is as good as any other" (2003: 60).

Departing from extant studies conducted on donor conception families, the empirical study that I have undertaken focuses on would-be parents' accounts and claims regarding the socio-legal context. In constructing social problems, it is important that the problem contains "victims who deserve sympathy" (Loseke, 2003: 82). Accordingly, the assumptions of the stakeholders about the acceptability of their demands have an impact on whether they will press claims. If the actors believe that their demands are not publicly acceptable, they will be less likely to press claims. For example, would-be parents are not likely to say that they do not agree with a policy that makes the interests of the child the paramount concern. The ascent of children's rights as a matter of public concern means that such an argument would be less likely to fit in any popular frame and gain public acceptance.

\section{Why virtual ethnography?}

Ethnographic studies conducted in digital space deal with social action and social organisation in online communities. Unlike interviews, during which the respondent presents herself to the interviewer, the members of discussion forums present themselves to their peers and to visitors to the forums. Virtual ethnography can therefore provide an insight into the discourses that are in use in collective definitional activities. 
As I discussed earlier, the accounts of would-be parents and their claims draw our attention to the ways that they would like to present themselves: these presentations could explain why would-be parents did not challenge the new law in formal modes of communication. The same assumption led me to perform a virtual ethnography, but this time my intention was to observe the interaction of the would-be parents among their peers. By employing two data collection methods - interview and a virtual ethnography - I also hoped to achieve a more comprehensive understanding of how would-be parents present the facts that they construct. Posts on the discussion forums have different characteristics to data gathered by interviews. This means that digital space has the potential to contribute to observing how social problems are defined. Discussion threads may for example provide the chronological natural history of collective definitional activities.

The virtual ethnography study I conducted enabled me to access what was already there, instead of constructing the data with the interviewee. Unlike interviews, in which the agenda is set by the interviewer, naturally-occurring settings like the discussion boards of online support groups enable users to determine the topics they would like to discuss, without the intervention of the researcher. Virtual ethnography is, in many respects, similar to observational data, as it escapes transformation. Murphy and Dingwall (2003) argue that, in comparison to observational data, interview data involve at least two or sometimes three transformations. The interviewer who chooses the questions to ask performs the first transformation. The second transformation is that of the 
respondent who restructures their original experience to reply to the question. The authors note that, in some cases, there may be a third transformation if the researcher proposes what the possible answers might be (2003: 54). The researcher will try to minimise this "chain of transformation", therefore the data derived from observational methods carry more credibility than those derived from interviews (2003: 54).

During data collection, the users of the website and I were able to escape from the "chain of transformation" to a certain extent, as the study I conducted was a form of participant observation. This is not to say that the data collected by this means were more reliable than the interview data as it minimised the one-toone interaction. Every kind of human interaction, including the digital form, involves re-creating aspects of the self, and the facts.

Finally, postings on the discussion forums enabled me to build up a picture of the kinds of practical problems with which donor conception families had to deal. Many of these were irrelevant to my research question: however this exercise enabled me to identify several issues that I failed to envisage while designing the interviews, such as the difficulties in finding a donor with matching characteristics due to the donor shortage, and the problems experienced with the clinics. I then updated my interview questions accordingly. 
Of course, collecting data from the Internet cannot escape criticism. I will discuss this issue in detail later in the chapter when I describe the study undertaken.

\section{Sampling, access and recruitment}

There was on major foreseen problem with this research: how to find people who had become or were attempting to become parents as a result of gamete donations? The potential participants in this study constituted a hard-to-reach population given the lack of contact information or databases to inform sampling. Using magazines and newspapers to advertise research can be highly effective with hard-to-reach populations, such as rape victims or sex workers (Benoit et al., 2005), however it can be quite expensive. In the absence of a formal setting where people could articulate their concerns while maintaining their anonymity, my recruitment strategy necessitated looking at alternative settings that brought them together. In this respect, the potential of the Internet to recruit participants was obvious. I envisioned that I would visit these online support groups for individuals receiving fertility treatment in order to: (1) recruit participants for interviews; (2) collect data from discussion boards to understand the reactions of would-be parents to the new law; and (3) explore whether there was any collective activity performed by would-be parents to challenge the law. 


\section{Recruiting participants for the interviews}

At the outset of the project I thought that it would be interesting to conduct an ethnographic study that included observation and interviews in a fertility clinic. However, I was not confident that negotiations to gain access to a clinic, or the ethical approval process for NHS settings, would be successful and these considerations discouraged me from attempting to negotiate access. Furthermore, I was not convinced that the UK clinics could help me with reaching my target population; for example, the clinics would not necessarily have access to patients who had, or considering having, treatment abroad.

An obvious way to reach out to potential participants was through advertising on online support groups where I observed the claims-making activities during this preliminary research. Infertility clinics are mainly marketed through the Internet. Accordingly, I assumed that my potential informants would be visiting cyberspace. These websites have the potential to attract any would-be parents interested in infertility services: patients share their experiences, exchange views, and find out practical information about clinics operating abroad. For example, the largest online community of UK infertility patients, fertilityfriends.co.uk, has over 26,000 members who had posted 2,316,170 posts as of 14 November 2008. Some of these support groups (INUK; fertilityfriends.co.uk; and acebabies) are also listed on the HFEA's useful links page for patients. 
I sent interview information to targeted organisations (the five largest online support groups: acebabies; infertilitynetworkuk (INUK); fertilityfriends.co.uk; Repromed; and IVF Connections) and used forums and online notice boards to announce the research. Initially, the research population was set as "those who received/ or considered receiving donor insemination abroad". However, my observations on the online support groups made me realise that those who received egg or embryo donation should also be included in my sampling. Although the donor anonymity debate has focused on the recruitment of sperm donors, egg shortage is even more severe, and I did not want to exclude embryo recipients either, as the problems that they were faced with were similar.

\section{Access negotiations to the online support groups: Locating an}

\section{informant}

Fontana and Frey (1998) argue that "the researcher must find an insider, a member of the group studied, willing to be an informant and to act as a guide to and translator of cultural mores and, at times, jargon or language" (1998: 59). I had such gatekeepers on each website. For example, fertilityfriends.co.uk requires researchers to contact the administrator to get an approval before sending a post. Having contacted the moderator, my post was placed on one of the message boards. 
Studies show that recruitment of donors is a problem especially in the countries where donor anonymity has been removed: waiting lists get too long and some couples prefer anonymous donors.

I am a second year PhD student at the University of Nottingham at the Institute for Studies of Genetics, Biorisk and Society. I am exploring the consequences of removal of donor anonymity for would-be parents who are willing to obtain donor insemination. It is hard to recruit participants in this area, so I would be grateful if you can help me.

I would like to interview 20 people considering donor insemination as a family building alternative. The average duration of the interviews will be one hour. Interviews will be taperecorded and transcribed, and all names will be changed. No information will be passed to the third parties. References from my supervisors will be provided upon request.

If you like to give interviews please contact me at ilke.ozdemir(agmail.com or from this web site. I'd really appreciate your help!

I look forward to hearing from you!

Best wishes

I also posted this advert on Repromed, the setting where I conducted the virtual ethnography study. The fact that my ad was approved on the fertilityfriends.co.uk website was noticed by one of the moderators at Repromed. Although I did not need an approval at Repromed to post an ad, the moderator put a notice on my announcement (in capital letters) saying "FOR EVERYONES INFORMATION THIS IS A GENUINE REQUEST AS IT WAS ALSO ON FERTILITY FRIENDS WEBSITE AND ALL REQUESTS ON THERE HAVE TO BE APPROVED BY THE ADMIN TEAM BEFORE THEY ARE ALLOWED TO POST". 
My other contact was the media officer of infertilitynetworkUK. She posted an ad on the message board of the website about the research:

\footnotetext{
"have a request from a PhD Student to interview people on the subject of donor anonymity and explore why people consider going abroad to receive treatment, perhaps due to the anonymity issues.

If you are interested please email me directly and I will send you all the details. The interviews can be conducted anonymously if preferred"
}

I was also able to post my ad on Acebabies and IVFconnections.net. Neither website has a procedure for screening research requests, but I e-mailed the administrators of the related discussion boards to inform them about my research ad. Printed ads were also handed out during National Infertility Day (NID) 2006, following permission obtained from the heads of the organising committee, Clare Brown, Chief Executive of the INUK, and Sheena Young, Head of Business Development. Unfortunately, I was only able to interview one person whom I met during the NID. Two participants (one donor, one would-be parent) contacted me through fertility friends. Another donor was found by word of mouth. Two people contacted me through INUK, three from Repromed and three from ivfconnections (including the only couple I interviewed). And lastly, as I describe below, I asked those who participated to send the information to other people they knew who might like to participate. Although more than 20 people were contacted, the interviews were eventually conducted with 11 parents and two donors. 


\section{Problems with recruitment and snowballing}

My plan to recruit participants ran into difficulties because those who were in favour of anonymous donation were reluctant to give interviews as confidentiality was of high importance to them. For example, on Repromed, despite the support of the moderator (she was also one of the most regular and well-known users who had over 2,500 posts), the instant response rate was low. (The message boards enable visitors to see how many times the post has been viewed. My post was viewed 260 times but the responses were in single figures.) Hine (2000) had the same experience with her posts on newsgroups. She says that this lack of response is fairly typical in her experience and that of others for generalised requests for research assistance from newsgroups. A similar point is made by Baym (1995) who speculates that people feel no obligation and have no incentive to respond. It is however important to consider the fact that online patient support groups may be slightly different to newsgroups. If I had intended to conduct covert research pretending to be a patient who wanted to learn about others' opinions about the removal of anonymity, I believe that the topic would have created a long thread.

The extract below from an online support group paints a picture of what it is like to be an informant in the donor anonymity debate and how the researcher is perceived. It is from Elaine, my first contact and the first interviewee.

I think the HFEA are the worst possible thing that could have happened to fertility treatment within the UK. I myself have given numerous, anonymous, interviews to people who are trying to fight our corner, but it's difficult when you don't want the world and his uncle to know your business - and that is, of course, why they keep winning! (Elaine). 
Elaine has tried to make her voice heard by giving 'anonymous' interviews to journalists and researchers. Nevertheless, she does not want to reveal her identity and, hence, cannot make claims in more formal ways, as she and her partner are not planning to disclose to their prospective children how they were conceived.

Giving interviews might compromise one's confidentiality: by agreeing to give an interview, informants agree to sign an informant consent form, ${ }^{31}$ have their voice recorded, provide some personal details including demographic information, and more importantly talk to a stranger about the unique story of their treatment (sometimes so unique that it makes their identity traceable).This may be particularly problematic for those who have received donor conception. For example, one pregnant woman I interviewed pointed out that although she was planning to disclose to her twins that they were donor-conceived, she did not want any strangers to know about their means of origins before the twins do. This seems to be a legitimate concern, not only for the potential participants who may not trust a PhD student in protecting their confidentiality but who might also feel that it is unfair to the unborn child who has given no consent. The resultant child, for example, might prefer to keep her means of conception as a secret; but if her parents have already made this public before she had a say on the matter, she will have no control over such information. In a way, although disclosure to the child may give the child autonomy, disclosure to 'others' may put it at risk. This is a dilemma that some would-be parents

\footnotetext{
${ }^{31}$ If the informant was reluctant to sign, s/he was given the option to agree with the terms verbally.
} 
have in mind, as will be highlighted by several of the accounts in Chapters Five and Seven. Moreover, being contacted might have made them realise that they had a particular life experience that made them a research interest - that they might have something controversial or confidential. Furthermore, if they did not spend much time thinking about the disclosure, coming across the ad or being contacted might have brought up a subject which had been avoided. The fact that potential research subjects were in the middle of a treatment or expecting a baby made the interview arrangements even more difficult.

Researchers studying 'hidden' populations may find that standard probability sampling methods are inapplicable because their potential informants lack a sampling frame, have privacy concerns, and constitute a small part of the general population (Heckathorn, 2002). Members of hidden populations may be involved in activities that are considered deviant, or they may be vulnerable, making them reluctant to take part in more formalised studies using traditional research methods (Atkinson and Flint, 2001). Snowball sampling, where one participant gives the researcher the name of another potential participant, enables access to such populations. Ultimately, I opted for this method. However, when I e-mailed potential informants, whose contact details had been forwarded by the key informant, this method proved problematic. Many respondents refused to participate because they thought their confidentiality had been violated by the referral. Two out of nine informants refused interviews immediately. Their responses documented their anxiety, fear and anger about being contacted. They asked me to delete their contact addresses and not to contact them again under any circumstances. I apologised, and 
assured them that I would delete all of our correspondence and their contact details, which I did. Three of the respondents did not reply to my e-mail. Four respondents were interested in giving interviews (the number includes the partner of one of the respondents) but reported that they were not impressed by the fact that my referral intruded upon their privacy. I had a long e-mail correspondence with these potential participants. They all agreed to talk to me only if I could visit them. Although they provided me with details of their infertility experience and the circumstances that led them to consider donor conception, I cannot quote them in this study as I assured them that our e-mail correspondence was not to be used in my thesis. Carrying out phone interviews was not an option; in fact, one informant said that it was unthinkable for her to talk to a stranger over the phone about her very intimate problems. This came as a surprise, as most of the parents I interviewed earlier preferred phone interviews. I agreed to conduct face-to-face interviews (and having learnt from this experience I did not mention phone interviews to any of the other potential participants). Having discussed where we would meet and when, all three changed their minds. One said that she would be very busy because she was pregnant. Another explained that her husband was not happy with her giving an interview. The third informant cut the contact without providing any explanation. After I concluded the interviews, a potential participant contacted my supervisor about his commentary in a newspaper on donor anonymity. Initially she agreed to give an interview but then she wanted to wait for a while as she realised she was pregnant. She informed me that she was expecting twins and was not in great physical shape. I did try to contact her after a while 
but she did not respond to my e-mails. Overall, at this stage I had got quite used to participants changing their mind after getting pregnant.

\section{What kind of interviews?}

Some writers urge researchers to be reflexive not only about what the interview accomplishes, but also about how the interview is accomplished (Silverman, 2001). Accordingly, in this section I will reflect on how the interviews in this study were accomplished.

At the outset of the project I hoped to conduct joint interviews. Unfortunately, this goal was not achieved. Joint interviewing, when the researcher interviews two people together, is commonly used in the context of inquiries involving people in marital relationships or living as couples. Although in my adverts I made it clear that I would like to talk to couples as well as individuals, men did not approach me or told their female partners that they would rather not participate in the interviews. Earlier studies had reported that women are more open about talking about infertility (Miall, 1986). Interestingly, during joint interviews, according to the evidence, it tends to be men more than women who are the 'scene-stealers' (Arksey, 1996; Shakespeare, 1993); men are more likely to be overbearing, to interrupt or speak on behalf of the other (Arksey, 1996; Jordan et al., 1992).

The interviews were conducted with eleven would-be parents (further details on the interview sample are presented in Appendix-1. It was not possible to 
provide information in a great detail about the users of Repromed, however some demographic information about the sample is provided in Chapter Five). and two donors between 8 February and 29 August 2006, except for one. This last interview was conducted on 14 May 2008. Overall, two written, one email, two face-to-face and eight phone interviews were conducted. All phone interviews and face-to-face interviews were tape-recorded. I told the participants that I could stop recording whenever they wished, but none of them asked me to stop recording at any stage of the interview. After each interview, I made brief written summaries comprised of medical histories, the treatment received, demographic measures, a summary of the highlights from the interview space, time, feeling, and the main issues raised. The interviews, on average, took an hour. I took notes, especially during the phone interviews. Note-taking was useful in directing my attention to the interview guide because during phone interviews it is possible to get distracted. All these records were used when it came to coding.

My initial opinion that face-to-face interviews are preferable to phone interviews has changed for several reasons. First, all interviews took approximately one hour, regardless of whether they were carried out by phone or not. This indicates that phone interviews can be as deep as face-to-face interviews. Secondly, I did not have problems with rapport building and did not feel that the face-to-face interviews were more comfortable than the phone ones. As I discussed earlier, some participants clearly preferred face-to-face interviews, whereas others insisted on speaking on the phone. In my experience it was clear that rather than what the researcher feels, it is important to conduct 
the interview in a way that suits the participant most. Perhaps this is particularly an issue when the interview topic is related to one's personal experiences.

Before conducting the interviews I reviewed a large amount of literature on donor conception families, and this contributed to the development of themes that would be brought up during the interviews. Although I had a list of questions and notes with me, I refrained from raising specific questions, unless it was necessary. The interviews were designed as semi-structured. Semistructured interviews were adopted in preference to more structured methods for very deliberate reasons. First, research can itself generate theoretical frameworks (Glaser and Strauss, 1967). For example, as we shall see in the data analysis chapters, the would-be parents' accounts indicate that the perceived stigma of infertility and having one's gametes substituted have a significant impact on disclosure patterns. Although I had read Goffman's stigma theory (1963), I did not design the interview questions to explore the stigma that the would-be parents might be experiencing. Nevertheless, the accounts generated the theme of stigma. Secondly, semi-structured qualitative interviews provide flexibility for the interviewees and the interviewer. The aim was to give the interviewees sufficient space in order that they could discuss their views on donor conception in their own terms.

The interviews assessed three areas of donor conception experience: the decision making process; disclosure; and claims-making (for and against policy change). I was primarily concerned with getting a sense of, and insight into, the 
perspectives of the would-be parents. I therefore refrained from asking precise questions, as they might exclude areas of discussion which I had not thought of. However, I used an interview guide which was altered several times in the course of the study as I refined areas of interest or ways of asking. At the beginning of each interview, I explained to the respondent what the research was about, and briefly talked about the themes I was exploring. The opening question of the interviews was usually, "Could you tell me about your experiences which led you to consider donor conception?" As I had provided a brief background of my research at the beginning of the conversation, after narrating their treatment history, the respondents usually ended up talking about disclosure and the disclosure policy themselves without any interruption. When there was a silence, I encouraged the interviewee to make comments about the issues, which according to my notes, they had not covered.

According to the traditional techniques, the interviewer should avoid getting in a 'real' conversation in which she answers questions asked by the respondent or providing her personal opinion. This was not my approach to the interviews. I engaged in a 'real' conversation with empathic understanding rather than distancing myself. This is not to say I took an empathetic approach to interviewing. Empathetic approaches take an ethical stance in favour of the individual or group being studied, hoping to be able to use the results to advocate social policies (Fontana and Frey, 1998). Presumably this approach makes the interview more honest and morally sound, overall, however, I agree with Atkinson and Silverman's (1997) view on the matter: researchers should 
not privilege any ways of looking at the world but should instead continue to question.

\section{Ethical issues}

Traditional ethical concerns focus on three issues: informed consent; the right to privacy; and protection from harm. All these issues were carefully considered before and after the interviews.

\section{$\underline{\text { Informed consent }}$}

All participants were given information about the aims of the study and how the interviews would be conducted. The participant consent form presented below was either signed by the participant before the interview or verbal consent (phone interviews) was taken and tape recorded. In a number of cases, where I conducted the interview by mail or e-mail, the consent form was posted/e-mailed. In each case I sent the form before the potential participant agreed to give an interview to make sure that they understood the research purposes and the content of the interview. After the first few interviews however, I told the participants that as long as they gave me verbal consent (which was tape-recorded) they did not have to sign the form. I took the view that if the participants had confidentiality concerns, signing any kind of form with their names on would be off-putting. 


\section{PARTICIPANT INFORMATION and CONSENT FORM}

This project is examining the consequences of the removal of donor anonymity for access to donor gamete donation by would-be parents and the practical impact of the growing policy preference for disclosure of donor conception (DC) status to children. The empirical data will be collected from twenty semi-structured open-ended interviews of would-be parents (who have obtained DC or are considering it as an option). Interviews will be tape-recorded and transcribed. Everything you say will be treated as confidential to the researcher and her supervisors, and nothing will be published in any way that will allow you to be recognized, and all names will be changed. The average duration of the interviews will be approximately one hour. The interviews will cover three areas of DC experience: your decision to seek $D C$, your current thinking about disclosing the use of DC to any children that you may conceive through this procedure, and your general view of present UK policy on the regulation of $D C$.

Project title Legislation of Donor Gamete Donation in the UK: The Consequences of Removal of Donor Anonymity for Would-Be Parents

For more information: http://www.nottingham.ac.uk/iss/research/Current-Research-

\section{Projects/Student projects/Ozdemir Donor.php}

Researcher: Ilke Ozdemir.

Supervisors: Prof Robert Dingwall and Prof Therese Murphy

- I have read the Participant Consent Form and the nature and purpose of the research project has been explained to me. I understand and agree to take part.

- I understand the purpose of the research project and my involvement in it.

- I understand that I may withdraw from the research project at any stage and that this will not affect my status now or in the future.

- I understand that while information gained during the study may be published, I will not be identified and my personal results will remain confidential.

- I understand that I will be audiotaped

- I understand that data will be stored.

- I understand that I may contact the researcher or supervisor if I require further information about the research.

Signed (research participant)

Print name

\section{Date}

\section{Contact details}

Ilke Ozdemir lbxio@nottingham.ac.uk

B113, Institute for Science and Society, West Wing, Law and Social Sciences Building, University of Nottingham, University Park, Nottingham, NG7 2RD, UK 


\section{Protection from harm}

My research topic was a sensitive and intimate one, and I expected the interviews to be challenging, especially for an inexperienced researcher like me. All participants were told that although the interview questions were not designed to be psychologically challenging they might cause emotional distress due to the sensitivity of the research topic. This could have deterred particularly the pregnant participants from giving interviews, nevertheless it was deemed necessary to protect the subjects from harm.

There are a number of issues which I felt were difficult. First, the opening question - "Could you tell me about your experiences which led you to consider donor conception?" - brought up the participant's treatment history. Most participants had a number of failed cycles and miscarriages. When the participants talked about their emotional experience of infertility treatment, and the frustration that each failed cycle or miscarriage caused, I felt sad, however I refrained from expressing my sympathy as I was not quite sure how to respond to these intimate details. A few participants also brought up issues about their relationship with their partner or children. For example, one participant talked about her dilemmas about having a child due to her partner's reluctance to receive treatment; another talked about the disclosure problems with her husband's non-biological children from a previous marriage which were a result of his ex-wife's affairs; and yet another talked about her attachment problems with the child that she had adopted after having an embryo donation. Some women also were not convinced that they could relate to a donor- 
conceived child and reflected on their worries about not being able to bond with the resultant baby.

One participant contacted me and wanted to give an interview as she was planning to become an egg donor. Although she was not a would-be parent, I was reluctant to turn down this request. I advised her that the interview might not be used in my study, but she was willing to talk to me. During the interview, I realised that she was 18 years old, never had a child before and knew only a little about the complications of donating eggs. At that point I could not help suggesting to her that she should talk to a counsellor. I knew that it was not my place to make suggestions, but during the natural flow of the interview there is little space for reflection. After a while she contacted me to let me know that a medical examination had revealed that she was suffering from infertility due to polycystic ovarian syndrome, therefore she would not be able to donate eggs.

\section{The right to privacy}

Anonymity was guaranteed to all respondents. All names were changed and no information was passed to third parties. The informed consent form included a statement about the participant's right to privacy: "Everything you say will be treated as confidential to the researcher and her supervisors, and nothing will be published in any way that will allow you to be recognized, and all names will be changed." 
The interviews required openness and emotional engagement. Since the interviews, I have been in touch with some of the participants as they showed an interest in my research. Some participants update me about developments in their lives (e.g. having new babies, finding potential participants for my research) for personal reasons. Although it would have been interesting to conduct follow-up interviews with those who had children as a result of gamete donation, I did not want to use our friendship to bring up my research-related inquiries. I believe that the subjects should not feel uncomfortable or threatened by the fact that they have shared confidential information with me, and I respect their right to privacy.

\section{Data saturation}

Purposive samples are the most commonly used form of non-probabilistic sampling, and their size typically relies on the concept of data saturation, the situation in which the data has been heard before. After the sixth interview the basic elements were present, but I continued recruiting participants until no new information or themes were observed in the data. Admittedly, I did not refuse any potential participants who approached me, as I was aware that there would never be many people who would want to give interviews. Furthermore, I interviewed one egg and one sperm donor who were aware that these interviews might not be used in this study. Their interviews are not analysed in this thesis, but they gave me an insight about what it was like to be a donor. The egg donor was also a member of Repromed, so we were able to talk about this support group which helped me to understand the community better. 


\section{Description of the virtual ethnography study}

While the interviews were continuing, I was also performing a virtual ethnography study on Repromed, one of the online support groups that I used as a recruitment channel for interviews. This study is described in greater detail in Chapter Five.

The reasons that led me to perform the virtual ethnography study were not related to the difficulties I ran into during the recruitment process. The interviews and the ethnographic study were conducted synchronously, but independently. The accounts of the Repromed users were not considered as a substitute for the interviews, and have been treated in their own right. Three interviewees were also members of the online support group and initial analysis and comparison between forum posts and interview accounts indicated little or no discrepancies between the narratives told. Nevertheless, I did not merge their interview accounts with their posts, as potential differences can be observed in narratives due to the different nature of data collection methods.

Collecting data from online environments is not new. A number of studies, particularly in fields of technology and media, have assumed that the Internet can be viewed as a social context in its own right. Hence, online communication can be analysed for the forms of meaning, the shared values and the specific contextual ways of being that emerge in this environment (Baym, 1995; Correll, 1995; Reid, 1995). 
Support groups increasingly use online environments to offer affirmation, consolation and understanding to individuals in distressed or vulnerable situations (Mann and Stewart, 2000).

An online discussion forum ${ }^{32}$ can be defined as "an interactive computer-based communication system organised around the interest of the users" (Ogan, 1993: 177). Hosting such data, digital space shows potential for ethnographic study.

\section{Virtual community}

It is worth mentioning that virtual ethnography is sometimes addressed as digital ethnography. This can cause confusion. By virtual ethnography I refer to ethnographic studies conducted on virtual 'communities', not to a digital method or a digital medium.

People interact, exchange views and share experiences in digital space, and create spaces resembling communities in the 'real' world. Rheingold (1994) argues that one of the explanations for this phenomenon is the hunger for community. He argues that communities can now be based on emotional or intellectual proximity, instead of geographic proximity:

People in virtual communities use words on screens to exchange pleasantries and argue, engage in intellectual discourse, conduct commerce, exchange knowledge, share emotional support, make plans, brainstorm, gossip, feud, fall in love, find friends and lose them, play games, flirt, create a little high art and a lot of idle

\footnotetext{
32 Internet forums are also referred to as web forums, message boards, discussion boards. discussion forums, discussion groups and bulletin boards.
} 
talk. People in virtual communities do just about everything people do in real life, but we leave our bodies behind. You can't kiss anybody and nobody can punch you in the nose, but a lot can happen within those boundaries. To the millions who have been drawn into it, the richness and vitality of computer- linked cultures is attractive, even addictive (1994: 3 ).

In digital space, despite the absence of physical matter, people build personal relationships and social norms that are real and meaningful (Paccagnella, 1997). Some researchers therefore use the 'community' metaphor to address these social assemblages. They suggest that Internet forums facilitate ongoing discourse between subscribers with a common interest, effectively creating a 'virtual community': “social aggregations that emerge from the Net when enough people carry on those public discussions long enough, with sufficient human feeling, to form webs of personal relationships in cyberspace" (Rheingold, 1994: 20). Therefore, virtual communities present opportunities for ethnographic research. Hammersley and Atkinson (1983) note:

[o]ur historical preferences for face-to-face communities and intense, local sites of interaction should not blind us to the fact that contemporary forms of communication can transform our sense of what is 'local' into widely distributed networks, and that communities can (and do) exist in many different forms (1983: 138).

For example, the density and speed of instant exchange of electronic messages "can create a more intense sense of shared experience and of a shared world" (1983). The community metaphor however has not escaped criticism. Online groups have been criticised for being homogeneous as the participants are similar people with similar interest (Baym, 1995). Further, because there is no moral obligation to stay in the community (the participants can leave with a mere click), some argue that, as virtual gatherings do not require 'inhabitance', 
they fail to create a sense of community (Jones, 1997). The lack of geographic proximity also means that online communities usually require less moral obligation, endeavour and commitment. Some worry that online groups will have negative effects on morality and ethics offline (Healy, 1997), and others are not convinced that online communities are an alternative to offline ones (Lockard, 1997). Doheny-Farina's (1996) statement voices these concerns:

A community is bound by place, which always includes complex social and environmental necessities. It is not something you can easily join. You can't subscribe to a community as you subscribe to a discussion group on the net. It must be lived. It is entwined, contradictory, and involves all our senses (1996: 37).

In academic discourse, it is clear that while community is a term which seems readily definable to the general public, it is infinitely complex and vague:

A community is a bounded territory of all sorts (whether physical or ideological), but it can also refer to a sense of common character, identity, or interests, as with the 'gay community' or 'virtual community'. Thus, the term 'community' encompasses both material and symbolic dimensions.... (Fernback, 1997: 39).

Brown (2006) has claimed that resistance to the idea of online communities stems from a nostalgic connection to the original conception of community when there were few other choices than for community to be defined by geographic proximity. Brown argues that if community is understood and defined by these a priori assumptions, the idea of virtual community will remain controversial. 
I have presented the debate over the community metaphor in order to clarify why I called my method 'virtual ethnography'. The study I present in Chapter Five is certainly different from a conventional ethnography study based on face-to-face interaction. In my opinion, virtual communities are not substitutes for 'real' ones; they are social phenomena in their own right. The digital space creates new forms of communication, relatedness and belonging. As Bruckman (2006) suggests, energy and time expended on developing definitions may not be the best way to proceed. Trying to understand how virtual assemblages emerge, live and are sustained could be a more productive way of evaluating community-likeness.

\section{Virtual ethnography}

Although the 'community' metaphor is debated in academic discourse, many observers and participants find this term appropriate because it captures their sense of interpersonal connection and internal organisation (Baym, 1995). The virtual community metaphor makes it possible to apply to cyberspace the methodologies that have been used to observe traditional communities. Observational studies on virtual communities are referred to as virtual ethnography. In traditional ethnography as Hammersley and Atkinson (1983) note:

[t]he ethnographer participates, overtly or covertly, in people's daily lives for an extended period of time, watching what happens, listening to what is said, asking questions; in fact collecting whatever data are available to throw light on the issues with which he or she is concerned (1983: 2). 
Obviously, text-based CMC (computer mediated communication) is not appropriate for all traditional observational techniques. Since there is no geographical research setting to be observed, virtual ethnography requires the researcher to pay attention to other indicators, mostly textual and graphic ones, such as images, abbreviations, language, etc. In this respect, as Pearson (1996) argues, analysing postings can be seen as documentary analysis.

There are multiple approaches to performing ethnographic studies on the online environment. Researchers may:

[t]hemselves participate in the activities of the group they are observing (participant observation); they may be viewed as members of the group but minimize their participation; they may assume the role of observer without being part of the group; or their presence may be concealed entirely form the people they are observing (Frankfort-Nachmias and Nachmias, 1996: 207).

Although I signed up as a member of the website, Repromed, the study I conducted cannot be regarded as participant observation. The research would have been more similar to participant observation in a real setting if I had been observing a chat room. 'Chat' is the form of CMC used to conduct real-time online discussions. In such an environment, researchers who wish to conduct overt research should introduce themselves, as their presence fairly closely resembles face-to-face interaction. In a real-time chat environment, users can take immediate action on whether to stay in the chatroom or log off after discovering the presence of the researcher. Informed consent is requested and 
given in 'real' time: interactively and instantly. Repromed did not provide an environment for a 'real time' chat. Although the web site provides certain chat facilities, there is no synchronised structure: if users in a certain forum are online at the same time they can follow the posts made by other users with a short time delay. Even if Repromed had provided a synchronised chat environment, I would have hesitated to announce my presence. As Paccagnella (1997) suggests, "a stranger wanting to do academic research is sometimes seen as an unwelcome arbitrary intrusion". Even in the case of 'soft', qualitative techniques, as in participant observation, problems arise because of the presence of the researcher in the field (1997).

\section{Ethical issues}

Ethnographic studies of virtual communities not only allow the researcher to conduct research in settings that would not exist in the real world but also enable them to make observations without informing the subjects being studied. However, subjects have the right to be aware that they are being researched and to be informed about the nature and purposes of the research. Therefore, researchers who want to make use of forum posts must decide how to tackle the issue of gaining consent from those who post to such forums and whether consent in fact needs to be obtained (Reid, 1995). Opinions on getting consent differ.

A number of ethical dilemmas arose related to quoting and analysing forum users' posts for the purposes of this study. One ethical dilemma was whether 
the users in publicly accessible forums should be informed that their posts were to be the subject of research. Does the researcher need permission to quote a posting from an Internet discussion thread?

Sudweeks and Rafaeli (1996) list different opinions on the rights of authors of the postings suggested during ProjectH (1993-1994), a large international group of researchers using computer-mediated communication to study computer-mediated communication, ${ }^{33}$. During the discussions, some researchers claimed that authors must be accredited and permission obtained if quotations are used. Given that forum posters are expecting that the audience is limited, definable and identifiable, and that the content is not redistributed and quantified, some have questioned whether the researchers have a right to intrude in the lives and activities of others, regarding such intrusion to be exploitation. It was suggested that, if copyright of public posts is surrendered on joining a list, this should be made clear to subscribers at the time of joining. Finally, some considered that the use of posts should be governed by professional and academic guidelines, for example, that short excerpts can be quoted without author permission. After lengthy debate, the group agreed on an ethical policy that would not seek permission for recording and analysis of publicly posted messages:

We view public discourse on CMC as just that: public. Analysis of such content, where individuals', institutions' and lists' identities are shielded, is not subject to 'Human Subject' restraints. Such study is more akin to the study of tombstone epitaphs, graffiti, or letters to the

\footnotetext{
${ }^{33}$ The participants of ProjectH represent fifteen countries, and numerous universities and commercial firms. Participants represent a wide range of age groups (early 20 s to late $60 \mathrm{~s}$ ), academic positions (graduate students to professors), and disciplines (approximately $40^{\circ} \%$ from the social sciences, $35 \%$ from the humanities and $25 \%$ from applied sciences.
} 
editor. Personal? - yes. Private? - no (Rafaeli, 1992, quoted in Sudweeks and Rafaeli, 1996: 121).

It is important to highlight that the project discussed above aimed to treat messages quantitatively. This policy cannot therefore be accepted as a universal ethic (Paccagnella, 1997). However, it does suggest that conversations on publicly accessible IRC channels or messages posted on newsgroups are not equivalent to private letters.

There is an ongoing debate regarding the adequacy of any analogy between online communicative venues and public spaces. Mann and Stewart (2000) suggest that there are parallels with the conventional face-to-face context where consent is usually not obtained:

Must researchers identify themselves if they are only participating the electronic equivalent of hanging out on street corners or doughnut shops where they would never think of wearing large signs identifying themselves as 'researchers'? (Garton et al., 1999: 93 quoted in Mann and Stewart, 2000).

Mann and Stewart note that, given the lack of consensus in the area, it is not surprising that researchers do not always declare explicitly whether they obtained consent for their study. However there are some research precedents. The authors quote Denzin's words with reference to his work where he participated in a mailing list:

I never identified myself to the group, nor did I obtain permission to quote from postings, thereby violating many of Schrum's (1995) ethical injunctions for electronic research (Mann and Stewart, 2000). 
In the absence of clear guidelines, it is worth providing an explanation of the ethical safeguards which I put in place for my study. First, observation of the postings took place with the knowledge and consent of the forum co-ordinator.

My correspondence with the forum moderator was as follows:

I am a PhD student studying at the University of Nottingham working on the removal of donor anonymity. I am particularly interested in this web site which provides an alternative route way of communicating for patients having infertility treatment. I am researching the way people exchange information and express support for each other in confidence without making official claims about the problems surrounding infertility treatment in the UK. I have been interviewing some of the users of this web site and with their reference I figured out Repromed provides an insight about the issues that I would like to explore.

I'd like to study and quote some of the postings in certain forums. Although I have an impression that Repromed is a public space I felt that it would be appropriate to ask your permission. I am not going to use Repromed's name and all the user names will be changed.

Please visit my web site if you want to check out my credentials:

http://www.nottingham.ac.uk/igbis/research/student project 1

eg donor insem.php

The reply from the moderator was as follows:

Dear Ilke

I would have no objection for you to use the Repromed website in your research. It would be appropriate to acknowledge this website as a source of your information. It is a publically accessible but clearly you would not wish to offend any patients by quoting them by name in any publication you produced (Administrator).

Interviews were also conducted with volunteer forum members to assess the relationship between the accounts presented in online and offline contexts, although few discrepancies were identified. The purpose of the study was explained to these users, and consent obtained about quoting their posts. 
However, I did not attempt to get consent from the entire population of the web site.

In this study, a number of reasons can be proposed to justify not informing the users that research was being conducted. First, the disclaimer on the web site itself clarifies that any information given by the user is considered public information. Secondly, the study was not conducted in private chat rooms: the forums were open to the public, even to unregistered users.

Because the Repromed website is open to public, I did not get any consent for viewing the posts. In many respects, the study that I conducted as a 'lurker' (a person who reads discussions on a message board with a limited participation) is similar to covert research. Murphy and Dingwall (2001) note that recent work recognises that the distinction between covert and overt research is less straightforward than sometimes imagined:

In complex and mobile settings, it may be simply impractical to seek consent from everyone involved. Unlike experimental researchers, ethnographers typically have limited control over who enters their field of observation. All research lies on a continuum between overtness and covertness (2001: 342).

The asynchronous structure of the setting raised ethical problems related to obtaining consent. I did not hide my identity as a researcher. I posted an ad to recruit participants for the interviews using my pseudonym and real name. I also e-mailed the admin and the forum moderators to obtain consent for the research, and some of the users to conduct further interviews and quote their posts. Nevertheless, due to the asynchronous structure of the forums, it was 
useless to announce my presence each time I visited the website. The forums closely resembled message boards: in such a setting, the posts remain unless the user takes an action (deleting or editing). If I sent a post announcing my presence, that post would stay even when I was offline along with the other posts. The impracticality of obtaining consent in an asynchronous structure is self-evident. More importantly, as noted above, the content of the website is considered public information.

\section{Online pseudonyms and copyright}

In cyberspace, pseudonyms can function just like a real name. Some people use the same pseudonym over an extended period of time within a community of people who come to know them by that name. The reputation associated with the pseudonym matters to them. Therefore, it has been suggested that pseudonyms should be treated as real names, and be changed (MediaMOO, 1997).

Paccagnella (1997) argues that just because particular online sources may be public, this does not mean that they can be used without restrictions. Therefore, not only the pseudonyms but also the identity of an institution and/or list should be changed. However, it shouldn't be necessary to take any more precautions than those usually adopted in the study of everyday life:

Changing not only real names, but also aliases or pseudonyms (where used) proves the respect of the researchers for the social reality of cyberspace. 
The argument that materials posted on the Internet are to be treated as authored material requiring permission for citation raises the question as to whether there is a need to protect the identity of the subjects or the name of the research setting (Ess, 2001). For example, fertilityfriends.co.uk permits quotations only if attribution to the name of the website is included:

$w w w$ fertilityfriends.co.uk hereby authorizes you to copy and display the content herein, but only for your personal or informational and noncommercial use. However, the content herein shall not be copied or posted in any network computer or broadcast in any media. Any copy you make must include this copyright notice. Limited quotations from the content are permitted if attribution to www.fertilityfriends.co.uk is included, but you may not display for redistribution any portion of the content without the prior written permission of $w w w$.fertilityfriends.co.uk. No modifications of the content may be made.

Such a disclaimer was not placed on Repromed. However, as presented earlier, after consulting the administrator of the website, I was advised to acknowledge this website as a source. The administrator only warned me not to use the real names of the users in my work. Even so, after careful consideration and consultation to the forum moderators, I decided to change the pseudonyms given that it is possible to relate certain pseudonyms to the real names.

\section{Sampling}

On the home page of Repromed, there is a link to the discussion area, which is the subject of the empirical work that will be presented in Chapter Five. This discussion area has different forums covering infertility, IVF and related treatments, intracytoplasmic sperm injection (ICSI), egg and sperm donation, adoption, pregnancy, new parents, etc. My study focuses on the forums dealing 
with issues related to gamete donation, going abroad for treatment, disclosure and donor anonymity. Forums not involving anything relevant to these items were excluded. However, if any post seemed to be relevant to the topics under examination it was analysed, regardless of which forum it was placed in. Although more than 5000 postings were scanned, the final sample included 900 postings sent between 13 July 2005 and 26 April 2006.

\section{Representativeness}

Despite the fact that virtual ethnography is an obvious candidate for developing a broad understanding of online behaviour within particular contexts (Preece and Maloney-Krichmar, 2005), some critics suggested that the representativeness of the findings is questionable and the study of online data alone is probably insufficient to understand how people use things they have read or said in their offline lives. For example, Bruckman argues:

It is important to remember that all Internet research takes place in an embedded social context. To understand Internet-based phenomena, you need to understand the broader context. Consequently, most "online research" really also should have an offline component (Hine, 2000: 52; quoted in Bruckman, 2002: 3).

As a response, Hine notes "in stressing the significance of access to users' offline contexts, we run the risk of implying that online interactions are not as authentic as offline ones, nor is the information the researcher generates from them" (2000: 52). She also argues that "the point for the ethnographer is not to bring some external criterion for judging whether it is safe to believe what informants say" (2000: 49). In my study, there was no reason to believe that the 
interview accounts were more sincere than the postings on the online discussion forums.

Some would-be parents do not use online support groups to exchange information and there are other online support groups that may have different concerns. However, Repromed was clearly one of the most active sites (based on the number of messages posted, and the depth of the threads) during this period and represents an important source of data on voices that were not fully heard in the public debates over ending donor anonymity.

\section{Data Analysis}

Qualitative studies aim to describe and explain a pattern of relationships, which can be with a set of conceptually analytic categories (Mishler, 1986; quoted in Huberman and Miles, 1998) Both inductive and deductive analysis are useful paths however, the iterative procedure that I adopted called for the use of analytic induction. Analytic induction suggests that there are regularities to be found in the physical and social worlds, and the theories and constructs that we derive express these regularities (Huberman and Miles, 1998). In order to uncover the constructs in would-be parents' accounts, I used an iterative procedure which corresponds to the 'grounded theory' (Glaser and Strauss, 1967) approach in qualitative research. Grounded theory acknowledges that analysis will be disjointed until the researcher has some acquaintance with the data (Huberman and Miles, 1998). This approach is based on the view that research can itself generate theoretical frameworks. 
Inductive approaches aid an understanding of meaning in complex data through data reduction (Thomas, 2005). For both the interviews and the posts on the discussion forum, my data analysis involved the development of summary themes or categories from the raw data. During the process, when a theme, hypothesis or pattern was identified inductively, I tried to confirm the finding which keyed off a new inductive cycle.

\section{Posts on discussion boards}

Internet postings resemble other common sources of data used by qualitative researchers. Virtual ethnography can be regarded as a form of interviewing, in that the responses to each other's comments elicit contributions from participants on a particular topic (Pearson, 1996). It can also be regarded as a form of observation, in that a researcher can witness naturally occurring interaction between the forum members on particular topics, unprompted by the researcher's questions or interventions (Pearson, 1996).

Analysing posts is similar to analysing texts. (Lincoln and Guba, 1985, quoted in Denzin and Lincoln, 1998: 110) distinguish documents and records on the basis of whether the text was "prepared to attest to some formal transaction". Records are prepared for official reasons, such as marriage certificates, driving licences, contracts and bank statements. Documents, on the other hand, are prepared for personal reasons and include diaries, memos and letters: posts, in that sense, are similar to documents. Posts on online discussion forums have the potential to become very important for qualitative research because, 
generally speaking, access to them can be easy and low cost, the data is transformed less during the analysis, and the stress of face-to-face interaction is avoided. In digital space, people "connect with strangers without much of the social baggage that divides and alienates" (Poster, 1994: 83). This means that virtual communities may provide marginalised or stigmatised individuals with a feeling of solidarity, while at the same time maintaining their anonymity. And user anonymity promotes conversations that might have been avoided if participants had to provide identifiable information: "[W]ithout visual cues about gender, age, ethnicity and social status, conversations open up in directions that otherwise might be avoided" (Poster, 1994: 83). On the other hand, as I have discussed earlier analysing posts does raise a range of ethical issues, as I have discussed earlier.

For data analysis, I first printed off the entire thread of the discussion topics that I included in my sampling. Documenting online data is important as sometimes websites are shut down or updated. This was the case with Repromed: although the website still exists, it has been updated due to an address change and the administrators have cleaned up the old posts and moved them to archives. Many posts, including the ones in my sample, are not accessible anymore.

After printing off the threads, I read them several times and identified common themes. Threads are similar to transcripts of a conversation and the posts are close to speech, or an extract from an interview. Some forum users who I 
interviewed noted that sending posts can at times be similar to keeping a diary, except that the diary is open to public.

Just like the interviews, the posts required a contextualised interpretation. For that reason, I considered the meaning of each post in its context (the context should be considered as the entire thread, and sometimes the discussion topic in general), rather than treating it as an independent piece of text. I also traced the pseudonym of the poster, and checked their medical history and their profile, as these were potentially directly related to the post that I was analysing. As some users are more familiar to each other than others, some posts had references to a medical condition, or an earlier discussion, that did not make any sense to me, the analyst. Therefore, in some instances, checking the profile information, and earlier posts or discussions might be was necessary. This was the most time-consuming part of the analysis.

\section{The Interviews}

I listened to each interview several times. As noted earlier, during or immediately after each interview, I made a summary, including demographic data about the participant, details of the interview (where, when, for how long, phone, written or face-to-face, etc.) and the general feeling of the interview (aggressive, friendly, reserved, distant, etc.). I revisited these notes while listening to the tape recordings of the interviews. The notes helped me to remember my immediate feelings and impressions. These steps were taken before I started making transcripts. 
I did not transcribe the interviews immediately after the interviews. All transcription was done when the fieldwork was finished. However, before I got to the transcription stage, I listened to all interviews and read my notes a number of times, and thought about the common themes. Although it was timeconsuming, having done transcription of the interviews on my own helped me to become more familiar with the narratives. Later, I read the transcripts several times to identify themes and categories. I then developed a coding frame. I used NVivo in the beginning, but then realised that it was more efficient to use manual tools such as highlighters for coding. If new codes emerged, I updated the coding frame, and reread the transcripts according to the new structure. This process helped me with developing categories, which were then conceptualised into broad themes.

\section{Some reflections}

This chapter has presented my account as a research student who intended to study a social problem which has not been articulated in conventional ways of communication. As I have explained, ethnographic studies enabled me to interrogate some of the policy assumptions about donor conception families, and the donor conception families' responses to these assumptions. This empirical study cannot claim to give definite answers to the question as to whether the new law encouraged or will encourage openness, but it can help us to understand social norms about donor conception and why it is unreasonable to expect that these will/ should change by legal initiatives. 
By trying to have would-be parents' voices heard, inevitably, I have also become an actor who is engaged in problem definition activities. This was not set as a goal, but was an inevitable consequence of my approach to data analysis. Spector and Kitsuse (1977) have argued that while studying a social problem, analysts are entitled to participate in these problems as practical actors, but they should not enter the social problems as experts. This is probably because Spector and Kitsuse wanted to promote social constructionism as a value-free and scientific way to examine social problems. Their approach does not contain an explicit social change agenda (Loseke, 2003). As I discussed earlier in Chapter Two, the strongest interpretations of social constructionism avoid making (even implicit) assumptions about objective reality. For them, the actual social conditions are irrelevant. However I chose to adopt contextual constructionism on account of its policy relevance, and I seek to locate claims-making within its socio-legal context. This involves making assumptions about the broader context from which claims adopt elements, analysing the nature of claims, and evaluating why certain claims, rights, and needs remain unrecognised in the public realm. The inclusion of socio-cultural context is an important part of my analysis and, for this reason, the thesis departs from the value-free relativist tradition of constructionism. Furthermore, by giving voice to the stakeholders who silenced their claims during the debate, this thesis itself can be considered as a definitional claimsmaking activity in relation to donor anonymity as a social problem. 


\section{CHAPTER FIVE: VIRTUAL ETHNOGRAPHY ON REPROMED}

As I mentioned in Chapter One, during the donor anonymity debate in the UK, would-be parents remained silent. The overarching question of this thesis is "how may donor conception families' reactions to the disclosure policy in the UK better be understood?" In Chapter Two I argued that, occasionally, stakeholders in a problem cannot articulate their claims in a conventional, formal manner because of the perceived lack of legitimacy attached to these claims. The silence of stakeholders does not mean that there is no problem to be postulated. I suggested that by studying the natural history of the donor anonymity debate we might better understand how donor anonymity was defined as problematic, what kind of claims-making discourse was perceived as legitimate, and how these claims were successful in bringing about a change in the law. I presented the natural history of the removal of donor anonymity in Chapter Three, revealing that the voices of would-be parents were missing from the public realm. Despite the absence of these parents from the public debate, the media reported that growing numbers of people were seeking fertility treatment abroad, with the most popular destinations being countries that maintained donor anonymity. I argued that this fertility travel indicated that there is a 'silent resistance' to the law which deserves to be subject of empirical investigation. 
In Chapter Four, I pointed out that, despite their reticence in voicing their concerns in formal modes of communication during and after the donor anonymity debate, infertility patients in the UK have been protesting anonymously against the new law on the discussion forums of online support groups. This means, however, that their voices may not be heard by public bodies, like the HFEA, which can only deal with issues through formal and transparent modes of communication. Hence, as I suggested in Chapter Four, these discussion forums should be seen as providing valuable data for exploring claims-making activities that have escaped the public eye.

This chapter describes the virtual ethnography study that I conducted on the patient discussion forums of Repromed (www.repromed.co.uk), which is the website of the Bristol Centre for Reproductive Medicine (BCRM). ${ }^{34}$ Repromed was one of the most active sites during the review of the law and represents an important source of data on voices that were not fully heard in the public debates over ending donor anonymity. I presented the rationale of this study in Chapter Four: it focuses on would-be parents' own communications in a setting where issues about gamete donation are discussed.

As noted in Chapter Four, my starting point was that fertility-patient support groups in cyberspace offer substantive data to understand collective claimsmaking by would-be parents. I acknowledge that, in many respects, cyberspace is different from the traditional settings in which ethnographic studies are carried out. While exploring collective definitional activities, particularly in 
cyberspace, the degree to which a setting has the characteristics of a community may be important. Moreover, given the sensitivity of my research topic, it was particularly important to find the right setting. I took the view that people might feel more comfortable sharing intimate aspects of their lives in a setting where they could become connected with others who had had similar experiences. According to Rheingold (1994), the social glue that binds formerly isolated individuals into a community is the ability to network, gain knowledge, or find 'communion' within cyberspace. ${ }^{35}$. Similarly to Rheingold, Watson argues that the continued interaction of participating members creates, re-creates, and maintains community in a particular online setting. The technological ability to communicate, however, does not itself create the conditions of community: community depends not only upon communication and shared interests, but also upon 'communion' (1997: 104).

I was keen to conduct my study in a setting where community-likeness and communion existed. However, there is no clear guidance on where such settings are to be found and how they are to be identified: researchers must make their own judgements. Watson (1997) suggests that this should not cause anxiety given that judgements have to be made about all sorts of things, and researchers should certainly be capable of making judgements about the claim of cyberspace residents to be a community.

\footnotetext{
${ }^{34}$ At the time of this study, the clinic behind the Repromed website was the University of Bristol's, Centre for Reproductive Medicine. This centre has now merged with the Southmead Fertility Service.

${ }^{35}$ He describes communion as a human feeling that comes from the communicative coordination of oneself with others and the environment.
} 
I used a range of criteria to evaluate the community-likeness of three potential settings: Repromed; fertilityfriends.co.uk; and infertilitynetworkUK. At the time at which I was conducting my field study, fertilityfriends.co.uk, provided the largest amount of data with 639,645 posts sent by 14,000 users. Being the largest on-line community of UK infertility patients, the website is recommended by the HFEA and also by other websites, including other online support groups and clinics that host online discussion forums. The opportunity to have access to this amount of data was tempting; at the same time, however, the large population suggested that it would be very difficult for any researcher to become familiar with the users. Indeed, the size of the population might also be a potential problem for members of fertilityfriends.co.uk, given that a website's popularity may threaten the possibility for, or existence of, intimacy (Watson, 1997). In this respect, infertilitynetwork $U K$ (702 members) and Repromed (881 members) seemed to be more suitable as settings for a study that I could feasibly conduct within the limitations of a PhD.

I also had to take account of the fact that user numbers in online settings can be inflated by peripheral users (those who tap into the community, drop a question and disappear) or 'lurkers' (those who read posts but do not post messages themselves). In order to get a clearer picture of the continuous presence of members, I made some rough calculations: my aim was to have an idea about the depth of the threads, and user involvement in discussions. These calculations showed that Repromed had the highest average 'post per topic' compared to the other two websites. This figure shows the depth of the threads, which indicates that "people carry on public discussions long enough" 
(Rheingold, 1994). Hence, although 'post per user' was higher in fertilityfriends.co.uk, I decided on Repromed as a more suitable setting because of the depth of its threads.

\begin{tabular}{|c|c|c|c|c|c|}
\hline & Members & posts & Topics & user & topic \\
\hline Fertilityfriends.co.uk & 13881 & 639645 & 30453 & $\mathbf{4 6}$ & 21 \\
\hline Repromed & 881 & 27829 & 704 & 32 & $\mathbf{4 0}$ \\
\hline InfertilityNetworkUK & 702 & 5615 & 661 & 8 & 9 \\
\hline \multicolumn{7}{|c|}{ Figures as of 17.04 .2006} \\
\hline
\end{tabular}

It must be said that objective indicators and calculations such as these can only offer limited help in assessing 'continuous presence', or community-likeness. Watson's observation on the community-likeness of Phish.net is worth quoting here:

Subjectively, when one looks into a virtual forum, it feels like what one knows as a community. One feature which makes a space like Phish.net appear to be a community is continuous presence of other people there. One can 'tap into' CMC [Computer Mediated Communication] communities for a wealth of prepared information, or to pose a question to a large group of people with diverse backgrounds of knowledge (1997: 105).

Similarly, Rheingold (1994) suggests that the community-likeness of an online setting can be assessed by a "sufficient human feeling". Scanning the posts to see whether users were familiar with one another and responded to each other's posts (rather than dropping a post and disappearing) gave me some insight into this. Compared to its counterparts, Repromed seemed to me to be more like a 'community' and a 'communion', mainly because of the 'intimacy' among its members. Repromed's users sometimes refer to each other using real names 
rather than pseudonyms, they organise off-line events among themselves, and they send their pictures and know each other's treatment histories. They notice quickly when a new member joins them. Community size may be one of the reasons that make this possible: Repromed has a relatively small and loyal member population compared to its counterparts. Another reason behind the intimacy at Repromed might be shared experience: most of the members had their first treatment at the clinic that hosts the website. Finally, members of Repromed enjoy a shared locality: this site is mainly used by patients having treatment in the South West region, specifically at clinics in the Bristol area. Clearly this shared locality may also be a key factor enabling members to organise offline events and meet each other.

More importantly, what made Repromed different from its counterparts was its member profile. The other support groups have a more inclusive member profile: different stakeholders (patients, nurses, doctors, clinicians, journalists, etc.) share their views on discussion forums. I assumed that I would be more likely to reach my target population through Repromed as almost all members are would-be parents, new parents, or patients who have had at least one cycle (successful or unsuccessful) at the clinic that hosts the site. This population represents the stakeholders whose voices were absent in donor anonymity debate. 


\section{Repromed as a research setting}

Repromed introduces itself as a website for anyone in the UK interested in reproductive medicine. On the home page there is a link to the discussion area, which is the subject of the study that I performed.

Visitors are required to give a small amount of information (user name and password) if they wish to be registered users. Much of this information is optional (real name, location, occupation, interests, date of birth, etc.). However, any information given by a user is considered as public information.

Repromed forums are open to everyone and sometimes even unregistered users may post in them. It is up to the 'forums administrator' as to whether to allow unregistered users to post in the forums. Some forums are set up to allow only certain users or groups of users to access them. And in order to view, read or post, in a forum, users may first need permission from the forum moderator or a forum administrator.

The forums are maintained in asynchronous structure. With asynchronous communication, participants do not need to be on-line simultaneously; they can read and respond at different times (Baym, 1995).

The discussion area lists the forum titles, how many topics and posts have been carried on each forum, the date and time of the last post sent, and the poster's name. When the user clicks on a forum title, a new screen comes up which 
conveys information about the topics, topic starter, replies, views and the last post (the date and the time of the post, and the poster's name). Topics 'started' by the users include infertility, IVF and related treatments, ICSI, egg and sperm donation, adoption, pregnancy and new parents. In order to see the thread of posts, one topic has to be selected and clicked on. The posts are in chronological order.

Users can start a new topic unless it is related to topics that already exist. Each topic involves a question, or a brief introduction about the inquiry. For example: "Is anyone currently trying or pregnant with a DI baby? How long did it take to conceive and how have your emotions been along the way?"

Users are not allowed to post any material which is vulgar, defamatory, inaccurate, harassing, hateful, threatening, invading of others privacy, sexually oriented, or in violation of any laws. Also, users are not allowed to post any copyrighted material that is not owned by themselves or the owners of these forums. Forum administrators and forum moderators, who have the highest level of control over the forums, can turn on and off features on the forums, ban and remove users, edit and delete posts, and create users and groups.

The page that presents the forum list enables visitors to see how many topics and posts each forum holds. During my study, the 'IVF\& Related Treatments' forum was the most popular, with almost 15,000 posts. More specific forums, such as 'Gamete Donation', held fewer posts; however compared to the other 
forums hosted by similar websites, ${ }^{36}$ Repromed's forum on the subject is a comprehensive one.

In Repromed, users are ranked according to the number of posts they send. During the time I was observing the website (February-April 2006), there were 881 registered users. ${ }^{37}$ Ranks in the forums indicate to which user-group a user belongs. The forum administrator sets up ranks using a ladder system based on the number of posts that users make. There were three users in the 'moderator group' who had around $2,400-3,250$ posts. These three users were registered at the beginning of 2004. The second group, which was called 'senior members', had 100-1,500 posts each. There were 87 senior members. 'Groupies' comprised the third largest group, with 61 users. These users had 40-100 posts. The largest group in Repromed was the 'newbies' who had less than 40 posts. The first posts were dated January 2003. By the time that I visited the website, users had posted 27,829 messages, on 704 topics, in 15 forums.

\section{Demographic information and the user identities}

The website did not provide any statistical information. Collecting demographic information about the entire population would have necessitated scanning approximately 900 user profiles. And, as noted earlier, the user number might have been inflated by lurkers. Random sampling would therefore have been both time-consuming and probably misleading (only continuous and active users represent the community). As a result, I made a non-random sampling.

\footnotetext{
${ }^{36}$ See, in particular, infertilitynetworkUK; acebabies.com; and ivfconnections.com.

${ }^{37}$ The following figures are as of 17 April 2006.
} 
For my sampling, I ranked the users by the number of posts that they sent, and I scanned the profiles of the first 44 users who had more than 220 posts. This sampling covered the profiles of users who owned 97 per cent of the total posts. Regarding this, the demographic data that I collected was highly representative of the active users. Sixteen of the 44 users did not provide their date of birth at registration. The age range of the other 28 users was from 28 to 43. The average age was 35 and there were two modes (the most frequently occurring age in the distribution) at 35 and 40.

It is, of course, debatable whether demographic information collected in cyberspace is reliable. When visual cues, such as gender and age, are of the utmost importance to users, it is fairly easy to fake or modify them (especially in text-based computer mediated communication). However, given that the common purpose of Repromed users is exchanging information about reproductive health and infertility treatment, appearing more physically attractive to other users may not be a primary concern. On these discussion forums, providing correct information about one's body markers (such as ethnicity, gender and age) is deemed necessary as infertility treatment is directly or indirectly affected by these parameters. In other words, if the Repromed users expect to get sensible advice, they will benefit from providing accurate information about their body markers. As a result, it can be suggested that the demographic information provided by Repromed users should be treated as reliable. 
In the off-line world, markers of gender and age are closely tied to social hierarchies but, in computer mediated communication (CMC), social-hierarchy formation does not need to establish itself along traditionally-structured lines. Poster (1990) claims that with CMC:

...for the first time individuals emerge in telecommunications with other individuals, often on an enduring basis, without considerations that derive from the presence to the partner of their body, their voice, their sex, many of the markings of their personal history (1990: 117).

Watson's (1997) work suggests that one's ethnicity, gender, sexual orientation, and age may not be of importance on certain discussion forums. For example, he found that missing visual cues were not essential for the formation of communion on Phish.net. The users had developed their own cues of importance, such as displayed knowledge, repeated presence, and extensive fan experience. Similarly, on Repromed, medical history is one of the most important components of user identities. Arguably, then, the users have developed their own cues of importance mostly based on their experience as patients. User signatures convey treatment details and any information relevant to the treatment, such as ages of the user and her/his partner. Two signatures exemplify this:

\footnotetext{
Me 30, DH 31

$\mathrm{DH}$ - no fishes

ME:FEB 061 st DIUI canc'd = metformin 090306 for $\mathrm{v}$ mild pco. March 06 DIUI= -ve

5 yrs TTC, 7 IUI ( 3 cancelled due to OHSS), 1 IVF, ICSI EC $6 / 9 / 04,+$ tve result 22/9/04, EDD 30/5/05, Gorgeous baby Tom born $1 / 6 / 05$ !
} 
These abbreviations provide a good illustration of meaning-making among the users. For someone who is not familiar with infertility treatment, the language used might be incomprehensible; for the users, whoever, this type of language is quite understandable. Repromed provides a list of abbreviations for newbies (those who are new to the website). Some of the abbreviations, especially the medical ones, are quite similar to those used in other online support groups: for example, a shortened form of a treatment, test or method. For example, BFN/BFP, which stands for Big Fat Negative/Positive, indicates the result of a pregnancy test, and is an abbreviation commonly used in many Internet forums on reproductive health. Some abbreviations however seem to be particular to Repromed. ${ }^{38}$ For example, BD, Baby Dance, means having intercourse in order to conceive a baby, whereas BM, Blueberry Muffins, ${ }^{39}$ is a phrase that stands for sex.

In my sampling, the most common abbreviations were: 2 ww ( 2 week wait); TTC (Trying to Conceive); Tx (Treatment); IVF (In Vitro Fertilisation); DI (Donor Insemination); ICSI (Intra-Cytoplasmic Sperm Injection); PM (Private Message); DP (Dearest Partner); IUI (Intra-Uterine Insemination); PMA (Positive Mental Attitude); LH (Luteinising Hormone); and, as noted above, BFN/BFP or +ve and -ve (Big Fat Negative/Positive).

\footnotetext{
${ }^{38}$ Arguably, as members of a community create social meaning through interaction with others, abbreviations will differ in similar online support groups.

${ }^{39}$ One of the users once posted that she had spent the afternoon cooking blueberry muffins with her partner. The other users took this as euphemism for trying to conceive.
} 


\section{Emoticons and avatars}

In $\mathrm{CMC}$, one way of replicating face-to-face communication is to position 'emoticons' strategically in the text. Some of the Repromed members place emoticons in their posts to establish a relational tone. These emoticons may include verbal descriptions of feelings, sounds, or small images. Smileys are perhaps the most commonly used of all emoticons: examples include the smiling face :-); the frown :-( ; and the wink ;- ). Avatars are another tool used to personalise posts. These are small icons or images shown next to the text. Two examples are as follows:

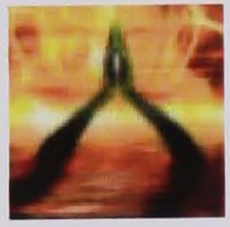

Avatar-1

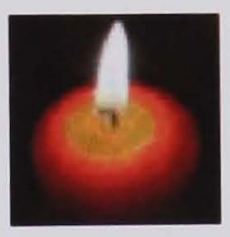

Avatar-2

An ultrasound image of the foetus, pictures of the user and her/his partner, images of candles, angels, flowers, scenes from nature, and spiritual symbols are the most common avatars used on Repromed discussion forums. The posts also carry graphics to show the progress of weight loss or of a pregnancy. An example of such graphics is as follows:

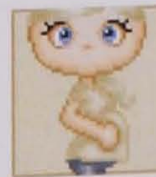

I'm 34 week s and 4 days pregnant! Only 38 days to go!

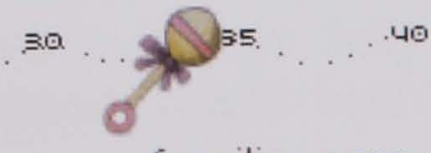

families com

Graphic 1 


\section{The setting up of the 'donor gamete' (later, 'egg and sperm donation') forum}

The data presented in this chapter draw mainly on the 'Egg and Sperm Donation' (formerly, the 'Donor Gamete' forum) forum on Repromed, which had the fullest coverage of issue of donor anonymity. I had the opportunity to find out about the setting up of this forum during one of my interviews. Before this forum was set up, fertility travel was being discussed in other discussion forums on the website. One of the patients, Elaine, who was receiving treatment at the BCRM (the clinic that hosts Repromed) had decided to receive treatment in Spain, mainly due to the removal of donor anonymity in the UK and length of waiting lists. She shared her experiences with other users of Repromed on discussion forums. She eventually met and became friends with six other women users. Like Elaine, these six women also ended up receiving treatment in Spain. According to Elaine, the fact that they were discussing their experiences on Repromed discussion forums was not well-received by the host clinic and the administrator set up a new 'Donor Gamete Forum' forum so that people receiving donor gamete treatment could interact in a setting separate from other patients of the clinic. The forum was set up in November 2005 with the following disclaimer:

After much discussion we have set up the Donor gamete forum. We are a little concerned about the oversees fertility treatment options as these are outside UK ethical and safety regulations, but we fully agree that UK patients receiving donor gamete treatment would benefit from mutual online support.

Regards, Admin 
Elaine expressed anger about this disclaimer. She claims that Repromed attempts to censor references to clinics abroad as "they can't stand to see all that money is going" to the clinics abroad:

Well, what can I say, except my comments would be censored!!!!!!!!!!!!!!!!!!!!!!!!!!!!! ( ...)I'm fed up with them having nothing but bad things to say every time it comes to going abroad for treatment.(...) Don't they know these "other" clinics have just as stringent guidelines as nay that can be laid before us in England????????????? All they seem to want to do is block us, every step of the way.(....)Spain, and many other countries, have taken the technology which started here and are now leaders in the technology. I guess they just can't stand to see all that money going somewhere else. It's a shame they didn't read Lord Winston's article the other week, where he expressly iterated exactly these points and said "when money comes into the equation, ethics go out the door"-how true! (Elaine).

In another post, she claims that people are travelling abroad to receive the help that the UK is "unable/unwilling to give":

I am outraged, flabbergasted, very angry indeed. Tell them not to worry, many other open minded IVF sites offer full support to people travelling abroad for the help that the UK very obviously is unable/unwilling to give!!!!!!!!!!!! (Elaine)

Some users expressed the view that the clinic was reluctant to have posts on its website advertising clinics abroad as it did not want to lose its HFEA licence. In reality, a large number of posts did make reference to overseas clinics, particularly to one clinic in Barcelona where a number of users received gamete and embryo donation:

I think what admin is trying to address is the fact that this is a forum provided for by them and as they are licensed by HFEA they can't be seen to be encouraging tx which falls outside the boundaries of the uk 
HFEA parameters. I think this is legal stance more then anything, this is

a public forum so you never know who is looking in (Heather).

Following this discussion, the moderator of the forum closed this thread saying:

Admin have responded to the request to set up a separate section within the Repromed forum so that people seeking treatment using donors can have their discussion focussed should they wish it. Neither Admin or the Moderators will prevent threads discussing treatment being sought abroad, in the same way that people receiving treatment at other UK clinics are free to discuss their experiences (Sandy).

Interestingly, five months later this forum was suspended as the clinic behind the site was concerned about the increasing number of posts advising users about overseas treatment facilities. I will discuss the closure and re-opening of the forum later in the chapter.

\section{Themes from the postings}

In what follows, I will present and analyse the posts according to the common themes that I identified during my analysis. The posts are not edited, except for the references to clinics or names of websites where sperm can be purchased. The contextual approach adopted in this thesis suggests that references must be made to social conditions in order to properly describe the context from which claims emerge. Therefore, while analysing the claims of the would-be parents I will not refrain from making references to objective indicators, such as donor statistics or surveys. The accounts of the would-be parents are not independent from the public debate, media presentations, anecdotal evidence, research findings - in short, they are not independent of various 'facts' which are 
culturally, socially or physically available to them in a broader context.

Ultimately, however, I am more interested in understanding where would-be parents' claims emerge from, and less interested in evaluating the accuracy of these claims.

\section{The donor shortage}

Most forum participants are on waiting lists for gamete donation and clearly associate the donor shortage with the change in the law to remove anonymity.

Examples of posts expressing this view are as follows:

I just think it's such a crying shame that the HFEA took it into their heads to remove the anonymity from donors thus drastically reducing the number of volunteers and now forcing us all to go abroad, where donors can remain forever anonymous (Elaine).

... the legal change has made a huge difference to the numbers of donors. The number of accepted Donors around the UK is in the low 100s now (I read this somewhere and it used to be in the 1000s) (Suzanne).

Apparently out of 500 applicants to give sperm in the last year only 2 actually do so, predominantly due the anonymity issue and the low sperm counts of the younger applicants. Very frightening stats don't you think? (Mandy)

BCRM have written to us today to say they are unable to offer tx as they have no available donors( iui with donor). We have to contact them again in 3 months if we haven't heard anything. Having been on this journey with CRM,since 2003, and having only just had first iui $\mathrm{DH}$ and I are now understandable at our wits end (Julia).

i do think that the change in the law has got every thing to do with it especialy if you are donating eggs or sperm and you are haveing difficulty consiving yourself.$i$ have also been told that sperm donations 
have gone down because there use to be alot of students that use to donate but have stoped because they dont want a knock on the door in 18 years do you know if it the same if you go out side theuk and have treatment and donate at the same time cause im not sure about that one from the first time i went for icsi to now things seame to have got more compucated and expensive lol (Sheila).

One of the users, Sylvia, claims that in order to resolve the sperm shortage, the law should be changed back, reinstating anonymity. She calls upon other users to sign her petition:

if you think sperm donors should be legally allowed to remain anonymous please sign my petition. $i$ am petitioning the prime minister of the uk to change the law so sperm donors can go back to being anonymous so the sperm shortage can be resolved. if you agree with this please sign at the following link: http://petitions.pm.gov.uk/spermdonor-anon/ (Sylvia).

Sylvia claims that the new law prevents "a loving couple from having the child they wish to have":

i think anonymity should be brought back after watching a documentary on it. being someone who possibly may need a sperm donor's help in the future id rather not be waiting for years because of the shortage if you agree could you please sign my petition. i understand the reasons why it shouldn't but why should we prevent a loving couple from having the child they wish to have?

come on sign it if you agree :D (Sylvia).

As I noted in Chapter Three, since the removal of donor anonymity, the Department of Health and the National Gamete Donation Trust have been running a campaign to raise awareness of donation and recruit new donors. While an initial fall in donor supply was predicted, the Department assumed that the donor profile would eventually change, with older men who have children coming forward for altruistic reasons. One user, Tara, draws attention to this: 
Well I read the SEED review I think the HFEA are hoping that older men will come forward and donate their sperm. Its a BIG chance they are taking. They should have left well alone I say. The simple truth is there are now less donors because of the anonymity issue and have they thought that these older men may want to stay anonymous. I dont think they would cherish the idea of a child knocking on their door in $18 \mathrm{yrs}$ time. Besides how would the rest of his family feel???? Have the HFEA taken this on board?? No I don't think so (Tara).

Tara expresses the view that, in changing the donor recruitment policy, the HFEA made false assumptions. Furthermore, in her view, the Authority did not handle the donor crisis well. She accuses it of infringing would-be parents' human rights:

\begin{abstract}
Anyway on another note we should thanks Dame Suzi Leather and her syndicate for causing this mess!! I wouldnt be surprised if a couple took them to the court of human rights - essentially they are stopping couples having a baby!! To me thats enfringing on our human rights. Of course this is my personal opinion, but I havent yet found anyone who is happy with what the HFEA have done (Tara).
\end{abstract}

These posts can be better understood when located in the donor anonymity debate. During that debate, both the claims-makers and the counter claimsmakers referred to experience from countries that had lifted anonymity. Sweden was the first country to remove anonymity. The Swedish Insemination Act 1984 was followed by an initial decline in donation ${ }^{40}$ (Daniels, 1994); however, shifts in recruitment methods led to a resurgence in donor numbers (Daniels, Ericsson and Burn, 1998). But it has been argued that the Swedish

\footnotetext{
${ }^{40}$ Prior to 1985,230 children were born in Sweden. After the law passed, the figure was 30 a year. Daniels (1994) reports that the reasons for the decline were reluctance of donors who want to remain anonymous, reluctance of couples who do not want to get DI where anonymity of donors is no longer guaranteed, doctors' opposition to the legislation (they were referring
} 
law is comprehensively avoided, with many infertile couples either obtaining insemination illegally or going abroad for treatment. ${ }^{41}$ The legislation may have therefore increased the psychological and medical risks involved in DI, for those who seek to avoid its measures (Daniels, Ericsson and Burn, 1998). By recommending that the donor be married and the donor's wife should be informed of the donor's decision (Daniels, 1994), the Swedish Act also created a new donor profile. A recent study conducted on Swedish sperm donors reveals that the mean and median age for providers in one clinic were 37 and 40 years and 34 and 33 years for the other (Lalos et al., 2003). While prelegislation donors were predominantly students donating for financial gain and men recruited from military establishments, post-legislation donors are older men in their late $30 \mathrm{~s}$ or $40 \mathrm{~s}$, married with children, motivated by a desire to help infertile couples (Daniels, Ericsson and Burn, 1998; Lalos et al., 2003). Some argue that the new donor profile is more ethical, and is therefore preferable. However, the fact that semen volume and motility decrease continuously with age ${ }^{42}$ (Eskenazi et al., 2003), and that such sperm is less capable of fertilising an egg, makes older sperm donors less desirable in practice. Moreover, despite having a significant impact on the donor profile, the Swedish Act has not been successful in changing disclosure patterns (Gottlieb, Lalos and Lindblad, 2000; Lalos et al., 2003).

couples to neighbouring countries), and an increase in government allowances for adopting a foreign child.

${ }^{41}$ There is evidence from one Danish clinic, where Swedish couples made up 39 per cent of the total number of couples who received DI between 1983 and 1992, and a Finnish clinic. where couples from Sweden made up 50 per cent of total patients (Daniels et al., 1998).

${ }^{42}$ In a convenience sample of healthy men between 22 and 80 years of age from a non-clinical setting, significant age-related decreases in semen quality were observed, most notably for semen volume and sperm motility. For example, a 20 per cent decrease was observed in semen volume in 50-year-old men compared to 30 -year-olds. 
Further evidence about the impact of disclosure on the supply of gametes in other countries has emerged more recently. In the Netherlands, 15 years of debate on the abolition of donor anonymity was associated with the number of donors decreasing by 70 per cent and the number of semen banks by 50 per cent (Janssens et al., 2006). Since the removal of donor anonymity in Norway in January 2005, clinics there have also reported donor shortages (Tisdall, 2006).

During the donor anonymity debate in the UK, the experience from other countries was interpreted in different ways, according to the agenda of the claims-makers. The post that I present below summarises how many of the would-be parents' on Repromed's forum view the matter: donor shortage should have been foreseen by the regulatory body and precautions should have been taken in advance.

They (HFEA) should have warned clinics to overstock a year ago in case this should happen. From what I could gather from the clinics I rang they had warned the HFEA that this would happen!! The HFEA knew there could be a dip in donors as this happened in Australia and New Zealand and Sweden, I would like to know if they ever recovered!! All I can say is well done (not) HFEA (Tara).

From the conversations I have had this week, it does feel as tho people have been completely unprepared for the law change (not xxx -name of the clinic) just the whole fertility sector!), i am cross to know that there as been precedent in Australia and the UK could have used this for guidance - but didn't. I didn't think that trying to conceive would entail so much fighting and would make me feel so much like a criminal (Suzanne). 


\section{Matching donors}

The users of the website express the view that the reduction in donors has also compromised their chances of finding a donor with a reasonable match to their own physical characteristics, or those of their partner. For example, Amanda refers to her conversation with a nurse during which she was told that donor sperm gets used up quickly and that clinics had problems getting donors because of the change in the law:

The nurse said they would match as best as they can but no guarantees, she said they would do their best, but they don't have as much choice as before the law changed (Amanda).

Some users think that it is important to 'match' the donor with the characteristics of the recipient family. This is expressed in terms of the importance of a physical resemblance. In one clinic, a user reported being told that there was a limited supply and they would do their best to match as near to her husband as possible.

I was also told by the clinic that dark hair and eyes were harder to come by!! I do think the HFEA have a lot to answer for. They have these great ideas!!!! But hey put them into practise and what do you get, zilch on the sperm front and couples with no donors and having to pay more money (Tara).

Even though at least one of the partners is not capable of contributing to the biological make-up of the baby, users desire a child that reflects their union as much as possible. Therefore, they look for a donor who resembles at least one 
of them. Despite the fact that there is no guarantee that the offspring will share those characteristics, users want to try with a matching donor rather than a random one:

I think with nature my view is what will be will be, but as we may have to use a sperm donor, it has been difficult for me to get my head around. I therefore would like as close a match as possible to hubby if you see what I mean. I am sure most people would agree that it is nice to get a match as near as possible and it does seem that your egg donor is quite close in colouring to you. I watched a program not long back about a white couple who got a black couples embryo, it turned out in the end that they had to give the black baby to the black couple even thought the white woman carried it and gave birth. I still think its reasonable to get a close match not only in colouring and build, but also in race. In the end I think its down to personal choice and how a couple feel about it (Tara).

Suzanne and her husband are worried about eye colour. She has green eyes and her husband has brown ones. Her husband thinks it would be 'odd' if their baby had blue eyes. As the DI appointment approaches, Suzanne gets nervous. A day before DIUI, she posts that she is very excited and she keeps worrying about what the donor looked like. She knows the eye and hair colour and the weight, but wishes she knew more details:

I wish that they had a few more details but I think that they are in short supply of donors as the characteristics of the donor match me more and not really my DP (Suzanne).

Jenny, who has a DI child, notes that she had similar worries before giving birth: 
just wanted to say that one of the huge things I was worried about before having G... (4 months old now) was her appearance and who she would look like. Most people say she is the spit of me, most also notice her colouring being the same as her Dad's and if I'm asked who I think she looks like, I say me or herself. Mind you, it wouldn't be a fib to say she looked like $\mathrm{DH}$, just cos the genes are borrowed, it doesn't mean she can't look like him (Jenny).

Physical resemblance is perceived to be important because users feel that even if the child knows about their origins, s/he should not have to deal with these kinds of questions. The following post is from a user who got pregnant following a frozen embryo transfer but had considered donor sperm as an option:

One big issue in our minds when chosing to use DS was will people notice that the child looks different to $\mathrm{Dh}$ or will they have some noticable difference to our looks and when we sorted that out in our heads it was fine for us (this was an issue for us because we didn't want to tell anyone and worried people would say they looked nothing like us it might sound silly but it's something that really worried us) (Miranda).

It is also the case, of course, the people choose their partners based in part on characteristics that attract them. Having a donor who is very clearly different from one's partner can also be seen as an indirect rejection of that partner:

the worst thing for me is what if hubby dies, I wont have anything to remember him by. I know this is really morbid, but it does keep going through my mind. Somebody did say that by nurturing some of him will come out in the child anyway, which is probably true so feel a bit better about it now (Tara). 
The accounts presented earlier indicate that users have had difficulties in accessing the treatment they need due to the donor shortage. But is the donor crisis as bad as these accounts suggest? Few studies are available, because the change in policy is relatively recent. One older study, conducted at two gamete donation clinics in the UK, indicated that 85 per cent of potential donors would not enter a sperm donation programme unless anonymity was maintained (Robinson et al., 1991). Robinson et al. concluded that, if anonymity was lifted, recruitment of new donors would be significantly reduced. This would be detrimental to gamete donation programmes and to the infertile couples who request this form of treatment. A more recent study, involving retrospective analysis of 1,101 potential sperm donors in a centre in Newcastle-upon-Tyne between January 1994 and August 2003, shows a significant decline in the number of men applying to be sperm donors, from around 175 in 1994 to 25 in 2003, with the sharpest drop occurring from 2000 onwards (Paul, Harbottle and Stewart, 2006). The authors suggest that "the significant decline in released sperm donors coupled with the potential effects of loss of donor anonymity means that new strategies for sperm donor recruitment are urgently required" (2006: 150). The study reveals that the acceptability rate of donors (donor release rate) also declined because of the introduction of stringent criteria aimed at improving standards of recruitment. At the end of the testing process, only 3.63 per cent of the men were accepted as suitable donors.

According to a $\mathrm{BBC}$ investigation in 2006,50 of the 74 clinics in the UK were reporting that they had insufficient sperm or none at all. The BBC found only 169 registered donors in the UK, with none in Northern Ireland, one in 
Scotland, and six in Wales (Dreaper, 2006). A BBC Scotland survey of

Scotland's five IVF clinics found a crisis in supply that had completely halted treatment in two clinics and brought long waiting lists in others.43 According to the HFEA registers (HFEA, 2008d), in 2000 there were 325 men registered as donors. The latest figures from the Authority show that this figure dropped to 307 in 2006. The substantial donor profile change that was reported in Sweden has also been observed in the UK: the HFEA register shows that whereas in 1994-1995 the most common age group for sperm donors was 18 24 years, 44 this figure changed to $36-40$ years in 2004-2005.

\section{Egg sharing: being a donor}

Despite being not as fully ingrained in secrecy as sperm donation, there is also evidence that egg donors are concerned about anonymity (van den Akker, 2006). Craft et al. (2005) surveyed past egg donors and recipients to explore whether loss of anonymity had an impact on egg donor recruitment. The results indicate that removal of donor anonymity for egg donors is likely to lead to a further restriction of already unsatisfactory egg donation programmes. ${ }^{45}$ The HFEA registers show that between 2000 and 2006, the number of egg donors

\footnotetext{
${ }^{43}$ The survey revealed that two of Scotland's four NHS clinics have suspended services because of a lack of donors. In one clinic, the waiting time for egg donation treatment has more than doubled since the law was introduced, from 2 years to at least 5 years. Another clinic had no new donations since the law was introduced and there had been between 30 and 40 patients that the clinic was unable to treat. One clinic reported that for the first time they had to start a waiting list for treatment using donor sperm at the end of last year and they were no longer able to offer any treatment until supplies became available (BBC News, 2006).

${ }^{44}$ In September 2005, the HFEA issued a report 'Who are the Donors?' which showed that modern sperm donors were typically family men aged between $36-40$ years. rather than the stereotype of a medical student in their teens or early 20s (HFEA, 2007).

${ }^{45}$ Egg donation is more intrusive than sperm donation: egg donors have to undergo a procedure stimulating their ovaries, cggs are then removed from the ovaries by a surgical procedure. The
} 
dropped from 1,242 to 812 (although, unlike sperm donors, the age distribution of egg donors has remained relatively unchanged over the last 10 years).

Currently, waiting lists for egg donation may vary from 18 months up to two years. ${ }^{46}$ Some clinics encourage women into egg sharing to circumvent these delays. In egg sharing, the cost of the treatment is paid directly by the recipient to the clinic which then provides a free treatment cycle for the donor. ${ }^{47}$ Johnson (1999) argues that egg sharing poses complex ethical issues: there are fundamental problems with respect to both patient autonomy and the commodification of eggs. The posts quoted below exemplify the problem that Johnson notes: neither Gina nor Amy would agree to share their eggs if egg sharing did not reduce the cost of their treatment. This procedure is "within the letter of the law, but arguably not within its spirit" (Johnson, 1999: 1915).

I dont really like the idea of sharing my eggs but if it means not having to get into debt then we will try it (Gina).

DH and I thought about it long and hard but decided not to as we were really worried about giving away the best eggs. I can see why it's so appealing to go for egg sharing as it dramatically reduces costs... but at the same time is also dramatically reduces the number of eggs.... sorry if I'm preaching to the converted but it's a big decision (Amy).

use of foetal or cadaveric eggs is prevented in current licensing practice, and UK law prohibits the purchase of eggs for cash (Johnson, 1999).

${ }^{46}$ Infertility Network UK Fact Sheets - egg donation, infertilitynetworkuk.com.

${ }^{47}$ In February 2007, the HFEA announced that women would also be allowed to donate their eggs to research, both as an altruistic donor or in conjunction with their own IVF treatment (they will receive treatment at a reduced cost in return for donation of some eggs). 
Diana calls egg sharing an "emotional minefield": she has to trust medical practitioners to ensure that her eggs are in good hands. It is interesting that Diana portrays her eggs as akin to children that need "nurturing" and "caring":

...as a donor you have to put your faith in these professionals that have parents they choose will be nurturing and caring, just as they will assess us if we decide to become recipients. Really it is an emotional minefield whichever way you look at it! (Diana)

Under the open donation system, egg sharing raises further concerns. Unlike other gamete donors, who have a choice not to donate non-anonymously, eggsharing donors have a reduced choice as they are infertile women whose financial circumstances compel them to 'volunteer' donations in order to subsidise their own treatment. In egg sharing, it is possible that the donor will not achieve a pregnancy whereas the recipient does. Gina notes:

I don't think I could do egg sharing because I think it would be awful if I was not successful, but the other lady was. It would really rub it in if I didn't have children, but my biological children were running around somewhere (Gina).

There is also the possibility of being contacted by the resulting child. Many users describe this situation as "a person knocking on our door":

The thing with donating my eggs is that I cant guarantee the receiving couple would not tell the child(ren) and am not sure if I would like to be contacted in 18 or so years. Its just the way I feel, especially if ours didnt work. I would always be wondering if I had a biological child somewhere! (Tara).

when I did my ICSI treatments I considered egg-sharing. but decided against it as I have not had any children. As the laws have now changed concerning anonymity and children finding their donors I am not so 
sure if I could handle a child knocking on my door in 18 years time (especially if we never had one!) (Tara).

how would I feel if I'd never got pregnant but 18 years later a child from one of the eggs I donated turned up at my door (Sofia).

i was just wondering, because when i went for icsi we desided to donate eggs to help with the costs and also i could help some one who longed for a child as much as we did .we went for the treatment but i did not prodce enoughtt egg to donate and this was the lowest point of the treatment for me .while $i$ was pregnat with my daughter $i$ heared on the new that by law the child could find out who there biolgical parent was just like adoption.this is one reason why $i$ dont think $i$ would want to do that again because $i$ dont think $i$ would like a child or young adult to knock on my door one day and what if the teatment that $i$ would have did not work.well $i$ supose the question is dose any one els know more infomation on this and has it put any one els off donating eggs or sperm (Sheila).

There were 500 egg sharers in the UK in 2004. HFEA registers (HFEA, 2008d) show that this figure had dropped to 323 in 2006 . The posts presented above may explain the reasons behind the reluctance of patients to join the programme.

\section{Donating eggs}

On Repromed, a number of egg donors posted their views on donating eggs. According to one, it is as tough a decision to be a recipient as it is to donate: "I think the decision to use a donor is as hard to make as to whether to be a donor" (Eve). Leona finds it difficult to write a goodwill message to the resultant child, because "it feels like I'm writing to a child I have given away for adoption": 
I donated eggs back in 2000 and again this year. The rules regarding donation have changed since my first time and now I have to fill in a form which includes a goodwill message to any children born resulting from the donation. I'm really struggling with this. I'm happy that I donated and I'd be over the moon if it was successful for the couples (the whole point of the donation in the first place). BUT I can't get my head around giving a message or personal details ie hobbies interests etc. It feels like I'm writing to a child I have given away for adoption. This isn't how I view it as any babies will belong to their mothers and not to me. Am I being too detached from it all? I've love to know what info a child born from donation would like to know? (Leona).

A number of users express concerns about the emotional difficulties involved in donating biological material that has the potential to become a child. The following post suggests that Leona would like to see egg donation by analogy with tissue donation. However, at least by comparison with her husband's experience in donating bone marrow, she did not get a positive reaction from people about her egg donation:

haven't really told many people about my latest donation because I didn't get very good comments last time. My Husband was found to be a bone marrow match to someone at the same time as i donated this year and everyone seemed so proud of him for that but i didn't get the same reaction. People don't seem to understand why i would want to donate eggs? I was even asked whether i would wonder if every child I saw on the street was mine? NO I don't. I've helped someone (I hope) to have their baby, not mine. I have mine with me ( and one in heaven) and other babies belong to their Mummies. I do not want to take anything anyway from the recipients. My job is done! (Leona).

Terry and Nicky also express the view that donating eggs is different from giving away a child: in Nicky's words, it is a "potential gift of life":

i am currently going through the process of being an altrustic egg donor, i've completed all my screening, being matched with two recepients and will soon be starting my injections. To be honest i have found the whole process ok, emotionally i mean, i have children, they know what their mum is doing and $\mathrm{i}$ know there maybe a possibility in 
18 years time i may have someone turn up on my door step. I know they will carry my DNA and genetically be half mine, but i don't see it as i'm giving my child(ren) away. I'm helping two couples hopefully become parents, with all the highs and lows that brings (Terry).

I don't see it as giving my children away either but I do see it as giving the potential gift of life. I'd like nothing more than to donate and have the couples dreams come true. No amount of payment in the world could top that knowledge that you helped someone achieve their dreams and have their own family. To give them a (hopefully) life long gift that they can mould and change and watch grow. That will be appreciated day to day whether they know the donor or not (Nicky).

In this discussion thread, several posts suggest that gamete donation is different from giving a child away for adoption. These views can best be understood when located in a broader context. As I showed in Chapter Three, an adoption analogy has dominated the donor anonymity debate. This analogy was initially employed to draw attention to the similarities between the rights of adopted and donor-conceived children with regards to knowing their 'biological parents'. The posts above indicate that the adoption analogy also has implications on how people view donating gametes. These users stress that donating gametes does not make them parents - the resultant child does not belong them. Instead, donating gametes is similar to donating tissue. These views echo O'Donovan's observations about donor conception. She argues that donor conception is a form of procreation: the act has its own integrity and completeness - it is the would-be parent(s)' act and the child is unquestionably their child. "The act of procreation which takes place by artificial insemination is undoubtedly the act of the couple, and more particularly of the mother" (O'Donovan, 1988: 36). In this act, social links are established between the procreator and the child, not with the donor. Some egg donors in this study however express anxiety that, in the public sphere, "donating a tissue which 
has potential to become a child" is conflated with "giving away a child". Presumably, the government's insistence on the adoption analogy, and on creating a donation culture where donors are considered as biological parents, is a challenge for potential egg donors who do not see egg donation as an "act of procreation" on their part.

The users describe donation as a "wonderfully generous gesture", "a lovely, generous and thoughtful gesture", "an incredible thing", and "an enormous decision". Whilst donating gametes is a "generous gesture", "having someone knocking on your door" (that is, being contacted by the resultant child) is an undesirable situation. Therefore the identity of donors should be protected, and "donors should not be punished" for "giving the gift of life". One user refers to an article about an anonymous sperm donor who was tracked down through the Internet by a 14 year old who claimed that the donor was his father. This user thinks that it is "scary" that the donor can be traced through the website:

i think they could trace by dna throught the website somehow, scary, no wonder not so many people want to be donors anymore, but the sad thing about it all is that its a shame, as people need them (Pam).

The anonymity issue is taken into consideration in both egg and sperm donation. Some users express concern about being identified by the resulting offspring if they become donors. Unsurprisingly, due to their own worries, they assume that fewer donors will be likely to come forward under the current law. Based on the user accounts, it might be argued that those who undergo infertility treatment express their sympathy for people who are on waiting lists 
for donor gamete donation. However, whether this sympathy outweighs the physical, emotional or moral implications of being a donor is questionable.

\section{Disclosure}

Before analysing the posts of would-be parents on the issue of disclosure, I will discuss the findings of a number of studies that investigated the degree to which donor conception parents disclosed, or were likely to disclose, information to their children about the circumstances of their conception. Despite expectations that children's right to official information will lead to greater parental openness, research draws a different picture. Gottlieb et al. (2000) studied the implications of the removal of anonymity in Sweden to see whether parents told their children they had been conceived through DI. Only 11 per cent of parents had told their child. The most common reasons for not telling were that it was 'unnecessary' and 'may hurt the child'. The authors concluded that legislation alone is not sufficient to change personal attitudes in a population. A more recent study of Swedish DI families reaffirmed the discrepancy between the legislators' intentions and parents' actions. Sixty-one per cent of the parents had told their children about the DI. Parents who did not intend to tell their children considered DI a private matter and were afraid of other people's attitudes. The same percentage, sixty-one per cent of the parents had not yet told their children about the possibility of identifing the donor (Lalos, Gottlieb and Lalos, 2007). And, as reported in Chapter Four, a recent UK study found that, despite the greater encouragement towards disclosure in recent years, less than 8 per cent of egg donation parents and less than 5 per 
cent of DI parents had begun to tell their children by the time of the child's third birthday (Golombok et al., 2006).

The research evidence identifies three main reasons for secrecy: first, that couples may view the decision not to disclose as protecting them from negative societal reactions, and preventing their child being considered different from others (Lalos, Gottlieb and Lalos, 2007; Nachtigall et al., 1997); second, that male partners may have concerns that the acknowledgement of infertility would cause their masculinity to come under suspicion (Courtenay, 2000; Glover et al., 1996; Miall, 1996; Nachtigall, Becker and Wozny, 1992); and third, that family relationships (particularly father-child) would be damaged if the child's real genetic identity was revealed (Gottlieb, Lalos and Lindblad, 2000; Lalos, Gottlieb and Lalos, 2007). I found that the users of Repromed express similar concerns.

\section{$\underline{\text { Stigma }}$}

Elaine has no intentions to disclose, as she does not want her children to be marginalised. Some of their friends and family members were only told that the couple was receiving help for conception, because the couple does not want any resultant children to be marked out:

Well, I for one have absolutely no intention of ever telling our children that they are anything other than "ours" because I feel that in every possible sense they are. I will carry this child and give birth to it. We don't want our children to feel "different" in any way and nobody ever needs to know anything. Being a parent isn't about the egg or the sperm, it's who wipes their bum/noses from the day they're born. Some of our friends and family know we're having "help" but that really is all they need to know. I don't want people for ever looking at my child and trying to work out if it looks Spanish or not! (Elaine). 
Suzanne's partner had cancer as a child, so his family has always expected that he would have problems in conceiving. Therefore, the couple decided to tell his family about the DI if they were asked. Although the family know that the couple is getting treatment, they never questioned what kind of treatment it was. Suzanne's family, on the other hand, do not live in the local area so the couple decided not to tell them. Suzanne comments:

We just feel it will be easier for DH if less people know. Only a few people know about our fertility issue, but not DI - usually 'cause I had a bad day and let it slip. But on the whole I want to keep it private. I don't view it as a lie, DH and I are trying to have a baby - true. He will be the father - true (Suzanne).

In the following post, Christine mentions that she wants to protect her partner from the "embarrassment" of infertility:

I know that my family and my partners would support us but also I feel that it's embarressing for my partner to have to tell others when I'm not sure if it's really necessary (Christine).

Samantha had a four-year history of unsuccessful DI treatment and she moved on for adoption. She says "using donor eggs seems far more acceptable than using donor sperm and far easier to talk about": the "donor girls" think that the most important subject is "wanting to be a family rather than where it came from, whose eggs/sperm, adoption etc". The users have the impression that men are not as comfortable as women when sperm donation comes into the picture: 
I think you are lucky if you have the choice of going done the route of supplying the donor - but it gives you another set of challenges to think of regarding who knows what and the emotions involved. i KNOW my hubby would not allow this. How would your DP feel about it? (Suzanne).

Male partners of those who obtain donor insemination are somewhat in disguise'. The Internet forums are important in giving voice to the male partner. Despite the fact that it is a very a long quote, I think it is therefore important to include Will's post here:

My wife and I had icsi treatment because of my low count. At first I didn't want a soul to know - I was terrified that all my aunts, uncles and cousins might initially assume that the problem was my wife's seeing as my family tend to think they're all perfect and therefore, by association so must I be. To save my wife suffering the thought of being whispered about I thought I'd have to tell them all the truth and then suffer the whispering myself. But then I decided it was none of their business and that they could think what they liked - xxx was happy with that too. They know we had treatment but the reasons remain unknown to them.

I know what you mean about not telling people the finer details. I don't think the girls at work want to know anyway (though it will stop them all asking when on earth I'm going to get round to having kids!) and I shudder to imagine my extended family's hushed whispers at get togethers-" "There is no fish in his pond you know". I guess at least my parents are going to have to know though if I'm going to ask them about any history of similar problems- that'll be a tough one-Mum's been a nan-in-waiting for years watching all her friends' children have children. I'm sure they'll be so supportive but taking the first step and telling them will be hard (Will).

Linda, Will's partner, says:

People ALWAYS assume it's the woman that has the problem and it makes me mad!!!!.....to me it doesn't matter..but why do people always assume that it's the woman who obsessively wants a family and are dragging the poor ole feela through hell to get there (Linda).

As a response, Betty says: 
I know exactly how you feel Linda. We had no idea that we had a problem and so to discover that it was with $\mathrm{DH}$ was a real bombshell. Only our parents know exactly what the problem is and we've refused to tell anyone else, but I always think they assume it's me, especially when they keep asking 'isn't there anything can be done about it, as Doctors know so much these days' and you end up with thinking 'you haven't got a clue!' (Betty).

These accounts indicate that Repromed users feel stigmatised. During the donor anonymity debate, one argument made by those advocating removal of donor anonymity was that the stigma surrounding donor conception had faded. But this stigma is profoundly clear in both the posts I read and in the accounts of my interview participants. Drawing on Goffman's (1963) Stigma framework, the issue of stigma will be discussed in detail in Chapters Six and Seven.

\section{Protecting the child}

The posts on Repromed suggest that would-be parents are mostly concerned about the potentially adverse affects of disclosure on a child's development. Some users express the view that knowing the truth can hurt the child:

If we go down the DIUI route I am not sure if I want the child to know (if I am blessed that is), I think sometimes knowing the truth can be more damaging to a child especially if told later in life. Their whole world must be turned upside down especially as who they thought was mum or dad isn't (Tara).

Golombok et al. (2006) found that only half of the DI parents in their study were open about the donor conception with maternal grandparents, and less than one-third told paternal grandparents. In line with these findings, the users of Repromed also express concern that, if they were to tell the child and other 
family members found out, their extended family might disapprove and reject the child. Elaine's husband has children from his previous marriage who are not biologically related to him. He did not know this until his infertility was established during the medical examinations which he and Elaine undertook. The couple do not intend to disclose this information to the children, who were aged 11 and 15 years at the time of my fieldwork. Elaine believes that disclosure would make them question their identity. Also, she fears that the grandparents would be frustrated:

My husband now knows that he's $99 \%$ certainly not the biological father of my two step daughters (he can't be), but what good would it possibly do to tell them? Other than completely destroy their sense of who they are? (...) It really is a personal choice, but I have absolutely no qualms about keeping quiet, after all, my husband's wife has done so for the last 11 years and still doesn't know that we know what she did!!! What do you think his parents would say if they knew??? So if we told them about our problems, they'd know their grandchildren weren't there grandchildren after all, assuming that it's all about whose egg/sperm it is. In fact, they still remain very much his children and their grandchildren, because it takes a lot more than a bit of DNA to be all of that (Elaine).

Another user, Helen, shares this view:

I suppose I'd be worried about telling people in case it had an effect on the child - would people see him/her differently - would they react differently to them than there other Grandchildren? (Helen).

Gabrielle joined Repromed to talk about the disclosure issues. She is reluctant to disclose to her parents because they will be "horrified and very unsupportive". However, Gabrielle is planning to disclose to the resultant child that she was conceived by egg donation, although she does not know when and how: 
I do feel any child of ours should know they were conceived through $\mathrm{DE}$ and there is an issue there in going to Spain as they will never know any further details about the Donor. I would still wish to tell them but as to others particularly my parents it would definantely be a question of when and how (Gabrielle).

The fact that there are social fathers who are not biologically related to their children directs other users towards disclosure:

As to the whole issue of telling, we decided to tell our close family and close friends as they are our support network and these people are there for us. And we will tell the child when the time comes (being positive here!) as we don't think of our situation as that unusual. After all, how many kids are brought up by their biological father nowadays? (Lisa).

In the UK, mothers are under no obligation to name a child's father on the birth certificate. In other words, with unassisted or 'natural' conceptions, the mother's interest in keeping the father's identity secret is allowed to trump a child's interests in knowing his/her identity. Moreover, as Jackson (2001) notes, a significant proportion of the naturally-conceived population is biologically unrelated to their presumed fathers. Estimates vary but a recent systematic review suggests that the figure lies somewhere between 2.0 and 9.6 per cent, with a median value of 3.7 per cent (Bellis et al., 2005). ${ }^{48}$ Infidelity may therefore be a statistically greater threat to accurate knowledge of one's biological origins than the relatively smaller number of donor assisted births (Jackson, 2001). Jackson draws attention to the inconsistency between revealing the parentage of children conceived by assisted means and allowing concealment of the parentage of those conceived by natural means. Her view is echoed by the informants in this study. They observe that people who had 
affairs are not obliged to disclose this information while those who undergo donor conception are expected to be open about it. Elaine uses an interesting metaphor: telling the child is like "having an affair" and then having to tell the spouse about it; it does nothing for the spouse but makes the "confessor" feel better. She believes that disclosure will do "damage" and cause "huge problems" when the children reach adolescence. Another user also claims that there is an analogy between having an affair and having DI:

Also there are loads of women out there who have had affairs and dont know or tell who the real father is, so some children grow up thinking that their father is the 'known' father when actually he isnt. Do we consider the welfare of children in this situation? (Tara).

As a matter of fact, during the donor anonymity debate the advocates of a child's right-to-know did address this analogy. As I noted in Chapter Three, during the debate in the House of Lords on 9 June 2004, Baroness Warnock argued:

There can be no moral justification whatever in deceiving a child about the circumstances of his birth. It is a very awkward doctrine to enunciate, considering the number of children born by adulterous relationships (HL Deb, 2003-04b).

Nachtigall et al. (1997: 89) argue that the nuances of a couple's disclosure decision-making process are complex and involve "an interaction between psychological states of the parents and the social, cultural and familial context within which this decision must be negotiated". User accounts are consistent with this argument. The child's welfare is of concern but a web of concerns,

\footnotetext{
${ }^{48}$ The higher figures quoted in some earlier studies are the result of sampling from populations
} where paternity is already disputed. 
beliefs, and past experiences also influences the disclosure decision. For example, Sarah had a successful DI treatment and is now the mother of a 3month-old baby. She feels that there is only ever "right for you" as no one has the same experiences, families, and feelings when it comes to what to do to create a family. She and her partner told their parents, Sarah's sister, and her partner's brother but they asked the brother not to share it with his children so that the child does not accidentally find out from one of them. During the pregnancy, they also told their very close friends, as Sarah was feeling the pressure of people thinking they had had IVF and not being able to talk about how she felt. Sarah also says that:

children who are told rarely see it as a big deal, but those who find out accidentally often do - but you will be the parent and you will know what's right for your child and your family (Sarah).

Suzanne, who is undergoing DI treatment, mentions that she and her partner had a meeting with their counsellor who wanted to get them thinking about how they would tell the baby it was conceived using donor sperm. She comments: "We were honest and said we would have to consider what was right for the child, when it was right for the child." Lora, another user, takes a similar view:

My DH [dear husband] felt same as you to start with that any child would not feel 'ours' if there was an identifiable 'dad' out there somewhere - but after a lot of thought we agreed it is the child's right, even if that is to choose to never look up anything at all about their donor, that really need to 'come first' (Lora).

Although the welfare of the child is perceived as paramount, user accounts indicate that opinions on 'what is best for the child' differ. Will disclosure harm the child? Will the child reject the social father? Will relatives see the 
child in a different way? Telling the child that he/she was conceived by medical assistance (some participants in the study refer to medical assistance as to "having help to conceive") is different from telling the child that he/she can find out who their biological father/mother is. A study by Lalos et al. (2007) on Swedish parents who obtained DI also shows that revealing the donor's identity may not be as natural as telling the child about DI in general terms. Among the parents who had disclosed the DI to their children, less than two thirds had also told them about their right to obtain information about the identity of the donor.

As the user accounts indicate, parents who choose not to disclose may justify their non-disclosure on the grounds that it protects the best interests of the child. O'Donovan (1988) argues that this kind of justification is dangerous:

The argument that the deceived would be better off not knowing, or would prefer not to know, runs into problems of lack of consent. There can be no consent in advance of lies about parenthood, for this would defeat the object. So the justification advanced is that the liar knows better than the victim what is good for the victim. This type of paternalistic argument, generally put forward in relation to persons of lesser capacity, is dangerous here. The child will develop into an adult (1988: 38).

Eekelaar (2006) also recommends openness in the child-parent relationship:

Children have interest in having knowledge of the physical truth because it provides an underlying certainty about the world they have come into, incapable of manipulation by the adults. The children may stake their claims against those who is responsible for their being. My argument has been that the interests that children have in knowing the physical truth are always stronger than those of the adults, because for children they give rise to claims in justice, whereas for adults they form 
the basis for attempts at exercising power, sometimes beyond the grave (2006: 75-76).

In line with O'Donovan's argument, Eekelaar (2006) notes that while assessing what is best for the child, attention will always need to be directed towards ascertaining the child's viewpoint. Moreover, efforts must be made to adopt the child's perspective, considering how the child would act if he/she was an adult. Advocating respect for a child's autonomy, he argues that openness will empower children against their parents' manipulative power. Both O'Donovan and Eekelaar warn against the dangers of a paternalistic mindset that treats children as people with lesser capacity.

However, parenthood is inherently paternalistic as all parents treat their children as persons of lesser capacity (at least) until they reach a certain age. While raising children, most parents consider the child's welfare and decide on what is best for her/him. The posts on Repromed indicate that parents of donorconceived children are no less paternalistic than parents of naturally-conceived ones. Some of the user accounts indicate that parents are more concerned with protecting the child from the potential harm of knowing the truth, rather than giving the child greater autonomy at any cost. Openness in the parent-child relationship is not always thought to be best for the child's interest. There are also posts however which suggest that it is best for the child to know about his or her origins. Nevertheless, what is clear is that legislative initiatives seem to have no significant impact on parents' assessment of their child's welfare. The 
members of Repromed stress the view that the decision on disclosure should be left to the parents. As one user, Samantha notes:

Like Elaine says the children conceived will ALWAYS be yours no matter how they were conceived. We are lucky to live in a society that gives us the choice of telling or not telling the child that you had a little bit of help to get there. Lets hope we all get there one way or another (Samantha).

\section{Fertility travel}

Following the removal of donor anonymity, would-be parents who prefer anonymous donors have no choice but to seek treatment abroad or purchase gametes (sperm) through the Internet, which has recently become illegal. The posts presented in this section are all excerpted from a thread about the options available for those who attempted to receive treatment in licensed clinics in the UK but for various reasons could not access the treatment they need.

Try xxx [a clinic in Spain] - anonymous donor sperm is 260 Euros per go and I flew from Bristol to Barcelona for $£ 50$ each way! (Elaine).

A shortage of donated gametes or embryos results in lengthy waiting lists. Given that fertility decreases with increasing age, many would-be parents choose to seek treatment abroad. Tara stresses that would-be parents "have to go to the ends of the Earth to get donor sperm":

Now it has happened, where and what do people needing donor sperm do??? If clinics dont start recruiting their own donors then we will have to go to the ends of the Earth to try and get one, thats our only choice, its so unfair (Tara). 
In another post, after complaining about the fees that each couple has to pay to undergo treatment, Tara addresses the risks of back-street arrangements. She notes that the new law leads people to consider less legitimate ways of overcoming their childlessness and to take health risks. For example, one can use the 'turkey baster' method and achieve pregnancy using fresh sperm, but this sperm cannot be screened for certain diseases. Licensed clinics are required to freeze and store the sperm for six months, the incubation period of HIV, before insemination to ensure that it is virus free.

...basically they are ruining couples (like us) chances of having a child using donor or want for a better word 'harder'- they are actually going to force this underground. Couples will go to other agencies (not so legitimate) and abroad to get donors is that fair??? The sad thing is that the women like us may not have as much in the way of protection against certain things like HIV etc I really think they have made the whole donor issue a lot worse (Tara).

Another user asks for others' opinions about an online sperm provider:

I have found this company on the web and wanted to know your views: [the web-site's URL] Having quickly read it through it seems as tho they send you the sperm and you self inseminate (?!) for under $£ 400$. I know people have been going abroad, but i can't find a place that does D IUI (Suzanne).

Tara says:

Also there is another site [the web-site's URL] as anyone thought or used this one??? I have heard they are fairly good. I have to say it makes me wonder whether all the sperm donors that went through clinics and wanted to remain anonymous are now going to these places in order to help people needing it??!!(Tara).

After this study was completed, in July 2007, the HFE Act was amended to prohibit distribution of gametes without a licence from the HFEA. Therefore, 
even if would-be parents would like to take a risk with fresh sperm, they have to think twice. As I explained in Chapter Three, the chair of the HFEA, Lisa Jardine, has 'strongly' advised "any person who became aware that a person or organisation may be procuring, testing, processing or distributing gametes without a licence to contact the police". The new regulations ensured that Internet sperm providers will be subject to the same rules as HFEA licensed clinics.

Suzanne's clinic found a donor for her but he did not match either her physical characteristics or those of her husband. They chose a donor profile from Spain, to be imported by their licensed clinic in the UK, but the clinic informed them that UK law prohibited the purchase of sperm from an anonymous donor. If would-be parents cannot purchase anonymous sperm online, they have no option but to go abroad for treatment, because even licensed clinics in the UK are prohibited from importing anonymous sperm.

Other reasons behind reproductive travel are addressed in the following post by Elaine. Specifically, the donors are anonymous, the cost of the treatment is the same, there are no waiting lists, and there is no HFEA:

In the end, I think more and more people will go to Europe for treatment, as it costs the same, is completely anonymous, has no waiting lists and, best of all, not $b 1^{* *}$ dy HFEA!!! That's not to say they aren't regulated, but by sensible people with our interests at heart!!! (Elaine). 
The following post by Tom summarises many of the issues raised by other users:

There are many infertility newsgroups out there, so it becomes quite easy to compare the approaches taken by different clinics. Some UK clinics seem to be several steps off the pace of both other UK centres and overseas centres. Treatments used almost routinely in other centres are dismissed with the excuse that it is not current clinic policy, or the treatment isn't proven. The result is that the patient feels that they are not being treated as an individual, and they are left with many unresolved questions about their particular situation, and they are paying a premium price for this unsatisfactory state.

In many cases patients find that they are managing their own treatment, pushing the medics to try something outside the standard for that clinic. This is probably the most wearing part of treatment for infertility, dealing with a system that you are not part of. It is probably also the reason why many more women in the UK will turn to overseas centres. Overseas treatment will also be favoured because any form of medical treatment in the UK means that at some stage the patient will come up against the NHS, a hugely expensive medical insurance scheme which has now turned into a useless quivering jelly of administrators, processes and targets; fertility treatment is way down the list of priorities (Tom).

The fertility travel survey conducted by INUK (Infertility Network UK, 2008) gives further insight into the phenomenon. INUK had 339 responses to the survey which was put on their website, and linked from a number of other sites. The first question was "Would you consider travelling abroad for fertility treatment?" 337 people answered this question and 256 of them (76 per cent) said "yes". 210 people responded and 129 people skipped the question "What would attract you to overseas fertility clinics?" The main attractions were short waiting times ( 70.5 per cent), cost of treatment ( 69.5 per cent), success rates (61 per cent), availability of donor eggs/sperm (53.8 per cent), positive reports from other patients who have been abroad ( 51 per cent), and anonymity of egg/sperm donors (23.3 per cent). For the 24 per cent of respondents who 
would not consider treatment abroad, the main reason was concern about standards in overseas clinics (selected by 67.5 per cent). Only 75 people responded to the question "What treatments you had?" Forty-one percent had egg donation, 7 per cent sperm donation, 1 per cent embryo donation, and 3 per cent surrogacy. Of those who had been abroad, 88 per cent were happy with the treatment they had ( 77 people answered this question). The question "What would you say were the positive points of overseas treatment?" was answered by 116 people. Short waiting lists ( 78 per cent), cost (66 per cent), availability of donor eggs/sperm (60 per cent), higher success rates (41 per cent), attitude of staff at clinic (38 per cent), atmosphere at clinic (40 per cent), facilities at clinic (36 per cent), and donor anonymity (30 per cent) were addressed as the main reasons.

120 of the 339 respondents answered the question "Which country did you go to for your treatment?" Spain was by far the most visited country for fertility treatment, with at least three times as many patients going there as anywhere else. The patients questioned had visited 22 different countries for treatment, and other popular destinations were Russia, the Czech Republic, the USA and India. Greece, Belgium, Cyprus and Barbados followed behind. Some of the more unusual and far-flung destinations included Thailand, China and Egypt. Spain appears to be the most popular destination for Repromed users due to donor anonymity, the large numbers of donors available, and the high success rates achieved. 


\section{Closure of the forum}

The Egg and Sperm Donation forum was suspended just after I completed my fieldwork. The website administrator informed me that the forum had been closed because members of the HFEA-licensed centre hosting the site were concerned about the increasing number of posts advising participants about offshore facilities for assisted conception using anonymous gametes. One week before the closure, at the First World Forum on Science and Civilization, Dame Suzi Leather, then chair of the HFEA had noted that "the Authority would urge patients to think twice and consider the risks and implications before going abroad for treatment". However, there is no direct evidence linking the HFEA to the closure of the forum.

The forum was reopened five months later with a disclaimer stating: "In view of popular demand the donor gamete forum has been reopened, but anyone thinking of going abroad for treatment should first consider the guidance provided by the HFEA, which is quoted below." The HFEA's warning about fertility treatment abroad (HFEA, 2006) and Leather's speech were both quoted. Repromed users made a range of posts, responded to the disclaimer, in which they express their discontent about the HFEA's approach to fertility travel:

I really do get fed up with the HFEA scaremongering about going abroad, especially when they've done so much to prevent successful treatment in the UK, for example, removing donor anonymity and successfully wiping out the entire UK sperm bank in one go!!!!!!! for 
one can only express my utmost admiration at the extremely expert and professional treatment I received at [name of the clinic], which was vastly better than the treatment I received in the UK and resulted in my gorgeous baby at the first attempt. In total, six of us became pregnant after only one or two transfers after going to [name of the clinic], two with twins, which would never have happened if we'd remained in the UK. I think that says it all! (Elaine)

I'd like to see the HFEA or perhaps other organisation carry out a full investigation into the standards of clinics abroad, to provide some hard evidence that will allow potential patients to make their minds up once fully informed (Will).

I do think the HFEA is very heavy-handed in its approach to this issue, and has also made some very poor regulatory decisions (especially about donor anonymity, for example) which may well end up encouraging people to seek treatment elsewhere. I guess they would open to considerable criticism if it could be shown that, in order to avoid the consequences of their approach, lots of people are travelling abroad for treatment, so now they are trying to discourage them with 'scare tactics'. Not a very grown up approach, really (Melissa).

I feel that if donor anonymity was guaranteed in the UK you wouldn't be going to abroad anyway. That's down to the government perhaps in places they shouldn't (Gemma).

On the note of the HFEA 'warning' all I will say is that I was offered a very high quality individualised treatment at $\mathrm{xxx}$ in Spain. I very carefully researched a number of clinics abroad as there were no further options left for me in the UK - I did not have 5 years to wait for Egg Donation in the UK. I was offered a service and support at Xxx that was not on offer at any of the three clinics I was under in the UK. Will, I agree whole heartedly with you - it would be good for the HFEA to produce some good statistical evidence of what they claim - I'd like to know just how many people have complained to them about treatment abroad (Kelly).

As noted earlier, at the time of this study, the clinic behind the Repromed website was the University of Bristol's, Centre for Reproductive Medicine. This centre has now merged with the Southmead Fertility Service. After the merger, as a result of a site update, most of the posts were removed from the website. I requested access to website archives, but the administrators did not respond to my e-mail. Fortunately, for data analysis I had printed out all the threads in the forum before the website update commenced. 


\section{Conclusion}

The virtual ethnography study presented in this chapter offers some potentially important insights into the manner in which would-be parents explore the issues of donor gamete donation interactively and collectively on discussion boards. The topics generated by users of Repromed provide an indication of the issues that they perceive as important or problematic with regards to donation.

The most important issue that users raise is that, despite the warnings of a likely donor shortage, the government lifted anonymity at the expense of would-be parents' access to treatment. Experience from other countries suggested that the proposed reforms would cause a decline in donations and the would-be parents express the view that the HFEA should have taken measures to avoid the preventable crisis. Both the government and the HFEA have expressed the view that there will be a revival in donations, but the would-be parents on Repromed do not share this view. As discussed in Chapter Three, despite the campaigns launched by the government, HFEA registers show that there is a continuing severe sperm shortage, with only a small revival in donor numbers of 6 per cent. Donor insemination treatments are down 28 per cent, with 4,225 treatments carried out in 2006 compared to 5,865 in 2005. Egg donations dropped from 1242 to 812 between 2004-2006 (HFEA, 2008d). The HFEA, as mentioned earlier, makes it clear that recruitment of donors is not its responsibility: "The HFEA's remit does not extend to the recruitment of donors; this is a matter for the sector and should be addressed as a matter of urgency. Our role is to develop and maintain policies which strike a balance 
between the needs of donors, recipients and donor offspring and which do not create unreasonable barriers to recruitment" (HFEA, 2008a).

Shortage of donor gametes means that patients have to wait longer for treatment and have less choice with respect to donor characteristics. This picture becomes clearer when one looks into the discussion threads about fertility travel and online sperm providers. The user accounts indicate that donor shortage problems lead couples to find alternative solutions to their childlessness. Would-be parents have readily available alternatives in their access to treatment in other medically-advanced countries. Success rates, the lower cost of treatment, donor availability, and anonymity make clinics abroad increasingly attractive.

As I showed in Chapter Three the HFEA refers to infertility travellers as " $a$ relatively small number of people" (HFEA, 2006). There are no official statistics about fertility travel, but INUK's recent survey shows that a majority ( 76 per cent) of would-be parents ( 256 out of 339 who responded to the survey) are 'considering' treatment abroad. The survey results also indicate that Spain is the most popular destination for infertility treatment. It is followed by a number of countries which also maintain donor anonymity. Obviously, wouldbe parents who strongly advocate the child's right to access identifiable information about the donor would not consider seeking treatment in countries where donor anonymity is maintained. Anne's post is worth quoting here: 
We decided against going abroad for tx [treatment], specifically because the donor remains permanently anonymous, as you say. It's a shame that the waiting lists for DE [donated eggs] are so much longer now that anonymity has been removed; but on the other hand, I can't imagine telling my child that they'd never be able to find out who their genetic parent is, should they wish to. Adopted kids can, so why not DE kids? Most people seem to want to know where they 'came from', at some point in their lives. I wasn't keen on the idea of saying, just someone from Spain... I imagine it would be very frustrating for them. And I wouldn't want to pretend they weren't from a donor. I know loads of people have tx abroad though and I'm not criticising that at all. Who knows, in a few years' time I might be out there myself! Never say never (Anne).

UK patients, who have similar views to Anne, are free to exercise their right to receive treatment elsewhere using gametes from identifiable donors (such as Sweden, Norway, and The Netherlands). But the fact that INUK's survey shows that countries with donor anonymity are the most popular fertility travel destinations suggests that there are many UK patients who want to use gametes from anonymous donors.

The user accounts show that a number of women who donated eggs under the anonymous donation system became reluctant to donate again after the change in policy. This cannot be explained as simply a fear of being contacted by the resultant child. These women express anxiety about the new donation culture, where their altruistic act is questioned by their social contacts: "why would anyone give their child away?" A number of egg donors in this study state that they would like to see their donation as analogous to donating tissue that happens to have the potential to become a person. They do not consider themselves to be a 'biological mother' to the resultant child. They also express 
anxiety about a form which they are expected to complete. These 'emotional letters' to which recipients refer, not only make the donors feel like they are 'giving away' their children for adoption, but also distresses the recipients who are convinced that there is a 'mummy' out there waiting for the resultant child, with 'open arms'. I will return to this issue in Chapter Six.

Becoming an egg donor is viewed as a highly altruistic act, and most of the users express their admiration for donors. It is however seen as involving a number of serious emotional risks, which many feel will deter potential donors. What is the value of a right to openness for a child who is never conceived because of the reluctance of gamete donors to take on a long-term commitment from which they may reasonably only expect to derive emotional costs rather than benefits? It is clear that the UK government's insistence on the comparability between adoption and gamete donation is highly questionable. This analogy is also a significant threat to the gamete donation culture.

If one looks at the accounts in discussion threads with regards to disclosure, there is no clear consensus on the issue of whether or not the child should be told. The posts say little about the content of the information to be shared with the child. Nevertheless, all posts relating to disclosure suggest that whether to tell or not, the content of the information, and the timing of disclosure are perceived as private family matters, and there is a consensus that the disclosure decision should be left to the parents. Some parents express the view that maintaining secrecy, or limiting information, about the child's conception is 
the safest way to protect the child, themselves, and the extended family. They prefer to tell their child that they got 'help to conceive' rather than that the identity of the donor who helped with the conception is accessible. There are would-be parents who take a different view, believing that the child should be told about the nature of her/his conception. While some users stress that the child has a right to know, others express concern about the possibility of inadvertent disclosure which would be potentially damaging to the child and to the parent-child relationship. The analysis of the posts suggest that the notion of kinship and family relationships is too complex and intimate to be directly influenced by regulations; disclosure policies do not have control over which secrets are revealed or kept in the family.

Presumably, the desire to overcome childlessness may outweigh the perceived necessity of the child knowing about the donor. A number of user accounts in this study suggest that, given a strong desire for children, even would-be parents who initially intended to receive gametes from identifiable donors seem to compromise this principle and seek treatment abroad to avoid the lengthy waiting lists. In short, the would-be parents' accounts indicate that a majority of parents are not willing to risk childlessness in order to safeguard the child's right to know. This is not surprising. Yet for those who cannot afford to travel, or are not willing to seek treatment abroad, the current policy may prevent donor-conceived children from being born unless more satisfactory donor recruitment mechanisms are introduced. 
The data presented in this chapter documents the protests of would-be parents against the disclosure policy. It suggests that there are two conflicting social problems related to donor anonymity: the donor conceived-child's right to know and would-be parents' right to seek assistance with conception. However, as the natural history of the donor anonymity problem revealed, in the absence of an explicit reaction from would-be parents, children's rights came to monopolise the rights claims in the donor anonymity debate. Arguably, involvement of would-be parents in the debate could have changed the trajectory of the problem. But as the users of the Repromed forums suggest, would-be parents may feel a strong need to keep donor conception a secret. As the accounts show, those who are most directly affected by the disclosure policy are also those who prefer to keep the means of conception secret and, in part, their desire for secrecy is about protecting the resultant child's welfare. Openness and transparency marginalise these people. They are also stigmatised; their "passionate desire to bring children to life at any cost" by receiving treatment abroad and using anonymous gametes is condemned. And, as I show in Chapter Six, their infertility (involuntary childlessness) and need for donor gametes are also associated with stigma. If claimants believe that there is no way to have their problem solved or recognised, they may choose to find alternative ways to cope with it (as a group or individually). Hence, silence by stakeholders does not necessarily mean that they do not see their condition as a social problem. In the next three chapters, using Goffman's (1963) Stigma theory, I will analyse interview data where would-be parents talk about their experiences and their coping strategies for dealing with the new law. 


\section{CHAPTER SIX: STIGMA AND DEVIANCE}

In the virtual ethnography study which I presented in Chapter Five, I identified a number of claims by the users of Repromed. The posts showed that a large number of would-be parents consider removal of donor anonymity as a problem. First, they are not convinced that disclosing the means of conception is in the best interests of the child. Secondly, even those would-be parents who intend to disclose express concern about the effects of the disclosure policy. The would-be parents on Repromed were united in the view that the removal of anonymity had identifiable detrimental effects: donors are reluctant to donate; UK clinics cannot meet the demand for gametes; and there are long waiting lists for patients who wish to get treatment.

These findings indicate that the removal of donor anonymity is defined as a social problem by would-be parents. However, additional data are needed in order to understand why would-be parents do not mobilise around this problem in a conventional manner: the posts on discussion forums offer limited information on this latter point. In this and the following chapters, I draw on data from interviews with people who have considered or received treatment abroad using donor gametes/embryos. As noted in Chapter Three, for members of marginalised social groups (such as would-be parents in the UK), self narratives are often the only means of making their voices heard (Wegar, 1997). The posts on Repromed discussion forums constitute such narratives, however, I found that the interviews allowed increased insight into the 
participants' experiences and enabled me to ask questions about the issues that I wanted to explore.

As I explained in Chapter Four, the interview questions were designed to assess specific areas of the donor conception experience, namely infertility treatment, disclosure, would-be parents' reactions to the new law, and fertility travel. Interestingly, the common themes I identified during my analysis of the interviews were more or less the same as those that were set by the users of Repromed discussion forums. Admittedly, as the interviews and the virtual ethnography study were conducted simultaneously, my interview guide was influenced by my observations of the discussion forums. However, it is also likely that users of Repromed and interview participants shared common concerns about the problems surrounding donor conception, as well as similar responses to the change in the law.

As I discussed in Chapter Four, much of the research concerned with donor conception families assumes that being a donor conception family is a pathological situation and must constitute a problem. The research also attempts to analyse the impact of this problem on family life and interprets parents' responses as indicators of the family's psychological and social adjustment to this pathological situation. However, as explained in Chapter Three, departing from studies concerned with psychological or social experiences of those who received donor conception, I aim to locate the interview accounts in the donor anonymity debate. 
During the interviews, the participants constructed a representation of the world in a particular way. Many distinguished themselves from 'normals' (those who can conceive naturally) and reflected on the stigma that surrounds infertility. The stigma of infertility (Miall, 1986; Greil, 1991; Kohler Riessman. 2000; Remennick, 2000) has been studied before. Like most social research on stigma, my analysis draws on Goffman's Stigma (1963) theory. While analysing the accounts of the would-be parents, I also draw on two studies that have elaborated Goffman's theory: namely, Dingwall's analysis of illness experience in Aspects of Illness (2001) and Voysey's work in A Constant Burden (2006), wherein Voysey interviews parents with disabled children to understand what it is like to live with a disabled child.

The interview data is divided into three: first, the nature of stigma, and the way that participants experience it; second, participants' information management; and third, participants' coping strategies in the face of the disclosure policy, namely 'fertility travel'. This chapter focuses on the first issue, that is, understanding the nature of the stigma invoked by the failure to reproduce and the use of donor gametes/embryos. Most participants reflect on the stigma surrounding infertility. Because their infertility is perceived as their own design, they attempt to defeat charges of deviance by explaining that undergoing treatment was not their 'choice'. Clearly, reproductive technologies do offer a 'choice' to those who cannot conceive using their own gametes: even if one cannot have one's 'own baby', one might be able to give birth to 'a baby' and that baby may even be genetically connected to oneself or one's partner. However, donor conception still invokes abnormality as having a 
genetically-related child is perceived to be natural desire and a social norm. Using donor gametes to conceive is therefore not so much a choice to reproduce but a choice to appear normal: "given the choice, to not so desire is somehow to be less of a person" (Strathern, 1992: 177).

\section{'Failing' to reproduce}

Goffman argues that "a necessary condition for a social life is the sharing of a single set of normative expectations by all participants, the norms being sustained in part because of being incorporated" (Goffman, 1963: 152). Society establishes the means of categorising individuals and the set of attributes perceived as ordinary for members of each of these categories. The routines of social intercourse enable us to deal with others without special attention or thought. When we meet someone, first appearances are likely to enable us to anticipate his or her category and attributes, their 'social identity'. Goffman goes on to argue that "we lean on these anticipations, transforming them into normative expectations, into righteously presented demands" (1963: 12). He calls the normative expectations about one's social identity 'virtual social identity', and the category and attributes s/he could in fact be proved to possess one's 'actual social identity'(1963: 12). Stigma (or a failing, a shortcoming, a handicap) represents a discrepancy between an individual's virtual (normative expectations about what that individual should be, "a characterisation in effect") and actual (the attributes she or he possesses) social identity (1963: 12). Failure or success in maintaining such norms has a very direct effect on the psychological integrity of the individual. 
A stigma is an "attribute that is deeply discrediting" within a particular social interaction (1963: 13). Goffman notes that this failing reduces the individual in our minds "from a usual and whole person to a tainted, discounted one" (1963: 12). He notes:

While the stranger is present before us, evidence can arise of his possessing an attribute that makes him different from others in the category of persons available for him to be, and of less a desirable kind - in the extreme, a person who is quite thoroughly bad, or dangerous, or weak (1963: 12).

Goffman argues that "an attribute that stigmatizes one type of possessor can confirm the usualness of another, and therefore is neither creditable nor discreditable as a thing in itself" (1963: 13). In other words, individual and social expectations have a big role in the bearer's experience of stigma. Stigma spoils one's identity: "it has the effect of cutting him off from society and from himself so that he stands a discredited person facing an unaccepting world" (1963: 31).

\section{Infertility, deviance and stigma}

The participants in this study want to be parents. Having failed to reproduce, they suffered a profound sense of failing: failing themselves, and failing the expectations of the social category to which they belonged. Stigma is not 
inherent in infertility itself but childlessness (which is a more evident status than one's infertility) can look like intentional deviance, a decision to reject the expectation that members of this social category will have children. As the Warnock Report (1985) pointed out:

Family and friends often expect a couple to start a family, and express their expectations, either openly or by implication...Parents likewise feel their identity in society enhanced and confirmed by their role in the family unit (Warnock, 1985: para 2.2).

During the interviews, several participants reflected on the ways in which infertility made them feel different from those who can conceive naturally. They talked about the personal shame ("blame", "fault", "stigma" and "failing") of not being able to reproduce naturally:

And it seems wherever you turn in infertility people are telling you there is no blame but then they seem to attach blame. You know, you feel that you are failing yourself. I feel that it is not my fault. You need fertility treatment. It is directed at you in a sort of blame way (Fiona).[emphasis added]

Because I think in my mind, I think there has perhaps been in the past, I don't know about it now, in my mind, there is stigma attached to infertility. It seems perhaps as a failing maybe (Darren). [emphasis added]

Fiona reflects on the isolation that she has been experiencing due to her childlessness. By the time of the interview, she had been trying to conceive for eight years. Feeling overwhelmed by people asking why they did not have children, Fiona and her husband finally disclosed to a few members of Fiona`s family that they were receiving help. Fiona experienced isolation due to her childlessness. She noted that she lost some of her friends; her childlessness did 
not gain much sympathy; and her friends who had children did not know how to connect with her and her husband. Eventually, the couple was excluded from social gatherings. Not only did her body let her down, but also she failed to meet the expectations of her family and friends.

You lose so many friends to infertility, you wouldn't think that. People don't know what to say to you or they move on and have families and they just exclude you from, you know, when they meet up with other friends who have children. They just leave you out of it, or they just say... They just don't understand there is lots of disappointment involved in infertility. Whenever we encounter, yet another disappointment (Fiona).[emphasis added]

\section{Defeating the charges of deviance: infertility and choice}

As Goffman suggests, a mere desire to abide by the norm is not enough as in many cases the individual has no immediate control over her or his level of sustaining the norm: "it is a question of the individual's condition, not his will; it is a question of conformance, not compliance" (1963: 153). He goes on to argue that one of the dimensions of stigma is the stigma bearer's perceived responsibility for the cause of the act. Observers may attach less stigma to a condition whose cause is perceived as being beyond the bearer's control. The participants in this study reflect on being blamed for their infertility; as I will explain later in the chapter, they present infertility as an illness for which one should not be held responsible. Parsons (1951) argued that illness is a form of deviance for which the sufferer cannot be held responsible. If so, why do participants reflect on "being blamed" for their "failing"? I will briefly discuss Dingwall's analysis of illness before I return to interview accounts. 
A persistent theme of Dingwall's book (2001) is that there are no illnesses in nature and "illness is the outcome of human classificatory activity" (2001: 76). Dingwall points out that one of the more vigorous debates within medical sociology has been on the issue of whether illness is deviance. He argues that much of the confusion has arisen from differences in the usage of term 'deviance'. When referring to deviance, I will adopt his definition: "to be accepted as a competent member of some collectivity, a person must display that he is ordinary, healthy and normal by the standards of fellow members of that collectivity ... any lapse is, in some sense, deviance" (2001: 71). According to Dingwall, deviance is a generic term covering all categories of breaches of social order and it "may be used as a term to apply to any violation of public morality" (2001: 71). Illness is behaviour that is non-conventional ${ }^{49}$ and is, in this sense, clearly deviant. It is behaviour not in accord with what is to be reasonably expected, "the ill person is someone who might have behaved otherwise but has failed to do so" (2001: 74). Deviance ascription is a twostage process: first the observer (or the actor) evaluates the conventionality of the behaviour to determine if there are possible grounds to support it; and second, the observer (or the actor) asses the theorecity, "the extent to which an actor is taken to be aware of what he is doing" (2001: 73). Dingwall argues “deviance involves not merely following the same rule, but also the observer's ability to conceive of the rule being followable in the situation in which it was not followed" (2001: 72). For a charge of deviance the actor must be seen as a theoretic actor. For example, it is unlikely that children would have

\footnotetext{
${ }^{49}$ Dingwall (2001: 72) uses the term 'conventional'. By using this term, he is drawing on McHugh's work where McHugh refers to conventional behaviour as a behaviour that is out of line with the relevant conventions of some setting. Having followed McHugh's usage, Dingwall nevertheless suggests that using the term 'non-conventional' might avoid confusion.
} 
responsibility imputed since they are not regarded as theoretic actors (2001: 76).

Dingwall argues that illness is behaviour that is non-conventional and therefore deviance; it is no less of a problem to the public moral order than any other form of deviance. However, illness is marked by a relatively low degree of theoreticity. Dingwall notes "the more an actor is held responsible, the more his condition will be regarded as intentionally provoked and deserving punishment rather than therapy" (2001: 75). Actors charged with deviance can therefore attempt to defeat the charge against them. In order to defeat the charge of deviance, theoreticity may be implied: Dingwall notes that "migraine sufferers tend to promote biochemical explanations for their disorder; associations of families with a schizophrenic member seek to discount explanations in terms of family disorder; and infertile persons argue that their inability to reproduce is due to force majeure rather than selfishness or sexual aberrance" (2001: 75). He then concludes that "illness is marked by a relatively low degree of theoreticity, but it may overlap with categories with a higher degree of theoreticity which set the tone for its treatment" (2001: 75). Accordingly, one might argue that infertility is marked by a higher degree of theoreticity, especially if it is considered a 'choice' or a preventable condition.

During the last decades, the numbers of infertile couples in the UK has been growing (as in the developed world more generally), mainly due to delayed childbearing by women who invest their younger years in education and career, and a higher prevalence of STDs and sperm pathology caused by 
environmental hazards (Remennick, 2000). Many sources, including the HFEA fertility guide for patients, point out that female fertility declines sharply after the age of thirty-five. Accordingly, in vitro fertilisation (IVF) success rates decline with age and most clinics will not treat patients over forty-five. ${ }^{50}$ The following extract from a news report contains a fertility expert's statement on the matter which exemplifies the information available to women who are considering trying to get pregnant:

\begin{abstract}
Almost all cases of infertility are preventable. Two of the main causes of infertility - age and sexually transmitted disease - could be avoided. This problem could be dealt with by women marrying early and having one partner. Women are non-monogamous. Frequently, they have more than one sexual partner. The assumption is that concentrating on a career and deferring embarking on a family is not going to have consequences, but it does. If we look back at what was going on previously, women were marrying earlier, having monogamous relationships and having children early...Women will not like hearing it, but infertility is preventable and wise women would find a compromise between their career and having children earlier...It is my responsibility to say this. Society needs to be confronted with the fact that infertility is preventable. I don't mean to be rude but it is important that, if women make different life choices, they should be aware of the consequences. They always say 'it won't happen to me' but it does (Professor Gedis Grudzinskas, Director of the Bridge Centre, London in Templeton, 2003).
\end{abstract}

Professor Grudzinskas notes that "women will not like hearing it, but infertility is preventable and wise women would find a compromise between their career and having children earlier". He also points out that another main cause for infertility, sexually transmitted disease, can be avoided. He considers infertility as a choice. In the same news report, the Child Infertility Support Network Scotland calls for the causes of infertility to be taught to schoolgirls:

\footnotetext{
${ }^{50}$ Male fertility also diminishes by a considerable degree with age: nevertheless it is generally women who are warned about the consequences of attempting to start a family late.
} 
What we really need is to educate women to be aware that if they wait until they are in their late 30 s to have their first child then they are putting themselves at risk of infertility. Previously, women would marry at 18 and have their first child immediately. There is now a new generation of women who could not imagine doing that. We cannot make people marry early and have children early, but we can make them realise the risks. We have got to start in schools. There is nothing we can do for the generation who are in their late $30 \mathrm{~s}$. We have got to educate schoolgirls to let them know that their fertility declines in their 30s (Sheena Young, Director of business development, Child Infertility Support Network Scotland, in Templeton, 2003)

Both extracts stress that, in most cases, infertility is preventable and women should be aware that by postponing having children they risk their chances. On these accounts, a majority of the interview participants are deviants. They are women whose infertility was caused by age; they could have avoided being infertile, but they did not. Drawing on Dingwall's analysis, I would suggest that infertility can be marked by different degrees of theoreticity depending on the status of the actor. For example, women who suffer from early menopause will be less theoretic actors than women whose infertility is caused by delayed childbearing. The latter are more theoretic actors as not only have they failed to meet the expectations of the society, but their infertility is perceived as of their own design.

However, sufferers may attempt to defeat the charge against them: it is possible to observe such attempts in the account that follows. Fiona experienced early menopause, and she finds it unfair that she is not eligible to get free treatment from the NHS (because her husband has two children from a previous marriage, the couple have to pay for infertility treatment). In the following extract, Fiona claims that infertility is an illness that needs to be treated. 
Comparing her condition to cancer, she stresses that her husband's parental status should not affect her access to free treatment:

If I had cancer they wouldn't refuse me cancer treatment because of my husband. They would treat me and at the end of the day because what happened to me with an early menopause we need to have the infertility treatment. I haven't chosen put myself through this or put my husband through this. Sometimes it is harder for the husband as well (Fiona). [emphasis added]

In the following extract, Tina, a more theoretic actor (like most of the participants), whose infertility is caused by age, explains that she is not infertile because she prioritised other achievements in life. She did not meet her partner until later in life and, furthermore, she did not know he was infertile:

I think here it is hard to be different in any way...IVF. Everytime I see it on the news, 'ah people are choosing to have their children later going through IVF'. It is not funny and it is bloody expensive, you didn't choose, that you just didn't meet your husband later on, and you didn't know he was gonna be sterile, did you? It wasn't even my fault they make it sound like it is a choice. It isn't. You would rather... I actually worked for my life never thinking the women who go through these. They are really strong trying 10 or more years ... working class women would not have the opportunity. You didn't choose it they make it sound like it is a choice, it isn't (Tina). [emphasis added]

What is common to all the accounts in this study, including the ones quoted here, is that they involve self-defence. By pointing to the underlying, essential normality of their situation (e.g. having an early menopause, delaying childbearing), they attempt to defeat the charges of deviance (Dingwall, 2001). All participants share the view that undergoing infertility treatment is not a 'choice' involving 'fault'; they present their failing as being beyond their control. 


\section{A choice to reproduce: using donor gametes/embryos to conceive}

For those who fail to conceive naturally there are medical interventions available. A thriving infertility industry offers solutions to what used to be an "indisputable sentence of Nature" (Remennick, 2000). If natural conception is not possible, donor gametes/embryos can be used and people who failed to reproduce without assistance can experience something close to biological parenthood. Donor conception therefore has the potential to satisfy a desire for a child, as well as the desire to appear normal.

As the participant accounts indicate, using donor gametes/embryos to conceive can be perceived as a choice to reproduce, but one of a different kind. Strathern (1992) argues:

Persons who otherwise did not have the choice now do have the choice to reproduce themselves, for now they possess access to the enabling technology. But the 'choice' to reproduce is like 'choice' for style: to not so desire is somehow to be less of a person. The assumption is that, given a chance, one will take it, part of the wider nexus of prescriptions that presents failure to exercise one's capacity for choice as failure of motivation...[I]f one cannot reproduce one's genes, one can reproduce (be parent to) choice itself (1992: 177).

The first choice of all would-be parents is genetic parenthood. As one participant says:

I am not choosing egg donation over my own children. If I could, I'd have my own children. I would, but you know... (Fiona). 
Rosie notes that no one would 'choose' having a genetically unrelated baby:

it is not something that most people going through with a $100 \%$ conviction, and of course it is not the way I would have chosen to do things. Not many people would say I don't wanna have my own child, I want to sort of give birth to a child that is not actually mine. No one would choose that (Rosie).

Rosie is sceptical about getting an egg donation because the resultant child will be her partner's child, but not her child:

I had doubts fears and worries about the whole thing [...] Originally I just thought that there is no way I could considering doing that. Even if it was an option, I just thought that I cant, I couldn't... that it wouldn't be my child, and it would be my partner's child, but it wouldn't be mine. I thought I can't actually do that (Rosie).

Fiona is still in the contemplation stages of receiving egg donation. She makes a distinction between having her own child and a child with a donated egg. She says that she "grieves" for not being genetically linked to the resultant child. She adds that building her family using donated eggs is a "big loss" for her as she will not be able to pass on her genes. However, for her and her husband having a donor-conceived baby is the only alternative to childlessness:

My husband, he wanted a child. I decided to just go on with it and if it felt ok. It has started to... it still not the same you know, if somebody gave me option to have my own genetic child I would jump into chance [...] I had and still have lots of grief about not having my own natural child. Even if egg donation worked we go on have a family that way there is still big loss for me about not passing on my genetics, not being actually physically related to this child, and I do struggle with that for a long time until it came down to you know, we will try this or we will remain childless for the rest of our lives (Fiona).

\footnotetext{
51'Grief' and 'loss' are rather common words that the participants use when they describe their feelings about the missing genetic linkage with the baby. Whether the participants adopted this vocabulary of emotional responses from some form of counselling is unknown.
} 
Fiona is dubious about how she will feel about the resultant baby and whether gestation will have a positive effect in terms of bonding. Despite her therapist's advice, she is not convinced that carrying the baby will be enough to establish a biological linkage:

My therapist keeps saying, you are still a biological mum, the embryo cannot survive without your womb, your blood you give birth, you carry the baby. And I also spoke to a couple of other people who had children through donor eggs and they are always saying you really really don't feel any different about this child (Fiona).

Becker (2000) notes that women who have gone through menopause prematurely, in their twenties or early thirties, or women in their forties and older, may be 'eager' to use donor eggs as it represents their only chance for a baby. She further suggests that women in their late thirties and early forties find it difficult to give up the idea of having a genetically related baby. Unlike Becker, with regards to their reaction to receiving eggs (or embryos in two cases), I found no clear-cut age categorisation among the women who participated in this study. Most of the participants in my study who considered donor eggs were over forty years old. Because age is a significant determinant of the effectiveness of treatment, they gave up using their own gametes after failed attempts in their early forties. One participant, who received embryo donation, was in her early forties and had a chance of using her own eggs to conceive. However, after a few failed attempts with IVF, she did not want to try to conceive with her own eggs any longer. She feared that the procedure would be time consuming, risking her chances of carrying a baby. The other participant, who was diagnosed with an unexplained infertility had tried several 
treatments to achieve pregnancy, including ICSI and sperm and egg donation (and she also considered adoption), until she finally achieved pregnancy using donated embryos. She wanted to start a family as early as possible and, surprisingly, embryo donation turned out to be the quickest way. She says "believe or not it [embryo donation] ended up being a faster way of having a child" (Lindsay). Due to conditions such as premature ovarian failure and early menopause, two of the participants in their early thirties knew that they could not conceive using their own gametes even before seeking treatment. ${ }^{52}$ One of them reported that she had no reservations about receiving donor eggs; the other expressed concerns. These findings indicate that, regardless of age, emotional responses to receiving gamete/embryo donation are personal, unpredictable, and variable. What is common to all the accounts, however, is that they involve self defence: using donor gametes/embryos is not a choice, it is deviance - no-one would choose it.

\section{The importance of a genetic link}

Using donor gametes/embryos to conceive is deviance because it departs from a powerful social norm. Strathern (1992) draws attention to the changing constructs of biological parenthood:

[W] hat is 'biological' is no longer subsumed under the parent-child relationship itself, the flow of blood that was supposed to connect parents and child through the act of procreation. It is literally the donation of genes. Blood could be imaged as some kind of metaphor for a bond; like the act of procreation it worked as a trope for a

\footnotetext{
${ }^{52}$ One participant who was in a same sex relationship reported no problems with the idea of receiving donor sperm.
} 
relationship between individuals, a symbol of a communicative event. Genes are the bits of information themselves (1992: 178).

Reproductive technologies create new forms of connectedness with the resultant baby (a woman can bear a baby and give birth to a baby to whom she is not genetically related) but the availability of technology does not appear to change the participants' understanding of normal parenthood and kinship. For example, for Fiona, "passing genes" is one of the main reasons for wanting to have a baby. When they decided to have a baby, she and her husband wondered what a "mixture" of her and him would look like. Fiona's husband's sperm count had been decreasing sharply since they decided to have a baby. She notes that achieving pregnancy would have been easier using donated embryos, than using donor eggs and her husband's sperm. Nevertheless, she does not consider embryo donation as an option at all. In embryo or sperm donation, she explains, men do not make a biological contribution which turns them into a social father:

No I don't think we could face that [embryo donation]. At least with the egg donation I get to play some part. With a sperm donor I think it turns the man into just like a social father, really, just somebody to bring the children up and he has very little part then my husband would have such ... such a little part (Fiona).

She does not see a point of having a baby that is not related to her or to him.

She wants to have at least one string of genetic connection with the resultant baby, even if it is from the father's side. She says that she "grieves" for the lack of physical resemblance; the baby will not look like her: 
One of the reasons ... there is many reasons people want to have children one of the reasons when we first started that, either way we wanted to have a family was we wanted to see what a mixture of him and me looks like. And to carry a baby that isn't gonna look anything like me and it is just a mixture of him and somebody else that's quite difficult anyways. I feel almost jealous feelings about that in a way but if we were looking to do without him either, that's not something I cannot contemplate that would be just having a baby for the sake of it then and I don't think we can put ourselves through that. And my husband already have two children anyways. So I don't think it would be something he would like to do either (Fiona).

Rachael and her husband have an adopted child. By adopting a child, the couple were not able to enjoy the ritual of having a biological baby. She expects that getting pregnant will enable her to "feel or - at least appear normal":

To feel normal - or at least appear normal, to be able to join in all those stupid conversations at preschool re labour and delivery, breast feeding etc. to experience the pregnancy and birth to have a child that is ours and that we aren't expected or feel obliged to share with birth families, to be able to give my husband a child that he is genetically connected to (Rachael).

As with Fiona, Rachael also says that it is important to "give" her husband a child to whom he is connected. Both Fiona and Rachael express the view that their partners would want to pass their genes on to the resultant child. Thompson (2005) argues:

It is grammatically appropriate that men would be genetically essentialist when there is no gestational role available to them and when the only way to overcome their faulty contribution to the couple's reproduction is through the genetic route or through displacement by a donor (2005: 121). 
Thompson also points out, however, that men tend to support their infertile wives when there is no male factor infertility, which indicates that men should not be seen as genetically essentialist. My observation is that all the would-be parents in this study, irrespective of gender, do value shared genetics. For example, three of the women, Tina, Fiona and Rachael, are already social parents. Tina and Fiona have stepchildren, and Rachael had adopted a child but she still wanted to have a child who is genetically related to her and her husband. She ended up receiving egg donation, which she does not see as entirely different from adoption. In the following extract from the interview, referring to the egg donor and the birth mother of her adopted child, she says "two people have already given me their babies". This suggests that she does not see the donor-conceived baby as hers:

I have given up the idea of having a child that looks like me. The emotional aspects to me were dealt with when we opted to adopt. Although I am extremely grateful that a stranger has stepped forward and offered to donate for me, well, two people have already given me their babies! You can't top that (Rachael)!

Rachael's husband, Mark, explains that they decided to obtain egg donation "because it was a logical step if Rachael wanted to be pregnant and give birth". He had his own reasons as well, such as passing on his genes and gaining autonomy:

So I could see a bit of me in the child. So we wouldn't have to deal with the wants and all birth family. Two birth families is enough (Mark). 


\section{Defeating the charges of deviance: "it is absolutely like a biological baby"}

Earlier in this chapter, I argued that the accounts of the participants indicate that they consider themselves as deviant because they failed to reproduce naturally. But, if having a donor-conceived baby is deviant, how will would-be parents achieve normalcy using these means of conception, and how will they normalise their kinship with the resultant baby?

Egg and embryo donation may be perceived as a 'compromise' to have a genetically- connected baby, however they do enable women to experience pregnancy. Lindsay who received embryo donation says that the pregnancy was wonderful, and she did not feel any different about the baby. She says:" I took the test and that was it. I had my baby in my uterus" (Lindsay). Janine, who was expecting twins, believed that pregnancy was crucial in establishing biological bonds:

Of course you can't avoid bonding. It is absolutely like a biological baby, I talk to my baby pray for my baby, yeah. I have a doctor scanner I can hear the heartbeat it is lovely it is like a normal pregnancy. [...]Y You have to take the medication, which, you know, is ok. Yeah, apart from that it is the same. The baby develops in the same way, your body changes in the same way, the baby develops in the same way, you have the same symptoms with everyone else...so...yeah (Janine).

It seems then that the gestational linkage might, to a certain extent, compensate for the missing genetic linkage. Tina, who had embryo donation, thought that the baby did not actually belong to her and her husband: nevertheless, the baby was not an "alien" either: 
I don't sort of sit and think of carrying an alien [...] I think this is early adoption, this is not actually biologically ours ... carrying, I think the bonus is there (Tina).

Although Tina calls embryo donation "early adoption", her account goes on to suggest that she does not see her unborn baby as an adopted baby: her gestational contribution in the development of the donated embryo distinguishes the baby from an adopted one. In the following extract, Tina explains why she did not want to adopt a child. She thinks that if one lacks a biological connection with a baby, one will be less tolerant: "you are more likely to lose your temper." Tina also thinks that giving unconditional love to an adopted baby is hard:

We are too old, he [her husband] has got children and we didn't want a damaged child unfortunately because they take so long for them to get adopted and usually you get a 6 year old with problems. I did actually work in a children's home for a year and I know what they are like, so I might have but my husband definitely wouldn't be interested in that [...] I think you are more patient when it is your own children, you have a newborn, I think. If somebody hands you a 6 year old and it starts screaming out loud, I don't think you are gonna have that unconditional love for it, put up with it. You are more likely to lose your temper. I do think you are less tolerant because you lack that connection. I wonder when somebody hands you screaming 3 old, and watching you under microscope see how you are doing, it is awful (Tina).

Tina's account suggests that biological connectedness is all that is needed for there to be unconditional love for a baby. Dingwall et al. (1995) refer to what Tina calls unconditional love as 'natural love'. They argue that it is assumed that all parents love their children as a fact of nature. Parental love is thought to be an instinctual phenomenon grounded in human nature to such an extent that it becomes very difficult to read evidence in a manner inconsistent with this 
assumption. In child abuse cases, where the natural parents are suspects, "the challenge amounts to an allegation that deviant parents do not share a common humanity with the rest of us" (1995: 87), because they are deficient in natural love. Couples receiving donor gametes/embryos may also be seen as potentially deficient in natural love for their donor-conceived child. The participants in this study seek to sustain their normalcy by asserting other interpretations of their situation which deny its undesirability and legitimate any suffering on their part (Voysey Paun, 2006). The participants are constrained to present their kinship with the donor-conceived baby in such a way that "they appear to be fulfilling the demands of normal parenthood" (2006: 2). Tina's account, for example, denies charges of deviance and deficiency: although the baby is not biologically theirs, they will love it as their biological baby because gestational pregnancy compensates for the missing genetic link and naturalises the kinship.

Thompson (2005) has argued that the understanding that blood relations usually reflect the genetic relationship had changed by the end of the twentieth century:

As a result of donor-egg in vitro fertilization and gestational surrogacy, the overlapping biological idioms of shared bodily substance and genes come apart. The maternal genetic material, including the determinants of the fetus's blood type and characteristics, is contributed by the egg, which is derived from the ovaries of one woman. Nonetheless, the embryo grows in and out of the substance of another woman's body; the fetus is fed by and takes form from the gestational woman's blood, oxygen, and placenta. It is not unreasonable to accord the gestating mother a biological claim to motherhood. Indeed, some have suggested that shared substance is a much more intimate biological connection than shared genetics and is more uniquely characteristic of motherhood. 
as genes are shared between many different kinds of relations (2005: 149-150).

Thompson's observations apply to my findings: a majority of the women in this study received egg or embryo donation so that they could have a biological claim to motherhood. This would not have been possible if they adopted a child (some of these participants had adopted children, or considered adoption before or after having a donor-conceived baby). For a majority, one of the reasons for receiving gamete or embryo donation was to make a gestational contribution to reproduction by 'shared blood' through pregnancy and child-birth. However, despite the growing understanding of the importance of the uterine environment in influencing gene expression, ${ }^{53}$ none of the participants commented on this potential influence. In other words, none of the participants expressed the view that these babies actually would be genetically different from how they would have been had they been carried to term in the donor's uterus. In other words, although the participants perceive using donor gametes/embryos as an approximation to genetic parenthood that enables them to experience pregnancy and child-birth, they do not perceive a genetic claim to parenthood.

\footnotetext{
${ }^{53}$ Recent research shows that gestation does influence the genetic make-up of an embryo and foetus. Epigenetics is relevant when considering the influence of the birth mother on the genetic make-up of a resultant child. Epigenetics refers to "all modifications to genes other than changes in the DNA sequence itself" (Downer, 2002). Genes can express in a number of different ways depending upon the environment. Hence embryonic and foetal development is an extremely dynamic process: "[I]t is not simply determined by the genotype, and so does not occur solely in the form of an encapsulated, hardwired developmental "programme". Instead, the developmental programme can be influenced by a range of environmental conditions and these interactions can have long-term consequences for later health and disease" (Gluckman and Hanson, 2005: 58)
} 


\section{Conclusion}

Having failed to reproduce naturally, the participants in this study experienced stigma and isolation. They failed themselves and failed to meet the expectations of the social category to which they belonged. Infertility increases with age: for a majority of the participants, their infertility is marked by high level of theorecity - it is perceived as their own design. Arguably, the availability of reproductive technologies increases the level of theorecity ascribed to those who cannot conceive naturally: as noted earlier, Strathern has argued that "given a chance, one will take it, part of the wider nexus of prescriptions that presents failure to exercise one's capacity for choice as failure of motivation" (1992: 177). On the one hand, the participants in this study wanted to become normal: they therefore chose this alternative route to parenthood. On the other hand, however, by doing so they departed from the social norm: using donor gametes/embryos may be as close an approximation to genetic parenthood as possible (Strathern, 1992), nevertheless it does not constitute an equivalent alternative for those for whom genetic relatedness to their children is of great importance. (Elsner, 2006): "A woman who has a child as a result of egg donation from another woman cannot have her own in the sense of her own genetically related child" (Chadwick, 1992: xvi).

The participant accounts indicate that a donor-conceived baby is perceived as different from a natural one. Although it is not always evident in the terms they use, the participants distinguish shared genetics from shared blood: to them 
genetic-relatedness means passing one's genes to one's offspring. For example, while referring to having a baby, they distinguish a naturally-conceived child from a donor offspring by using certain expressions indicating the nature of full genetic linkage ("real baby", "real mummy", "a child of my own", etc.).

The participants who were still undergoing treatment were uncertain about kinship with a potential baby. They reported that they could not overcome their "grief" about not having a baby of their own. In other words, their accounts indicated that having a donor-conceived baby might not qualify them as 'normal' parents. Conversely, the pregnant participants reported that, despite their use of donor gametes, the pregnancy, the baby, and their feelings about the baby were 'normal'. Although shared blood was not seen to be as powerful as shared genetics in building biological linkage, they reported that the natural flow of pregnancy seemed to help with bonding with the baby and feeling the same as everyone else. Voysey has argued that in drawing upon everyday understandings of normal family practices, parents are drawing upon ideological prescriptions. Accordingly, what the would-be parents in my study say tells us not only how it is to be a donor-conception family, it also presents socially constructed accounts of 'normal parenting'. The difference between the accounts of non-pregnant and pregnant participants is evident. While nonpregnant participants reflect on having doubts about bonding with a donorconceived child and 'grief' for not being able to have their own child, the pregnant participants attempt to normalise their relationship with the unborn baby: the baby is not different from other babies. These participant accounts should be read by taking into consideration the fact that moral expectations 
about motherhood might not be easily dismissed by would-be parents. Voysey argues that: "parents say what they say because the alternative is not to be regarded as parents at all", and "in our society this is more or less equivalent to not being regarded as a competent person" (2006: 54-55). The ways in which the would-be parents seek to restore being a normal family tells us "both about its moral force and about the kinds of accounts that are honoured in our society" (Dingwall, 2001: 58).

Although I am not able to evaluate to what extent the pregnant participants were emotionally or physically satisfied, gestational pregnancy - in one participant's words - enables them to "feel normal or at least appear normal". Donor conception makes it possible for would-be parents to enjoy the cultural and social practices of gestation: having a 'bump', carrying the baby and feeling the movements of it, monitoring foetal development through scans, sharing these images with friends and family and, finally, going in labour. To the participants in this study, the bump is a visible sign of normalcy; it may drive the would-be parents' and their social network's attention to the ends of conception, rather than the means of it. Having coped with the anomaly that infertility evokes, would-be parents may find comfort in the 'ordinariness' of pregnancy and childbirth. The child who is born as a result of these arrangements might be perceived as one's own child, even if s/he is genetically related to another person(s). Donor conception then cannot promise to satisfy a desire for a genetically-related child but it has the potential to satisfy a sociallyinduced desire that presumably all would-be parents have: that is, the desire to appear as a 'normal family'. 
Ultimately, the interviews were guided by one main question: why did not would-be parents press claims against the removal of donor anonymity? The interview accounts show that to understand this reticence, we need to understand deviance and stigma. It seems that the voices of would-be parents are suppressed because of the potential stigma which is actually underlined by the new law. The following chapter deals with how participants control stigma about donor conception in their daily lives and how the current law compounds stigma by obliging them to display their potentially stigmatising condition. 


\section{CHAPTER SEVEN: 'PASSING' AS 'NORMALS': INFORMATION MANAGEMENT}

At the beginning of this thesis I argued that the silence of would-be parents in the public realm does not mean that they do not view the removal of donor anonymity as a social problem. The fact that infertility is viewed as stigmatising may affect how comfortable would-be parents are about disclosing their use of a donor to their children or their social contacts, or pressing claims publicly against the legal imposition of disclosure. In this chapter, as in Chapter Six, I use Goffman's Stigma (1963) theory. Here I focus on disclosure, examining the ways in which participants control the information which they perceive as potentially stigmatising in interaction with others and the resultant child, and how the new law disrupts their coping strategies.

Both failing to reproduce and using donor gametes/embryos to conceive made participants feel different from normal parents and constituted a charge of deviance. Goffman notes "even where an individual has quite abnormal feelings and beliefs, he is likely to have quite normal concerns and employ quite normal strategies in attempting to conceal these abnormalities from others" (1963: 156). He goes on to argue:

Stigma involves not so much a set of concrete individuals who can be separated into two piles, the stigmatized and the normal, as a pervasive two-role social in which every individual participates in both roles at least in some connexions and in some phases of life. The normal and the stigmatized are not persons but rather perspectives (1963: 163-64). 
As I showed in Chapter Six, whilst participants who were undergoing treatment were negative about having a genetically unrelated baby, the pregnant participants noted that gestational pregnancy, and 'shared blood', had potential to make this new form of connectedness 'normal' to them. In other words, although having a donor-conceived child may invoke abnormality, pregnancy and child-birth may help bonding with the baby and, more importantly, the resultant baby will appear 'ordinary' to outsiders. Participants may, then use passing strategies to conceal the infertility treatment and the child's origins, because as long as donor involvement in conception is concealed, there is nothing that marks out a donor-conceived baby from any other. As long as they can control information about their infertility and/or donor conception they are, in Goffman's words, 'discreditable', but not 'discredited'. Clearly however the legal imposition of disclosure would force the participants to display their deviance.

\section{'Passing': disclosing infertility and infertility treatment}

Goffman distinguishes the stigma of the 'discredited' from that of the 'discreditable'. The discredited person's failure might be quite evident (like a scar on the face), and known to others before they contact him or her. When the stigmatised person is not discredited but discreditable, the differentness of the person is neither immediately apparent nor known beforehand to others. The stigma experienced by the participants in this study falls into the category of a discreditable stigma. 
Goffman notes that there are some stigmas that are so easily concealed that they have very little effect on the individual's relations to strangers: such stigmata have their effects chiefly upon intimates. Given that infertility itself is not a visible 'failing', the evident part that can be known to others is the bearer's (involuntary) childlessness. Accordingly, the issue is not that of managing tension generated during social contacts, but rather that of managing information about one's infertility: "to display or not to display; to tell or not to tell; to let on or not to let on; to lie or not to lie and in each case to whom, how, when and where" (1963: 57). Goffman defines the management of undisclosed discreditable information about the self as 'passing'. ${ }^{54}$

The need to appear normal and to manage stigmatising information are not idiosyncratic needs but the foundations of everyday life. Few people are totally without discrediting attributes. In fact, normal and stigmatised can play each other's roles:

One can assume that the stigmatized and the normal have the same mental make-up, and that is necessarily is the standard one in our society; he who can play one of those roles, then has exactly the required equipment for playing out the other, and in fact in regard to the stigma or another is likely to have developed some experience in doing so $(1963: 156)$.

\footnotetext{
54 It is worth noting that Goffman's work has been criticised on a range of grounds. Some argue that it does not offer the "possibility of any serious attempt by stigmatized individuals to destigmatize themselves" (Gussow and Tracy, 1968: 317). In fact, Goffman touches on destigmatisation, where he discusses 'passing' strategies. Secondly, it has been argued that his theory does not tell us much about how individuals mediate the stigma depending on their social class, gender and age (Miall, 1986). But Goffman does not deny the impact of social structure on stigma management; rather he uses a more inclusive term, "social identity", to cover all social attributes. The fact that his theory "assumes a selfdetermining, autonomous individual with choices, and a mass society that allows for privacy" (Miall 1986 , p. 113) was however rightly found to be problematic by some authors who could not apply the theory in different cultures, in particular in the Asian context. Nevertheless, this is not a problem in this study, which presents the accounts of a Western population.
} 
Goffman notes that because stigma management is a general feature of the society, and the normal and the stigmatised are parts of the same complex, the stigmatised person can be called a 'normal deviant', rather than a 'deviant'. The participants in this study are able to play both parts in the "normal-deviant drama" (1963: 159). They employ various strategies to control information about their infertility and infertility treatment. Fiona, for example, would have preferred not to tell anyone about her infertility, particularly about donor conception, but people started to figure out that the couple were receiving help to conceive:

I have only told two friends. And I told nobody in my family. There are few people in my family that know that we are having fertility treatment just simply because, you know, they grown tired after eight years of asking when we're gonna have a family... And we got to the stage where they can see we are hurt every time they ask, or you know, sometimes we don't answer or... not that easy and that sort of saying it and they know about the miscarriages we had as well, so, my family has kind of gathered that we are having treatment. But I never actually said, yes we are having treatment...so my family don't know and I have only told a couple of friends (Fiona).

Goffman notes that, in passing, one strategy available to discreditable person is "handling his risks by dividing the world into a large group to whom he tells nothing, and a small group to whom he tells and upon whose help he then relies" (1963: 117). Rachael's account is a good example of the type of information-control that Goffman outlines. Rachael did not expect to find support from most people about her infertility treatment. She thought that people would be interested in the treatment merely in a negative way: "people gossip, people are nosey, and few are interested in a caring supportive way." Moreover, she and her husband were surrounded by "fertile myrtles", people 
who easily achieved pregnancy without getting any medical help. Rachael and her husband thought that those who had conceived naturally would not understand what they had been going through. They handled the risks to which they felt exposed by dividing their social network into two: a small group of people who would be supportive and helpful were told about the treatment, whereas a large group of people who would be critical were not told:

We hide it from everyone apart from my parents and one couple who are our support. Because we are surrounded by fertile myrtles who think trying for three months is infertility! People gossip, people are nosey, and few are interested in a caring supportive way. People don't announce "we had sex on Tuesday night and believe we have conceived our future son or daughter" so why should they know when retrieval or transfer is? (Rachael).

Rosie disclosed her treatment to individuals who had similar experiences:

It [disclosing] was very hard with friends who were pregnant etc. Actually I found it not really helpful to tell people ... I told some people who either had been treated something similar or been through or experiencing infertility or have experienced...for other people it is just...there is nothing really for them to say (Rosie).

Goffman suggests that a strategy of those who pass is "to present the signs of their stigmatised failing as signs of another attribute, one that is less significantly a stigma" (1963: 117). For example, men may have concerns that the acknowledgement of infertility would cause their masculinity to come under suspicion, and ask their partners to conceal their condition. Such concern is rooted in experience of stigma (Nachtigall, 1993). Despite the high incidence of male infertility "the condition is invariably cast as a female problem that requires medical intervention" (Storrow, 2006: 398). Miall (1986) argues that 
although physically infertile women feel more stigmatised, physically fertile women manage information more actively to protect their husbands from the stigma associated with sexual dysfunction. It is possible then through information control that a couple would reconstruct their narratives about treatment according to what they believe to be more socially acceptable. The following account exemplifies this strategy. Liz's husband has azoospermia. Being worried about how people will react to her husband's condition, when she is questioned about her childlessness she conceals the fact that they are suffering from male factor infertility:

We have not told our friends. I am more than happy to tell my friends it is my fault we cannot conceive, which we have done. It's far easier for them to think I have the problem rather than my husband, in a way I suppose to protect his feelings. It always seems far more acceptable for it to be the female problems rather than the males when in fact its more like a 50/50 split (Liz).

Goffman notes that another passing strategy is that the individual "can voluntarily disclose himself, thereby radically transforming his situation from that of an individual with information to manage to that of an individual with uneasy social situations to manage, from that of a discreditable one to that of a discredited one" (1963: 123). Darren's account exemplifies something akin to this. Darren and his wife could not conceive due to male factor infertility (azoospermia). He had always thought that there was stigma attached to infertility, and when he found out about his condition he did not want to talk about it. While surfing on the Internet to find information about the condition, he came across the Repromed message boards. After joining Repromed, he started feeling more open about talking about his condition and treatment. On reflection, he says that he overcame negative feelings about his infertility by 
being extremely open about it; in fact, he went, he says, "over the top being open about it". Sharing the details of the treatment with people made him feel 'normal', almost 'proud' that he and his wife had a problem. He notes that by talking, he tried to prove to himself, rather than to anyone else, that infertility was not something to be ashamed of. Darren's description of his motives is a good example of what Goffman refers to as "being ashamed to be ashamed" (1963: 155):

I suppose, maybe because I was worried that it [infertility] might happen to me, that I might feel others thought that about me, perhaps its because I wanted it not to be like that, I have almost gone over the top being open about it so that people see me as not feeling that I should be stigmatised. I felt normal, almost proud of that we had a problem in a while. Maybe I am trying to be more open to justify to myself that there is no reason to be embarrassed about it (Darren).

Darren argues that, although infertility is fairly common, people do not talk about it. It was not until he talked about his condition that his friends came forward with similar stories:

One in six couples have problem in conceiving and not necessarily all of those seek treatment, but lets say one in ten, you still expect to know somebody that either have treatment, or know somebody that knew somebody who had treatment. Now, of course I discovered now through being more open. The more I talk about it with friends and colleagues, the more they are likely to come back with a story about it. But otherwise I would never heard about it unless I said about my treatment [...]I think it is because it is very intimate (Darren).

Would-be parents who are going through treatment need to pass, not only socially, but also 'biologically' (Thompson, 2005). By passing biologically, I mean achieving success in conceiving using infertility treatment. Many 
participants in this study who had failed cycles and miscarriages reflected on the emotional cost of not being successful in achieving pregnancy.

It is really really hard when you are going through it because on the one hand, you hope there is a child. On the other hand, you know that every time you try again it is such an emotional rollercoaster hard to know that you are going to put yourself through something that is gonna be so painful and so emotional and... it is really really hard to... I didn't really want to do it again but then you know I had to... I had to give a one more try . The more times I did it [having IVF cycles using donated eggs] I think the less people I wanted to know. I didn't find it [disclosing] helpful and, and it was a strain having everyone asking me "how is it going?", "what's happened?", "did it work?" You know, that was really hard (Rosie).

Another participant, Darren argues that talking about infertility treatment is 'embarrassing': "everybody knows that you are trying to conceive and there is a lot of expectation on you." Embarrassment has to do with unfulfilled expectations (Goffman, 1956). It occurs whenever "some central assumption in a transaction has been unexpectedly and unqualifiedly discredited for at least one participant" (Gross and Stone, 1964: 2). Darren notes that if one tells that one is getting treatment, one has to deal with intimate questions as to whether it worked: "in fear of having to tell somebody that 'no, it hasn't worked", he did not tell many people about his condition in the earlier stages of the treatment:

There is definitely I think people feel that there is something to hide about infertility and it is embarrassing to talk about it and it is personal. One of the things that I suppose if you compare people having fertility treatment with people conceiving a child in usual way, many many couples wouldn't tell anyone else that they are trying to conceive whereas if you are going through fertility treatment everybody knows that you are trying to conceive and there is a lot of expectation on you. We were very lucky and our treatment worked first time but as you know from reading the forum [Repromed's discussion forum] it is not always the way. People have four-five treatments before conceiving and then I guess there is a lot of ... a lot of people know about it. Then there 
is a lot of people that you have to tell when it hasn't work and so maybe that's one of the reasons why people keep things more private I think. Certainly the reason, one of the reasons that we thought about keeping sort of quiet about it early on, and certainly one of the reasons why I didn't tell people at work early on I told important people that I needed to tell like management at work so that I could take time off to go for the treatment but otherwise I only told one very close colleague and a few friends. That was it. [...]I guess people...yeah that might be one of the reasons because of that fear of having to tell somebody that no, it hasn't worked whilst you wouldn't have that if you were conceiving normally, you wouldn't be ringing everybody every month, oh we tried again...it would be almost a not normal thing to do perhaps (Darren).

Another participant, Bette, who is in a same- sex relationship, achieved pregnancy using donor sperm. Bette notes that she wants to wait for a while before telling people for the same reasons as Darren: if the pregnancy fails she does not want anyone to know that she has been trying to get pregnant but it has not worked. It is worth noting that this is not an uncommon feeling among people who try to conceive naturally. However, a person who receives medical help to achieve pregnancy might feel that her or his attempt raises more curiosity than anyone else's, as it represents a challenge against nature. Also, failing to conceive despite medical help might be even more embarrassing than infertility itself:

You try not to say because it is so because when you have to say that it hasn't worked that's not nice but ehm..but our family knows, and close friends know.[...] I am just a little bit pregnant...It is all that...If it worked, that's fine, then I would be willing to talk about it. But if it doesn't then I wouldn't want people to know that I have been trying it and it didn't work (Bette). 


\section{Disclosing having a donor-conceived baby to others: having a 'sort of a monster'}

Public attitudes toward donor conception (using donor sperm in particular) suggest that approval for third-party involvement is lower than for adoption or other reproductive technologies (Klock, 1993). As others have noted, reproductive technologies embody a tension between that which is constructed as natural (reproduction) and that which is rational (technology). Throsby (2004) for example argues:

This tension finds an uneasy resolution in the notion of "giving nature a helping hand" as long as the final outcome is a baby. The gametes, the end product and the desire for a child are still understood as "natural", and the use of the technology to facilitate this outcome is rendered invisible once the child is born, since there is nothing to mark an IVF baby out from any other (2004: 54).

In contrast to traditional IVF (using the couple's own gametes), when medical intervention goes further than 'giving nature a helping hand' and donor gametes get involved, would-be parents may have to deal with two issues. First, as I have shown in Chapter Six, they have to come to terms with not being genetically connected to the resultant baby. Secondly, they have to consider whether the information about child's origins should be revealed. In earlier studies on disclosure, it has been argued that privacy about the conception allows both the child and parents to be protected from any negative societal attitudes, and prevents the family from being treated differently (Nachtigall et al., 1997), and also that both of these concerns are rooted in the experience of stigma (Nachtigall, 1993). As I showed in Chapter Six, all of the 
participants valued having a genetically connected baby and some participants reported being uncertain about their kinship with a donor-conceived baby. If a person is uncertain about having a donor-conceived child, disclosing information about the donor conception to others could be problematic would-be parents may fear that the baby will be marked out if his/her donor origin is known.

Having a donor-conceived child constitutes a permanent charge of deviance against the family. There are two charges of deviance: first, the selfishness of the would-be parents, who engage in 'manufacturing' a baby, and second, the donor-conceived child itself is deviant - it might be perceived as not quite human. If information is revealed about the origins of the child, the parents might have to manage the tension around the child's unnatural means of conception. But, unless the child's origin is known, there is nothing that marks out a donor-conceived baby from any other, and both the baby and the parents can 'pass'. By disclosure, the 'subnormality' (Voysey Paun, 2006) of the resultant child may become evident. The participants in this study may therefore try to hide the origins of the donor-conceived child, not only from others but also from the child him- or herself.

Using donor eggs to conceive, Rosie found it very hard "not to tell" about her treatment, because she enjoyed being open about everything else in her life. However, after disclosure, she did not find people's reactions to be helpful. Both Rosie's parents and her partner's found donor conception difficult to understand. They dealt with the situation by avoiding the subject: 
I am quite an open person so I don't really like to have to hide things because I find it more stressful than tell people but it is very hard because of some people's reaction. Even talking about just going through ordinary IVF. Some people for example my mother or my partner's parents they find it very difficult to understand and they think the best thing is not to talk about it, not to bring it up whereas to me that's actually worse than if you... if you say something or if you say you are going through something and they say, oh nevermind, lets talk about something else (Rosie).

The fear of being marginalised may lead would-be parents to be more cautious about telling people about their treatment. Fiona did not want to tell people that she was using donated eggs to conceive because she thought that people would mark out the baby. Fiona comments on the widespread beliefs that, first, kinship is biological and, second, family members should resemble each other. Of course, identifying whether a baby resembles its parents rests on a particular kind of circular reasoning: there is a genetic link between parent and child, therefore the child should resemble the parents (Becker, 2000). If the observer knew that the child was donor conceived, he or she might claim to see no resemblance. For Fiona, having her child subjected to such an examination would generate a great deal of discomfort. She perceives donor conception as a taboo subject, and she fears that people might ridicule her and mark her child out as the "donor baby":

Because it is still a subject of quite taboo I think in the society. It is not a subject that people talk about and I should imagine of people I know here on the Island [...] It is all silly little worries and fears like that and even things like if we do manage to have a baby you know, I am already worrying about the comments that you get from the people... "oh doesn't she look like you" that would really upset me because I know the baby wouldn't. But then if people say "oh she doesn't look like a bit like you" that's gonna upset me as well. It so feels like a no win situation... well I think when people say those things, they, people just see what they want to see with babies as well they are desperate to 
see so...I think that's one of the reasons as well...it is a petty reason I know, but that's one of the reasons that I want to keep it as a secret. Because you know, I don't want people to go on like 'alright yeah, alright yeah...it is the donor baby, isn't it?' (Fiona). [emphasis added]

The attitudes of friends and family can trigger negative thoughts about treatment. For example, Rosie says that she was really hurt when a friend accused her of creating a "monster" and being "selfish" for wanting a baby. Already being cynical about the treatment, her friend's reaction led Rosie to question her decision to receive egg donation:

That was really hard and then when I came to make the decision to go for the donor egg. I had a very difficult experience with a...more than close friend of mine for many years. When I told her I was considering, she had a very very negative reaction to it and said that that I was incredibly selfish to do that, despite the fact that she has three children... and she said it was selfish because I was going to kind of create this sort of monster that wasn't even my child and yeah...Rather than she was wondering why I didn't adopt because there is always children out there and I was just selfish for saying I wanted to have a baby and how could I do this... it was very very it was yeah very strong reaction [...] She was also saying, well you don't need to have a child to fulfil yourself and you know, again it was sort of easy for her to say that and she said... she had a very negative reaction I think kind of morally and everything about it so that's been very hard because we are not...yeah I don't really feel the same about her after we sort of made it up. It was really really emotional but I couldn't really accept her attitude. She is an intelligent person. She knew, she thought it was more wrong than doing IVF because it wasn't going to be even my genes it was another woman, and I was creating a thing... who knows what it will be like and on top of that it was selfish because I was doing it just because I wanted the baby. And I asked her why, did you have children, you didn't do for the sake of the children, you knew that it was for yourself and your husband you wanted to do it.... she said yes it is different, because it is a natural instinct to want to pass on your genes and you are gonna have a baby that isn't even yours (Rosie). [emphasis added]

Rosie's friend's reaction is a vivid example of a genetically essentialist view.

Rosie states that her friend thought donor conception was wrong because the child would not be genetically linked to Rosie. According to Rosie's friend, 
reproduction is motivated by one's natural instinct to pass on one's genes. It may therefore be acceptable to give nature ' $a$ hand' as long as the medical intervention does not go too far. Donor conception is, however, "more wrong than IVF" because it is a major intervention in nature. This sort of opposition to gamete donation is not uncommon. Chadwick (1992) for example has argued that avoidance of doubt over one's genetic origins is hugely important. She emphasises that "when one does not know where 50 per cent of one's genes come from, it can cause unhappiness" (1992: 126). According to Chadwick, this unhappiness is so serious that "we must be cautious about producing a situation where children feel they do not really belong anywhere, because their genetic history is confused" (1992: 39). Chadwick goes on to argue that since not all desires for a child can be satisfied, some form of selection must be operated and she concludes:

It seems wise to restrict artificial reproduction to methods that do not involve donation of genetic material. This rules out AID, egg donation, embryo donation and partial surrogacy (1992: 39).

Rosie's friend refers to donor-conceived baby as a "sort of a monster". This invokes Dr. Frankenstein and his Monster, an attitude of fear toward reproductive technologies. Frankenstein stands as "a warning of the dangers inherent in scientists' ruthless and unending pursuit of knowledge" (Mulkay, 1997: 116-117).

Rosie's friend thought that Rosie was “creating a thing, who knows what it will be like" (given that the baby would carry someone else's genes), and that it was "selfish" to make a baby for the sake of it. The would-be parents in my 
study were familiar with representations of donor-conceived babies as 'manufactured'. For example, the mother of another participant, Tina, advised her to stop trying as she was opposed to the embryo donation process, which she called "buying a baby". An American theologian, Professor Paul Ramsey, expresses the view that acceptance of IVF inevitably leads to acceptance of the notion of "manufacturing":

I'd rather every child to be born illegitimate than for one to be manufactured.... Already women think of themselves as machines of reproduction. Look at the ease with which young girls have abortions, so sure that they can have another child any time when they want. And now women are selling their bodies for nine months and people are talking about freezing fertilized eggs. Pretty soon, a woman will be able to go to the supermarket and pick out an embryo (Ramsey, 1980, quoted in Newton, 1983: 85).

In the extract above, a few themes invoke Huxley's Brave New World: manufacturing babies, machines of reproduction, going to a supermarket and picking up embryos.

Ramsey is American, but in the UK as well people who oppose embryo research have openly used elements taken from science fiction or dystopias (Mulkay, 1997: 123). Edwards (the test-tube baby pioneer) notes that science fiction such as Brave New World has had a negative impact on the public debate on reproductive technologies.

The trouble really started way back in the 1930s, by courtesy of the brilliant Aldous Huxley. In his novel Brave New World...Admittedly some of Huxley's notions have come true. Fifty ova can now be collected from a human ovary. This is a modest figure compared with his thousands, yet his ideas still grip prophets of doom more than any other science fiction, as the numbers of human embryos growing in 
vitro rise year by year, and as his fellow writers whip up forebodings dire enough to alarm even the most phlegmatic science watcher (Mulkay, 1997: 120).

\section{Disclosing to the child}

As I showed in Chapter Three, during the donor anonymity debate there was a focus on conflicting rights between the resultant child and the would-be parents. By removing donor anonymity the UK government decided that the child's right to know should be championed at any cost, rather than weighed against the competing interests of would-be parents. The government considered registering 'by donor' on birth certificates of donor-conceived children to force parents to disclose to the child: the current regulations do not provide for this (although the matter has been kept under review), Nevertheless, as highlighted in Chapter Three, the regulations have placed increased pressure on would-be parents and donor-conception families, thereby creating tension for them. The HFEA advises would-be parents:

It is certainly best to be open with your child/children about the circumstances of their conception. Secrecy on this subject isn't in their interests and they will have a right to find out about their origins from our register when they reach 18 . There is evidence that finding out suddenly, later in life, about donor origins can be emotionally damaging to children and family relations. So it is in your child/children's best interest to tell them early in childhood. It is vital that your child hears about their donor from you and not from other people (HFEA, 2008c [emphasis added]).

During the donor anonymity debate, parents who intended to keep donor conception a secret were accused of violating moral standards. As I pointed out 
in Chapter Three, Baroness Warnock's speech in the House of Lords during the debate on the new regulations could be said to exemplify this view: "it is deeply morally wrong to pretend that a child is the son or daughter of a father or mother who is not his or her real biological parent. To insist on pretending shows self-interest on the part of the parents-that they are interested in their own status, not that of the child... To treat a child as though it were a toy or a pet--to suggest that it does not particularly matter where it came from because it is your child-is genuinely immoral" (HL Deb, 200304b), emphasis added). It seems that both the HFEA and Baroness Warnock are warning parents against non-disclosure. Some parents' inclination towards secrecy is condemned: disclosure is considered to be in best interests of the child. Nevertheless, as we shall see, the participants' understandings of welfare and kinship are different from those of the policy makers.

It seems to me that Goffman's observations help to explain the dilemma that would-be parents have about disclosing to the child:

[A] child with a stigma can pass in a special way. Parents, knowing of their child's stigmatic condition, may encapsulate him with domestic acceptance and ignorance of what he is going to have to become. When he ventures outdoors he does so therefore as an unwitting passer, at least to the extent that his stigma is not immediately apparent. At this point his parents are faced with a basic dilemma regarding information management, sometimes appealing to medical practitioners for strategies. If the child is informed about himself at school age, it is felt he may not be strong enough psychologically to bear the news and in addition may tactlessly disclose these facts about himself to those who need not to know. On the other hand, if he is kept too long in the dark, the he will not be prepared for what is to happen to him and, moreover, may be informed about his condition by strangers who have no reason to take the time and care required to present the facts in a constructive, hopeful light (1963: 113). 
Children are not as skilled at information control as their parents. As some participants suggested, a child might not be able to judge with whom she would like to share such information. If the donor-conceived child is told about her origins, especially at an early age, she might be willing to share the news with everyone she knows, including those who can use this information against her, or those who does not need to know. She might be bullied at school, or be overwhelmed by questions concerning her origins. On the one hand, the stigma can be easily concealed; as long as the donor conception is kept a secret, the family can appear normal. On the other hand, if she is not told about her origins at an early age, she might be devastated when she is finally told, because she was "kept too long in the dark". Moreover, she can find out about her origins by accident, which might be even more traumatic than the fact itself. The remainder of this chapter deals with dilemmas in the disclosure decision.

\section{Parents' right to pass information on child's behalf}

Lindsay, who had a daughter, Sandy, as a result of embryo donation, told her "you came in a different way, you are special". Sandy is now four years old. Lindsay still struggles about how to manage the information about Sandy's origins:

I am struggling...that is, you know I have told people information that is basically Sandy's information and that is where I have the dilemma. Because she is not old enough to know who she would like to tell, and who she would not like to tell. And I am doing it on her behalf... And the information, once it is out you can't get it back. That is the reason that I keep cautious, not anything to do with me but because she might not want anyone to know (Lindsay). 
Lindsay expresses concern that Sandy is too young to control information. She believes that her daughter has a right to know, but as a parent, Lindsay is responsible for how this information is controlled without causing any harm to her daughter. In other words, she is not willing to give autonomy to her daughter at the expense of her welfare. Moreover, she is not certain about how to control information on Sandy's behalf. Lindsay thinks that this information 'belongs' to Sandy. She says of her daughter:

She is not of an age that we can discuss it with her. So I think she has a right to know, but I am not sure if I have the right to pass that information on behalf of her. I do believe that it is Sandy's information. I am not worried that people look down on me if the find out, that doesn't worry me at all. But she might be telling to people at age seven, and then, when she reaches age fourteen: "oh, I don't want people to have known". Because she is young, she is not old enough to understand the full impact of what happens when you talk to people (Lindsay).

Two years after Sandy was born, Lindsay and her husband also adopted a baby boy from South Africa. Their son, Martin, is black and, as Lindsay points out, it is quite evident to everyone that he is adopted, given that the rest of the family is white. On the other hand, their daughter is white so there is no reason for anyone to suspect that she is not genetically linked to Lindsay and her husband. The couple agree that their children should be told about their origins. They have a conflict, however, on what information should be shared with other people. Lindsay's husband believes that it would be fair that they reveal how their daughter was conceived, because the fact that their son is not genetically related is evident to everyone. However, Lindsay thinks that they should be more cautious about disclosing their daughter's origins because, 
unlike their son, their daughter should be given an opportunity to control this information:

My husband has a stronger view on whether we tell anyone and everyone. We are both white, so is Sandy. Because Martin is black, the whole world knows that he is adopted or came from somewhere else. Just because Sandy has the same colour with us people assume the opposite. He [my husband] thinks we should tell everyone. But I think, it is really Sandy's information. If I could, I would not tell everyone that Martin is adopted, either (Lindsay).

Alice has a similar dilemma about revealing the information about her twins' origins. Alice got pregnant using her late husband's frozen sperm and donor eggs. She notes that her twins might have trouble with the fact that their father passed away before they were born. Therefore, she wants to wait for the right time before telling the children about their means of origin. She expresses concern that if the egg donation is known, she cannot avoid her children being bullied at school by other kids. Hence she has shared her treatment only with immediate family and close friends:

They're gonna have enough trouble with not having... and their father passed away before they were born. If they come to an age I wanted it to be...I know how easy it is... I know everything that keeps the child at school, pick on things, this will be a big thing really (Alice).

Alice is planning to write a book about her journey in seeking treatment using her deceased husband's frozen sperm. She stresses that Diane Blood's case is her inspiration and she wants to give hope to people who have a similar situation to hers. ${ }^{55}$ In fact, she was tempted to make a documentary with the $\mathrm{BBC}$ about her conception. However, whilst she was willing to talk about how 
she got pregnant using her late husband's sperm, she did not want to reveal the fact that she received donor eggs. Alice did not want to make this particular part of the treatment public before her twins were born and told about their origins. The $\mathrm{BBC}$ did not accept her terms and her plans to make a documentary have not materialised.

I was at the beginning stage of making a doc with BBC. One thing I wanted them not to mention I had egg donation :I don't want the world to know before my child knows, when I consented to my child, using my husbands sperm I am fine. I really want to encourage them to do but BBC was not happy with keeping the whole donor egg thing confidential (Alice).

Lindsay and Alice regard the information about the donor conceived child's origins as the child's own information. They are therefore reluctant to pass this information to other people on their child's behalf. They also express concern about a child's competence in managing the information. Young children may be eager to share the details of their origins at a young age. But once they start to realise the content of the information that they have been sharing with everyone, they might feel that they have made a mistake. And, as one participant says "once the information is out, you can't get it back". These parents are concerned not to give the child greater autonomy 'at any cost'.

\section{Having the genetic parent in the picture}

It might be expected that parents who lack a genetic link with the child might be more anxious about kinship issues than natural-conception families. Fiona's consultant told her that the donor-conception process would lead to a normal

${ }^{55}$ Dianc Blood was permitted to export the sperm of her deceased husband from the UK to 
pregnancy; she would feel like a biologically related mother. However, once she becomes a parent she is expected to think about disclosure. In other words, although she has been told that she will be the 'mum', she still will not be able to enjoy normal parenting.

My consultant spent a long time telling me the things we would be saying, before. I would be the biological mother, that the embryo can't survive without me, my blood feed it, I carry it, I give birth to it, I am the mum. She, my consultant have spend a long time really impressing that upon me, to trying help me to come to terms with egg donation and then, to feel then I have to treat my child differently from the way other parents can treat their children. It is sort of a little information that's he has given me. On the one hand they are telling me oh yes, you'll be the mum, you give birth to it. That's all it counts, that sort of thing and on the other hand, they are telling you what you have to tell your child (Fiona).

In donor conception, because of the intimate nature of the transaction involved, the donor still remains a 'parent' of a kind, but overall a parent without rights and "therefore presumably without obligations toward the child" (Strathern, 1992: 176). For some of the would-be parents in this study, the fact that their child can contact the genetically related parent(s) is deeply worrying. For example, although Fiona expresses the view that the resultant child will be biologically related to her, and therefore the child does not need to know his donor origins, she also reflects on her fear of the resultant child wanting to meet the donor. Her narrative contains a scenario in which she describes the feelings of the egg donor. In this scenario, Fiona pictures the egg donor as someone whose child was taken away. By the time the child finds out about the donor a reunion will be inevitable, which will cause the donor pain, especially if she does not have a child of her own. Clearly, this scenario is not impossible

Belgium in order to receive treatment there that was unlawful in the UK. 
- especially in egg sharing, where the donor does not know whether the recipient got pregnant with her share of eggs.

I think I would always worry if... it is the kind of thing that a teenagers go through back in your face at some point, "you are not my mum anyway", and it is the kind of thing that how would I feel if that child than go looking for the donor in the future and also what sort of reaction they might give meeting her, if that donor are usually having IVF and so if that donor gone on and have no children, and I have a son or a daughter through that donor. How are they gonna feel when this child turns on their door step? That must be an awful situation to be in (Fiona).

Fiona empathises with the feelings of the donor who has remained childless, and she notes that one cannot come to terms with childlessness, but one can move on. Nevertheless, if the donor meets with a child who is genetically related to her, she might have difficulties in coming to terms with the truth. In Fiona's opinion, disclosure is opening a can of worms, as it will not only affect the parent-child relationship but also will upset the donor.

Just sort of 18 years later not come to terms with childlessness, cause I don't think you do, but find a new way of life and all of a sudden this child turns upon your doorstep. That you have this child walking around with your genetics in 18 years. I think that must be very, very difficult for the donor to come to terms with, as well. I just feel in some ways to tell children, to open up to lose the anonymity it is opening a can of worms to the future as well (Fiona).

Fiona notes that her decision 'not to tell' is an emotional decision rather than a rational one; it is a way of protecting herself:

You know in theory my head agrees but my heart doesn't. My heart feels like I want to it is a case where I protect myself in a way. I don't want the child I gave birth to just feel I need to go and look up 
somebody else when they turned 18. It is more of a protection again, for myself (Fiona).

Pennings (2000) argues that "the general intention behind the organization of the procedure is to make the donor invisible and to conform the new-founded family to the ideal of the natural family" (2000: 508). An unknown, depersonalised donor allows donor conception to be seen as a medical process and supports the normative formation of family (Grace, Daniels and Gillett, 2008). Most participants in this study prefer anonymous donors. For example, Rosie notes that she would prefer her donor to be anonymous because she would not want the donor get involved in her child's life:

I wouldn't want this aspect of someone having some kind of claim on my child and...If I had a child so...yeah. I - I again, if it was like surrogate and you really knew the person and it would be maybe different although it would be somebody I knew or relative, I think it would be different. But if it is just somebody I knew, sort of could contact them but you wouldn't want them getting involved. I think that would be much worse than just someone who is anonymous (Rosie).

Rosie notes that she would tell her children that they were donor conceived, but from her 'selfish' point of view, she would prefer using an anonymous donor to avoid her children contacting the donor:

I- So you would tell the child how they were conceived but would not tell them they have an opportunity of contacting this person?

R- No, not really. No. I suppose maybe for the child it would be... I just didn't go through the whole thought process that much it is not something that I want to think about that much it is very difficult to imagine. I just don't know how whether this child would prefer to know. I mean I suppose they would ...so is most of children probably would if told them that they would want to know they would. It is a natural instinct to say, "who is my real, my genetic mother?" from the child's point of view it would be even worse it is worse but from my 
point of view, from my selfish point of view I prefer them to be anonymous (Rosie).

Tina's case is a good example of the complex relationships that embryo donation generates. Tina received anonymous embryo donation and had a baby boy as a result. If the donors were known and relationships were established between these two families, her son would have two pairs of parents: Tina and her husband as social parents, and the donor couple as their biologically-related parents. Had the couple who provided the embryo had their own children, Tina's son would have sibling(s) as well. Under these circumstances, Tina's son would already have parents, siblings and probably other relatives such as grandparents, uncles and aunts to whom he is genetically linked. By getting treatment in Spain, and using embryos from an anonymous couple, any potential social connection which would challenge her nuclear-family structure has been avoided. Recently, Tina went back to Spain and got pregnant using another embryo donated by the same couple, so that her son can have a biologically-related sibling. She is not planning to disclose to her children about their means of origin.

In the following extract, Tina comments on the arrangements that need to be made:

We will destroy every piece of paper that got my name on it. My GP knows, and my consultant knows, but these records are sealed. The child cannot get an access to them. Even they did they could still not find their parents. You can't. It is illegal. You cannot do. It is sealed. Unless there is a severe genetic thing at which point doctors in Spain would investigate for you to find you but they can't find that anyway, the doctors in Spain would not tell them (Tina). 
Before she received embryo donation, Tina considered using donated eggs. She says that she was concerned that the egg donor would be waiting for the child to turn up. Tina mentions that egg donors write emotional letters to their prospective offspring, which she finds "very off putting". She describes the donor as an alternative 'mummy':

What you will find very off putting is ...women donating will do a long emotional letter to their child about how much they love him, and valuing him... and they are waiting for him...with their open arms which is the last thing you want if you are already a mummy: "oh, by the way there is another mummy waiting for you!"'(Tina).

Interestingly, the posts of donors on Repromed discussion forums which I presented in Chapter Five also showed that donors found writing these letters to be challenging. Writing a letter to an unborn child made them feel like they were "giving away a child". It seems then that the donation culture that the UK government aims to create is far from meeting the expectations of the parties who are involved in this practice.

Lindsay received embryo donation from semi-known donors. Since then, the donors have been a part of their lives. The donors made sure that Lindsay and her husband were Jewish, they checked the couple's bank statements to make sure that they had enough money to look after the resultant child, and even decided on how many embryos should be implanted: "The donors said maximum two. They had twins and they thought it was more than enough." Lindsay agreed to receive embryos from this couple because it was quicker than any other treatment method. She says: "believe or not it [embryo 
donation] ended up being a faster way of having a child." She narrates her experience as follows:

I started looking into Internet, and I eventually found people who were willing to donate embryos to us and that could happen straight away. Somebody said there was a couple, they were posting that they had Jewish embryo that they wished to donate. They were looking for a Jewish couple. I am Jewish, my husband isn't but I considered it anyway. The story was that they had these embryos, they had these embryos from an infertility treatment and they wanted a known donation. They didn't want an anonymous donation. They didn't want to give the embryos for research... They wanted to know what kind of people we were, how much income we had was it enough to support a child, little bit about our families. They weren't religious, we are not religious but they wanted some kind of continuity. The situation in the UK was I wanted a known donation. I wanted to know where my embryos or my donor eggs were coming from. In the UK it wasn't possible. The descriptions you were given is the woman is a nurse, and the man is a carpenter. And you can have those embryos, you must be able to. And that was very unsatisfactory for me (Lindsay).

Since the birth of their daughter, Sandy, Lindsay has been in touch with the couple who live in America. The donors also have a daughter two years older than Sandy and Lindsay thinks the two girls look exactly the same. Lindsay sent Sandy's pictures to the donor couple but beforehand some members of the family issued warnings about this:

My brother's wife said don't send her [Sandy's] pictures to them, and if you send the pictures make sure that you are in the picture, too! (Lindsay)

Sending pictures might have consequences. For example, having noticed the resemblance between Sandy and their daughter, the donor couple might want to be a part of Sandy's life. They might see Sandy as a child who was given away. Therefore, if pictures must be sent, Lindsay should be in them in order to remind the donor couple that she is the 'real' mother. 
Bette used donor sperm to get pregnant. (By the time of the interview, her partner was planning to use the same donor's sperm in the future.). Bette notes that she will be open with her child about the sperm donation. Being in a samesex relationship, she notes that she and her partner do not consider disclosure as an issue; the child can figure out that a donor played a part in its conception. Nevertheless, she says that she does not want the child to contact the donor until $\mathrm{s} / \mathrm{he}$ becomes an adult in case the donor gets involved in their life. Bette expresses the view that the child will not necessarily want to contact the donor:

B- Most children even if they do know choose not to contact anyway. That's sort of interesting. I am sure I would feel a little bit funny about it when they do it... if they decide to make contact but ...I don't think it is as bad I don't think as threatening in our case because neither of us...you know...a dad. So I'd be alright ...yeah it would be...it would be very interesting... yeah I think I'd be fine.

I-I thought you said you didn't want father to be involved.

B- Yes...but I think once they turn into adult it is a bit different.

Some participants who indicated their intention to disclose had not decided on what information should be revealed (e.g,. that the child was conceived with 'medical assistance', that the child was conceived with help of 'a' donor, that the child was conceived with help of an 'identifiable' donor), or when to disclose. Another concern was whether the child would understand her means of conception. For example, Hannah, who used surrogacy and donor eggs, had disclosed to her children. However, she said that her children were a bit young to understand what they were told: "they are obviously bit young to understand." 


\section{Accidental disclosure}

Having had treatment in Poland, Alice notes that the eggs that were used in conception were donated by a Polish donor. She stresses that her twins will be half Polish and her children have a right to know that they have a Polish background. Even if she does not tell them, she fears that her children can find out about their background by genetic screening. Accidental disclosure might have negative consequences:

In terms of genetic background, yes they would know genetically they are half Polish. Nowadays there is so much genetic testing going on. You can't take the risk that your child find out what's going on. Their trust in you will be shattered (Alice).

Despite her worries, she thinks that knowing one's origin is a right, and accidental disclosure can hurt the child:

I would definitely disclose ${ }^{56}$ to my child. My child will know this special lady who donated made their lives possible. I think it is very important to explain in a natural way. I suppose my experience is my sister was adopted. I wouldn't do any other way (Alice).

Fiona is also anxious about accidental disclosure. Her account indicates that she and her husband are reluctant to tell anyone about donor conception to prevent the child from finding out about their origins by accident from a member of the family or a friend "as secrets have a way of coming out":

It is a hard one. Our gut reaction at the moment is that we don't want to tell. We don't want to tell the child, we don't want to tell our families, we want to keep it between ourselves but at the same time we also feel

\footnotetext{
${ }^{56}$ Donor anonymity operates in Poland so the identity of the donor will not be available to the twins. As discussed earlier, the content of the information that is available to the offspring is of great importance: for many would-be parents' anxiety stems from the possibility that the child may want to contact the donor.
} 
it is probably would be best to tell the child because secrets have a way of coming out don't they? (Fiona)

By the time that the interviews were conducted, Rosie had postponed her treatment for a while. She said that she only thought about disclosure theoretically. She had come across an article in a woman's magazine about children who had a 'terrible' reaction to accidental disclosure. She noted that, as her family and friends already knew about her treatment, the resultant child could find out about its origins accidentally, which would cause him/her to suffer:

I think that obviously it is only theoretical, and I thought about it theoretically yes, I would certainly like to think that I would tell them at some point about how they came about, because I think it is something that will be so terrible if it came out some other way and of course because I had told some people and told family it is possible that those things can come out. And I think if that was to come out and my mistake, and my child didn't know, I think that would be such a terrible having been aware of certain things like that articles about I mean I read many things. I remember reading an article in magazine like Marie Claire or something about children of donors basically sperm donors, and there were two people, and they had different reactions one of them, you know really had a terrible reaction. The other one had really been ok about it and didn't have a problem with it but I think it is really terrible to have secrets in family, and I think you know, if you find a way to tell a child when they are quite young...but of course it is all very theoretical for me (Rosie).

The participant accounts show that disclosing to the child and disclosing to the family and friends are not entirely separate issues. If family and friends know, there is always a risk of accidental disclosure to the child; if the child knows, it may be only a matter of time before s/he spreads the word. 


\section{The truth may hurt the child}

Some participants express the concern that if their family know, the grandparents might perceive the resultant child differently from their other grandchildren to whom they are genetically linked. Fiona, for example, fears that her parents may treat her child differently than her brother's children:

I am also concerned about how my parents will react for example. I've got brothers when my brothers go on to have children. Will they treat my brother's children differently to mine, knowing that they are related to my brother's children and not to mine (Fiona).

Some participants stressed that knowing their biological origins was of no significance in children's lives; it is social parents who give a child its identity. Tina has two step-children from her husband's previous marriage. When she and her husband could not conceive, Tina thought that there was something wrong with her. However, during the tests it was revealed that her husband could not have been a biologically-related father to his two children because he was sterile. They decided not to say anything to the children. They have the same attitude towards their unborn child; he will not be told about the embryo donation. In the following extract, Tina explains why children should not be told that their biological parents are different from the ones they know. She thinks that telling the 'truth' would cause nothing but pain:

You don't want to break a child's heart when they are 18 by saying you are not mine. There is no point in that [...]I understand what they are saying. But I think that being parent isn't about who gives the egg or sperm, it is about bringing up a child... and I don't see what difference it makes in their lives if you don't say that's not your biological dad...If we told these children now that's not your daddy how would it help them? They say it is for child's benefit. I can't see that because if you destroy child's confidence by saying that person you thought it was 
daddy since you were...he has done everything for you. But it is not your dad and the other person did an unselfish act made a donation, he doesn't want a responsibility, does he? I just think what it would cost? What would you gain from it? Who gains? (Tina)

\section{The disclosure policy and discrimination}

Donor conception families have been under the focus of psychologists who have attempted to understand their functioning (e.g., the emotional experiences of the recipients, the relationship problems of partners, disclosure to the resultant child and the psychological health of donor offspring). In recent years, particularly since the donor anonymity debate started, there has been an increasing focus on such families as a result of official concern about the welfare and rights of donor offspring. The UK government and the HFEA seem to be certain about how these children's rights should be protected: children who are born as a result of using donor gametes or embryos should be told that they can access identifiable information about their donors at a young age. Usually, parents decide autonomously what secrets will be kept from their children. They may agree to withhold certain facts from their children to protect them from feeling different. A baby might be a result of an affair for example, or sexual violence. Although 'natural-conception' families can employ information-control without constraint, the current law places an ethical demand or obligation on donor-conception families to disclose origins to their child. The accounts quoted in this section document the participants' responses to these demands. 
Goffman (1963) argues that in many cases the stigmatised person may exhibit all the normal prejudices held toward those who are stigmatised in another regard. As I showed in Chapter Six, the participants perceive using donor gametes/embryos as deviance and, hence, potentially stigmatising. Invoking a counter-morality that denies their deviance, they compare their condition to another potentially stigmatising condition and conclude that donor conception is not as morally unacceptable as, for example, having a child as a result of a one-night-stand. In a way, they present donor conception as a more 'normal' (socially acceptable, or morally correct) way of family-building than certain ways of natural conception (i.e. having affairs or short term relationships). In the following extract, Tina talks about how some family-building practices before the arrival of assisted reproductive technologies. She says that in the past, if one wanted a child, one could have an affair, and this would be unspoken. She points out that the removal of anonymity does not apply to people like her husband's ex-wife, who got pregnant as a result of an affair:

I often wondered people like my husband's ex-wife. If you try for a few years and find that you can't... She obviously didn't know [that he was sterile] about him. How many women go out and seduce some bloke? You want a child, and how many, you wonder say in 1960s or something...It was an unspoken thing, if you find out that the man had had a problem, then the woman turned to see... She went off, have a little fling. Cause in those days you would expect a baby in a year. You wouldn't wonder how many women just go out... and men knew it... sort of...didn't say anything (Tina).

Fiona points out that the government does not intervene in other areas of family life and do not tell people how to bring their children up. She stresses that she is doubly discriminated against: nature has discriminated against her. and now it is the policy makers who remind her that she is different. 
The government don't tell in other areas of family life. They don't tell people what they must tell their children or how they must bring them up. So when you are already had such a battle, by the time we get another donor now and if we go through a cycle of successful we will be been trying for a child for nine years. Now, that itself is hard enough and put an enormous strain on a relationship as well. Being dictated what you have to tell the child it doesn't seem right to me. People have accidental pregnancies or you know, they just decide they want to have a baby therefore they get pregnant straight away. They are not told what they have to tell their children. I just don't feel like there should be any difference. [...] Nature already discriminated against me and it feels like the law was written that way as well (Fiona). [emphasis added]

Fiona and her husband have been foster parents to nine children. None of the children knew who their father was. Like Tina, Fiona also comments that the state does not intervene in disclosure matters if the family is built through natural conception, regardless of the means. Fiona expresses the view that the disclosure policy is not only discriminatory against those who use donor conception, but also against the resultant children. Her foster children do not know who their fathers are, because their mothers were not encouraged to be open about their means of conception:

Another thing that makes it more difficult for me is that the foster children I have. In every single case we had nine foster children and in every single case none of them have known their genetic father. They have all been a result of one-night stands or short relationships and the government isn't there, telling these mums that they have to provide their children with genetic background so... I can't help feeling a bit discriminated against. The young girls that we've got fostering at the moment they have no dads, there is six children in their family from the same mum with six different dad. Not one of them knows their dad and you know, their mum isn't forced to reveal anything to them, or even tell them the names of their dads or anything. And they know nothing about their background on their paternal side. So I do feel a bit sort of preached to be told that I have to tell any resultant children...You know, when there is so many people they don't tell their children thing it does feel a bit discriminatory, I think. The foster children I had, and they are not allowed any genetic information, their mummies aren't 
forced to give them and neither can she because in the case of youngest two, they were from one night stands, she doesn't even have names for these children. So if that's ok for these children and then it should be ok for mine. At least mine are wanted children and they are gonna be brought up in a stable mother and father relationship unlike the foster children we have (Fiona). [emphasis added]

The participants' accounts contain a comparison of the rights of donorconceived children and naturally-conceived ones who do not necessarily know their origins. As I showed in Chapter Three, during the donor anonymity debate this sort of comparison and moral justification was condemned. Baroness Warnock argued that there could be no "moral justification whatever in deceiving a child about the circumstances of his birth" and it was a "very awkward doctrine to enunciate, considering the number of children born by adulterous relationships" (HL Deb, 2003-04b) [emphasis added].Warnock's speech presupposes that "a single way of organizing the family will and should work for everybody" (Pennings, 1997). Such a moral position condemns donor-conception families for exercising their right to organise their life according to their own moral principles and creates anxiety. For example, Fiona argues that the disclosure policy makes her "rebellious" against openness. She would be more positive about disclosure if she were not "forced". Although under the current legislation she is not compelled to tell her donor-conceived child about its origins, Fiona feels that she is "dictated", "forced" and "preached to" about disclosure:

I am not against it [disclosure]. I do think it is child's best interest to tell, I really do but that's an intellectual decision not an emotional decision as regards actually telling the child. If we are lucky enough to have one in the future, I hope I will, but I know that I would be really worried about telling and I certainly don't like being forced to tell. I also think that we would come around to that conclusion a lot quicker if 
we weren't forced to tell. We would estimate that decision as good sensible parents. I think we would come to the right answer but being forced to tell sort of makes me back away, you know, makes me want to do the opposite, makes me feel a bit rebellious as well (Fiona).[emphasis added]

Pennings (1997) argues that in a democratic system although the majority has the political right to impose its views on the minority, a number of important ethical values should be considered: autonomy, tolerance and respect for different moral positions. Pennings goes on to argue that "imposing a moral opinion on persons who do not share this view increases the risk of conflicts" (1997: 2690). The potential consequences of such conflicts are obvious: the accounts quoted above suggest that the new disclosure policy may be increasing subterfuge rather than openness.

\section{Conclusion}

As I explained in Chapter Three, advocates of the disclosure policy suggested that infertility and donor conception would become less of a taboo subject and less stigmatising, and that removing the donor anonymity would further help to ease the stigma. It is unlikely that the new law will achieve this. As indicated by the participant accounts in Chapter Six, the reason for the initial secrecy derives from the deep individual and private pain felt by those who find themselves infertile (McWhinnie, 2001: 814). Having a donor-conceived child affords individuals and couples a cloak for this. The participants in this study employ information control strategies to conceal their infertility and the origins of the child from their social contacts or from the child herself in order to manage stigma. If donor conception is kept a secret, the family and the child 
may pass as normal. The new law may therefore reinforce stigma rather than remedying it.

Although policy makers and experts assert that information control is not in the best interests of the donor-conceived child, would-be parents operate with notions of what 'any' parent would do under such circumstances. Accordingly, they use strategies that are employed by anyone in society who finds themselves discreditable in any phase of their lives. By concealing potentially stigmatising information about the child's origins, they want to protect the child and their family from harm. Disclosure to the child is a complicated decision and it appears to be an ongoing process. For that reason, neither the accounts of Repromed users, nor the interview accounts, claim to be a definitive statement of prospective parents' disclosure decisions. However, these accounts clearly demonstrate that this decision is not straightforward. Some parents are concerned with protecting the child from being stigmatised, not being treated as a 'monster'. By withholding information on their child's behalf, the parents can protect their children from feeling "tainted" (Goffman, 1963). Some participants feel that the child is not capable of understanding and controlling the information that is disclosed her. Some consider that this information belongs to the child and they have no right to pass on the information on behalf of the child.

On the one hand, there is increased value being placed on genetic parenthood. On the other hand, however, there are increased possibilities of assisted 
conception using donor gametes/embryos. These facts resolve into a single answer: "the parent must be the one who desires to be a parent" (Strathern, 1992: 178). The accounts in my study show that this approximation is not straightforward under the new law. Although the law is based on the principle that the parents will be those who intended that a child would be born to them, there is still equivocation given that they do not supersede the 'genetic parents' (Strathern, 1992: 178). In an anonymous donation system, the genetic parents remain invisible and disclosure can be manageable, whereas if the donors are identifiable the consequences of disclosure may be less predictable, for example the child might want to meet the donor. Not being genetically linked to the donor-conceived child might lead would-be parents to feel threatened by the presence of a donor in the child's life. For some of the participants, the fact that their child can contact the genetic parent(s) is a very real threat. Arguably, such anxiety may also constrain disclosure: they want to protect their fragile identity as parents. As I explained in Chapter Three, during the donor anonymity debate, adoption was regarded as a morally and psychologically relevant model for approaching the need to find out identifiable information about their origins that was claimed by some children born through donation: the recipient couple raise a child that is genetically related to the providing couple/or a donor and who may have full/half genetic siblings elsewhere (MacCallum and Golombok, 2007). This situation, however, does not parallel adoption because the recipient mother is also the gestational mother, and the birth story of the resultant child does not involve relinquishment. It is then questionable whether donor offsprings' interest in knowing their origins is identical to that of adopted children and whether would-be parents should be 
given the same advice as adoption families about disclosure. Donor conception is an approximation to normal parenting and to the nuclear family structure; the participants in this study received gametes/embryos to protect this structure. If the child is told that she may contact her donor, she may attempt to find her 'genetic parents', not necessarily because of a 'natural' desire to know her origins, but because such a desire is constructed, recognised, and legitimised by the law.

Although people are usually entitled to control discreditable information in their everyday lives, donor-conception families' are advised not to do so. Some of the accounts document the participants' frustration and anger about being treated differently from 'normal families'. Some participants consider that the disclosure policy discriminates against donor-conception families by comparison with those with naturally conceived children who do not necessarily know their origins, either. People who conceive naturally (but for example, as a result of an affair or a one-night stand) are not told what to tell to their children. The policy reminds the donor conception families that donorconceived children are different from others (they are ascribed different rights such as knowing their means of conception), and this difference must be displayed if they want to be the family that policy reformers have idealised. Overall, the accounts show that disclosure is perceived as a matter of information management, rather than an absolute right that should be given to the child at any cost. Disclosure cannot, then, be imposed on donor conception families as a moral obligation. As Thévoz (1997) points out, openness and truthfulness in family relationships and respect for the child's autonomy are 
ethical demands, which are almost impossible to convert into a legal obligation.

A major question that I wanted to answer during the interviews was why, given their concerns about the disclosure policy, the participants did not raise their voices during the debate? One reason behind their reticence may well be the fact that would-be parents are caught in a vicious cycle. Those who are affected by the policy change may also be the ones who have confidentiality concerns and who cannot face publicity. As one participant notes:

It is a catch 22 situation. If you like it if you kick up a fuss about it, you gonna have to make yourself known, which defeats what you are kicking up a fuss about (Fiona). 


\section{CHAPTER EIGHT: FERTILITY TRAVEL AS AN AVOIDANCE STRATEGY}

Throughout this thesis I have studied the removal of donor anonymity as a social problem which is not or cannot be articulated by would-be parents in formal modes of communication. I argued that the views of these stakeholders have escaped the public eye. In Chapter Three, I argued that the socio-political climate was not ideal for these stakeholders to press their claims. I also argued that due to the perceived illegitimacy of their claims and their confidentiality concerns, would-be parents used alternative modes of communication to lodge complaints and exchange views about the donor anonymity problem. In Chapter Five, I presented an ethnographic study that I conducted on an online support group, Repromed, and showed that, despite their silence during the debate, would-be parents continue to protest anonymously against the new law on the discussion forums of online support groups. I argued that, for members of marginalised groups like donor conception families, narratives maybe the only means of making their voices heard. The interview data I presented in Chapters Six and Seven exemplified alternative forms of claims-making activities. In these chapters I showed that most participants did not want to use gametes/embryos from identifiable donors, because they wanted to keep donor conception as secret to protect their children from being marked out, bullied or stigmatised. Drawing on Goffman's Stigma (1963) theory, I argued that information control in donor conception families was not idiosyncratic and parents with a donor-conceived child operate with notions of what 'any' parent 
would do under such circumstances (Voysey Paun, 2006). Would-be parents want to conduct their family affairs autonomously as normal families: therefore they felt discriminated against by the new law that potentially requires them to be open to the resultant child about his/her means of conception.

Spector and Kitsuse (1977) argue that social problems which do not get recognition may develop in two directions: First, the stakeholders may create alternative institutions to represent themselves as a means of developing a social and political base for changing the existing policy. This option was neither possible nor desirable for these stakeholders. Secondly, the stakeholders may base their activities on the contention that it is no longer possible to work in the system. The stakeholders may withdraw from the institutional system to create alternative institutions as limited solutions for group members. Would-be parents in the UK have readily available alternative institutions. The national regulatory restrictions on availability of infertility treatment have created an international market for services. European law guarantees free movement to avail of services lawfully available in other Member States, including medical services such as infertility treatment. Growing numbers of would-be parents, including Repromed users and interview participants, exercise their right to seek cross-border treatment. 


\section{Fertility Travel}

Health travel owes its existence to the lack of world-wide legal consensus on treatments which will be provided. There is also a cost dimension: the costs of treatment may vary considerably from one country to another. Pennings (2002) argues "allowing people to look abroad demonstrates the absolute minimum of respect for their moral autonomy" (2002: 341). He suggests that what drives people abroad to seek treatment is not necessarily laws but "may also be the personal moral convictions of the health care provider, institutional policy guidelines, and recommendations by committees" (2002: 337). The interview accounts show that the participants seek treatment abroad not necessarily because of the law itself (given that they are not compelled to disclose), but the socio-legal environment that requires them to display their differences.

\section{Anonymity of Donors}

In the UK, would-be parents who want to use gametes from anonymous donors have no choice but to seek treatment abroad. The state has stringent control of the procurement, testing, processing and distribution of gametes and embryos for human use: these services must be licensed by the HFEA or subject to an agreement with a licensed service. Imported gametes or embryos must also meet UK requirements, and all medical fertility and non-medical fertility services such as Internet sperm providers must comply with the UK standards. For example, even if sperm is anonymously donated in Poland according to the Polish regulations, UK would-be parents cannot purchase it online, or have it 
imported by their licensed clinic in the UK. They can, however, travel to Poland and receive donor insemination there in any clinic.
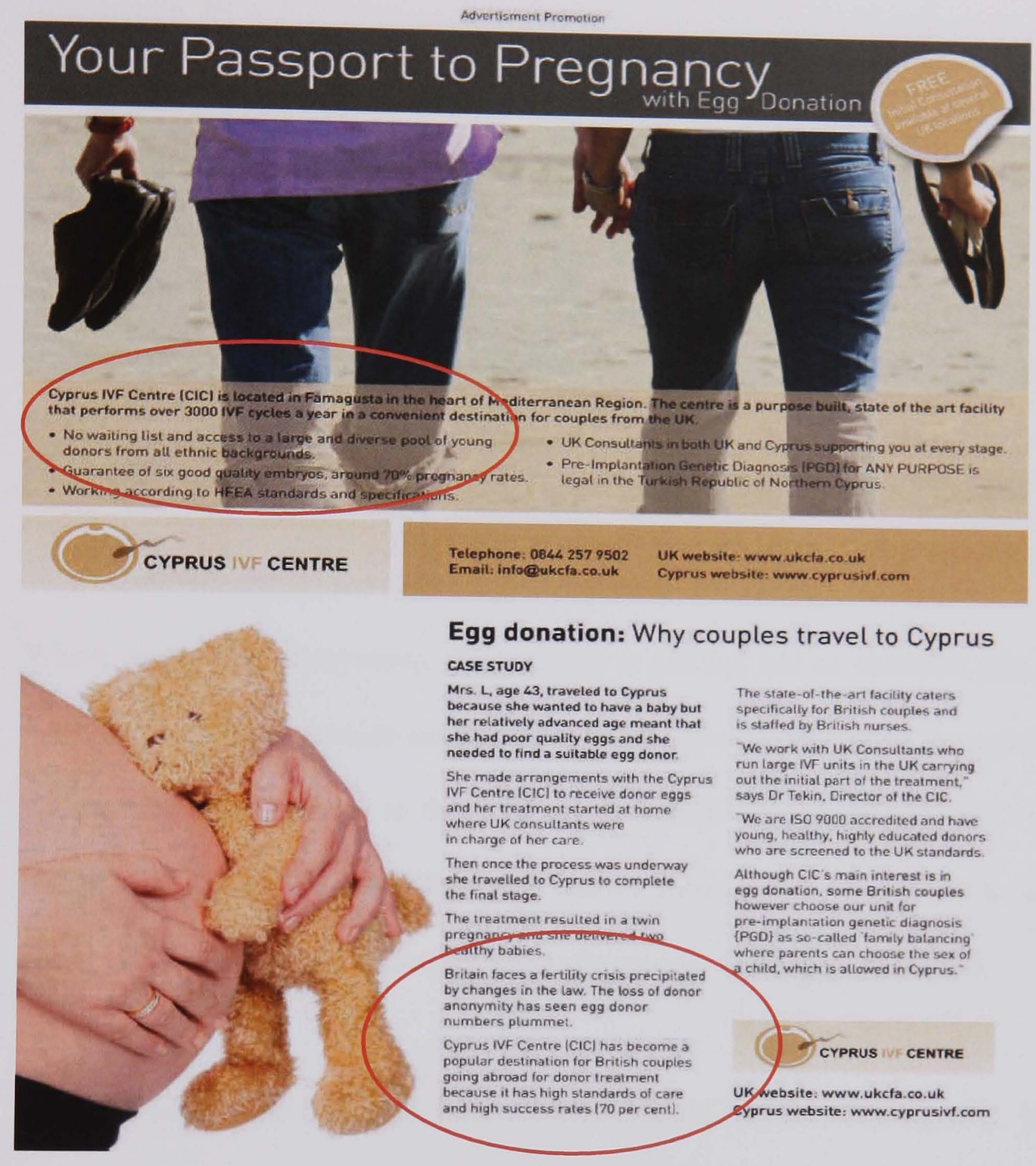

Picture 4: The advertisement notes that there are no waiting lists, and the patients have access to "a large and diverse pool of young donors from all ethnic backgrounds". It also notes that "Britain faces a fertility crisis precipitated by changes in the law. The loss of donor anonymity has seen egg donor numbers plummet". The clinic has "young, healthy, highly educated donors who are screened to the UK standards" and it claims to be working according to HFEA standards, except for the fact that donors maintain their anonymity in the Turkish Republic of Northern Cyprus. (Fertility and Pregnancy, Media Planet, 7 December 2008) 
It is important to distinguish disclosure of identifiable and non-identifiable information. By making donors identifiable, the law attempts to build a parental connection between the donor and the child, established by the passage of genes. O’Donovan (1988) argues:

[t]he only basis for a successful defence of gamete-donation is the outright denial that the donor is in any way personally present through his genetic contribution. We must regard the sperm and ovum rather in the same light as we would regard a donated kidney, as human material but not as personally human. Bodily spare parts are exchangeable because, although they belonged to someone in particular, and grew at the behest of his genetic constitution, they do not convey his genetic individuality (1988: 43).

Where donors are anonymous, the donation is nothing but an altruistic gift, or marketed service, to provide assistance to another person in conceiving a child, "to contribute one's genes to the creation of a child is not congruent with the social role of parenthood" (Wallbank, 2004: 260). Even the donors do not know whether or not their gametes were effective in achieving conception.

Tina and her husband had decided to receive sperm donation in the UK, but they changed their minds, and sought treatment in Spain, due to the removal of donor anonymity in the UK:

Even though we both wanted DI, the law was changing. We could find old donor sperm, you didn't have to tell. With new donor sperm you have to tell (Tina).

Some participants express the view that having access to a donor's identity and being told about donor conception are different matters: by removing donor anonymity, the HFEA risked the sustainability of gamete donation. For 
example, Alice is uncertain as to whether knowing the identity of the donor would make a big difference to the donor-conceived child. Alice states that policy makers should have weighed the cost of lifting anonymity for would-be parents. Disclosure policy, she thinks, is preventing couples from being parents:

\begin{abstract}
Although I can understand, you know, for a child it is important to know what the background is, it is not possible in some families, even in natural families and you have to weight out what the cost of removal of donor anonymity would be. It may make a difference it may not. Look at how many couples left in the situation who want to be parents, left in the situation where they have to wait long periods. [...] I know we all want to our children best we can but almost preventing couples to have the opportunity of becoming parents because... Because these couples want this baby, they... It is a tricky one. For me personally, I am a bit biased, coming from the point that I have donor egg I would say the disclosure policy is not the best policy that HFEA came up with (Alice).
\end{abstract}

Alice states that, instead of lifting anonymity, the HFEA could provide a detailed profile of the donor without giving identifying information:

I personally think that you can give information about donors without disclosing their identity if there is a way of doing at national level it is anything, the colour, hair colour, height etc., just knowing what kind of genetic background, did my father have the same, you know, eyes with me, what similar height. I think children who know that, it would suffice. Because we are not talking about adoption. If anything, knowing who the person is being born but not being born to that family knowing that different family. These children born of donor insemination, they won't know anything different (Alice).

Alice claims that donor-conceived children will be satisfied with knowing about the characteristics of the donor; they do not necessarily need to know the identity of the donor: 
Again going back to the whole child's right to know thing, I think there are ways that disclosing information without necessarily giving away the donors identity because I really wonder whether and it would be interesting to see whether it would make any difference to children who were born with donor egg or sperm to know who their donor is as oppose to the characteristics of about their donor...and some of them may not want to know who their donor is, and may just prefer to know the characteristics but of course we wont be able to tell that before 18 years of time (Alice).

She notes that the government removed donor anonymity based on an adoption analogy. She claims that this analogy is wrong because gestation distinguishes gamete donation from adoption: she carries the baby, she is going to give birth to the baby, and the baby will not know anyone else apart from her as mother:

I think they are taking back step from adoption. But it is not like adoption, because I am carrying this child. It is in my body. I will give birth to this child; this child doesn't know anyone else apart from me as mummy. That's not the case in adoption (Alice).

During the interviews other participants also talked about adoption cases in their family histories to highlight the differences between adoption and donor conception. For example, Fiona's father was adopted, and, when he discovered his birth certificate by accident, he was devastated. But Fiona stressed that her father never wanted to find out about his birth parents. Similarly, Alice's sister was adopted, and so was her father. She thought that at times her sister would wonder who her birth parents were but this never had a significant effect on her life. Tina, on the other hand, talked about the fact that her father abandoned her when she was a baby. She did not remember anything about her biologicallyrelated father, and she always perceived her step father as her 'real dad'. She stated that she neither wanted to meet her father, nor get to know him. She 
thought that people wanted to know their birth parents so that they could blame them for the troubles they had been through.

\section{Waiting Lists}

All participants have suffered from the donor shortage which they viewed as a consequence of the new law. Rosie claims that lifting anonymity has had a negative effect on donor recruitment in the UK. She compares the programme in the UK to that in Spain, arguing that the latter is successful because the donors are able to preserve their anonymity:

They say it [removal of donor anonymity] doesn't have any effect but I can't see how it doesn't. I mean I - I am sure it will. It is logical that and I am sure the programme in Spain would not be so successful, let's say if the donors were anonymous I think that they want to be anonymous. I don't think they want to be known or want to be contacted (Rosie).

Alice also claims that the removal of donor anonymity caused a reduction in donations because the open donation system in the UK frightens donors:

I don't think donor egg is allowed in Germany. So there is a lot infertility tourism going around all across the Europe and beyond some people go to Barbados. It is far reaching but how can you not equate the two? The removal donor anonymity will of course cause a huge deduction in donors who want to come forward, of course that will scare people and they are not going to want to donate. People who donate sperm have done it in past are frightened. People who egg share or donate sperm all have done so in the past are frightened, majority of them are. In 18 years past time this adult can come to the door step, say "you are my genetic father and mother", that's why (Alice). 
Alice wonders how the HFEA will respond to the statistics revealing the decrease in donor numbers following the removal of donor anonymity:

So it will be interesting to see what the HFEA confront with when they have to reveal statistics how many donors moved away to the... There is so much opportunity going on at this moment. The way HFEA operates today, their statistics not include anyone who has gone abroad for treatment. So that's just completely not part of research to them, "oh no one is going abroad for treatment, you know because we are not doing the research in that area anyway" (Alice).

Alice went to Spain and Poland, the countries that allow the treatment she needed (to get pregnant using the embryo which was created by insemination of her late husband's frozen sperm using donor eggs). She could have received the treatment in the UK, but she did not want to be on a waiting list for eggs. Alice states that it is the removal of donor anonymity and the long waiting lists which drive people abroad:

It is difficult because you know I can see what they are trying to doing but I just wonder, you know, whether, sorry to use this but throwing out the baby with the bath water really, because it is driving people abroad and I think because I mean just in the website on infertility friends that has doubled and tripled it is obviously growing. People are not willing to wait and you know 30 s $40 \mathrm{~s}$... They are not going to wait a couple of years they take the best option going to Spain, Russia or Poland where there aren't any waiting lists, cost is not a problem (Alice).

Alice notes that the idea of going abroad was suggested by an HFEA consultant, who thought that after the removal of donor anonymity waiting lists would get longer:

In Poland there are no restrictions on egg donation but the success rates are high. In UK removal of donor anonymity... and I was told by interestingly enough...HFEA consultant told "go abroad", and it was 
before the removal of anonymity. He said only gonna worst after the law comes. He was the first one who got me thinking go abroad (Alice).

Rosie states that due to the removal of donor anonymity waiting lists are long in the UK. Given her age, Rosie wanted to start her treatment immediately:

I knew that in the UK it was very difficult the whole egg donation thing and the UK, lack of anonymity there were less donors you know...just didn't seem... and I didn't want to wait any longer I wanted to get on with it (Rosie).

Regardless of their views for or against disclosure, both the users of Repromed and the interview participants considered that the disclosure policy had led to a collapse in donations.

\section{Donors with a physical resemblance to the would-be parents}

For couples who want to receive donations from a donor with a physical resemblance to them, the donor shortage in the UK is an obstacle. Clinics situated in countries where abundant supplies of gametes are available often promise to match the physical characteristics of the donors with those of the would-be parents. A brief review of the postings on message boards on the Internet indicate that clinics avoid making such promises in the UK due to the donor shortage. As I showed in Chapter Five, Repromed users express the view that the reduction in donors has also compromised their chances of finding a donor with a reasonable match to their own physical characteristics, or those of their partner. Accordingly, would-be parents might consider travelling abroad in order to find a donor who resembles them. 
Becker (2000) argues that the donor's physical similarities to the social parent are important because it gives the notion of biological continuity to the parents. She notes that having the child resemble oneself reduces the level of "cognitive dissonance" that social parents experience, as it is a cultural expectation that children resemble their parents. Becker claims "because use of donor gametes is less widely accepted than adoption, parents of donor children, regardless of their stance on donor confidentiality, want to maintain a degree of confidentiality about the child's origins" (2000: 162). For example, one of the reasons that motivated Rosie and her partner to get treatment in Spain was the likelihood of finding a donor who resembled their physical appearance.

I am not actually English racially. I am actually Jewish, Polish Jewish and my partner is quite dark skinned. I thought Spain....and we are not very tall...so we thought actually Spain is pretty good for us anyway in terms of matching. So I didn't look anywhere else (Rosie).

\section{Payment to egg donors}

This subsection deals with the payment to donors and helps us to understand how the participants present the commercial side of fertility travel. Although the question regarding payment to donors was not raised during the interviews, the issue was brought up particularly by the egg recipients. Donated embryos are usually 'surplus': couples who go through IVF may end up producing more embryos than they can use, and choose to donate some (for treatment or research), rather than destroying or storing them. In other words, embryo donors do not undergo treatment to donate their embryos. Sperm donation, on 
the other hand, is not considered as an invasive procedure. However, unlike sperm, eggs are not a self-renewing, copious and accessible tissue and are never detached from the body in the normal course of events (Waldby. 2008). Donating eggs involves stimulating the ovaries, and the multiple follicles, shutting down the donor's reproductive cycle, several hormone injections, and a surgical procedure to retrieve the eggs. Being familiar with the complexity of IVF procedure (or having been involved in egg sharing), many participants expressed the view that egg donation was not an easy process and they would like egg donors to be paid for their efforts. The participants did not think that payment would cause abuse, because to them the amount paid would not be high enough to encourage people go through this procedure repeatedly. For example, in the following extract, Rosie says that the payment is not 'huge' enough to encourage people to donate repeatedly:

I don't have a problem with it...I think it is good that they pay people [in Spain]. I mean they don't get a huge amount of money. It is only like 7 or 800 Euros or something...it is not... having been through IVF I mean, I don't think it is a lot of money because it is quite you know, quite heavy process to go through. I know that they are ok, they get paid but it is not a big amount, and they just do this thing they get paid money for doing it and that's it. So yes, I believe in donor anonymity. I think that what they are doing in Spain is good (Rosie).

Rosie points out that she is comfortable with the idea of donors being paid, because then she can see the process as a business arrangement. She thinks that for a student for example, this is not a bad way of earning some money.

I like to think that it is a business arrangement and they check people out and it is all above board and they are young people who are typically students and I think ok, well sounds ok, probably for a student again it is a good, not a bad way of earning some money (Rosie). 
Rosie's account also indicates that the donors deserve to be paid for undergoing IVF, which is a 'quite heavy process'. Similarly, Tina too, draws attention to the difficulties of donating eggs. She thinks that egg donors should be paid, because unlike sperm donation, egg donation is not easy:

In Spain you pay woman 600 pounds. It is a cultural thing. It is not nice having been through it. You wouldn't keep doing it. For men it is easy (Tina).

Another participant, Alison, shared her eggs and received sperm donation from an identifiable donor, in case the resultant child would like to meet the donor. In a way, she is an egg donor herself. Although she supports the open donation system, she expresses concern about the decreasing donor numbers, and the long waiting lists. She says that there are too many expectations from the donors: they are identifiable, and only get their travel expenses paid. Like the other participants, Alison states that she would like the donors to get paid.

I had mixed feelings because I would choose an identifiable donor but obviously it means that the supplies greatly reduced so it is tricky. If it was up to me, I would I'd leave the identified part, but I 'd like them get paid, you know...I think it is a double $\mathrm{xxx}$ that you have to be identified and you only got travel expenses for your travel (Alison).

'Reciprocity', the expectation that if one does something for someone, at some point the favour will be returned, might be a useful term to understand the accounts of the participants. Putnam (2000) uses the term 'generalized reciprocity' which implies that there may be anonymous exchanges of objects or favours, in contrast to gift exchange in traditional societies, where the 
identity of the giver and receiver are critical to understanding the functioning of the gift (Mauss, 1966).

The participant accounts indicate that the egg recipients in this study did not consider payment to donors as an ethical problem, or as exploitation of poor women. On the contrary, they claim that it is unjust that donors are not getting any rewards for their efforts. The fact that the donor is getting paid might actually comfort the recipients as they can regard the transaction as a fair one. This transaction can even be perceived as a business arrangement, as one of the participants suggested. Presumably, making a payment turns the transaction into a commercial one where there are no expectations on either side beyond the immediate exchange of cash or goods, as opposed to exchange of gifts where the exchange of gifts is embedded in and constitutes evidence of a continuing relationship. This is not to say that the recipients do not feel gratitude for the donation, but their accounts indicate that they would be more comfortable in an exchange that both parties get something from. As they cannot return the favour in any other way, they want donors to be paid.

\section{High standards of clinics abroad}

All the participants had followed the postings on online support groups for infertility, or websites hosted by fertility clinics such as Repromed to find out information about treatment abroad. Waldby (2008) notes, "multilingual websites and internet communication have made international partnerships and patient bookings much easier, facilitating the growth of such IVF tourism" 
(2008: 20). For example, when Rosie needed egg donation, she started doing research about the procedure and found a website called IVF Connections. She read the postings on message boards and found out that the success rates were high in Spain, especially in one clinic in Barcelona (the postings on message boards indicate that this clinic is particularly popular among the UK patients due to the high success rates). These postings praised the success rates in one particular clinic:

I started looking into it and I found a website called IVF Connections, and through that I started doing research and reading message boards, hundreds and hundreds of postings. And you know, found out really what was going on in Spain and a lot of people from UK were going to Spain and this is working. Seems to be incredible success rates in that particular clinic...later on, I was a bit more cynical about the success rates but that was... and just reading the stuff from the board at that time everyone seemed to be successful, that was really incredible. It was just like very good feeling...so many people were getting pregnant and so basically I thought about it. If all these women try that, what's so special about me that I couldn't consider it? Why don't we go, it is in Barcelona, we like Barcelona, it is a nice place you know, go and have a consultation and I heard that they were very quick and the indication of the cost that was a concern but I was lucky. I had enough money to do it. So we went to first consultation February last year and...I had a good feeling about it, maybe not so wonderful as some of the other women who think it was the most, really fantastic but I had a good feeling. I felt comfortable with them they just had test taken on an English doctor that was really kind of reassuring as well. So basically we decided to go ahead there and then (Rosie).

Alice is content with the treatment she received in Spain and Poland. She says that the consultation process is more open and advanced in comparison to the consultation provided in the UK. Moreover, the cost of the treatment is lower abroad:

What I experienced In Poland and Spain, compared to clinics here they have more experience. The doctors out there are willing to take time to 
talk to you. Not wait 5 years. This is our recommendation, you can have 2 or $3 \ldots$ In Poland you decide how many embryos can be implanted they talk to you. In private clinic the consultation is so rush. They look at your notes. Even it is in different country you have their e-mails. I have the mobile number of the doctor. Also my personal situation... in cost of 1 treatment in this country I can have 2 treatment (Alice).

Tina had embryo donation in Spain. She stresses that donor anonymity was the main reason that drove her abroad, but she also comments on her other motives. She started her treatment in the UK in a private clinic. When they found out that they could not conceive due to male factor infertility, Tina and her husband decided to receive sperm donation. However, they were advised to get ICSI (the technique involves picking up a single live sperm and injecting it directly into the centre of an egg which significantly increases the chances of achieving pregnancy) instead, which could enable Tina to get pregnant using her husband's sperm. Given that ICSI is much more expensive than sperm donation, and more complicated, Tina did not take the clinicians' advice. When she heard from a friend that the success rate was only 5 per cent for her age group, she decided that the clinic was giving her false hope, and her treatment was a waste of time. The treatment was expensive, there were no donor eggs available (after failed attempts using her own eggs, Tina decided to use donor eggs), the waiting lists were too long, and the donors were identifiable:

So we did 2 cycles in the UK. I, and when I had my second one in October I found that the success rate in my age group is $5 \%$. They just take your money! (Tina).

She thinks that private clinicians have business minds, and when money comes in to equation, their advice is not reliable: 
In the beginning when we found out that it was him we asked for DI. They said no, you must have ICSI. DI is for 500 pounds, ICSI is 5500. Lord Winston said when money comes to the equation ethics kind of $\mathrm{xxx}$ the door. With donor sperm you have a straight insemination, 10\% chance, it is not that great but it was... and they said no...your husband has some sperm and you must try to have your husband's child (Tina).

Tina and her husband finally decided to get treatment in Spain using anonymous frozen embryos. The clinic staff in the UK warned Tina against getting treatment abroad. They thought the clinic in Spain was not ethical:

My clinic here in England took an extremely poor view of me going Spain... questioned the ethics and the professionalism of the clinic in Spain. They completely, you know, put a down view on the whole thing (Tina).

Despite the concerns raised by the clinicians, for Tina the advantages of undergoing treatment in Spain were obvious: the clinics were more advanced, there were donors available, anonymity was preserved, and there were no waiting lists:

In Spain, the bigger they are. Their equipment is the latest thing. In England it is all rubbish, you wait for hours and you spend the same money, the same cost. [...]I would have done here, which you can't. There is no donor egg available. This is just the problem. And if you have one, you have to tell the child. Waiting lists are five years. At my age you couldn't wait. In Spain there is no waiting list (Tina).

\section{Fertility travel and 'tourism'}

As I showed in the Chapter Five, in April 2006, the then chair of the HFEA, Suzi Leather issued a public statement warning British citizens against the poorly regulated treatment in overseas clinics: 
We know that a relatively small number of people choose to travel abroad to undergo fertility treatment and that sometimes the treatment is packaged as a "holiday" where the patient can convalesce in the sun. However, we are concerned about people who choose to have their treatment abroad should know about the potential risks. We have heard of some clinics which offer treatment to patients that is so dangerous that it has been banned in the UK. For example implanting five embryos which significantly raises the chance of multiple pregnancy, the biggest risk of IVF for both mothers and babies. It is very sad when we receive complaints from patients about their treatment abroad and we are not able to help or reassure them. We would urge patients to think twice and consider the risks and implications before going abroad for treatment. (Suzi Leather, chair of the HFEA, in HFEA, 2006 [emphasis added]).

The accounts quoted here and in Chapter Five indicate that many would-be parents express the view that the standards of infertility treatment are demonstrably as high, if not better, than those in the UK. In this statement Leather refers to those who travel abroad to get treatment as "a relatively small number of people" (HFEA, 2006). INUK's fertility survey, which I discussed in Chapter Five, shows that this argument is debatable: of 339 people who responded to the survey, 76 per cent would consider travelling abroad for treatment. Leather's statement annoyed the would-be parents. For example, according to Alice, the HFEA is "like an ostrich", burying its head in the ground. She is dubious that the Authority represents the patients' opinions in its decisions. Alice says that, in the absence of statistics revealing the number of people seeking treatment abroad, the HFEA will continue denying the facts.

And I see a couple of programmes where they have interviewed Suzi Leather. She's just said 'if people wants to go abroad that's their issue, we don't look at clinics abroad we look at clinics from UK". I am thinking yes, but it is actually your making that driving them abroad, you know and there is no recognition of that. No understanding. It is a bit like, the HFEA is like an ostrich, buried in the ground sometimes 
that the way I feel about them sometimes so I think the more that you know we can get our point across as users of fertility clinics and fertility services the better I think. ... and it is one thing to do surveys, but who represents the patients in these big decisions that they make? Is there anyone? Not that I know of ...So I have mixed feelings about them (Alice).

The would-be parents also reacted to Leather's remark that fertility treatment was marketed as a holiday. Like many other would-be parents sending their protests to online support groups (e.g. Repromed, INUK), Alice, for example, stresses that infertility treatment is not a holiday.

You want a baby, the media made out this whole fertility tourism thing "yeah, you go on holiday and have your treatment" and it is like "yeah you get to go to a different place and some Spain or whatever". But it is not a holiday, there are so much going on in your body in your mind you know (Alice).

Storrow (2006) notes that the meanings of tourism are various: despite the fact that, for most people, tourism evokes the ideas of travelling for pleasure, it can also mean the "occupation of providing services for tourists" (2006: 300). According to Storrow, to use the term 'fertility tourism' to refer to "the network service set up to provide infertility treatment to travellers from abroad" is consistent with the latter definition, which defines tourism as an industry. Storrow points out that this industry markets fertility travel so as to “create a fantasy of conceiving a child during a romantic holiday" (2006: 327). However, usage of the term 'tourism' gets a negative reaction from the wouldbe parents and compounds stigma. Pennings (2004) argues that commentators frequently express disapproval when talking about fertility travel and that this attitude may be based on a number of convictions: "a belief in moral truth, a desire to ensure that others observe our standards, the belief that ethical rules 
apply to everyone, everywhere" (2004: 2691). Referring to fertility travel as 'tourism' symbolises such judgements. Would-be parents might be uncomfortable with the way that the treatment is represented in the public domain, as any association of infertility treatment with a holiday package may seem to undermine the severity of the treatment they have received and the seriousness of their intentions. I can presume three main reasons for that. First, terms such as 'reproductive tourism' or 'fertility holiday' suggest that there is something pleasant about getting treatment abroad. It implies something 'frivolous'. In contrast, many would-be parents describe infertility treatment as physically and emotionally 'painful'. Second, 'tourism' is usually a leisure activity which is 'voluntary'. The voluntary side of tourism might not fit into would-be parents' presentation of their infertility. As I have shown in Chapter Six, they describe their condition as an 'illness' which requires an emotionally and physically exhausting treatment. They claim that fertility treatment is a need, not a treat: they did not 'choose' to get treatment, rather their body failed them in a manner beyond their control. Third, would-be parents do not want to be associated with tourists of morally questionable markets. Similar terms like 'organ tourism', 'poverty tourism', and 'sex tourism' - have negative connotations. These terms imply the exploitation of the labour and resources of the poor.

The choice of language to describe this travel is also evidence of the stigma that the would-be parents have to deal. Compliance with UK legislation is felt as stigmatising but the moral entrepreneurs behind the reforms have tried to characterise avoidance as equally stigmatising. This attitude may be based on 
a belief in moral truth, the belief that ethical rules apply to everyone (Pennings, 2004). Would-be parents face an inappropriate kind of moral absolutism while they are exercising their right to seek treatment abroad.

\section{Reactions to the disclosure policy}

Storrow (2006) notes that not all reproductive laws are generated by moral certainty on the part of their supporters:

At times, proposal to regulate assisted reproduction arise in reaction to the perception that its use creates ethical or social problems that need to be addressed. Such regulation sometimes takes the form single-issue lawmaking aimed at putting a stop to certain practices that either create a moral outcry or generate ethical confusion (2006: 304).

For example, he notes that the UK curtailed the practice of surrogacy not because of any strong consensus about its ethical questionability but because it was unnecessary to permit this in the UK given the availability of surrogates for hire in other parts of the world. He notes that "the view in Britain seems to have been that since surrogacy would occur no matter what policy the government adopted the practice might as well be banned and fertility tourism permitted to ensue" (2006: 305). Storrow further argues that, given the ready supply of anonymously donated gametes in Denmark and the US, the UK may well have had similar views when it removed anonymity. He notes:

It is in precisely this way that fertility tourism acts as a moral safety valve permitting national parliaments to express local sentiments while simultaneously acknowledging the moral autonomy of those who do not agree with those sentiments (2006: 305). 
Imposing a moral opinion on citizens who have not consented to these rules and principles threatens peace and cooperation in society (Pennings, 2002). Interestingly, in the UK, would-be parents did not press claims against these restrictions partly because it was relatively easy to travel from countries with restrictive policies to places where the desired services could be obtained, and partly because confidentiality mattered to them. Nevertheless, the reticence of the would-be parents does not mean that they do not consider the new law as a problem. The ethnographic studies I conducted voiced the concerns that escaped the public eye. Like many other participants, Fiona has been trying to be heard, yet anonymously:

The HFEA the government did do a consultation at the end of the November last year, and they went over all current procedures and over all the things they were thinking about bringing in. [...] And I did take part in that consultation and replied very strongly about my feelings.... So I did take part in that consultation and I replied to the government directly. And also INUK [Infertility Network UK] were asking for opinions, so I did send my opinions so that they could submit. They wanted to submit their opinion on behalf of their members so I did make sure that I was involved in that. But again it was all done anonymously so I dont think I could do anything other than that (Fiona).

Alice took part in surveys, anonymously, because she wanted to get her voice heard:

I take part in surveys with HFEA because I feel like, I want to get my point of view across to them. So whenever possible I do mention the fact that removal of anonymity causing waiting lists, it is driving people abroad, and I think there is the thing annoys me the most about HFEA is they are not prepared to recognise that (Alice).

Alice notes that the HFEA is not prepared to recognise the fact that the open donation system is driving people abroad. In her view the HFEA does not take 
patients' views into consideration in policy making. She claims that the Authority does not communicate with "the people they try to serve", neither consulting nor explaining to them why certain decisions were taken:

Sometimes they do decisions without consulting the people who they try to serve. To be honest yeah... again all going back to removal of donor anonymity and as someone who go through this treatment it wasn't, I do feel as someone going fertility treatment it wasn't ever explained to us why they took this decision. So yeah, I see them as being a little bit on high making these decisions but really not understanding the struggles that people going through when they go through fertility treatment. I mean a lot of European countries still have the donor anonymity and can't understand why, you know, in this age HFEA made a law to remove anonymity in this country. And there is a couple of other things as well, that I just I can't understand why they have done them. But you know, I sit for people who they meant to be looking out for. I am not sure (Alice).

The would-be parents are caught in a vicious circle: those who prefer anonymous donation are reluctant to press their claims because confidentiality matters to them and they are intimidated by the force of the rights-based discourse of openness. Given this reticence, their voice is unheard by public bodies, like the HFEA, which can only deal with issues through formal and transparent modes of communication. As a result, they can come to be colonised by the views of those who are less constrained, like the advocates of the child's right to know. 


\section{Conclusion}

According to Storrow (2006), the current phenomenon of European fertility travel is a symptom of globalisation and "owes its existence to the interplay between member states' individual (some would say idiosyncratic) policies on 'responsible' procreation and the globalist policy of free movement of persons within Europe thought to be essential to the continued integration of European nations" (2006: 298). Storrow argues that policy making that appears to adopt local values rather than globalist trends depends upon tourism for its viability against organised resistance.

The main causes of fertility travel can be summarised as follows: treatment is prohibited in the country of origin because the application is considered ethically unacceptable; the technique is considered medically unsafe; the treatment is not available; the would-be parents are considered to be unfit parents in their country; the waiting lists are too long; or the costs are too high (Pennings, 2000). Sometimes a combination of motives exists. The participant accounts and the posts on Repromed indicate that avoiding the UK law eliminating donor anonymity and the consequent lengthy waiting lists are the main reasons that drive would-be parents abroad to seek treatment. Shortage of donors with preferable characteristics and high standards of clinics are among the other reasons cited by the would-be parents.

A majority of the Repromed users and the interview participants received or considered receiving treatment in Spain, which is one of the most popular 
fertility travel destinations in Europe. This is in line with the findings of the INUK survey. It is argued that Spain is a particularly attractive destination because it combines high medical standards with a liberal approach to regulation (Waldby, 2008). In Spain there are no waiting lists, and donor anonymity is preserved. Donor anonymity policy is a significant consideration for would-be parents who strongly believe that the resultant child should have no access to identifying information about the donor who played a role in their conception. The accounts in this thesis demonstrate that would-be parents appear to start thinking about disclosure before they get treatment. Given that there is a supply of gametes/embryos from both identifiable and anonymous donors (including European countries such as Sweden and Norway), it is unlikely that anyone takes a haphazard decision about choosing a destination to get treatment without giving thought to the donor anonymity issue. The popularity of Spain shows that many would-be parents in the UK prefer anonymous donors to identifiable ones.

Pennings (1997) notes that "those who argue for the legal imposition of either anonymity or identification presuppose that a single way of organizing the family will and should work for everybody. This is a short-sighted and false idea" (1997: 2839). The HFEA has no jurisdiction outside the UK. For those who do not want to receive gametes/embryos from identifiable donors, or those who cannot afford waiting in lengthy lists for treatment, fertility travel acts as a safety valve. The would-be parents' reluctance to mobilise around pressing claims to protest the removal of donor anonymity partly reflects the variety of ways in which they can avoid the impact of this legislation. 


\section{CHAPTER NINE: CONCLUSION}

This thesis has been guided by one over-arching question: how may donor conception families' reactions to the disclosure policy in the UK better be understood? After introducing the theoretical approach taken in the thesis, namely, social constructionist theories of social problems, I explored the natural history of the donor anonymity debate in the UK, and identified the claims-making activities that led to the 2004 Regulations which abolished donor anonymity. This examination revealed that the decision to abolish donor anonymity was strongly influenced by a discourse that asserted donorconceived children's 'right-to-know' their genetic origins. It is also clear that, despite the differences between the biological and social context of adoption and assisted conception, adoption has been regarded as a morally and psychologically relevant model for approaching the need to find out about their origins that has been claimed by some children born through donation. The 2004 Regulations endorsed this reasoning by giving donor offspring and adoptees similar legal entitlements. But one important voice was not heard in this debate, namely that of would-be parents: in other words, those who would carry the burden of informing children of their origins, should they so choose. The ethnographic studies I presented in Chapters Five, Six, Seven and Eight sought an explanation for this silence.

In this final chapter, I will retrace the steps that I have taken in the thesis. I will then discuss the implications of the work as whole and I will focus in particular on the policy directions. 


\section{Social problems around donor anonymity}

Social constructionist theories of social problems explore how people come to define a certain condition as problematic, not the social condition itself. Schneider (1985) argues that many analysts, including himself, who describe their research as constructionist have trouble keeping the study of problemdefinition (claims-making) activities separate from that of social conditions. $\mathrm{He}$ notes that when analysts see conditions as 'real problems' which they want to help remedy through sociological investigation, it is a struggle for them to bracket their assumptions and focus on definitional activities. This was certainly a challenge for me. The silence of would-be parents in the donor anonymity debate might be taken to indicate that there is no problem for them. Yet there were indications of discontent among would-be parents which led me to challenge the basic assumptions of constructionism and to study the removal of donor anonymity as a social problem which cannot be expressed by wouldbe parents in formal modes of communication.

In terms of theoretical contribution, throughout this thesis I argued that the study of absent voices is a challenge to the conventional constructionist view of social problems, which sees them as the result of successful claims-making. In introducing data on voices that were not fully heard in the public debates over ending donor anonymity, one aim of this thesis is to suggest a more inclusive approach to 'claims-making' definition in social constructionist theories of social problems. 
Secondly, linked to the problem above, I have argued that the social constructionist approach to social problems has practical difficulties if one is examining the claims-making activities of hidden or hard-to-reach populations. Individuals, particularly ones who have confidentiality concerns, can participate in claims-making activities through a variety of ways other than public gatherings or protests about the definitions of troublesome conditions. I have assumed that in some cases, claims-making may be repressed by an opposing group, or may not emerge due to a lack of public support or institutional power. It is also possible that the stakeholders of a problem cannot press their case due to the perceived illegitimacy of their claims. I suggested that analysis of such social problems may necessitate looking into alternative definitional activities where performing a collective activity is not possible or is not seen as desirable by the stakeholders of the problem. By investigating would-be parents' perspectives through interviews and a virtual ethnography study conducted on the Internet, this thesis aimed to address these two weaknesses.

Early work on social problems followed a natural history model. Specifically, it was argued that every social problem had a history, and social problems developed through a series of stages. I argued that, like other social problems, the donor anonymity problem may have followed developmental stages. In outlining a natural history of the abolition of anonymity, I have attempted to identify these stages and illustrate the way in which certain interests, assumptions and claims caused a change in the law. 
The natural history model revealed that there are two social problems surrounding donor anonymity: the donor-conceived child's right to know, and the would-be parents' right to seek treatment. By studying the natural history of the donor anonymity debate I identified a number of important claims that were made by advocates of the child's right-to-know.

\section{The child's right to know as a social problem}

Any social condition is a potential subject for claims-making, but it is claimsmakers who shape the public's sense of what the problem is. In Chapter Three, I examined the donor anonymity debate in the public eye through media representations. This examination helped me to identify a number of important claims that were made by proponents of the child's right-to-know, and to explain how donor-conceived children came to monopolise rights language. During the debate that led to the 2004 Regulations, without any significant objection from would-be parents, the donor anonymity problem came to be owned by advocates of the child's right-to-know. The view that donorconceived children have a right to have access to identifiable information was legitimised by two principal claims. First, such children have as much right to find out about their genetic origins as adopted people do. Studies on adopted children show that a child's knowledge of his or her background is crucial to the formation of positive self-identity. The position of donor-conceived people should be aligned more closely with that of adopted people, with access to identifying information about their donor. Genealogical knowledge is necessary for the development of identity: by denying access to their donor's 
identity, the government infringes the human rights of donor-conceived children. Second, it was claimed that the secrecy and stigma surrounding assisted conception had faded and more parents were planning to tell their child about donor conception. The removal of donor anonymity had the potential to ease the remaining stigma.

In the absence of an explicit reaction or opposition from would-be parents, counter-claims activities were performed by the medical community and the patient support group, INUK. These counter-claims making activities focused on the donor shortage. But the fact that would-be parents would suffer due to the donor shortage could find only little sympathy when weighed against the child welfare arguments raised by the child's right-to-know camp. The involvement of would-be parents in the debate might have changed the problem's trajectory if these parents had attempted to create a public or political issue by talking about their rights and experiences. But the interests of would-be parents were not represented and, in the absence of a counterdiscourse constructed by these parents or their representatives, claims concerning the child's right-to-know monopolised the human rights argument. As a result, would-be parents' right-to-seek treatment was compromised for the perceived needs of donor-conceived children.

Instead of mobilising around the public donor anonymity debate, would-be parents used online discussion forums to express and exchange their views anonymously about the new law. There were also other indications of a social problem: fertility travel and purchase of sperm online increasingly featured in 
the media after the new law came into effect. I concluded that this "silent resistance' to the new law deserved to be the subject of empirical investigation.

As detailed in Chapters Five to Eight, I used ethnographic studies to investigate would-be parents' reactions and claims that remained unrecognised in the public realm. Admittedly, the confidentiality concerns of would-be parents generated a methodological problem for the study by making recruitment quite difficult. It was hard to contact potential participants, and where contact was established, I ran into difficulties in convincing individuals to give interviews. I solved this problem by using the Internet as a recruitment channel and a data collection source. I used two different data collection methods: a virtual ethnography study on the postings of would-be parents to online discussion forums, and semi-structured and open-ended interviews. In the following section I summarise the findings from these ethnographic studies. As I have mentioned in the outset of the thesis, the people whose views are presented here are a sub-group of would-be parents. This study does not claim to include a representative sample of people seeking donor conception in the UK.

\section{The donor anonymity problem as defined 4 by would-be}

\section{parents}

Both the posts and the interview accounts showed that understanding the nature of the stigma invoked by the failure to reproduce and the use of donor gametes/embryos was important if we wanted to understand would-be parents' silent resistance to the legal imposition of disclosure. The accounts showed that 
there were two main reasons why would-be parents (the users of Repromed discussion forums and the interview participants) did not mobilise publicly around the donor anonymity problem. First, they had confidentiality concerns and they were therefore engaged in information control to conceal a condition which they saw as potentially stigmatising. Second, they could avoid the law by travelling to countries with donor anonymity for treatment purposes.

\section{Stigma and deviance}

When cultural norms and values encourage reproduction and celebrate parenthood, childlessness becomes an 'involuntary deviance' (Birenbaum and Sagarin, 1976: 35, quoted in Miall, 1986) and a potentially stigmatising status. Having a donor-conceived child affords individuals and couples a cloak for this deviance. However, donor conception still invokes abnormality as having a genetically-related child is perceived to be both a natural desire and the social norm. Having a donor-conceived child constitutes a permanent charge of deviance against the family. There are two such charges: first, the selfishness of would-be parents, who challenge nature and engage in 'manufacturing' a baby against the odds; and second, the donor-conceived child itself is deviant it might be perceived as not quite human.

Having departed from the conventional route to parenthood, many participants reported uncertainty about using donor gamete/embryos to conceive. In other words, the would-be parents themselves categorised having a donor-conceived child as a negative attribute. As one interview participant pointed out, no one would choose give birth to a child with whom one did not have a genetic relationship. It was therefore important to have an information control strategy 
that would give the resultant child and the parents the greatest comfort and ease so as to make the experience as 'natural' as possible. If donor conception is kept a secret, the family and the child may pass as normal. Hence, the legal imposition of disclosure may reinforce stigma rather than reducing it.

Clearly, reproductive technologies offer a choice to those who cannot conceive using their own gametes; one might be able to give birth to 'a baby' and that baby may even be genetically connected to oneself or one's partner. This situation, however, does not parallel adoption given that here the recipient mother is also the gestational mother. Donor conception is an approximation to genetic parenthood which means that the adoption analogy is misleading. Adoption is a family-building activity that involves pre-existing individuals, whereas donor conception is directed towards creating a child in order to create a family (Haimes, 1998). In other words, adoption is a substitute for procreation whereas donor conception is a form of procreation: the act has its own integrity and completeness - it is the would-be parent(s)' act and the child is unquestionably their child. "The act of procreation which takes place by artificial insemination is undoubtedly the act of the couple, and more particularly of the mother" (O'Donovan, 1988). In this act, social links are established between the procreator and the child, not with the donor. By basing its assumptions on an adoption analogy, the new law clearly disregards wouldbe parents' biological claim to parenthood which differentiates them from adoptive parents. 


\section{Information control and disclosure}

Unlike the normal family, in the donor-conception family, parenthood is fragmented or separated. This separation is not desirable, and is potentially stigmatising for donor-conception families. As Haimes (1992) argues, in donor conception "the sheer fact of wanting to preserve elaborate devices for retaining anonymity is an indication that the genetic tie is actually regarded as very important indeed" (1992: 132). When anonymity is preserved, the donor's contribution to the conception remains invisible, hence gestational, biological and social parenthood can still be mediated and integrated (perhaps even more so than in a natural-conception family where the child is the result of an affair). In an open donation system, however, the donor cannot easily be dismissed. Despite having no legal obligations or responsibility, once the donor is known s/he has a potential to become an 'informal' parent to the resultant child, thereby separating the biological and social parentage that the would-be parents try to keep together.

In considering the best interests of the child and the family unit as a whole, would-be parents have to consider the degree of privacy they wish to maintain, and the possible role of a genetic parent in their daily lives (Becker, 2000). The accounts in this study revealed the potential difficulties in the relationship between the non-genetic parent(s) and the child. The users and the participants reported that they had unresolved feelings about not being the genetic parents and uncertainty about whether to disclose donor conception to the resultant child and others. Another stated reason was that now that donors were 
identifiable, the child might wish to contact the donors. The would-be parents did express gratitude for the donation. But their gratitude did not necessarily mean that they would like to have a complete stranger involved in their child's life. Some egg recipients also mentioned that contact might be frustrating for the donor, especially if the donor does not have children of her own. These findings contradict earlier reports. The reasoning given previously by nondisclosing gamete donation parents (before the removal of the donor anonymity) was that disclosure would cause frustration if the child wished to trace donors (MacCallum and Golombok, 2007). In other words, when donors are anonymous some parents may keep donor conception secret in order to protect the child from the frustration of not being able to contact the donor. But the accounts in my study suggest that if donors are identifiable, some parents may opt for secrecy in order to protect the family as a unit from a donor intruding into their lives. The discrepancy in the findings seems to suggest that both donor-involvement and donor-absence might be perceived as problematic.

All of the posts and interview accounts relating to disclosure suggested that whether to tell or not, what is to be disclosed, and when that disclosure should occur were perceived as private family matters: there was, in other words, a consensus that the disclosure decision should be left to the parents. The reasons given by the would-be parents who had already decided against disclosure to the child were similar to those given in earlier investigations: the view that disclosure could be more harmful than beneficial to the child; the view that there was no reason to tell; the wish to avoid any potential difficulties in the relationship between the non-genetic parent and the child: and the fear that the 
grandparents might reject the child (Cook and Golombok, 1995a; Cook and Golombok, 1995b; Murray and Golombok, 2000; MacCallum and Golombok, 2007). Although a relatively small number of participants and Repromed users thought that it was in the child's best interests to know, there was a consensus that a child would not be skilled enough to make sense of this information or skilled enough to judge with whom to share it. The participants took the view that protecting the best interests of the child meant managing this 'potentially stigmatising' information on behalf of the child, rather than giving the child autonomy at any cost. The accounts of Repromed users and interview participants revealed that these would-be parents were not only engaged in information control to protect the unborn child and but also to protect their family unit as a whole. Information control allowed them to perform a public display of normalcy which would protect their family privacy.

The overpowering discourse of the 'child's right-to-know' led interview participants and Repromed users to invoke a counter-morality to defeat the charges against them. Many pointed out that openness with the child was not always preferable or possible. They also noted that there were many children who were born as a result of affairs, or short term relationships, in naturalconception families who did not know their genetic origins. The would-be parents did not present their deviance a 'moral failure' as such, but rather as akin to an illness over which they had no control. The disclosure policy, which as we have seen applies only to donor-conception families, was perceived as discriminatory both against donor-conception families and naturally-conceived children who may not have been told by their parents about their origins. Given 
that natural-conception families had not been 'advised' or encouraged via legislation to be open with their children, the need for identifying information was seen as neither essential nor universal. Like 'normal' parents, the would-be parents also wanted to have autonomy to decide what is best for their child and what information should be openly communicated in their family.

In the UK, as O'Donovan (1989) argues, the concept of identity being appealed to "is produced by legal and social structures which attach value to concepts of identity linked to genitors" (1989: 102). Shenfield (1994) also argues "the law has always been an important adjunct to the societal understanding of identity, symbolically reinforcing the notions of paternity and maternity, which can give rise to complex problems of filiation in assisted reproduction" (quoted in Shenfield and Steele, 1997) The new law ignores would-be parents' identity as biological parents and marginalises donor conception families.

The intention to disclose depends on the perceived normative values (not being genetic parents to the resultant child) and the degree of privacy, confidentiality, or openness that would-be parents wish to maintain. The current law compounds stigma by obliging them to separate biological and social parenthood and to display their differences from natural-conception families.

Goffman (1963) notes that "what will conceal a stigma from unknowing persons may also ease matters for those in the know" (1963: 126). My findings suggested that many would-be parents were reluctant to raise their voices during the donor anonymity debate because they did not want to be exposed to 
publicity. Some would-be parents who tried to have their voices heard by using online discussion forums, giving anonymous interviews and/or participating in the HFEA's public consultations stated that the HFEA did not take patients' views into consideration in policy making. Presumably public bodies can only deal with issues through formal and transparent modes of communication; but. as my study highlights, pressing claims against the policy change in formal ways would have 'exposed' would-be parents, perhaps permanently stigmatising the resultant children and their family units.

\section{Fertility travel}

The users of discussion forums on Repromed and the interview participants were united in the view that the removal of anonymity had identifiable detrimental effects: donors are reluctant to donate; UK clinics cannot meet the demand for gametes; there are long waiting lists for patients who wish to get treatment; and reduction in donors has also compromised would-be parents' chances of finding a donor with a reasonable match to their own physical characteristics or those of their partner.

The would-be parents who want to use gametes from anonymous donors have no choice but to seek treatment abroad. Given the shortage of donors and long waiting lists, even those would-be parents who favour openness are left with no choice: if they wish to avoid the lengthy waiting lists, they have to consider travelling abroad. The accounts of the Repromed users and the interview participants showed that would-be parents saw the donor shortage as a direct 
consequence of the removal of donor anonymity. The would-be parents blamed the HFEA for the circumstances that 'oblige' them to seek treatment abroad. The fact that obtaining treatment abroad has been condemned by the HFEA is a cause of further frustration for the would-be parents. These parents also expressed the view that their concerns were not taken into consideration by the HFEA. Further research examining the communication gap between the stakeholders and the HFEA would contribute to developing strategies that will inform policymaking.

Regardless of their views about the new law, many would-be parents express the view that they do not wish to be treated differently from 'normal' families. Many would-be parents also express their discontent about being given parental advice and 'dictated' by the HFEA as to how to communicate with the donor conceived children about their origins. It would be fruitful for HFEA to address these concerns and find a more favourable language to address donor conception families, without marginalising or infantilising them.

Ignoring the moral autonomy of the would-be parents inevitably drives some of them abroad to seek treatment to organise their family lives as they see fit. The movement of the would-be parents to other jurisdictions indicates that some people choose to cope with the problem by avoiding the law, rather than making official claims to challenge the policy-makers. Their reluctance to mobilise around pressing claims against the removal of donor anonymity partly reflects the variety of ways in which they can avoid the impact of this legislation: fertility travel acts as a safety valve. As I have mentioned in 
Chapter Eight, this is often described, pejoratively, as fertility or reproductive 'tourism'. The label 'tourism', however, trivialises and obscures the serious issues that underlie cross-border travel in search of treatment. As the accounts in this study show, restrictive regulations, gamete shortages and waiting lists are clearly overlapping concerns, but the connection between them is not necessarily immutable. Exploring the extent to which regulatory regimes and consumerist reproductive culture play a role in UK patients' fertility travel would be fruitful.

\section{Policy directions}

Although there is no evidence that any one policy is the best solution, legislators tend to impose one position on donor anonymity (Pennings, 1997). The UK government has made it clear that it does not intend to reverse the removal of donor anonymity (Department of Health, 2006). Yet the silent resistance of would-be parents to the new law should be addressed by policy makers: suppressed claims are likely to generate new problems.

The donor anonymity problem can be solved by balancing the rights of recipients and donor offspring. The most obvious alternative policy would be to let the parties decide for themselves. Pennings (1997) suggests 'a double track policy', a system still in use in the United States. The model was initially introduced because of the difficulty of attracting egg donors and it is currently used in most donor gamete/embryo programmes. The advantage of a double track policy is that both donors and recipients are given a choice. The model 
takes moral pluralism as its starting point: "it is built on the admission that no position is inherently better than the others and that consequently the parties should be able to decide under which conditions they want to participate" (Pennings, 2004). Potential donors have the choice to enter the programme as either anonymous donors or identifiable ones, and the recipients can choose between these two 'pools'. The advantage is obvious: the model is selfregulating and choice is given to both donors and recipients: "[W]ithout any form of coercion or external force, the practice is directed in such a way that no person can say that his rights are infringed. The power balance is guaranteed by the simple fact that every party can veto any proposal of any other party" (Pennings, 2004: 2842). Obviously, a double track policy does not offer a solution to the problem of donor-conceived children who believe they have a right to know the identity of their donor(s): parents can still keep the information from the child and where a child does not suspect his or her circumstances of conception, no question of tracing one's genetic origins exists (Liu, 1991: 85). But in this respect the double track system would not be any worse than the current one and, as I go on to argue, there are other features of the system that suggest it deserves serious consideration.

In the UK, a double track system might reduce the numbers of would-be parents travelling to other jurisdictions for treatment, thereby helping to allay the fears of the HFEA and, crucially, reducing the need for warnings that seem to block the opportunity for communication between the Authority and wouldbe parents. Less prohibitive laws might also help to reduce the problem of exploitation of donors from poorer countries. Moreover, if the double track 
system was introduced in the UK, the government could still make its moral position explicit by providing services with identifiable donors though the NHS (i.e., without charge).

There are two equality-type arguments that might be raised against the double track system. It might be argued, first, that the system installs or facilitates improper discrimination given that it allows for different treatment of children (depending on the pool chosen) and, second, that it is also discriminatory if those who have sufficient private resources can 'buy' their way out of identifiable donation. These arguments are debatable, however. First, in the absence of measures that compel disclosure, the current system does not eliminate discrimination: it is parents decide whether or not to disclose, acting as gatekeepers to the right to know. Secondly, the current system is no better at avoiding 'buy-out' by those with sufficient wealth: although anonymous donation is prohibited under the law (Pennings, 2004), those who can afford it are able to seek treatment abroad using anonymous gametes/embryos, thereby avoiding waiting lists as well.

The removal of donor anonymity is a failed policy, unsupported by evidence and based on a misconception of the relative weight to be given to the different rights involved. The policy undermines the sustainability of gamete donation while failing to promote communication within families and drives would-be parents abroad. The government did consult before introducing the policy change but as I have shown the odds were stacked against the inclusivity of this consultation: the government was not likely to get a public reaction from 
would-be parents because, as their accounts show, those who are most directly affected by the disclosure policy are also those who prefer to keep the means of conception secret. And, because they have no reason to stop fearing publicity, it is unlikely that these would-be parents will feel able to take a public stand against the effects of the new law. For the would-be parents in this study complying with the new law creates is perceived as stigmatising; yet, as they point out, the moral entrepreneurs behind the reform have also characterised avoidance in such a way as to make it stigmatising. Rather than public condemnation of those who choose to maintain secrecy about donor conception and those who travel abroad to avoid the law and its effects, the UK needs to work towards an inclusive, fully informed debate on the relationship between the right to know one's genetic identity and family rights, including family privacy. Without such a debate, would-be parents might well take the view that 'assisted conception' is a misleading and contradictory term. 


\section{References}

[2002] EWHC 1593 (Admin).

HC Deb (2003-04) 416 col. 60WS. Available at: $<$ http://www.publications.parliament.uk/pa/cm200304/cmhansrd/vo040 121/wmstext/40121m01.htm $>$ [Accessed January 2009].

The Human Fertilisation and Embryology Authority (Disclosure of Donor Information) Regulations 2004 SI 2004/1511.

Adoption and Children Act 2002 (c.38). London: HMSO. Available at: $<$ http://www.opsi.gov.uk/acts/acts2002/ukpga 20020038 en_l> [Accessed January 2009].

Arksey, H. (1996) Collecting data through joint interviews. Social Research Update, 15, 1-4.

Arthur, C. (2003) Ministers retreat on sperm donor identity. The Independent. 29 January 2003 ed.: Independent News and Media Limited. Available at: $\quad<$ http://www.independent.co.uk/life-style/health-andwellbeing/health-news/ministers-retreat-on-sperm-donor-identity606065.html $>$ [Accessed January 2009].

Atkinson, P. and Silverman, D. (1997) Kundera's Immortality: The Interview Society and the Invention of the Self. Qualitative Inquiry, 3(3), 304.

Atkinson, R. and Flint, J. (2001) Accessing hidden and hard-to-reach populations: snowball research strategies. Social Research Update, 33(1).

Baym, N. (1995) The emergence of community in computer mediated communication. In: S. G. Jones (Ed.) Cybersociety: Computer Mediated Communication and Community. Thousand Oaks, CA: Sage Publications, pp. 138-63.

BBC News (1998) Push for sperm and egg donors. BBC News. Available at: $<$ http://news.bbc.co.uk/1/low/health/113119.stm $>$ [Accessed January 2005].

BBC News (1999) Government reviews sperm donor anonymity. BBC News, 26 July 1999. Available at: $<$ http://news.bbc.co.uk/1/hi/health/404096.stm $>$ [Accessed January 2009].

BBC News (2002a) Call to end sperm donor anonymity (1). BBC News, 14 May, 2002. Available at: $<$ http://news.bbc.co.uk/1/hi/health/1986683.stm> [Accessed January 2009]. 
BBC News (2002b) Call to end sperm donor anonymity (2). BBC News, 26 June 2002. Available at: $<\underline{\text { http://news.bbc.co.uk/1/hi/health/2065329.stm }>\text { [Accessed January }}$ 2009].

BBC News (2004) Sperm donors to lose anonymity. BBC News, 21 January 2004. Available at: <http://news.bbc.co.uk/1/hi/health/3414141.stm> [Accessed January 2009].

BBC News (2006a) Figures from Scotland's IVF clinics. BBC News. Available at: $\quad<$ http://news.bbc.co.uk $/ 1 /$ hi $/$ scotland $/ 5065050 . \mathrm{stm}>\quad$ [Accessed August 2008].

BBC News (2006b) Sperm donor law 'not a deterrent'. BBC News. Available at: $\quad<$ http://news.bbc.co.uk/1/hi/england/5054910.stm $>$ [Accessed January 2009].

Becker, G. (2000) The Elusive Embryo: How Women and Men Approach New Reproductive Technologies, University of California Press.

Becker, H. S. (1966) Introduction. In: H. S. Becker (Ed.) Social Problems: A Modern Approach. New York: John Wiley \& Sons Inc.

Bellis, M. A., Hughes, K., Hughes, S. and Ashton, J. R. (2005) Measuring paternal discrepancy and its public health consequences. Journal of Epidemiology and Community Health, 59, 749-754.

Benoit, C., Jansson, M., Millar, A. and Phillips, R. (2005) CommunityAcademic Research on Hard-to-Reach Populations: Benefits and Challenges. Qualitative Health Research, 15(2), 263.

Best, J. (1993) But Seriously Folks: The Limitations of the Strict Constructionist Interpretation of Social Problems. Reconsidering Social Constructionism: Debates in Social Problems Theory, 129-47.

Best, J. (1995) Images of Issues: Typifying Contemporary Social Problems, Aldine Transaction.

Best, J. (1997) Secondary Claims-making: claims about threats to children on the network news. In: G. Miller and J. Holstein (Eds.) Social Problems in Everyday Life: Studies of Social Problems Work Greenwich, Conn: Jai Press, pp. 73-95.

Best, J. (1999) Damned Lies and Statistics: Untangling Numbers from the Media, Politicians, and Activists, Berkeley and Los Angeles: The University of California Press.

BioNews (2002) Poll on donors favours information. BioNews, 01 July 2002. Available at: <http://www.bionews.org.uk/new.lasso? storyid =1297> [Accessed January 2009]. 
Blumer, H. (1971) Social Problems as Collective Behavior. Social Problems, 18(3), 298-306.

Blyth, E. (2006) Competing interests in sperm donor secrecy. The Times. September 23, 2006 ed. London: Times Newspapers Ltd. Available at: $<$ http://www.timesonline.co.uk/tol/comment/letters/article1074373.ece $>$ [Accessed January 2009].

Blyth, E. and Frith, L. (2008) The UK's gamete donor 'crisis' - a critical analysis. Critical Social Policy, 28(1), 74-95.

Bockman, S. (1991) Interest, Ideology, and Claims-Making Activity*. Sociological Inquiry, 61(4), 452-470.

British Association for Adoption \& Fostering (2005) BAAF Response to Department of Health Review of the Human Fertilisation and Embryology Act. Available at: $<$ http://www.baaf.org.uk/res/consultations/consultreponse embryo.pdf $>$ [Accessed January 2009].

British Fertility Society (2002) Publication of consultation document on donor anonymity and British Fertility Society's response. Available at:

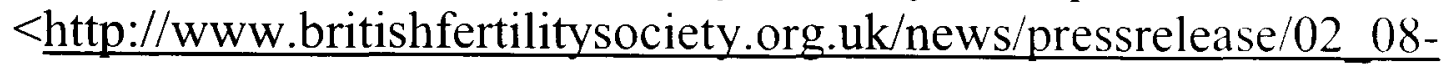
donor_anonymity.html > [Accessed August 2008].

British Fertility Society (2006) BFS Donor Survey 2005/6.

British Fertility Society (2007) British Fertility Society Response to the White Paper on the Human Fertilisation and Embryology Act. Available at: $<$ http://www.britishfertilitysociety.org.uk/news/documents/Final\%20B FS\%20response $\% 20$ to $\% 20$ White $\% 20$ paper $\% 2024.4 .07$. pdf $>$ [Accessed January 2009].

British Medical Association (2008) Parliamentary Brief: Human Fertilisation and Embryology Bill. Available at: $<$ http://hfebill.files.wordpress.com/2008/05/hfe-bill-hoc-2nd-readingbrief-final-apr-08.pdf $>$ [Accessed January 2009].

Brown, C. E. (2006) On-line Interaction and Facilitation Seminar. Purdue University. $<$ http://matei.org/ithink/2007/10/15/communities-online/> [Accessed January 2009].

Browne, A. (2004) Sperm firm gears up for new Viking invasion of Britain. The Times. November 27 ed. London: News International Ltd.

Bruckman, A. (2002) Studying the Amateur Artist: A Perspective on Disguising Data Collected in Human Subjects Research on the Internet. Ethics and Information Technology, 4(3), 217-231.

Bruckman, A. (2006) A New Perspective on "Community" and its Implications for Computer-Mediated Communication Systems. Montreal. Quebec, 

Canada: Proceedings of CHI 2006 (Works in Progress, Extended
Abstracts).

Campbell, C. (2006) Donor identity rules and IVF. The Times. September 21. 2006 ed. London: Times Newspapers Ltd. Available at: $<$ http://www.timesonline.co.uk/tol/comment/letters/article645747.ece> [Accessed January 2009].

Chadwick, R. F. (Ed.) (1992) Ethics, Reproduction and Genetic Control (Revised Edition), New York: Routledge.

Conrad, P. (1997) Public Eyes and Private Genes: Historical Frames, News Constructions, and Social Problems. Social Problems, 44(2), 139-154.

Cook, R. and Golombok, S. (1995a) Ethics and society: A survey of semen donation: phase II-the view of the donors. Human Reproduction, 10(4), 951-959.

Cook, R. and Golombok, S. (1995b) A survey of semen donation: Phase II, the view of donors. Human Reproduction, 10, 951-959.

Correll, S. (1995) The ethnography of an electronic bar: the Lesbian Café. Journal of Contemporary Ethnography 24(3), 270-98.

Cotterrell, R. (1992) The sociology of law : an introduction, London: Butterworths.

Courtenay, W. (2000) Constructions of masculinity and their influence on men's well-being. Social Science Medicine, 50(10), 1385-401.

Craft, I., Flyckt, S., Heeley, G., Layland, S., Thornhill, A. and Kelada, E. (2005) Will removal of anonymity influence the recruitment of egg donors? A survey of past donors and recipients. Reproductive BioMedicine Online, 10(3), 325-9.

Cromby, J. and Nightingale, D. J. (1999) What's wrong with social constructionism. In: D. J. Nightingale and J. Cromby (Eds.) Social Constructionist Psychology: A Critical Analysis of Theory and Practice. New York: Open University Press.

Daniels, K. R. (1994) The Swedish Insemination Act and its impact. Australian and New Zealand Journal of Obstetrics \& Gynaecology, 34, 437-439.

Daniels, K. R., Ericsson, H. I. and Burn, I. P. (1998) The views of semen donors regarding the Swedish insemination act 1984. Medical Law International, 3(2-3), 117-34.

Daniels, K. R. and Taylor, K. (1993) Secrecy and openness in donor insemination. Politics, 12(2), 155-70.

Deech, R. (2006) Competing interests in sperm donor secrecy. The Times. September 23, 2006 ed. London: Times Newspapers Ltd. Available at: 
$<\underline{\text { http://www.timesonline.co.uk/tol/comment/letters/article 1074373.ece }}$

$>$ [Accessed January 2009].

Denzin, N. K. and Lincoln, Y. S. (Eds.) (1998) Collecting and Interpreting Qualitative Materials: Dealing with Empirical Materials and Interpretations: Sage Publications.

Department of Health (2001) Donor information consultation: providing information about gamete or embryo donors. Available at: $<$ http://www.dh.gov.uk/assetRoot/04/01/87/74/04018774.pdf $>$

[Accessed January 2009].

Department of Health (2003) Summary of Responses Received to the Donor Information Consultation - Providing Information about Sperm, Egg and Embryo Donors. Available at: <http://www.dh.gov.uk/assetRoot/04/07/18/43/04071843.pdf $>$ [Accessed January 2009].

Department of Health (2006) Review of the Human Fertilisation and Embryology Act: Proposals for revised legislation (including establishment of the Regulatory Authority for Tissue and Embryos) Cm. $6989 . \quad$ Available at: $<\underline{\text { http://www.hfea.gov.uk/docs/White_Paper_Dec } 06 \text { web version.pdf }}$ $>$ [Accessed January 2009].

Department of Health (2007) Government Response to the Report from the Joint Committee on the Human Tissue and Embryos (Draft) Bill, Cm 7209. London: HMSO. Available at: $<$ http://www.dh.gov.uk/en/Publicationsandstatistics/Publications/Public ationsPolicyAndGuidance/DH 079127> [Accessed January 2009].

Dingwall, R. (2001) Aspects of Illness (Second Edition), Aldershot: Ashgate.

Dingwall, R., Eekelaar, J. and Murray, T. (1995) The Protection of Children: State Intervention and Family Life (Second Edition), Aldershot: Avebury.

Dingwall, R. W. (1997) Accounts, interviews and observations. In: G. Miller and R. W. Dingwall (Eds.) Context and method in qualitative research. London: Sage, pp. 51-65.

Doheny-Farina, S. (1996) The Wired Neighborhood, Yale University Press.

Donor Conception Network (2007) Donor Conception Treatment Outside The UK. Available at: <http:/'www.donor-conceptionnetwork.org/overseasdrs.htm $>$ [Accessed January 2009].

Dreaper, J. (2006) IVF donor sperm shortage revealed. BBC News. Available at: $<$ http://news.bbc.co.uk/1/hi/health $/ 5341982$.stm $>$ [Accessed August 2008]. 
Dyer, C. (2002) Pressure increases on UK government to remove anonymity from sperm donors. British Medical Journal, 324(7348), 1237.

Dyer, C. (2003) Egg or sperm donation children will be entitled to more information. British Medical Journal, 326(7383), 240.

Eekelaar, J. (2006) Family Law and Personal Life, Oxford: Oxford University Press.

Elsner, D. (2006) Just Another Reproductive Technology? The Ethics of Human Reproductive Cloning as an Experimental Medical Procedure. Journal of Medical Ethics, 32, 596-600.

Eskenazi, B., Wyrobek, J., Sloter, E., Kidd, S. A., Moore, L., Young, S. and Moore, D. (2003) The association of age and semen quality in healthy men. Human Reproduction, 18(2), 447-54.

Ess, C. (2001) Internet research Ethics. Computer Ethics: Philosophical Enquiries (CEPE) conference. Lancaster University, December 14-16, 2001. Available at:

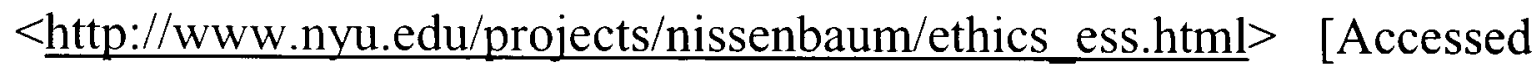
January 2009].

Feast, J. (2002) The right to an identity. The Observer. 16 June 2002 ed. London: Guardian News and Media Limited. Available at: $<$ http://www.guardian.co.uk/politics/2002/jun/16/comment.theobserver $\underline{1}>$ [Accessed January 2009].

Fernback, J. (1997) The Individual within the Collective: Virtual Ideology and the Realization of Collective Principles. In: S. Jones (Ed.) Virtual Culture: Identity and Communication in Cybersociety. Sage Publications, pp. 36-54.

Fontana, A. and Frey, J. H. (1998) Interviewing: The art of science. In: N. K. Denzin and Y. S. Lincoln (Eds.) Handbook of qualitative research. London: Sage Publications, pp. 47-78.

Frankfort-Nachmias, C. and Nachmias, D. (1996) Research methods in the social sciences, London: Arnold.

Frith, L. (2001) Gamete donation and anonymity: The ethical and legal debate. Human Reproduction, 16(5), 818-824.

Fuller, R. C. and Myers, R. R. (1941) The natural history of a social problem. American Sociological Review, 6(3), 320-321.

Glaser, B. G. and Strauss, A. L. (1967) The discovery of grounded theory, New York: Aldine de Gruyter.

Glover, L., Gannon, K., Sherr, L. and Abel, P. D. (1996) Distress in sub-fertile men: A longitudinal study. Journal of Reproductive and Infant Psychology, 14, 23-36. 
Gluckman, P. D. and Hanson, M. (2005) The Fetal Matrix: Elolution, Development and Disease, Cambridge University Press.

Goffman, E. (1956) Embarrassment and Social Organization. American Journal of Sociology, 62(3), 264.

Goffman, E. (1963) Stigma: notes on the management of spoiled identity, London: Penguin Books.

Golombok, S., Brewaeys, A., Cook, R., Giavazzi, M. T., Guerra, D. Mantovani, A., van Hall, E., Crosignani, P. G. and Dexeus, S. (1996) Children: The European study of assisted reproduction families: family functioning and child development. Human Reproduction, 11(10), 2324-2331.

Golombok, S., Cook, R., Bish, A. and Murray, C. (1995) Families Created by the New Reproductive Technologies: Quality of Parenting and Social and Emotional Development of the Children. Child Development, 66(2), 285-298.

Golombok, S., Lycett, E., MacCallum, F., Jadva, V., Murray, C., Abdalla, H., Jenkins, J., Margara, R. and Rust, J. (2004a) Parenting infants conceived by gamete donation. Journal of Family Psychology, 18, 443 52 .

Golombok, S., Lycett, E., Maccallum, F., Jadva, V., Murray, C., Rust, J., Abdalla, H., Jenkins, J. and Margara, R. (2004b) Parenting infants conceived by gamete donation. Journal of Family Psychology, 18(3), 443-452.

Golombok, S., Murray, C., Brinsden, P. and Abdalla, H. (1999) Social versus Biological Parenting: Family Functioning and the Socioemotional Development of Children Conceived by Egg or Sperm Donation. The Journal of Child Psychology and Psychiatry and Allied Disciplines, 40(04), 519-527.

Golombok, S., Murray, C., Jadva, V., Lycett, E., MacCallum, F. and Rust, J. (2006) Non-genetic and non-gestational parenthood: consequences for parent-child relationships and the psychological well-being of mothers, fathers and children at age 3. Human Reproduction, 21(7), 1918-1924.

Gottlieb, C., Lalos, O. and Lindblad, F. (2000) Disclosure of donor insemination to the child: The impact of Swedish legislation on couples' attitudes. Human Reproduction, 15(9), 2052-2056.

Grace, V. M., Daniels, K. R. and Gillett, W. (2008) The donor, the father, and the imaginary constitution of the family: Parents' constructions in the case of donor insemination. Social Science \& Medicine, 66(2), 301-314.

Greil, A. L. (1991) Not Yet Pregnant: Infertile Couples in Contemporary America, New Brunswick, NJ: Rutgers University Press. 
Gross, E. and Stone, G. P. (1964) Embarrassment and the Analysis of Role Requirements. American Journal of Sociology, 70(1), 1.

Gussow, Z. and Tracey, G. S. (1968) Status, ideology and adaption to stigmatized illness: a study of leprosy. Human Organization, 27, 316325 .

Haimes, E. (1992) Gamete donation and the social management of genetic origins. In: M. Stacey (Ed.) Changing Human Reproduction: Social Science Perspectives. London: Sage Publications, pp. 119-147.

Haimes, E. (1998) The making of the DI child': changing representations of people conceived through donor insemination. In: K. R. Daniels and E. Haimes (Eds.) Donor Insemination: International Social Science Perspectives. Cambridge: Cambridge University Press, pp. 53-75.

Haimes, E. V. (1993) Do clinicians benefit from gamete donor anonymity? Human Reproduction, 8(9), 1518-1520.

Hammersley, M. and Atkinson, P. (1983) Ethnography: Principles in Practice. London. Tavistock Publications.

HC Deb (2003-04) 416 col. 61WS. Available at: $<\underline{\text { http:} / / \text { www.publications.parliament.uk/pa/cm200304/cmhansrd/vo040 }}$

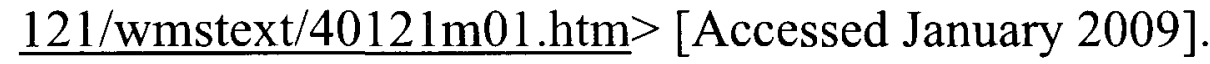

Healy, D. (1997) Cyberspace and Place: The Internet as Middle Landscape on the Electronic Frontier. In: D. Porter (Ed.) Internet Culture. London: Routledge, pp. 55-68.

Heckathorn, D. D. (2002) Respondent-Driven Sampling II: Deriving Valid Population Estimates from Chain-Referral Samples of Hidden Populations. Social Problems, 49(1), 11-34.

Henderson, M. (2007) Sperm donor figures rising despite loss of anonymity. The Times. May 42007 ed. London: Times Newspapers Ltd. Available at:

$<$ http://www.timesonline.co.uk/tol/news/uk/science/article1744309.ece $>$ [Accessed January 2009].

Hine, C. (2000) Virtual Ethnography, London: Sage Publications.

HL Deb (2003-04a) 662 col. 344-348. Available at: $<$ http://www.publications.parliament.uk/pa/ld200304/ldhansrd/vo04060 9/text/40609-22.htm\#40609-22 head0> [Accessed January 2009].

HL Deb (2003-04b) 662 col. 356. Available at: <http:/ жww parliament thestationery-office.co.uk/pa/ld200304/ldhansrd/vo040609/index/40609x.htm> [Accessed January 2009].

Holstein, J. A. and Miller, G. (2003) Challenges and Choices: Constructionist Perspectives on Social Problems, New York: Aldine. 
Holstein, J. A. and Miller, G. (2006) Reconsidering Social Constructionism: Debates in Social Problems Theory, Aldine Transaction.

Horton, P. and Leslie, G. (1981) The Sociology of Social Problems, Seventh Edition., Englewood Cliffs, NJ: Prentice-Hall Inc.

Huberman, A. M. and Miles, M. B. (1998) Data Management and Analysis Methods. In: N. K. Denzin and Y. S. Lincoln (Eds.) Collecting and Interpreting Qualitative Materials: Dealing with Empirical Materials and Interpretations. Sage Publications, pp. 179.

Human Fertilisation and Embryology Authority (1991) Human Fertilisation and Embryology Authority Code of Practice (6th Edition). London: Human Fertilisation and Embryology Authority. Human Fertilisation and Embryology Authority (2005a) SEED Report: A report on the Human Fertilisation \& Embryology Authority's review of sperm, egg and embryo donation in the United Kingdom. London: Human Fertilisation and Embryology Authority. Available at: $<$ http://www.hfea.gov.uk/docs/SEEDReport05.pdf $>$ [Accessed January 2009].

Human Fertilisation and Embryology Authority (2005b) Sperm, Egg and Embryo Donation (SEED) policy review: Findings of the clinic survey. Available at: $\quad$ http://212.49.193.187/cps/rde/xbcr/SID-3F57D79BECEBEBD1/hfea/seed_review.pdf $>$ [Accessed January 2009].

Human Fertilisation and Embryology Authority (2006) Press release: Thinking of going abroad? Think twice about going abroad for fertility treatment. Available at: <http://www.hfea.gov.uk/en/l123.html $>$ [Accessed January 2009].

Human Fertilisation and Embryology Authority (2007a) Press release: Number of sperm donors up following anonymity law changes. Available at: $<$ http://www.hfea.gov.uk/en/1523.html $>$ [Accessed January 2009].

Human Fertilisation and Embryology Authority (2007b) Press release: Who are the UK's sperm donors? - Fertility regulator presents national picture of the people who donate. Available at:

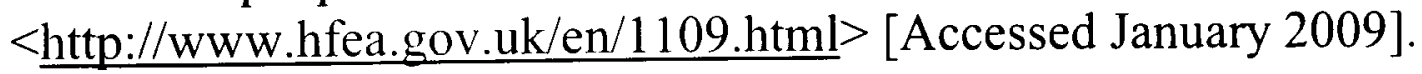

Human Fertilisation and Embryology Authority (2008a) BFS report on sperm donation in the UK: HFEA response. Available at: $<$ http://www.hfea.gov.uk/cps/HFEA/files/2008-07-

02 Authority paper response to BFS report_452.pdt> [Accessed January 2009].

Human Fertilisation and Embryology Authority (2008b) FAQs about new EU standards (EUTCD). Available at: < http://www.hfea.gov.uk/en/1565.html $>$ [Accessed January 2009]. 
Human Fertilisation and Embryology Authority (2008c) For parents of donorconceived

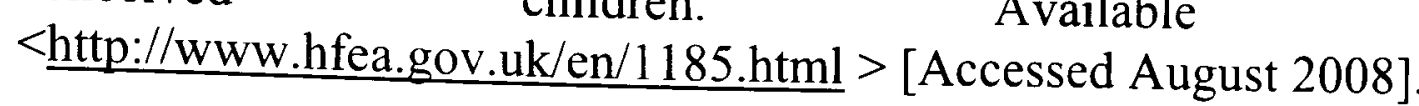

Human Fertilisation and Embryology Authority (2008d) Number of sperm and egg donors. Available at: <http://www.hfea.gov.uk/en/1462.html> [Accessed January 2009].

Human Fertilisation and Embryology Authority (2008e) Press release: HFEA figures reveal more than 10,000 women had successful IVF treatment in 2006. Available at: <http://www.hfea.gov.uk/en/1735.html $>$ [Accessed January 2009].

Human Fertilisation and Embryology Authority (2008f) Human Fertilisation and Embryology Authority Code of Practice (7th Edition). London: Human Fertilisation and Embryology Authority. Available at: http://cop.hfea.gov.uk/cop/COPContent.aspx?M=0\&S=2\&SM=134\#co ntent[Accessed May 2009].Ibarra, P. R. and Kitsuse, J. I. (1993) Vernacular Constituents of Moral Discourse: An Interactionist Proposal for the Study of Social Problems. In: M. Gale and J. A. Holstein (Eds.) Constructionist Controversies: Issues in Social Problems Theory. Piscataway, NJ: Aldine Transaction, pp. 21-54.

Infertility Network UK (2008) INUK Fertility Tourism Survey 2008. Bexhill on Sea: Infertility Network UK.

Jackson, E. (2001) Regulating Reproduction: Law, Technology and Autonomy, Oxford: Hart Publishing.

Janssens, P. M. W., Simons, A. H. M., van Kooij, R. J., Blokzijl, E. and Dunselman, G. A. J. (2006) A new Dutch law regulating provision of identifying information of donors to offspring: background, content and impact. Human Reproduction, 21(4), 852-856.

Jardine, L. (2008) Internet sperm providers are illegal. The Guardian. 23 September, 2008 ed. London: Guardian News and Media Limited. Available

at: $<$ http://www.guardian.co.uk/uk/2008/sep/23/ukcrime.lawl $>$ [Accessed January 2009].

Johnson, M. (2004) Speech by Melanie Johnson MP, 21 January 2004. Donor anonymity and review. Available at: $<$ http://www.dh.gov.uk/en/News/Speeches/Speecheslist/DH 407149()> [Accessed August 2008].

Johnson, M. H. (1999) The medical ethics of paid egg sharing in the UK' Opinion. Human Reproduction, 4(7), 1912-1918.

Johnston, H., Laraña, E. and Gusfield, J. R. (1994) Identities, Grievances, and New Social Movements. In: E. Larana, H. Johnston and J. R. Gusfield (Eds.) New Social Movements: From Ideology to Identity. Philadelphia: Temple University Press, pp. 3-35. 
Joint Committee on the Human Tissue and Embryos (Draft) Bill (2007) Human Tissue and Embryos (Draft) Bill - Volume II: Evidence. London: The Stationary Office.

Available

at: $<$ http://www.publications.parliament.uk/pa/jt200607/jtselect'jitembryos 169/169ii.pdf $>$ [Accessed January 2009].

Jones, S. (1997) The Internet and its Social Landscape. In: S. Jones (Ed.) Virtual Culture: Identity and Communication in Cybersociety. Sage Publications, pp. 7-35.

Jordan, B., James, S., Kay, H. and Redley, M. (1992) Trapped in Poverty? Labour-market decisions in low-income households, London: Routledge.

Klock, S. C. (1993) Psychological aspects of donor insemination. Infertil Reprod Clin North Am, 4(3), 455-469.

Klock, S. C., Jacob, M. C. and Maier, D. (1994) A prospective study of donor insemination recipients: secrecy, privacy, and disclosure. Fertility and Sterility, 62(3), 477-484.

Kohler Riessman, C. (2000) Stigma and Everyday Resistance Practices: Childless Women in South India. . Gender and Society, 14(1), 111-135.

Lalos, A., Daniels, K., Gottlieb, C. and Lalos, O. (2003) Recruitment and motivation of semen providers in Sweden. Human Reproduction, 18(1), 212-16.

Lalos, A., Gottlieb, C. and Lalos, O. (2007) Legislated right for donorinsemination children to know their genetic origin: A study of parental thinking. Human Reproduction, 22(6), 1759-68.

Lawford-Davies, J. and Forsyth, L. (2004) The end of donor anonymity. The Lawyer, 6 May 2004.

Lawson, A. (2006) Dangers and dilemmas of donor conception. The Times. September 26, 2006 ed. London: Times Newspapers Ltd. Available at: $<$ http://www.timesonline.co.uk/tol/comment/letters/article650047.ece $>$ [Accessed January 2009].

Lee, R. C. and Morgan, D. (2001) Human Fertilisation and Embryology, London: Blackstone Press.

Lemert, E. (1951a) Social Pathology: A Systematic Approach to the Theory of Sociopathic Behavior, New York, McGraw-Hill.

Lemert, E. M. (1951b) Is There a Natural History of Social Problems? American Sociological Review, 16(2), 217-223.

Liu, A. (1991) Artificial Reproduction and Reproductive Rights, Aldershot, UK: Darmouth. 
Lockard, J. (1997) Progressive politics, electronic individualism and the myth of community. In: D. Porter (Ed.) Internet Culture. London: Routledge. pp. 219-232.

Loseke, D. R. (2003) Thinking about Social Problems: An Introduction to Constructionist Perspectives, New York: Aldine De Gruyter.

Loseke, D. R. and Best, J. (2003) Social Problems: Constructionist Readings, New York: Aldine de Gruyter.

Lynxwiler, J. and DeCorte, C. (1995) Claims-Making and the Moral Discourse of Hard Core Rap Music. In: J. Holstein and G. Miller (Eds.) Perspectives on Social Problems, . Elsevier, pp. 3-27.

MacCallum, F. and Golombok, S. (2007) Embryo donation families: mothers' decisions regarding disclosure of donor conception. Human Reproduction, 22(11), 2888-95.

Maclean, S. and Maclean, M. (1996) Keeping Secrets in Assisted Reproduction-the Tension between Donor Anonymity and the Need of the Child for Information. Child and Family Law Quarterly, 8(3), 243251.

Mann, C. and Stewart, F. (2000) Internet Communication and Qualitative Research: A Handbook for Researching Online, London: Sage Publications Inc.

Mauss, M. (1966) Essay on the Gift, Allen \& Unwin.

McVeigh, K. (2007) Online ads for sperm donors called offensive. The Guardian. 26 March 2007 ed. London: Guardian News and Media Limited. Available at: $<$ http://www.guardian.co.uk/media/2007/mar/26/newmedia.advertising $>$ [Accessed January 2009].

McWhinnie, A. (2001) Gamete donation and anonymity: Should offspring from donated gametes continue to be denied knowledge of their origins and antecedents? Human Reproduction, 16(5), 807-17.

MediaMOO (1997) MediaMOO Symposium: The Ethics of Research in Virtual Communities. Available at: $<$ http://www.cc.gatech.edu/ asb/MediaMOO/ethics-symposium97.html $>$ [Accessed January 2009].

Medical News Today (2007) Infertility Network UK Response to HFEA Press Release On Latest Figures For Sperm Donor Recruitment. Available at: $<\underline{\text { http://www.medicalnewstoday.com/articles/69785.php }>\text { [Accessed }}$ January 2009].

Merton, R. K. (1971) Epilogue: Social problems and sociological theory. In: R. Merton and R. Nisbet (Eds.) Contemporary social problems New York: Harcourt Brace Jovanovich, pp. 793-846. 
Miall, C. E. (1986) The Stigma of Involuntary Childlessness. Social Problems, 33(4), 268-282.

Miall, C. E. (1996) The Social Construction of Adoption: Clinical and Community Perspectives. Family Relations, 45(3), 309-317.

Miller, G. and Holstein, J. A. (1997) Social Problems in Everyday Life, Stamford, CT: Jai Press.

Mishler, E. G. (1986) Research Interviewing: Context and Narrative Cambridge, MA: Harvard University Press.

Mulkay, M. (1997) The Embryo Research Debate: Science and the Politics of Reproduction, Cambridge: Cambridge University Press.

Murphy, E. and Dingwall, R. (2001) The ethics of ethnography. In: P. Atkinson, A. Coffey, S. Delamont, J. Lofland and L. Lofland (Eds.) Handbook of ethnography. London: Sage Publications, pp. 339-351.

Murphy, E. and Dingwall, R. (2003) Qualitative Methods And Health Policy Research, New York: Aldine.

Murray, C. and Golombok, S. (2000) Infertility. Oocyte and semen donation: a survey of UK licensed centres. Human Reproduction, 15(10), 21332139.

Nachtigall, R. D. (1993) Secrecy: An Unresolved Issue in the Practice of Donor Insemination. Pcogs Transactions. American Journal of Obstetrics \& Gynecology, 168(6), 1846-1851.

Nachtigall, R. D., Becker, G. and Wozny, M. (1992) The effects of genderspecific diagnosis on men's and women's response to infertility. Fertility and Sterility, 57, 113.

Nachtigall, R. D., Tschann, J. M., Quiroga, S. S., Pitcher, L. and Becker, G. (1997) Stigma, disclosure, and family functioning among parents of children conceived through donor insemination. Fertility and Sterility, 68(1), 83-89.

Newton (1983) Surrogate Motherhood: The Ethical Implications. In: J. M. Humber and R. F. Almeder (Eds.) Biomedical Ethics Reviews - 1983. Humana Press, pp. 47-68.

Nottingham University Hospitals NHS Trust (2008) Press release: Sperm Donors Wanted: Out to Advert. Available at: $<\underline{\text { http://www.nuh.nhs.uk/newsdesk/pressreleases/2008/04_April } 100408}$ htm> [Accessed January 2009].

O'Donovan, K. (1988) A right t know one's parentage? International Journal of Law, Policy and the Family, 2(1), 27-45. 
O'Donovan, K. (1989) 'What shall we tell the children? Reflections on children's perspectives and the reproductive revolution. In: D. Morgan and R. Lee (Eds.) Birthrights. London: Routledge, pp. 96-114.

Ogan, C. (1993) Listserver Communication During the Gulf War: What kind of medium is the elcectronic bulletin board? Journal of Broadcasting and Electronic Media, 37(2), 177-196.

Paccagnella, L. (1997) Getting the seats of your pants dirty: strategies for ethnographic research on virtual communities. Journal of ComputerMediated Communication, 3(1).

Parsons, T. (1951) The Social System, London: Routledge.

Paul, S., Harbottle, S. and Stewart, J. A. (2006) Recruitment of sperm donors: the Newcastle-upon-Tyne experience 1994-2003. Human Reproduction, 21(1), 150-158.

Pearson, M. (1996) Look who's talking: a pilot study of the use of discussion lists, by journalism educators and students. Paper presented to Association for Education in Journalism and Mass Communication. Anaheim, CA.

Pennings, G. (1997) The 'double track' policy for donor anonymity. Human Reproduction, 12(12), 2839-2844.

Pennings, G. (2000) The right to choose your donor: a step towards commercialization or a step towards empowering the patient? Human reproduction, 15(3), 508-514.

Pennings, G. (2002) Reproductive tourism as moral pluralism in motion. Journal of Medical Ethics, 28(6), 337-341.

Pennings, G. (2004) Legal harmonization and reproductive tourism in Europe. Human Reproduction, 19(12), 2689-2694.

Poster, M. (1990) The Mode of Information: Poststructuralism and Social Context, University Of Chicago Press.

Poster, M. (1994) Second media age? Arena Journal, 3, 49-91.

Preece, J. and Maloney-Krichmar, D. (2005) Online communities: Design, theory, and practice. Journal of Computer-Mediated Communication, $10(4)$.

Putnam, R. D. (2000) Bowling Alone: The Collapse and Revival of American Community, Simon \& Schuster.

Reid, E. (1995) Virtual worlds: culture and imagination. In: S. G. Jones (Ed.) Cybersociety: Computer Mediated Communication and Community: Thousand Oaks: CA: Sage Publications, pp. 164-83. 
Remennick, L. (2000) Childless in the Land of Imperative Motherhood: Stigma and Coping Among Infertile Israeli Women. Sex Roles, 43(11), 821841 .

Rheingold, H. (1994) The Virtual Community: Finding Connection in a Computerized World, London: Secker \& Warburg.

Rhodes, B. (2002) Donor-conceived children demand more rights. BBC News. Available at: $\quad<$ http://news.bbc.co.uk/1/hi/health/2178661.stm $>$ [Accessed January 2009].

Robinson, J. N., Forman, R. G., Clark, A. M., Egan, D. M., Chapman, M. G. and Barlow, D. H. (1991) Attitudes of donors and recipients to gamete donation. Human Reproduction, 6(2), 307-309.

Rose, A. M. (1971) History and Sociology of the Study of Social Problems. In: E. O. Smigel (Ed.) Handbook of the Study of Social Problems. Chicago, IL: Rand McNally, pp. 3-18.

Rubington, E. and Weinberg, M. S. (1971) The Study of social problems, London: Oxford University Press.

Schilling, G. and Conrad, R. (2001) Secrecy and openness in donor offspring. Human Reproduction, 16(10), 2244-2245.

Schneider, J. W. (1985) Social Problems Theory: The Constructionist View. Annual Review of Sociology, 11(1), 209-229.

Schover, L. R., Rothmann, S. A. and Collins, R. L. (1992) The personality and motivation of semen donors: a comparison with oocyte donors. Human Reproduction, 7(4), 575-579.

Shakespeare, P. (1993) Performing. In: P. Shakespeare, D. Atkinson and S. French (Eds.) Reflecting on Research Practice: Issues in health and social welfare. Buckingham: Open University Press.

Shenfield, F. (1994) Filiation in assisted reproduction: Potential conflicts and legal implications. Human Reproduction, 9, 1348-1354.

Shenfield, F. and Steele, S. J. (1997) What are the effects of anonymity and secrecy on the welfare of the child in gamete donation? Human Reproduction, 12, 392-395.

Silverman, D. (2001) Interpreting Qualitative Data: Methods for Analysing Talk, Text and Interaction, Sage.

Simpson, S. (1998) Call to trace sperm donor parents. BBC New's. 18 November 1998 Available at: <http://news.bbc.co.uk/1/hi/health/217012.stm> [Accessed January 2009]. 
Snowden, R. and Mitchell, G. D. (1983) The Artificial Family: A Consideration of Artificial Insemination by Doctor, London: Unwin Paperbacks.

Spector, M. and Kitsuse, J. I. (1977) Constructing Social Problems, Menlo Park, CA: Cummings Publishing Company.

Stg Co Deb (2003-04) Draft Human Fertilisation and Embryology Authority (Disclosure of Donor Information) Regulations 2004 (First Standing Committee) col. 6.6 Available at: $<$ http://www.publications.parliament.uk/pa/cm200304/cmstand $/$ delegl/

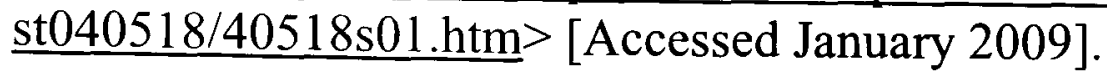

Storrow, R. F. (2006) Quests for Conception: Fertility Tourists, Globalization and Feminist Legal Theory. Hastings Law Journal, 57, 295-331.

Strathern, M. (1992) After Nature: English Kinship in the Late Twentieth Century, Cambridge: Cambridge University Press.

Sudweeks, F. and Rafaeli, S. (1996) How Do You Get a Hundred Strangers to Agree? In: T. M. Harrison and T. Stephen (Eds.) Computer Networking and Scholarly Communication in the Twenty-first-century University. SUNY Press.

Templeton, S.-K. (2003) Women are 'to blame' for infertility. Sunday Herald. August 32003 ed.

Thévoz, J. M. (1997) The rights of children to information. In: D. Evans (Ed.) Creating the Child: The Ethics, Law and Practice of Assisted Procreation. The Hague: Martinus Nijnoff Publishers, pp. 195-209.

Thomas, D. R. (2005) A general inductive approach for qualitative data analysis. Auckland, NZ: University of Auckland. Available at: $<$ http://www.health.auckland.ac.nz/hrmas/resources/Inductive2003.pdf $>$ [Accessed January 2009].

Thompson, C. (2005) Making Parents: The Ontological Choreography Of Reproductive Technologies, Cambridge, Mass: MIT Press.

Throsby, K. (2004) When IVF Fails: Feminism, Infertility and the Negotiation of Normality, London: Palgrave Macmillan.

Tisdall, J. (2006) Homosexuals unfit sperm donors. Aftenposten. Available at: $<$ http://www.aftenposten.no/english/local/article l414364.ece $>$ [Accessed August 2008].

Triseliotis, J. (1973) In Search of Origins, London: Routledge \& Kegan Paul.

Turner, A. J. and Coyle, A. (2000) What does it mean to be a donor offspring? The identity experiences of adults conceived by donor insemination and the implications for counselling and therapy. Human Reproduction, 15(9), 2041-2051. 
van den Akker, O. (2006) A review of family donor constructs: Current research and future directions. Human Reproduction Update, 12(2), 91-
101 .

Vercollone, C., Moss, H. and Moss, R. (1997) Helping the Stork: The Choices and Challenges of Donor Insemination, New York: Hungry Minds Inc.

Voysey Paun, M. (2006) A Constant Burden: The Reconstitution of Family, Life, Ashgate.

Waldby, C. (2008) Oocyte Markets: Women's Reproductive Work in Embryonic Stem Cell Research. New Genetics and Society, 27, 19-31.

Waldman, E. A. (2006) What Do We Tell the Children? Capital University Law Review, 35(2), 517-561.

Wallbank, J. (2004) The role of rights and utility in instituting a child's right to know her genetic history. Social and Legal Studies, 13, 245-64.

Waller, W. (1936) Social Problems and the Mores. American Sociological Review, 18, 604-611.

Warnock, M. (1985) A Question of Life: The Warnock Report on Human Fertilisation and Embryology, Oxford: Blackwell.

Watson, N. (1997) Why we Argue about Virtual Community: a Case Study of the Phish.net Fan Community. In: S. Jones (Ed.) Virtual Culture: Identity and Communication in Cybersociety. Sage Publications, pp. 102-132.

Wegar, K. (1997) Adoption, Identity, and Kinship: The Debate Over Sealed Birth Records, Yale University Press.

Westhues, K. (1973) Social Problems as Systemic Costs. Social Problems, 20(4), 419-431.

Willson, M. (2005) Sperm donor crisis in the UK. Medical News Today, 11 November 2005.2 Available at: $<\underline{\text { http://www.medicalnewstoday.com/articles/33393.php }>\quad \text { Accessed }}$ January 2009].

Winston, R. (2006) Sperm donors and secrecy. The Times. September 22, 2006 ed. London: Times Newspapers Ltd. Available at: $<$ http://www.timesonline.co.uk/tol/comment/letters/article646731.ece $>$ [Accessed January 2009].

Woolf, M. (2006a) Britain's sperm crisis. The Independent. Independent New's and Media Limited. Available at: $<$ http:i/www.independent.co.uk/lifestyle/health-and-wellbeing/health-news/britains-sperm-crisis409902.html > [Accessed January 2009]. 
Woolf, M. (2006b) Sperm: Your country needs you. The Independent. 30 July 2006 ed.: Independent News and Media Limited. Available at: $<$ http://www.independent.co.uk/life-style/health-and-wellbeing/healthnews/sperm-your-country-needs-you-409841.html > [Accessed January 2009].

Woolgar, S. and Pawluch, D. (1985) Ontological Gerrymandering: The Anatomy of Social Problems Explanations. Social Problems, 32(3), 214-227. 
Appendix 1 - Information about the interview participants

\begin{tabular}{|c|c|c|c|c|c|c|c|c|}
\hline Name & $\begin{array}{l}\text { Marital } \\
\text { status }\end{array}$ & Sex & Age & $\begin{array}{l}\text { Sexual } \\
\text { orientation }\end{array}$ & $\begin{array}{l}\text { Medical } \\
\text { Condition }\end{array}$ & $\begin{array}{l}\text { Considering } \\
\text { treatment }\end{array}$ & $\begin{array}{l}\text { Treatment } \\
\text { received }\end{array}$ & $\begin{array}{l}\text { Existing } \\
\text { children }\end{array}$ \\
\hline Darren & Married & $\mathrm{M}$ & 36 & Heterosexual & Azoospermia & No & ICSI treatment & Twins by ICSI \\
\hline Fiona & Married & $\mathrm{F}$ & 31 & Heterosexual & $\begin{array}{l}\text { Early } \\
\text { menopause }\end{array}$ & Egg donation & Donor eggs & Foster parent \\
\hline Tina & Married & $\mathrm{F}$ & 41 & Heterosexual & Unexplained & Another cycle & $\begin{array}{l}\text { Donor egg, } \\
\text { ICSI and } \\
\text { embryo }\end{array}$ & Pregnant \\
\hline Rosie & Cohabiting & $\mathrm{F}$ & 42 & Heterosexual & Unexplained & Egg donation & Traditional IVF & None \\
\hline Hannah & Married & $\mathrm{F}$ & 43 & Heterosexual & Unexplained & No & Donor eggs & Twins by surrogacy \\
\hline Carol & Married & $\mathrm{F}$ & 34 & Heterosexual & $\begin{array}{l}\text { Premature } \\
\text { Ovarian } \\
\text { Failure } \\
\end{array}$ & Adoption & N/A & None \\
\hline $\mathrm{Liz}$ & Married & $\mathrm{F}$ & 32 & Heterosexual & $\begin{array}{l}\text { Premature } \\
\text { Ovarian } \\
\text { Failure }\end{array}$ & $\begin{array}{l}\text { Embryo } \\
\text { donation }\end{array}$ & Donor eggs & I child adopted \\
\hline Mark & Married & $\mathrm{M}$ & 34 & Heterosexual & Azoospermia & No & None & 1 child adopted \\
\hline Alice & Widowed & $\mathrm{F}$ & 33 & Heterosexual & $\begin{array}{l}\text { Premature } \\
\text { Ovarian } \\
\text { Failure }\end{array}$ & Egg donation & $\begin{array}{l}\text { Donor eggs and } \\
\text { deceased } \\
\text { husband's } \\
\text { frozen sperm }\end{array}$ & Pregnant \\
\hline Bette & Cohabiting & $\mathrm{F}$ & 34 & Homosexual & None & Maybe & $\begin{array}{l}\text { Sperm / shared } \\
\text { eggs }\end{array}$ & Pregnant \\
\hline Lindsay & Married & $\mathrm{F}$ & 46 & Heterosexual & Unexplained & No & Embryo & $\begin{array}{l}\text { One adopted, one by } \\
\text { embryo donation }\end{array}$ \\
\hline Cindy & Single & $\mathrm{F}$ & 18 & Heterosexual & $\begin{array}{l}\text { Polycystic } \\
\text { Ovary } \\
\text { Syndrome }\end{array}$ & Donating eggs & None & None \\
\hline Tom & Single & $\mathrm{M}$ & 21 & Heterosexual & None & No & Donating sperm & None \\
\hline
\end{tabular}

